\title{
1,4-Diaza-1,3-butadiene ( $\alpha$-Diimine) Ligands: Their Coordination Modes and the Reactivity of Their Metal Complexes
}

\section{GERARD VAN KOTEN and KEES VRIEZE}

\author{
Anorganisch Chemisch Laboratorium \\ J. H. van 't Hoff Instituut \\ University of Amsterdam \\ Amsterdam, The Netherlands
}

I. Introduction.

II. The 1,4-Diaza-1,3-butadiene (R-DAB) Ligand

A. Preparation.

B. Structural and Bonding Features

III. Metal-1,4-Diaza-1,3-butadiene Complexes: Synthesis, Structure, and Bonding.

A. Introduction . . . . . . . . . . . . . 156

B. Monodentate $(\sigma-\mathrm{N} ; 2$ 2e) 1,4-Diaza-1,3-butadienes . . . . 157

C. Bridging $\left(\sigma-\mathrm{N}, \sigma-\mathrm{N}^{\prime} ; 2 \mathrm{e}+2 \mathrm{e}\right)$ 1,4-Diaza-1,3-butadienes . . . 165

D. Chelate Bonded ( $\left.\sigma, \sigma-\mathrm{N}, \mathrm{N}^{\prime} ; 4 \mathrm{e}\right)$ 1,4-Diaza-1,3-butadienes . . 167

E. Complexes Containing Bridging $\sigma-\mathrm{N}, \mu^{2}-\mathrm{N}^{\prime}, \eta^{2}-\mathrm{C}=\mathrm{N}^{\prime}(6 \mathrm{e})$

Bonded 1,4-Diaza-1,3-butadiene Ligands

F. Complexes Containing Bridging $\sigma-\mathrm{N}, \sigma-\mathrm{N}^{\prime}, \eta^{2}-\mathrm{C}=\mathrm{N}, \eta^{2}-\mathrm{C}=\mathrm{N}^{\prime}$

(8e) Bonded 1,4-Diaza-1,3-butadiene Ligands

IV. Structural Aspects

A. The Influence of Steric and Electronic Factors on the Type of

Products Formed

B. Structural and Fluxional Features

Reactivity

Ligands.

A. Complexes with (Intermediate) $\sigma$-N (2e) Bonded 1,4-Diaza-1,3butadiene Ligands

B. Complexes with $\sigma, \sigma-\mathrm{N}, \mathrm{N}^{\prime}$ (4e) Bonded 1,4-Diaza-1,3-butadiene Ligands

C. Stoichiometric C-C Coupling Reactions Involving $\sigma-\mathrm{N}, \mu^{2}-$ $\mathrm{N}^{\prime}, \eta^{2}-\mathrm{C}=\mathrm{N}^{\prime}$ Coordinated 1,4-Diaza-1,3-butadiene Ligands

D. Catalytic C-C Coupling Reactions Involving $\sigma-\mathrm{N}, \mu^{2}-\mathrm{N}^{\prime}, \eta^{2}-$ $\mathrm{C}=\mathrm{N}^{\prime}$ Coordinated 1,4-Diaza-1,3-butadiene Ligands

E. Catalytic Reactions . 


\section{I}

\section{INTRODUCTION}

Molecules containing the 1,4-diaza-1,3-butadiene skeleton have attracted much interest because of both their versatile coordination behavior and the interesting properties of their metal complexes. In particular, extensive chemistry has been carried out with 2,2'-bipyridine and phenanthroline, which are both known to coordinate to metal centers in the chelate bonding mode ( 1 ).

Relatively less well investigated, but increasingly of interest to various research groups, is the coordination chemistry of the most simple representative of this class of compounds, i.e., the 1,4-disubstituted 1,4-diaza1,3-butadienes, $\mathrm{RN}=\mathrm{CR}^{\prime}-\mathrm{CR}^{\prime \prime}=\mathrm{NR}$. These compounds are particularly fascinating since they have a flexible $\mathrm{N}=\mathrm{C}-\mathrm{C}=\mathrm{N}$ skeleton, they appear to have unusual electron donor and acceptor properties as compared to the above-mentioned bidentate nitrogen donors, and they can potentially act in a variety of coordination modes. The latter bonding modes involve not only the lone pairs of the $\mathrm{N}$ atoms but also the $\pi-\mathrm{C}=\mathrm{N}$ bonds.

Recently other aspects have also come to light that involve the chemical activation of R-DAB ${ }^{1}$ and the subsequent stoichiometric and catalytic reactions in which the activated ligand plays a crucial role in the reaction processes.

In view of these novel developments it was considered worthwhile to review in depth the synthesis, structures, and properties of the various types of 1,4-diaza-1,3-butadiene complexes known at present. Furthermore, applications of these compounds in organic synthesis and catalysis will be discussed. Attention will be devoted to the possible relation(s) between the type of coordination and the type of reaction occurring. Our survey is restricted to complexes of the R-DAB ligand in which the $\mathrm{R}$ group is connected to $\mathrm{N}$ via a carbon atom and does not cover complexes of $2,2^{\prime}$ bipyridines or 2-pyridinecarbaldehydeimines. ${ }^{2}$

\footnotetext{
' Most 1,4-diaza-1,3-butadienes that are known have the general formula $\mathrm{RN}=\mathrm{CR}^{\prime} \mathrm{CR}$ " $=\mathrm{NR}$ and herein this will be abbreviated to R-DAB( $\left.R^{\prime}, R^{\prime \prime}\right)$. The important subgroup of this class is $\mathrm{RN}=\mathrm{CHCH}=\mathrm{NR}[\mathrm{R}-\mathrm{DAB}(\mathrm{H}, \mathrm{H})]$ but for economy of space if the $\mathrm{R}$ grouping is specifically stated then the form $\mathrm{R}$ substituent-DAB is used and this implies proton substitution at the $\alpha$ diimine carbon atoms, e.g., $t-\mathrm{Bu}-\mathrm{N}=\mathrm{CHCH}=\mathrm{N}-t$ - $\mathrm{Bu}$ and $\mathrm{HN}=\mathrm{CHCH}=\mathrm{NH}$ become $t$-Bu-DAB and $\mathrm{H}$-DAB, respectively. For the general case applying to all variously substituted 1,4-diaza-1,3-butadienes, including the rarely encountered $R N=C^{\prime} C R^{\prime \prime}=N R^{\prime \prime}$ species, the abbreviation used is R-DAB.

${ }^{2}$ An account of the metal-1,4-diaza-1,3-butadiene research which has been carried out in the authors' laboratory is presented in Ref. 2 .
} 
II

\section{THE 1,4-DIAZA-1,3-BUTADIENE (R-DAB) LIGAND}

\section{A. Preparation}

1,4-Diaza-1,3-butadienes ( $\mathrm{R}$-DAB $)^{1}$ may be prepared by condensation reactions involving either glyoxals $(3-7), \alpha$-ketoaldehydes $(8-10)$, or $\alpha, \beta$-diketones $(8-11)$ with primary amines $\mathrm{RNH}_{2}$. In the case of methylglyoxal it has been established $(8)$ that the reaction with amine proceeds in two steps [see Eqs. (1) and (2)]. In the first step the $\alpha$-imino ketone formed is only stable enough to be isolated when $\mathrm{R}$ is a bulky group such as $t$ - $\mathrm{Bu}(8-10)$. This result suggests that this reaction occurs with high chemiospecificity (8) and this is probably due to the higher reactivity of the aldehyde group toward amines than the keto group.

$$
\begin{gathered}
\mathrm{O}=\mathrm{C}(\mathrm{Me}) \mathrm{C}(\mathrm{H})=\mathrm{O}+\mathrm{RNH}_{2} \rightleftarrows \mathrm{O}=\mathrm{C}(\mathrm{Me}) \mathrm{C}(\mathrm{H})=\mathrm{NR}+\mathrm{H}_{2} \mathrm{O} \\
\mathrm{R}=t-\mathrm{Bu} \text { or } \mathrm{EtMe}_{2} \mathrm{C} \\
\mathrm{O}=\mathrm{C}(\mathrm{Me}) \mathrm{C}(\mathrm{H})=\mathrm{NR}+\mathrm{R}^{\prime} \mathrm{NH}_{2} \leftrightarrows \mathrm{R}^{\prime} \mathrm{N}=\mathrm{C}(\mathrm{Me}) \mathrm{C}(\mathrm{H})=\mathrm{NR}+\mathrm{H}_{2} \mathrm{O} \\
\mathrm{R}^{\prime}=i-\mathrm{Pr}
\end{gathered}
$$

Further reaction of the $\alpha$-amino ketone occurs only with less bulky amines [Eq. (2)] (8) resulting in formation of an asymmetric R, $\mathrm{R}^{\prime}-\mathrm{DAB}(\mathrm{Me}, \mathrm{H})$ ligand.

Some of the R-DAB $\left(R^{\prime}, R^{\prime \prime}\right)$ ligands are not very stable as free molecules (e.g., $\left.\mathrm{R}=\mathrm{R}^{\prime}=\mathrm{R}^{\prime \prime}=\mathrm{Me}\right)(11)$ and these must be synthesized in the coordination sphere of a metal. Examples will be discussed in Section III,D,1.

\section{B. Structural and Bonding Features}

It was concluded from NMR spectra (12), dipole moments (13), and IR spectra (14) that the R-DAB molecule exists in solution in the $E$ (anti) configuration at both $\mathrm{C}=\mathrm{N}$ double bonds, while the conformation of the central $\mathrm{C}-\mathrm{C}$ bond is predominantly $s$-trans. ${ }^{3}$ It was deduced that the $\mathrm{N}=\mathrm{C}-\mathrm{C}=\mathrm{N}$ dihedral angle lies between 90 and $140^{\circ}$ (13).

In the gas phase, according to electron diffraction analysis, $t$ $\mathrm{BuN}=\mathrm{CHCH}=\mathrm{N} t-\mathrm{Bu}$ has for the majority of the molecules a gauche conformation with respect to the central $\mathrm{C}-\mathrm{C}$ bond with a torsion of about

\footnotetext{
${ }^{3}$ The terms $s$-trans and $s$-cis refer to torsional isomers around the central carbon-carbon bond of the 1,3-diene skeleton.
} 
$65^{\circ}$ from the $s$-cis ${ }^{3}$ form. However, a small amount of the $s$-trans form is also calculated to be present $(15,16)$.

Recently we determined the structure of $c-\mathrm{HexN}=\mathrm{CHCH}=\mathrm{N} c$-Hex $(c-\mathrm{Hex}-\mathrm{DAB})$ in the solid state by $\mathrm{X}$-ray crystallographic structure analysis in order to obtain insight into the $\mathrm{C}=\mathrm{N}$ and $\mathrm{C}-\mathrm{C}$ bond lengths and angles in the free molecule (see Table I and Section IV, B,1). The structure revealed a perfectly flat $\mathrm{N}=\mathrm{C}-\mathrm{C}=\mathrm{N}$ skeleton in the $E$ - $s$-trans- $E$ conformation (17). The similarity between the central $\mathrm{C}-\mathrm{C}$ distances in $c$-HexDAB and isostructural 1,3-butadienes (see Table I) is particularly striking and indicates that we are dealing with a pure $\mathrm{C}\left(s p^{2}\right)-\mathrm{C}\left(s p^{2}\right)$ bond. In Table I the bond lengths and angles in the $\mathrm{N}=\mathrm{C}-\mathrm{C}=\mathrm{N}$ unit of a series of related 1,4-diaza-1,3-butadiene molecules are given.

NDDO (neglect of diatomic differential overlap) (16), CNDO/2 (15) and $a b$ initio calculations $(18,19)$ on the conformational structures of $2,2^{\prime}-$ bipyridine, H-DAB and Me-DAB show that the $s$-trans form is indeed expected to be the most stable one (16). For example, for 2,2'-bipyridine an energy difference of $26.8 \mathrm{~kJ} \mathrm{~mol}^{-1}$ was calculated between the less stable planar $s$-cis form and the more stable planar $s$-trans conformation. The destabilization of the $s$-cis form is caused by the interaction of the lone pairs and by the steric hindrance of the ortho hydrogen atoms. Values ranging between 20 and $28 \mathrm{~kJ} \mathrm{~mol}^{-1}$ were calculated to be necessary to overcome the rotational barrier to produce the cis arrangement that is present in the chelate form of many $\alpha$-diimine-transition metal compounds.

Inspection of molecular models shows that substitution of methyl groups at the central $\mathrm{C}$ atom destabilizes the $E$ - $s$-trans- $E$ conformer in particular when the $\mathrm{R}$ substituent is triply branched at $\mathrm{C}^{\alpha}$. In this case the $E$-s-cis$E$ conformer becomes relatively much more stable. Notable exceptions are the so-called 1,4-diaza-1,3-butadien-2-ylmetal complexes in which one of the central $\mathrm{C}$ atoms is $\sigma$-bonded to a square planar trans- $\mathrm{ClL}_{2} \mathrm{Pd}$ moiety, e.g., $\mathrm{PdCl}\left[\mathrm{C}\left(=\mathrm{NC}_{6} \mathrm{H}_{4}(\mathrm{OMe}-p)-\mathrm{C}(\mathrm{Me})=\mathrm{NC}_{6} \mathrm{H}_{4} \mathrm{OMe}-p\right]\left(\mathrm{PPh}_{3}\right)_{2}(20)\right.$ (see Table I). Since the Pd coordination plane is almost perpendicular to the planar $E$-s-trans- $E$ skeleton it is internally recognized as a very small substituent. Accordingly, complexes are known containing the 1,4-diaza-1,3butadien-2-yl ligand in both the $E$-s-trans- $E$ and the $E$-s-cis- $E$ conformation.

Also of interest are the relative donor-acceptor properties of the various organic molecules containing the $\mathrm{N}=\mathrm{C}-\mathrm{C}=\mathrm{N}$ skeleton. NDDO calculations of the LUMO (lowest unoccupied metal orbital) energies indicated that the $\pi$-acceptor capacity increases in the order 2,2'-bipyridine $<2$ pyridinecarbaldehyde- $N$-methylimine $<$ R-DAB (26).

Finally, it should be mentioned that some UV-PES spectra in combination with UV spectra have been recorded $(11,27)$ for some R-DAB 


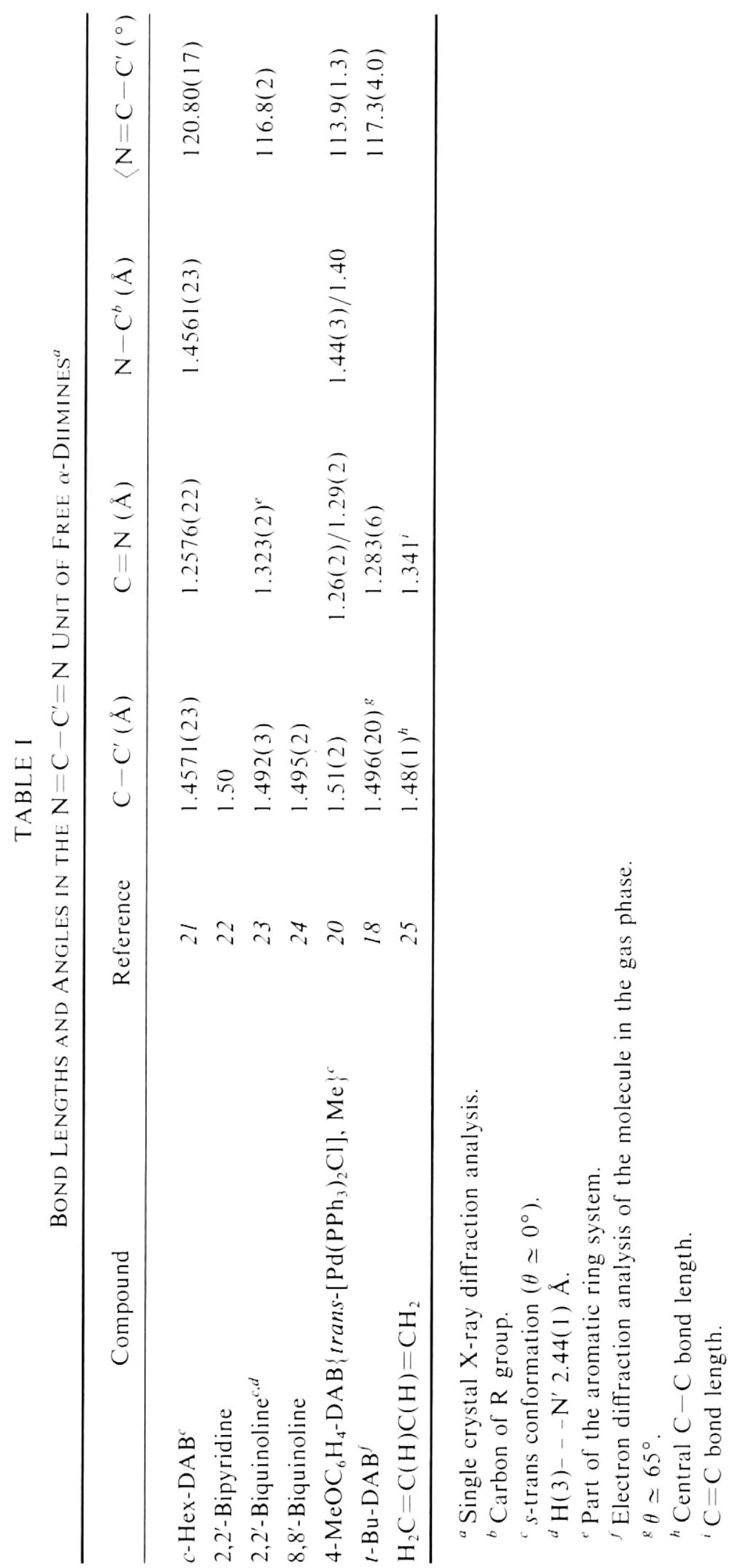


ligands. The results are not very revealing, but comparisons indicate increasing polarity in the $\mathrm{C}=\mathrm{X}$ bond on going from 1,3-butadienes to 1,4diaza- and 1,4-dioxo-1,3-butadienes (R-DABs and glyoxals respectively) (11).

\section{III}

\section{METAL-1,4-DIAZA-1,3-BUTADIENE COMPLEXES: SYNTHESIS, STRUCTURE, AND BONDING}

\section{A. Introduction}

The reports of metal complexes with R-DAB ligands date back to 1953 when Krumholz (28) described the synthesis of some ferrous complexes, e.g., $\left[\mathrm{Fe}(\mathrm{Me}-\mathrm{DAB})_{3}\right] \mathrm{I}_{2}$. The unusual stability and characteristic color being ascribed to the presence of $\pi$ bonding between the metal and the nitrogen atoms. Since then numerous examples of metal-R-DAB complexes have been synthesized and their bonding studied by spectroscopic and theoretical methods.

A consistent structural feature of these complexes appeared to be the chelate bonding of the R-DAB ligand. Since the free R-DAB molecule exists in the $E$-s-trans- $E$ conformation (see Section II,B) this implies that upon coordination to the metal center rotation around the central $\mathrm{C}-\mathrm{C}$ bond must have taken place to give the $E$-s-cis- $E$ conformation present. In fact it is very surprising that it was not before 1978 that the first examples were found of the other possible interactions with metal centers by Frühauf, Vrieze, and van Koten $(29,30)$. The earlier reports by Kliegman and co-workers concerning the behavior of R-DAB molecules toward perchloric acid had already pointed to the possible existence of other coordination modes $(12,31)$. They found that in addition to the monobasic behavior of most R-DAB molecules those with bulky R groups (e.g., otolyl) appeared to be dibasic in nature. It was proposed that the monobasic behavior is due to formation of a five-membered, highly stabilized, planar ring system. This is only possible if the $\mathrm{N}=\mathrm{C}-\mathrm{C}=\mathrm{N}$ skeleton can assume the $E$-s-cis- $E$ conformation according to Eq. (3).

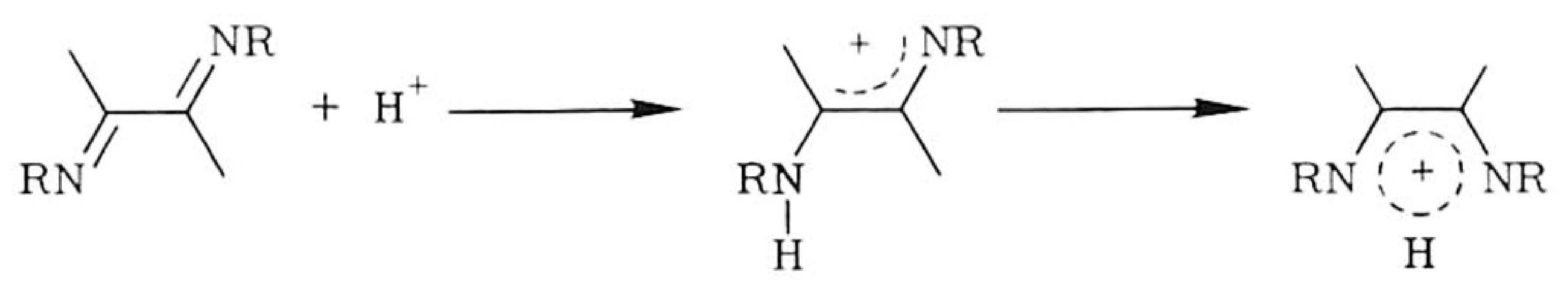


By contrast, if the $\mathrm{R}$ groups are bulky the $\mathrm{N}$ atoms are assumed to be blocked from interaction with the proton in the $E-s$-cis- $E$ conformation (4). In these cases the R-DAB ligand is diprotonated in the $E$-s-trans- $E$ conformation.

It is exactly this influence of the steric nature of the $\mathrm{R}$ substituents of the R-DAB ligand on the stability of the conformation of the $\mathrm{N}=\mathrm{C}-\mathrm{C}=\mathrm{N}$ skeleton that affects the type of metal interaction found (32). Other factors are the nature of the metal center itself and the coordinated ligands. The various bonding modes found for the 1,4-diaza-1,3-butadiene ligand are shown in Fig. 1. The planar $E$-s-trans- $E$ conformation will be particularly suited either for coordination to one metal center via the lone pair of one $\mathrm{N}$ atom ( $\sigma-\mathrm{N}$ monodentate) or for a bridging coordination mode between metal centers via the lone pairs on each of the $\mathrm{N}$ atoms $\left(\sigma-\mathrm{N}, \sigma-\mathrm{N}^{\prime}\right.$ bridging). Furthermore, conformations ranging from gauche to planar $E$-s-cis$E$ also allow the involvement of one $\pi \mathrm{C}=\mathrm{N}$ bond in addition to the two lone pairs on the $\mathrm{N}$ atoms resulting in a bridging coordination mode ( $\sigma$ $\left.\mathrm{N}, \mu^{2}-\mathrm{N}^{\prime}, \eta^{2}-\mathrm{CN}^{\prime}\right)$. Finally the planar $E-s$-cis- $E$ conformer can be either chelate bonded to one metal center $\left(\sigma, \sigma-\mathrm{N}, \mathrm{N}^{\prime}\right.$ chelate) or chelate bonded to one metal atom and $\eta^{2}$-bonded via both $\pi \mathrm{C}=\mathrm{N}$ bonds to a second metal center thus attaining a bridge bonding mode $\left(\sigma-\mathrm{N}, \sigma-\mathrm{N}^{\prime}, \eta^{2}-\mathrm{CN}, \eta^{2}-\mathrm{CN}^{\prime}\right)$. It is obvious that pure $\eta^{2}-\mathrm{C}=\mathrm{N}, \eta^{2}-\mathrm{C}=\mathrm{N}^{\prime}$ bonded R-DAB ligands in the $E$ $s$-cis- $E$ conformation are only possible when both $\sigma$ lone pairs are first involved in bonding to either one or two metal centers $(31,33)$.

In the following sections these various coordination modes will be successively treated thus revealing the fascinating versatile coordination behavior of this ligand. This versatility becomes particularly evident when one compares the coordination modes of the R-DAB ligand with the single $\sigma, \sigma-\mathrm{N}, \mathrm{N}^{\prime}$ chelate coordination mode observed for related 2,2'-bipyridine. The R-DAB ligand has the unique property that it enables the metal center to adjust its electron density by changing its point of attachment to the $\mathrm{N}=\mathrm{C}-\mathrm{C}=\mathrm{N}$ system (2); the latter donating either 2,4 , 6, or 8 electrons.

\section{B. Monodentate $(\sigma-N ; 2 e)$ 1,4-Diaza-1,3-butadienes}

So far stable complexes containing monodentate R-DAB have only been reported for the square planar $d^{8}$-metals $\mathrm{Pd}^{\mathrm{II}}, \mathrm{Pt}^{\mathrm{II}}$, and $\mathrm{Rh}^{1}(29,32,34$, $35)$. Compounds of the type trans $-\mathrm{PdX} \mathrm{X}_{2}(\mathrm{R}-\mathrm{DAB})_{2}$ have been obtained from the reaction of $\operatorname{PdX}_{2}(\mathrm{PhCN})_{2}$ with $t$-Bu-DAB or EtMe ${ }_{2} \mathrm{C}-\mathrm{DAB}$ (29). The NMR spectra of these compounds were consistent with the trans structure shown in Fig. 2. The R-DAB ligand is coordinated via the $\mathrm{N}$ lone pair in 


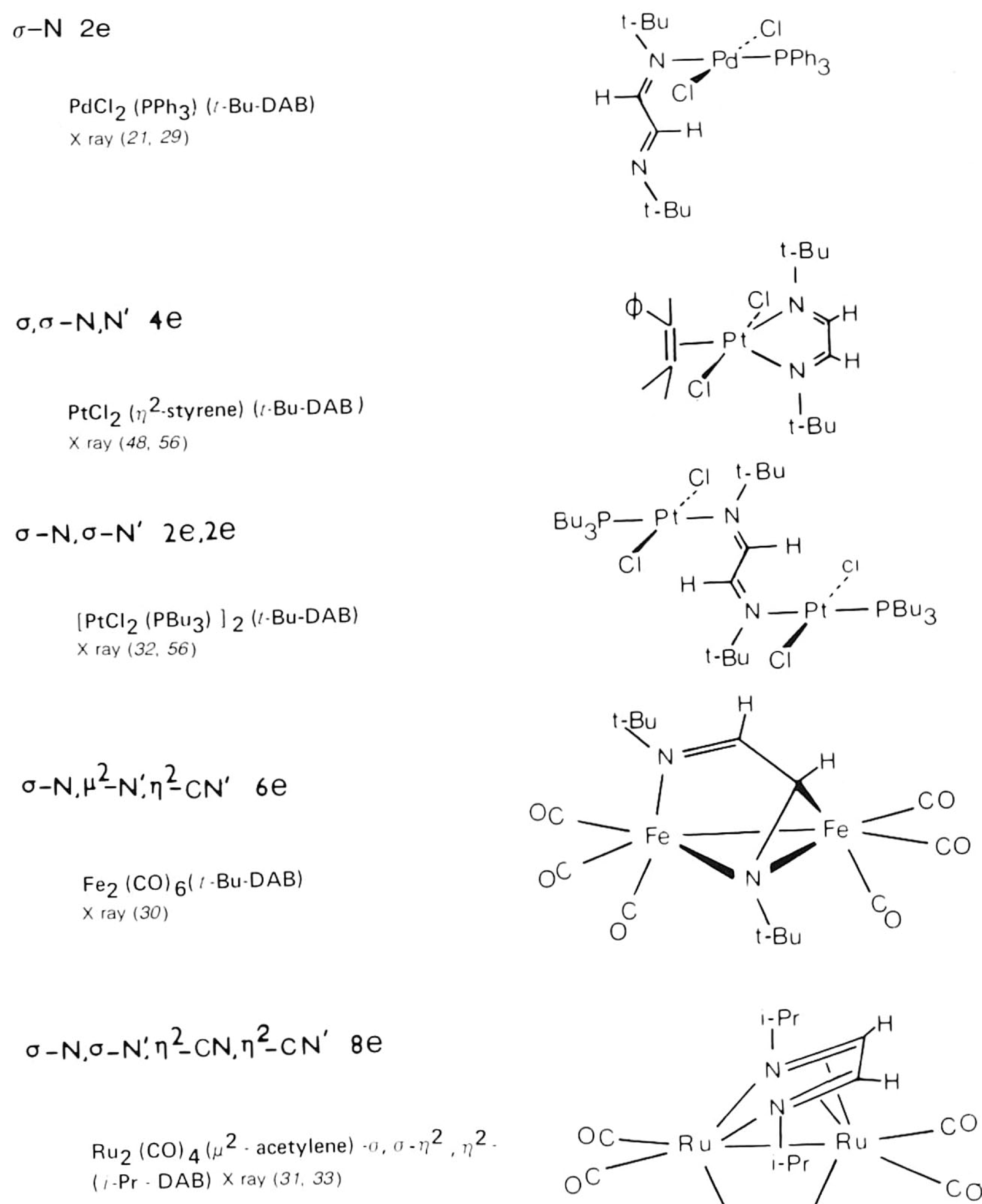

Fig. 1. Examples of metal-R-DAB complexes, illustrating the various coordination possibilities.

the $s$-trans conformation with the coordinated $\mathrm{C}=\mathrm{N}$ site in the $E$ conformation and as a result the $\mathrm{N}=\mathrm{C}-\mathrm{C}=\mathrm{N}$ skeleton is almost planar. This conclusion is based on the anomalously low field shift of the $\mathrm{H}^{\beta}$ proton upon coordination. The magnetic anisotropy of the planar complex would necessarily result in a deshielding of $\mathrm{H}^{\beta}$ located close to the metal above the coordination plane in this conformation. 


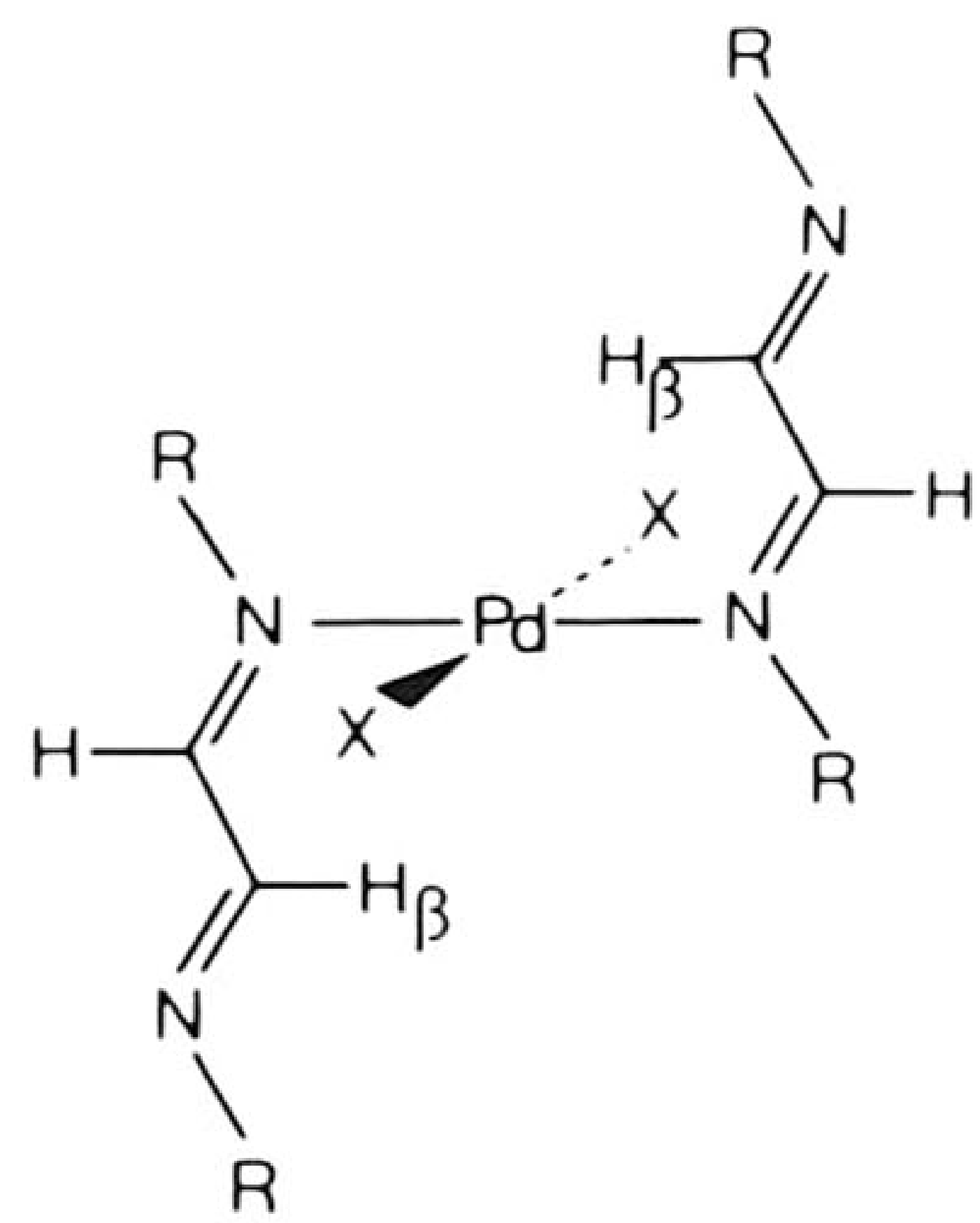

(a)

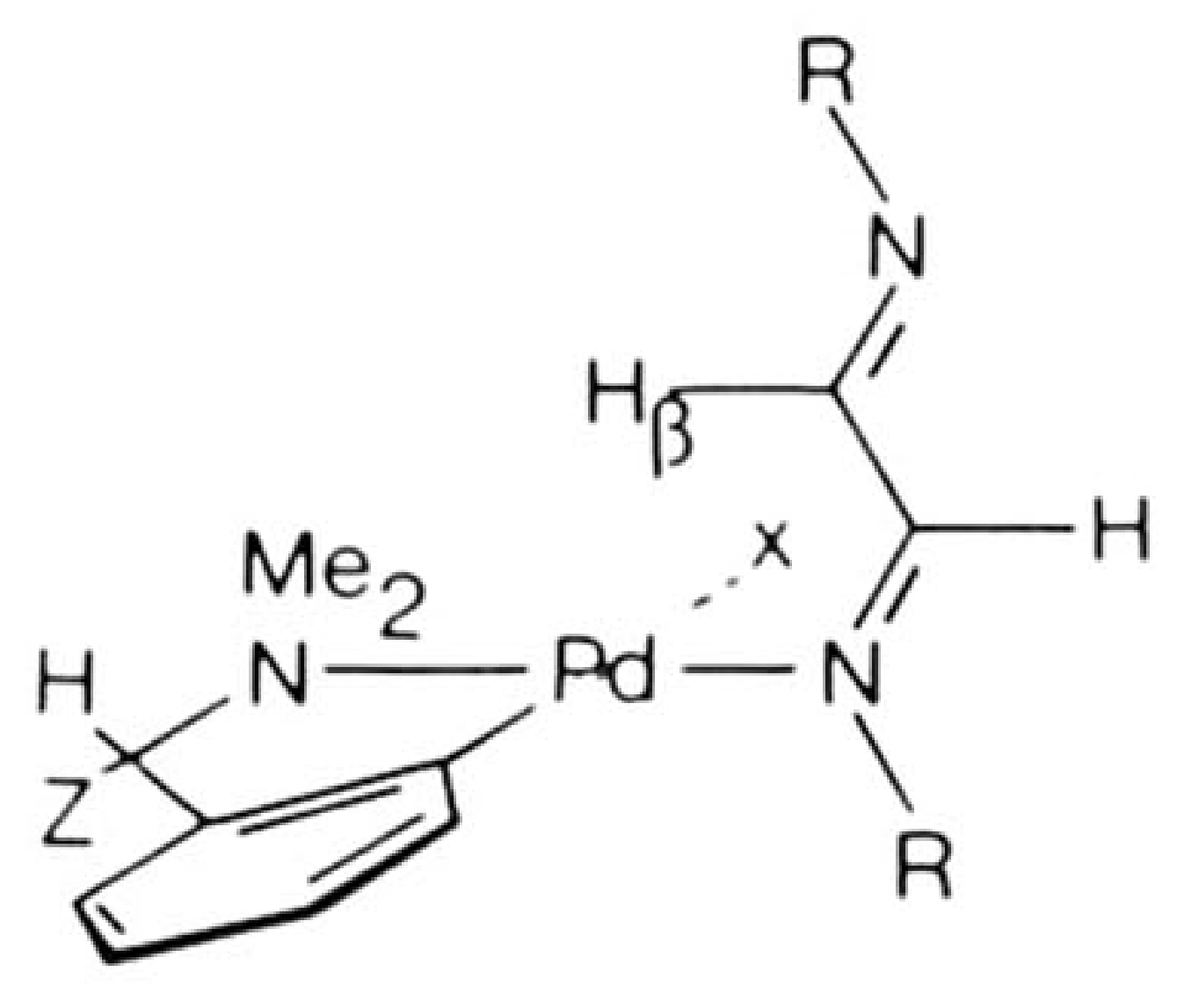

(b)

Fig. 2. Proposed structure (a) of trans $-\mathrm{PdX} \mathrm{X}_{2}(\mathrm{R}-\mathrm{DAB})_{2}\left(\mathrm{R}=t\right.$ - $\left.\mathrm{Bu}, \mathrm{EtMe}_{2} \mathrm{C} ; \mathrm{X}=\mathrm{Cl}, \mathrm{Br}\right)$ (29), and (b) of trans- $N-\mathrm{PdX}\left(\mathrm{C}_{6} \mathrm{H}_{4} \mathrm{CH}(\mathrm{Z}) \mathrm{NMe}_{2}\right)(\mathrm{R}-\mathrm{DAB})\left(\mathrm{R}=t-\mathrm{Bu}, \mathrm{EtMe}_{2} \mathrm{C} ; \mathrm{X}=\mathrm{Cl}, \mathrm{Br}\right.$; $\mathrm{Z}=\mathrm{H},(S)-\mathrm{Me})(36)$.

That the planar $E$-s-trans- $E$ conformation is indeed preferred for monodentate bonded R-DAB (as well as for $\sigma-\mathrm{N}, \sigma-\mathrm{N}^{\prime}$ bridging R-DAB, see Section III,C) can be concluded from the structure in the solid state of trans- $\mathrm{PdCl}_{2}\left(\mathrm{PPh}_{3}\right)(t$-Bu-DAB) (2l) (see Fig. 1 and Table II). The $t$-Bu$\mathrm{DAB}$ ligand is coordinated via one $\mathrm{N}$ atom while the second imino- $\mathrm{N}$ atom is free. $\mathrm{H}^{\beta}$ resides above the $\mathrm{Pd}^{\mathrm{II}}$ coordination plane at a calculated distance of $2.6 \AA$. One important aspect of this structure is the fact that the $\mathrm{N}=\mathrm{C}-\mathrm{C}=\mathrm{N}$ skeleton is somewhat bent toward the $\mathrm{Pd}$ coordination plane in order to minimize contact of the $t$-Bu group with the cis ligands.

Complexes similar to trans- $\mathrm{PdCl}_{2}\left(\mathrm{PPh}_{3}\right)(t-\mathrm{Bu}-\mathrm{DAB})$ have been prepared via the bridge splitting reactions shown in Eq. (4) which proceed via formation of complexes with $2: 1 \mathrm{M}: \mathrm{R}-\mathrm{DAB}$ molar ratios (29).

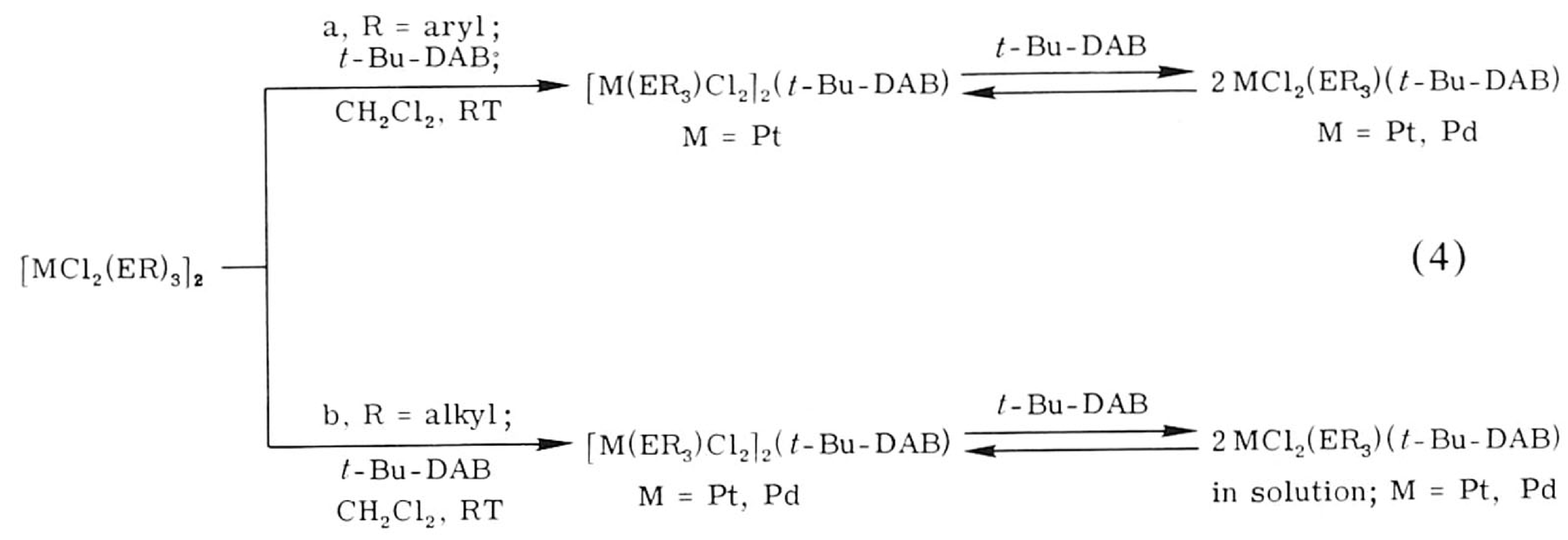

Both the $2: 1$ and $1: 1 \mathrm{Pt}-\mathrm{R}-\mathrm{DAB}$ complexes with a trans triarylphosphine or -arsine ligand are stable and isolable but in the case of Pd this 
Bonding mode; number of electrons donated. Compound
Distances $(\AA)$ and angles $\left({ }^{\circ}\right)$

$\mathrm{M}-\mathrm{N} \quad \mathrm{N}-\mathrm{M}-\mathrm{N} \quad \mathrm{C}=\mathrm{N}$

A. Monodentate $(\sigma-\mathrm{N} ; 2 \mathrm{e})$ trans $-\mathrm{PdCl}_{2}\left(\mathrm{PBu}_{3}\right)(t-\mathrm{Bu}-$ $\mathrm{DAB})$

B. Bridging $\left(\sigma-\mathrm{N}, \sigma-\mathrm{N}^{\prime}\right.$;

$2 \mathrm{e}+2 \mathrm{e})$

$\left[\text { trans }-\mathrm{PtCl}_{2}\left(\mathrm{PBu}_{3}\right)\right]_{2}(t-$

$\mathrm{Bu}-\mathrm{DAB})$

C. Chelating $\left(\sigma, \sigma-\mathrm{N}, \mathrm{N}^{\prime}\right.$;

$$
4 \mathrm{e})
$$

$\mathrm{Mo}(\mathrm{CO})_{4}(\mathrm{R}-\mathrm{DAB}) \mathrm{R}=i-$

$\operatorname{Pr}$

$\mathrm{R}=2,6-(i-\operatorname{Pr})_{2} \mathrm{C}_{6} \mathrm{H}_{3}-$

DAB

$\mathrm{MoCl}\left(\eta^{3}-\mathrm{C}_{4} \mathrm{H}_{7}\right)(\mathrm{CO})_{2}(c-$

Hex-DAB)

$\mathrm{WBr}\left(\eta^{3}-\mathrm{C}_{3} \mathrm{H}_{5}\right)(\mathrm{CO})_{2}(c-$

Hex-DAB)

$\mathrm{MnBr}(\mathrm{CO})_{3}(c-\mathrm{Hex}-\mathrm{DAB})$

$\mathrm{ReCl}(\mathrm{CO})_{3}(i-\mathrm{Pr}-\mathrm{DAB})$

$\mathrm{Mn}(t-\mathrm{Bu}-\mathrm{DAB})_{2}$

$\mathrm{Ru}\left(p-\mathrm{MeOC}_{6} \mathrm{H}_{4}-\mathrm{DAB}\right)_{3}$

$\mathrm{RuCl}_{2}(i-\mathrm{Pr}-\mathrm{DAB})_{2}$

$\mathrm{Rh}\left(i-\mathrm{Pr}_{2} \mathrm{CH}-\mathrm{DAB}\right)(\mathrm{CO})_{2}-$

$\mathrm{RhCl}_{2}(\mathrm{CO})_{2}$

$\mathrm{Fe}(\mathrm{CO})_{3}\left(2,6-i-\mathrm{Pr}_{2} \mathrm{C}_{6} \mathrm{H}_{3}-\right.$

$$
\mathrm{DAB})
$$

$\mathrm{Fe}(\mathrm{NO})_{2}(t-\mathrm{Bu}-\mathrm{DAB})$

$\mathrm{Fe}(\mathrm{CO})(i-\mathrm{Pr}-\mathrm{DAB})(2,3-$

$$
\left.\mathrm{Me}_{2} \mathrm{C}_{4} \mathrm{H}_{4}\right)
$$

$\mathrm{Ni}(c-\mathrm{Hex}-\mathrm{DAB})_{2}$

$\mathrm{Ni}(\text { xylyl-DAB })_{2}$

$\mathrm{Ni}(\mathrm{CO})_{2}\left[\mathrm{Me}_{2} \mathrm{~N}-\right.$

$\mathrm{DAB}(\mathrm{Me}, \mathrm{Me})]$

$\mathrm{NiBr}$ (metalated $i-\mathrm{Pr}_{2} \mathrm{CH}$ -
N.R.

1.277

1.283

2.238

2.222

$2.237(4)$

$2.219(10)$

2.057(14)

$2.050(15)$

2.258(18)

2.232(19)

2.06

2.06(3) mean

2.04-2.10

$2.000(6)-$ $2.051(6)$

$2.118(5)$

$2.109(5)$

1.927(3)

2.03

1.930(1)

1.924 mean

1.928 mean

$1.97(3)$

$1.99(5)$

$1.820(13)^{d}$

$1.995(14)^{e}$
N.R.

1.275

1.288

$1.283(7)$

$1.303(16)$

$1.294(27)$

$1.274(30)$

$1.345(36)$

1.264(39)

1.32

$1.34(5)$ mean

$1.28-1.38$

1.291 mean

78.4(3) and $77.8(3)$

$78.8(2)$

$1.282(8)$

$1.304(8)$

1.329(5)

1.26

$1.311(2)$

1.321 mean

1.342 mean

83.1 mean

$1.22(6)$

$1.22(5)$

$1.294(24)$ 


\begin{tabular}{|c|c|c|c|c|}
\hline $\mathrm{C}-\mathrm{C}^{\prime a}$ & $\mathrm{C}-\mathrm{C}^{\prime}-\mathrm{N}$ & $\mathrm{N}-\mathrm{C}^{\alpha}$ & Section & Reference \\
\hline $1.485(9)$ & $124.17(67)$ & $1.494(8)$ & $\begin{array}{l}\text { III, B } \\
\text { (see Fig. 1) }\end{array}$ & 21,29 \\
\hline $1.48(2)$ & $118.2(13)$ & $1.52(2)$ & $\begin{array}{l}\text { III,C } \\
\text { (see Fig. 1) }\end{array}$ & 32 \\
\hline 1.443 & N.R. & N.R. & III,D, $2, \mathrm{~b}$ & 37 \\
\hline 1.467 & N.R. & N.R. & III,D, 2,b & 37 \\
\hline $1.448(7)$ & $118.05(49)$ & $1.494(6)$ & $\mathrm{III}, \mathrm{D}, 2, \mathrm{~b}$ & 38 \\
\hline $1.466(17)$ & $116.28(106)$ & $1.506(14)$ & $\mathrm{III}, \mathrm{D}, 2, \mathrm{~b}$ & 39 \\
\hline $1.490(22)$ & $\begin{array}{l}112.12(1.86) \\
118.43(1.80)\end{array}$ & $\begin{array}{l}1.453(17) \\
1.473(22)\end{array}$ & III,D, $2, \mathrm{c}$ & 40 \\
\hline $1.378(45)$ & $116.95(2.62)$ & $\begin{array}{l}1.508(37) \\
1.462(32)\end{array}$ & III $, D, 2, c$ & 41 \\
\hline 1.38 & N.R. & N.R. & $\mathrm{III}, \mathrm{D}, 2, \mathrm{c}$ & 42 \\
\hline $\begin{array}{l}1.37(5) \text { mean } \\
1.33-1.45\end{array}$ & N.R. & N.R. & III $, D, 2, d$ & 43 \\
\hline 1.40 mean & 117.7 mean & N.R. & III,D, 2,d & 44 \\
\hline $1.466(8)$ & $118.1(6)$ & $1.507(7)$ & III,D, $2, \mathrm{e}$ & 45 \\
\hline $\begin{array}{l}1.390(5) \\
1.45\end{array}$ & $\begin{array}{r}114.2(3) \\
\text { N.R. }\end{array}$ & $\begin{array}{c}1.491(7) \\
1.441(4) \\
\text { N.R. }\end{array}$ & $\begin{array}{l}\text { III,D, 2,d } \\
\text { III,D, 2,d }\end{array}$ & $\begin{array}{r}110 \\
42\end{array}$ \\
\hline $1.405(3)$ & N.R. & $1.407(2)$ & III,D, 2,d & $111 \mathrm{~b}$ \\
\hline 1.400 mean & N.R. & 1.479 mean & III $, D, 2, f$ & 9 \\
\hline 1.374 mean & 116.06 mean & 1.421 mean & III,D $, 2, \mathrm{f}$ & 10 \\
\hline $1.54(4)$ & $\begin{array}{l}110.4 \\
119.3\end{array}$ & & $\mathrm{III}, \mathrm{D}, 2, \mathrm{f}$ & 46 \\
\hline $1.454(24)$ & 111.4 & $\begin{array}{l}1.504(20) \\
1.483(22)\end{array}$ & $\mathrm{III}, \mathrm{D}, 2, \mathrm{f}$ & 47 \\
\hline
\end{tabular}


TABLE II

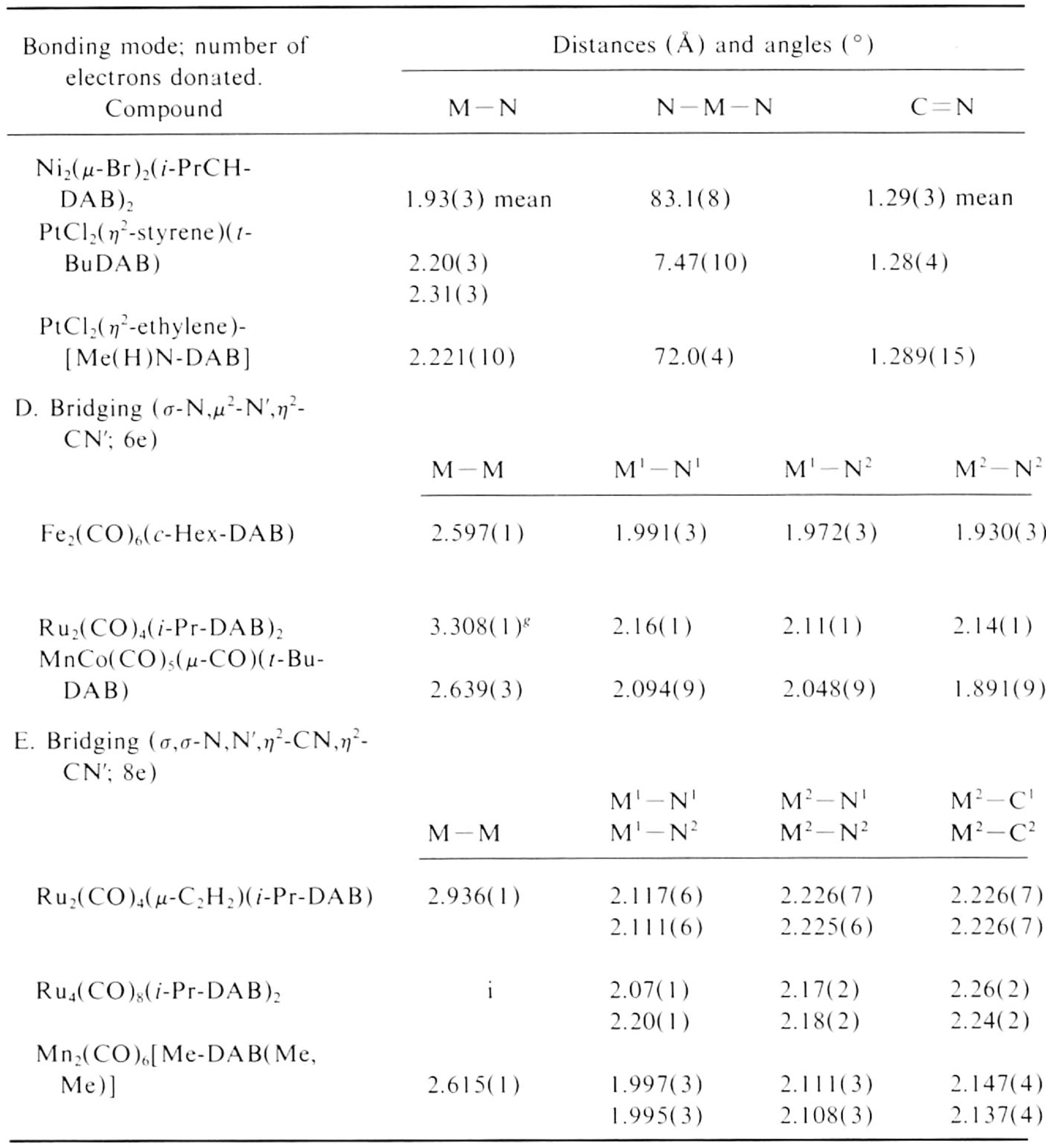

${ }^{a}$ Central $\mathrm{C}$ atoms (imino-carbon atoms)

${ }^{b}$ Coordinated imino- $\mathrm{N}$ atom.

'Free imino- $\mathrm{N}$ atom.

${ }^{d}$ Trans to $\mathrm{Br}$.

"Trans to C.

is only so for the $1: 1$ complexes. By contrast, the use of trialkylphosphines or -arsines yielded the $2: 1$ platinum or palladium complexes as stable solids [Eq. (4)] and 1: 1 complexes were formed in solution. The intermolecular exchange processes between the dinuclear and mononuclear species and free R-DAB are slow on the NMR timescale (29). However, ${ }^{1} \mathrm{H},{ }^{13} \mathrm{C},{ }^{15} \mathrm{~N}$, ${ }^{31} \mathrm{P}$, and ${ }^{195} \mathrm{Pt} \mathrm{NMR}$ studies of ${ }^{15} \mathrm{~N}$ labeled (35) and nonlabeled (29) com- 


\begin{tabular}{|c|c|c|c|c|c|c|c|}
\hline \multicolumn{2}{|l|}{$\mathrm{C}-\mathrm{C}^{\prime a}$} & $C-C^{\prime}-N$ & \multicolumn{2}{|l|}{$\mathrm{N}-\mathrm{C}^{\alpha}$} & \multicolumn{2}{|l|}{ Section } & Reference \\
\hline \multicolumn{2}{|c|}{$1.38(3)$ mean } & \multirow[t]{2}{*}{$117(2)$ mean } & $\begin{array}{r}1.48(3) \\
\text { mean }\end{array}$ & & \multicolumn{2}{|c|}{$\mathrm{III}, \mathrm{D}, 2, \mathrm{f}$} & 47,147 \\
\hline $1.51(5)$ & & & $1.46(4)$ & \multicolumn{3}{|c|}{ III $, \mathrm{D}, 2, \mathrm{f}$} & 48 \\
\hline $1.50(2)$ & \multicolumn{2}{|c|}{$116(1)$} & N.R. & \multicolumn{3}{|c|}{$\mathrm{III}, \mathrm{D}, 2, \mathrm{f}$} & 49 \\
\hline$M^{2}-C^{2}$ & $C^{2}-N^{2}$ & $\mathrm{~N}^{\prime}=\mathrm{C}^{\prime}$ & $C^{1}-C^{2}-N^{2}$ & $C^{1}-C^{2}$ & $\theta^{f}$ & Section & $\begin{array}{l}\text { Refer- } \\
\text { ence }\end{array}$ \\
\hline $2.069(3)$ & $1.397(4)$ & $1.280(5)$ & N.R. & $1.435(5)$ & $12.2^{\circ}$ & $\begin{array}{l}\text { III,E } \\
\text { (See } \\
\quad \text { Fig. 1) }\end{array}$ & 30 \\
\hline $2.14(1)$ & $1.43(1)$ & $1.30(1)$ & $115.9(6)$ & $1.45(1)$ & 5.0 & III,E & 50 \\
\hline $2.065(11)$ & $1.358(16)$ & $1.260(16)$ & $115.2(11)$ & $1.405(15)$ & 11.0 & III,E & 51 \\
\hline & $\begin{array}{l}C^{1}-N^{1} \\
C^{2}-N^{2}\end{array}$ & & & $C^{1}-C^{2}$ & & & \\
\hline & $1.395(10)$ & & & $1.396(11)$ & $\simeq 0^{\circ h}$ & $\begin{array}{l}\text { III,F } \\
\text { (See }\end{array}$ & 31 \\
\hline & $1.451(9)$ & & & & & Fig. 1) & \\
\hline & $1.39(2)$ & & & $1.42(3)$ & & III,F & 31 \\
\hline & $1.43(2)$ & & & $1.40(3)$ & & & 52 \\
\hline & $\begin{array}{l}1.392(5) \\
1.388(4)\end{array}$ & & & $1.407(5)$ & & $\mathrm{III}, \mathrm{F}$ & 53 \\
\hline
\end{tabular}

${ }^{f}$ Dihedral angle between $\mathrm{N}^{\prime}=\mathrm{C}^{\prime}$ and $\mathrm{N}^{2}-\mathrm{C}^{2}$.

${ }^{g} \mathrm{Ru}-\mathrm{u}^{-}-\mathrm{Ru}$ distance.

${ }^{h} R u^{\prime} N^{\prime} N^{2}$ plane makes dihedral angle of $14^{\circ}$ with the $N^{1} C^{1} C^{2} N^{2}$ plane.

${ }^{i} \mathrm{Ru}^{3}$ (in metallocycle) - $\mathrm{Ru}^{\prime}$ (between metallocycles) 2.838(2); $\mathrm{Ru}^{2}$ (in metallocycle) - $\mathrm{Ru}^{\prime}$ 2.848(2); $\mathrm{Ru}^{2}---\mathrm{Ru}^{3} 2.994(2) ; \mathrm{Ru}^{4}\left(\right.$ nonbridged) $-\mathrm{Ru}^{2} 2.838(2) ; \mathrm{Ru}^{4}-\mathrm{Ru}^{3} 2.846(2) \AA$.

pounds showed that only at low temperature (slow exchange limit) is the $\mathrm{R}-\mathrm{DAB}$ ligand monodentate bonded and rigid with a ground state conformation deduced to be similar to that in trans- $\mathrm{PdCl}_{2}\left(\mathrm{PPh}_{3}\right)(t$-Bu-DAB $)$ (Fig. 1). At room temperature the metal is rapidly changing its point of attachment by the process shown in Fig. 3.

At $-55^{\circ} \mathrm{C}$ the spectrum belonging to isomers $\mathrm{A}$ and $\mathrm{A}^{\prime}$ is observed (char- 


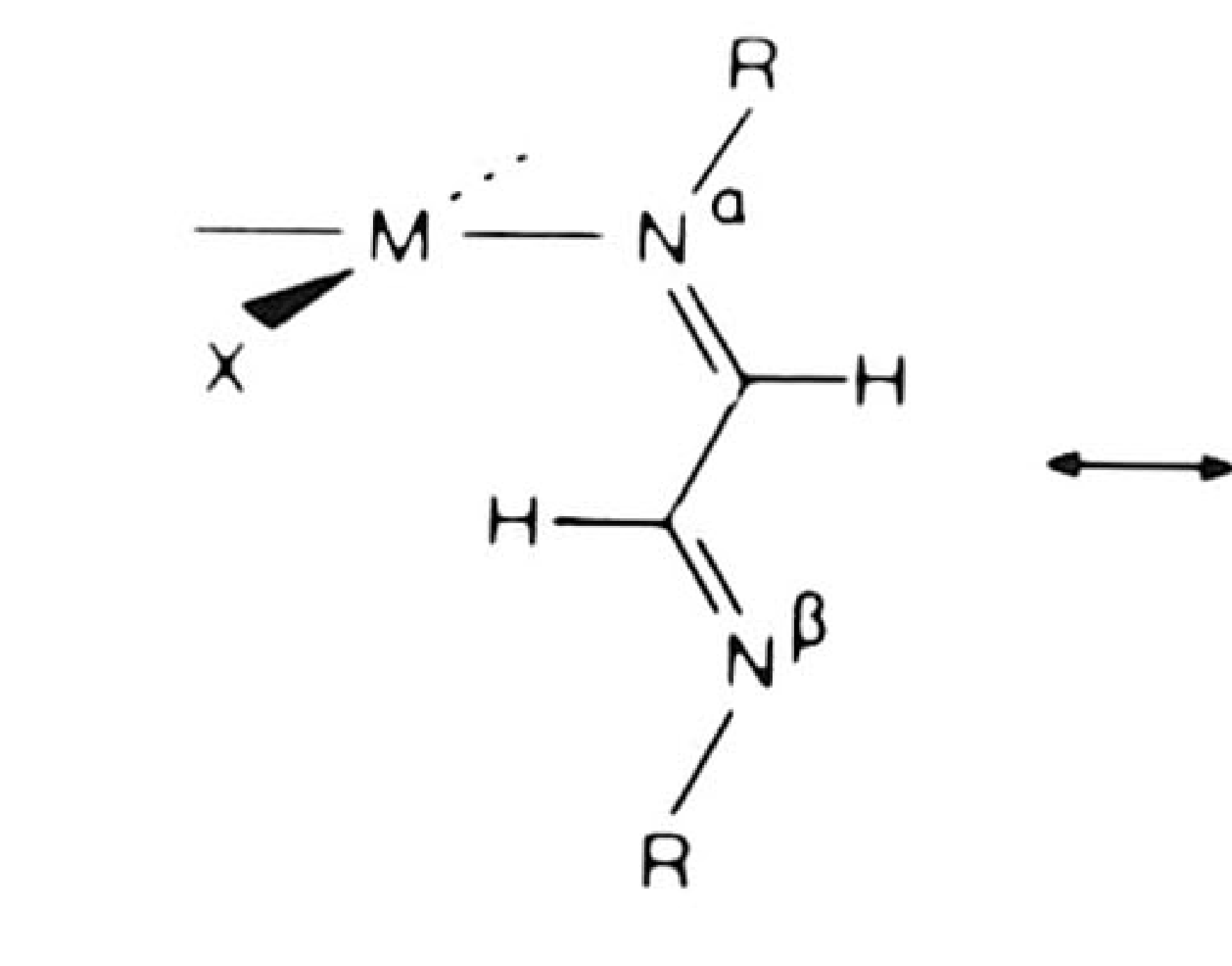

A<smiles>[X][M]N([R])C(/C=N/[R])=[N+]([R])C</smiles>

$A^{\prime}$

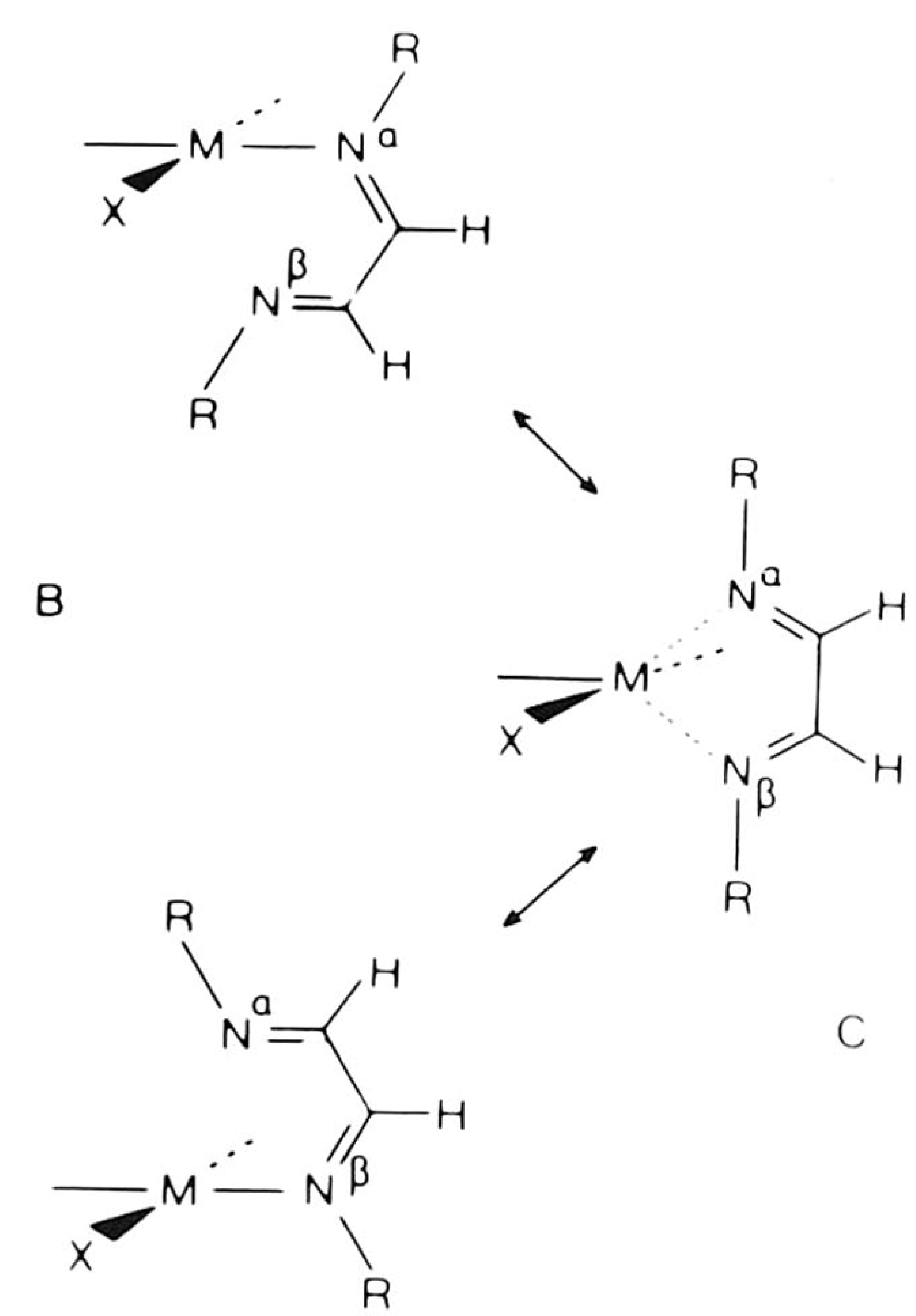

$B^{\prime}$

FIG. 3. Proposed mechanism for the fluxional behavior of trans- $\mathrm{MX}_{2}\left(\mathrm{PR}_{3}^{\prime}\right)(\mathrm{R}-\mathrm{DAB})(29)$ and trans- $N-\mathrm{MX}\left(\mathrm{C}_{6} \mathrm{H}_{4} \mathrm{CH}(\mathrm{Z}) \mathrm{NMe}_{2}\right)(\mathrm{R}-\mathrm{DAB})(36)\left(\mathrm{M}=\mathrm{Pt}\right.$ or $\mathrm{Pd} ; \mathrm{X}=\mathrm{Cl}, \mathrm{Br}$, or $\mathrm{I} ; \mathrm{R}^{\prime}$ $=\mathrm{Ph}, \mathrm{Bu} ; \mathrm{R}=t-\mathrm{Bu}$ or $\mathrm{EtMe}_{2} \mathrm{C} ; \mathrm{Z}=\mathrm{H}$ or $(S)-\mathrm{Me}$ ) complexes in solution (changing the point of attachment of the metal to the R-DAB ligand via $\sigma-\mathrm{N} \rightleftarrows \sigma, \sigma-\mathrm{N}, \mathrm{N}^{\prime}$ rearrangement).

acterized by the low field shift of $\mathrm{H}^{\beta}$ ). At room temperature a situation is reached in which the process $\mathrm{A} \rightleftarrows \mathrm{A}^{\prime}$ via $\mathrm{B}$ is rapid on the NMR time scale. This process involves $E$ to $Z$ inversion at the free $\mathrm{N}$ site and rotation around the central $\mathrm{C}-\mathrm{C}$ bond in order to bring the lone pair into the coordination sphere of the metal. In the intermediate or transition state B (cf. Ref. 35) the central metal is rehybridized from square planar to a trigonal bipyramidal configuration.

Replacement of one $\mathrm{Cl}$ and one phosphine ligand in the $\left[\mathrm{PdCl}_{2}-\right.$ $\left.\left(\mathrm{ER}_{3}^{\prime}\right)\right]_{n}(\mathrm{R}-\mathrm{DAB})(\mathrm{E}=\mathrm{P}, \mathrm{As})$ complexes by a carbon-nitrogen donor ligand leading to the compounds shown in Fig. $2 b$ even further destabilizes the $\mathrm{Pd}-\mathrm{N}$ (imine) interaction. For these compounds, which can only be studied in solution, an intramolecular process similar to that outlined for the $1: 1$ complexes in Fig. 3 has been established (36).

The decrease of the $\mathrm{M}-\mathrm{N}$ bond strength going from the Pd-R-DAB complexes $\mathrm{PdX}_{2}(\mathrm{R}-\mathrm{DAB})_{2},\left[\mathrm{PdX}_{2}\left(\mathrm{PR}_{3}^{\prime}\right)\right]_{2}(\mathrm{R}-\mathrm{DAB}), \mathrm{PdX}_{2}\left(\mathrm{PR}_{3}^{\prime}\right)(\mathrm{R}-\mathrm{DAB})$ to $\mathrm{PdX}\left(\mathrm{C}_{6} \mathrm{H}_{4} \mathrm{CH}_{2} \mathrm{NMe}_{2}-2\right)(\mathrm{R}-\mathrm{DAB})\left(\mathrm{R}=t\right.$ - $\mathrm{Bu}, \mathrm{EtMe}_{2} \mathrm{C} ; \mathrm{X}=\mathrm{Cl}, \mathrm{Br}$, or 
$\mathrm{I} ; \mathrm{R}^{\prime}=\mathrm{Bu}$ ) can be explained by an increase in electron density caused by the ligands trans to the imine- $\mathrm{N}$ atom thereby reducing the possibility of $\sigma$ donation from this $\mathrm{N}$ atom to the metal (36).

There is evidence for intermediates containing $\sigma$-monodentate bonded R-DAB molecules, e.g., the $1: 1 \mathrm{Et}_{3} \mathrm{Al}-\mathrm{R}-\mathrm{DAB}$ complexes which are stable only at temperatures below $-10^{\circ} \mathrm{C}$ (for $\mathrm{R}=t$ - $\mathrm{Bu} \delta \mathrm{H}^{\alpha}$ is 7.65 and $\delta \mathrm{H}^{\beta} 8.90$ ppm again pointing to an $E$-s-trans- $E$ conformation for the monodentate bonded ligand) (54). The course of these reactions at room temperature is discussed in Section VI,B.

Finally, the reaction of $\mathrm{M}(\mathrm{CO})_{5} \mathrm{THF}(\mathrm{M}=\mathrm{Cr}, \mathrm{Mo})$ with Ph-DAB at $-60^{\circ} \mathrm{C}$ afforded $\mathrm{M}(\mathrm{CO})_{5}(\mathrm{Ph}-\mathrm{DAB})$ in which, according to IR and NMR spectra, the Ph-DAB ligand is $\sigma-\mathrm{N}(2 \mathrm{e})$ bonded to the bulky $\mathrm{M}(\mathrm{CO})_{5}$ group. This complex is converted above $-20^{\circ} \mathrm{C}$ to $\mathrm{M}(\mathrm{CO})_{4}(\mathrm{Ph}-\mathrm{DAB})$ (55).

\section{Bridging $\left(\sigma-N, \sigma-N^{\prime} ; 2 e+2 e\right)$ 1,4-Diaza-1,3-butadienes}

It has already been pointed out that the $\sigma$ - $\mathrm{N}$ monodentate and the $\sigma$ $\mathrm{N}, \sigma-\mathrm{N}^{\prime}$ bridging bonding modes of the R-DAB ligand are very much related because both have the $E$ - $s$-trans- $E$ conformation of the $\mathrm{N}=\mathrm{C}-\mathrm{C}=\mathrm{N}$ skeleton as a common structural feature. As for the $\sigma-\mathrm{N}$ monodentate R-DAB complexes the structure of one example of a bridge bonding mode, i.e., of stable $\left[\mathrm{PtCl}_{2}\left(\mathrm{PBu}_{3}\right)\right]_{2}(t$-BuDAB $)[\mathrm{Eq}$. (4)] has been established by X-ray structure determination $(32,56)$ (see Fig. 1). Indeed this structure contains a planar $\mathrm{ClPtN}=\mathrm{C}-\mathrm{C}=\mathrm{NPtCl}$ skeleton while $\mathrm{H}^{\beta}$ resides at a calculated $\mathrm{Pt}---\mathrm{H}^{\beta}$ distance of $2.6 \AA$ which again is within the distance of $3.2 \AA$ expected for van der Waals contacts. These structural features are retained in solution as can be concluded from, for example, ${ }^{15} \mathrm{~N}$ and ${ }^{195} \mathrm{Pt}$ NMR data (35) and the characteristic low field shift of $\mathrm{H}^{\beta}$ in the ${ }^{1} \mathrm{H}$ NMR spectrum (32).

Likewise the 1:1 complex containing the cyclometalated Pd unit (see Fig. 2b) can be converted to a dinuclear complex $\stackrel{\mathrm{Pd}\left(\mathrm{C}_{6} \mathrm{H}_{4} \mathrm{CH}\right.}{-}$ $\left.\left.\overline{(Z) N} \mathrm{Me}_{2}-2\right) \mathrm{X}\right]_{2}(\mathrm{R}-\mathrm{DAB})(\mathrm{Z}=\mathrm{H}$ or $(S)-\mathrm{Me} ; \mathrm{X}=\mathrm{Cl}, \mathrm{Br}, \mathrm{I} ; \mathrm{R}=t$-Bu, $\mathrm{EtMe}_{2} \mathrm{C}$ ) that can be isolated when $\mathrm{R}=t$ - $\mathrm{Bu}$. This compound has a similar structure to $\left[\mathrm{PtCl}_{2}\left(\mathrm{PBu}_{3}\right)\right]_{2}(t-\mathrm{Bu}-\mathrm{DAB})$ i.e., an $E$ - $s$-trans- $E \quad \mathrm{PdN}=$ $\mathrm{C}-\mathrm{C}=\mathrm{NPd}$ skeleton with the $\mathrm{N}$ ligands in each $\mathrm{Pd}$ coordination plane in trans position (36).

Other complexes with bridging R-DAB ligands, again comprising metals from the $d^{8}$ series, have been derived from the bridge splitting reactions [cf. Eqs. (4)] of $\left[\mathrm{MCl}\left(\eta^{3} \text {-allyl }\right)\right]_{n}(\mathrm{M}=\mathrm{Pd}, n=2 ; \mathrm{M}=\mathrm{Pt}, n=4)$ with various $\mathrm{R}-\mathrm{DAB}$ ligands (57). In the presence of $\mathrm{NaClO}_{4}$ exclusively complexes $\left[\mathrm{M}\left(\eta^{3}\right.\right.$-allyl $\left.)(\mathrm{R}-\mathrm{DAB})\right] \mathrm{ClO}_{4}\left(\mathrm{M}=\mathrm{Pd} ; \mathrm{R}=\mathrm{C}_{6} \mathrm{H}_{4} \mathrm{OMe}-p ; \mathrm{M}=\mathrm{Pt}\right.$; $\left.\mathrm{R}=\mathrm{Ph}, \mathrm{R}^{\prime}=\mathrm{Me}\right)$ were isolated containing $\sigma, \sigma-\mathrm{N}, \mathrm{N}^{\prime}$ chelate bonded $\mathrm{R}$ - 
DAB [see Eq. (5)]. However, in the absence of strong anions complexes with $\left[\operatorname{PdCl}\left(\eta^{3} \text {-allyl }\right)\right]_{2}(\mathrm{R}-\mathrm{DAB})$ stoichiometry were observed pointing to the presence of $\sigma-\mathrm{N}, \sigma-\mathrm{N}^{\prime}$ bridging R-DAB ligands. These complexes were only stable for the $t$-Bu-DAB ligand and then only when in apolar solvents. Replacement of one $\mathrm{H}$ for Me destabilized the dinuclear species and produced (in methanol) the ionic complex $\left\{\mathrm{Pd}\left(\eta^{3}\right.\right.$-allyl $\left.)[\mathrm{R}-\mathrm{DAB}(\mathrm{H}, \mathrm{Me})]\right\}$ $\left[\mathrm{PdCl}_{2}\left(\eta^{3}\right.\right.$-allyl $\left.)\right]\left(\mathrm{R}=\mathrm{C}_{6} \mathrm{H}_{4} \mathrm{OMe}-p\right)$ with a $\sigma, \sigma-\mathrm{N}, \mathrm{N}^{\prime}$ chelate bonded R$\mathrm{DAB}(\mathrm{H}, \mathrm{Me})$ ligand in the cation. This is in line with our earlier suggestion (see Section III,A) that the presence of methyl groups at the central C atoms stabilized the $E$-s-cis- $E$ conformer relative to its $s$-trans isomer. On the other hand it must be recalled that for these complexes the bridging bonding mode can also be assumed because the Pd center has a square planar coordination geometry.

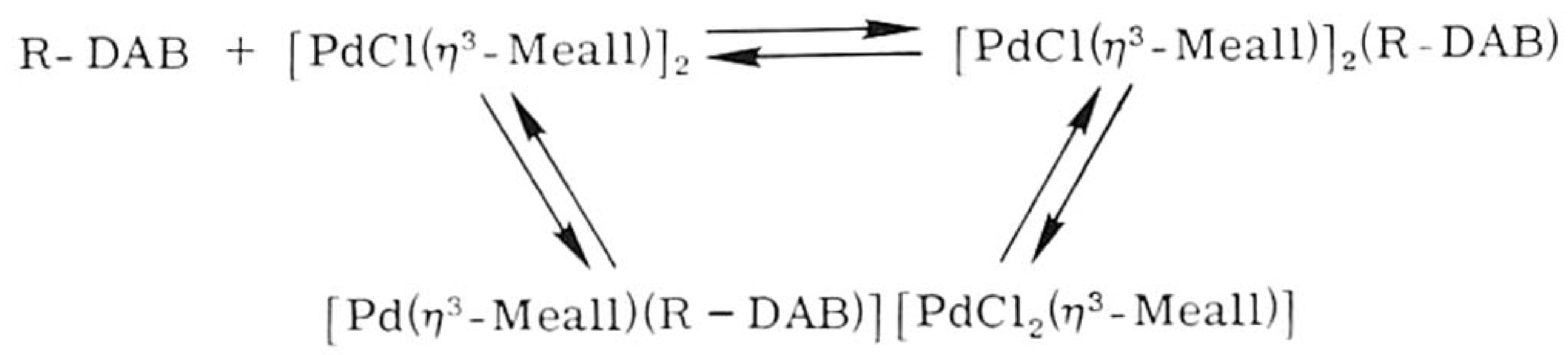

With regard to the above it is not surprising that the mononuclear $\mathrm{Pd}^{0}$ compound $\mathrm{Pd}\left(\eta^{2}\right.$-olefin $)(\mathrm{R}-\mathrm{DAB})$ can be converted to a dinuclear $\mathrm{Pd}^{0}$ compound with a $\sigma-\mathrm{N}, \sigma-\mathrm{N}^{\prime}$ bridge bonding mode by addition of a coordinating molecule [see Eq. (6)]. The dinuclear compound (containing three coordinate $\mathrm{Pd}^{0}$ ) is stable because the metal has the required planar geometry. Equation (6) furthermore shows that oxidative addition of $\left[\operatorname{Pd}\left(\eta^{2}\right.\right.$-olefin $)(t$ $\mathrm{Bu}-\mathrm{DAB})]$ with methylallyl chloride produces $\left[\mathrm{PdCl}\left(\eta^{3}-\mathrm{Meall}\right)\right]_{2}(t-\mathrm{Bu}-$ DAB) (58).

$$
\begin{gathered}
2 \operatorname{Pd}\left(\eta^{2} \text {-olefin }\right)(t-\mathrm{Bu}-\mathrm{DAB})+\text { olefin } \longrightarrow\left[\operatorname{Pd}\left(\eta^{2} \text {-olefin }\right)\right]_{2}(t \text {-Bu-DAB }) \\
\text { MeallCl } \downarrow-\text { olefin and } t \text {-Bu-DAB } \\
\left\{\left[\operatorname{PdCl}\left(\eta^{3} \text {-Meall }\right)\right]_{2}(t-\text { Bu-DAB }\} \quad \text { olefin }=\operatorname{dmf}(e m f)\right.
\end{gathered}
$$

Bridging R-DAB ligands have also been observed in $\mathrm{Rh}^{\mathrm{I}}$ chemistry (34, $59-61)$. Bridge splitting reactions of $\mathrm{Rh}(\mathrm{CO})_{2}(\mu-\mathrm{Cl})_{2} \mathrm{Rh}(\mathrm{CO})_{2}$ with $\mathrm{R}$ $\mathrm{DAB}$ afforded complexes with $\left\{\left[\mathrm{RhCl}(\mathrm{CO})_{2}\right]_{2}(\mathrm{R}-\mathrm{DAB})\right\} \quad(\mathrm{R}=t-\mathrm{Bu}$, $\mathrm{Et} \mathrm{Me}_{2} \mathrm{C}$ ) stoichiometry. The actual species and ratios present in solution is dependent on the branching at $C^{\alpha}$ and $C^{\beta}(34)$. It appeared that due to the weaker Rh-R-DAB bonding there exists in solution an equilibrium mixture of the dinuclear species $\mathrm{RhCl}(\mathrm{CO})_{2}\left[\mu-\left(\sigma-\mathrm{N}, \sigma-\mathrm{N}^{\prime}\right)-\mathrm{R}-\mathrm{DAB}\right]-$ $\mathrm{RhCl}(\mathrm{CO})_{2}$ and the ionic species $\left[\mathrm{Rh}(\mathrm{CO})_{2}(\mathrm{R}-\mathrm{DAB})\right]\left[\mathrm{RhCl}_{2}(\mathrm{CO})_{2}\right]$.

If the ligand is $t$-Bu-DAB the dinuclear complex is the major species. Intermolecular exchange between these dinuclear and ionic $\mathrm{Rh}$ species is 
fast on the NMR time scale at room temperature (34) (Section III,D,2,e).

Bridging R-DAB has also been reported in the reaction of the 1,4-diaza1,3-butadien-2-ylpalladium compound with $\left[\mathrm{RhCl}(\mathrm{CO})_{2}\right]_{2}$ shown in Eq. (7) $(60)$.

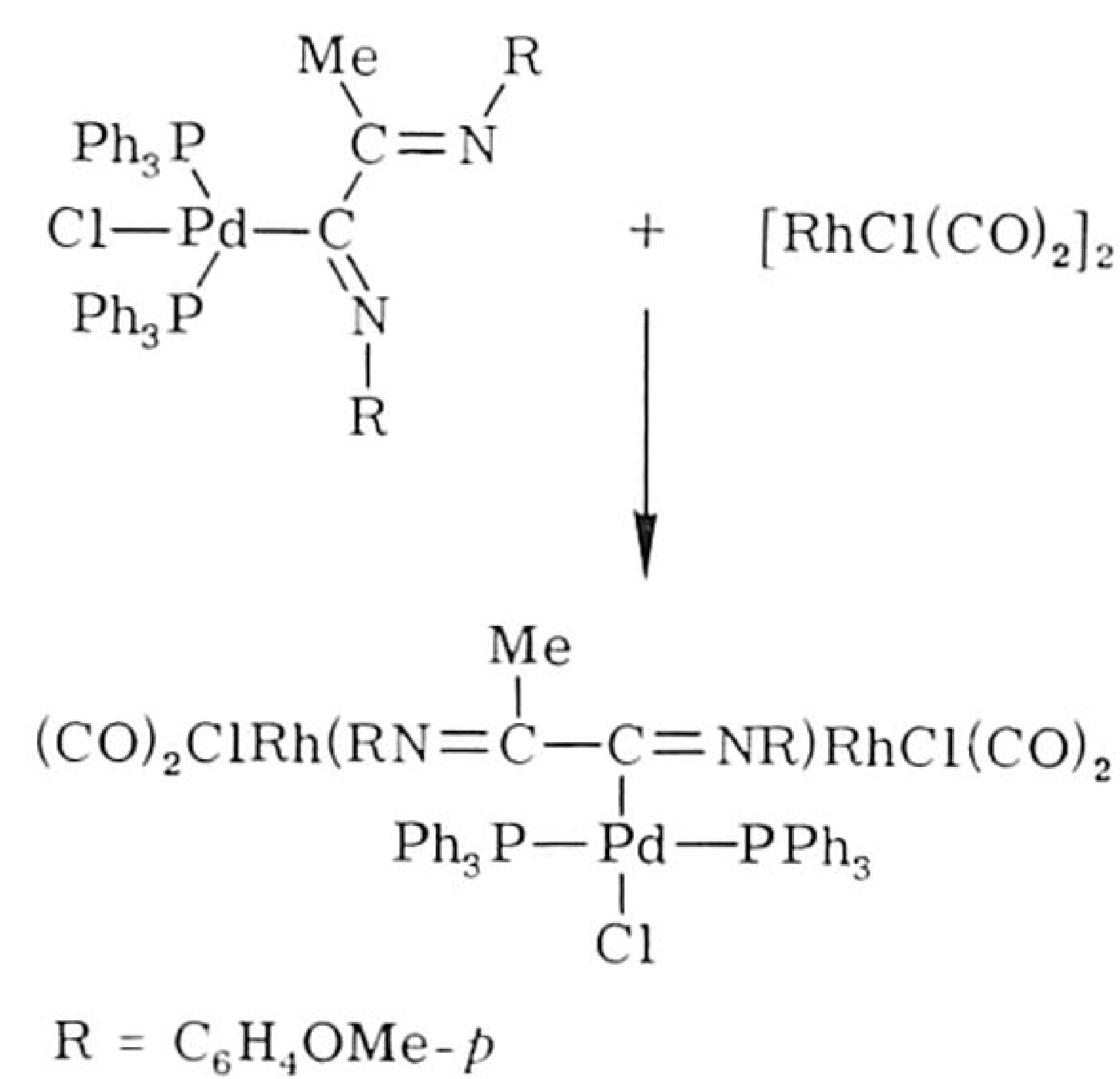

\section{Chelate Bonded $\left(\sigma, \sigma-N, N^{\prime} ; 4 e\right)$ 1,4-Diaza-1,3-butadienes}

The chemistry and structural aspects of metal complexes containing chelated bonded R-DAB have been well explored in contrast to the other bonding modes that have been realized only recently. Accordingly a vast amount of information is available that will be covered in two sections. First, the commonly applied synthetic routes will be discussed. Second, the specific synthetic and structural features will be treated with the complexes arranged according to the group to which the metal belongs. In this latter section the main results and general conclusions emerging from the sometimes detailed investigations of the bonding features of these complexes by MO calculations, resonance Raman spectroscopy (RR), and NMR and ESR spectroscopy will also be put forward.

\section{General Synthetic Methods}

Most complexes have been prepared by mixing a metal salt with the R$\mathrm{DAB}$ ligand in the required molar ratio. Examples are the syntheses of $\mathrm{MCl}_{2}\left(p-\mathrm{MeOC}_{6} \mathrm{H}_{4}-\mathrm{DAB}\right)$ complexes of $\mathrm{Zn}, \mathrm{Cd}$, and $\mathrm{Hg}(62)$.

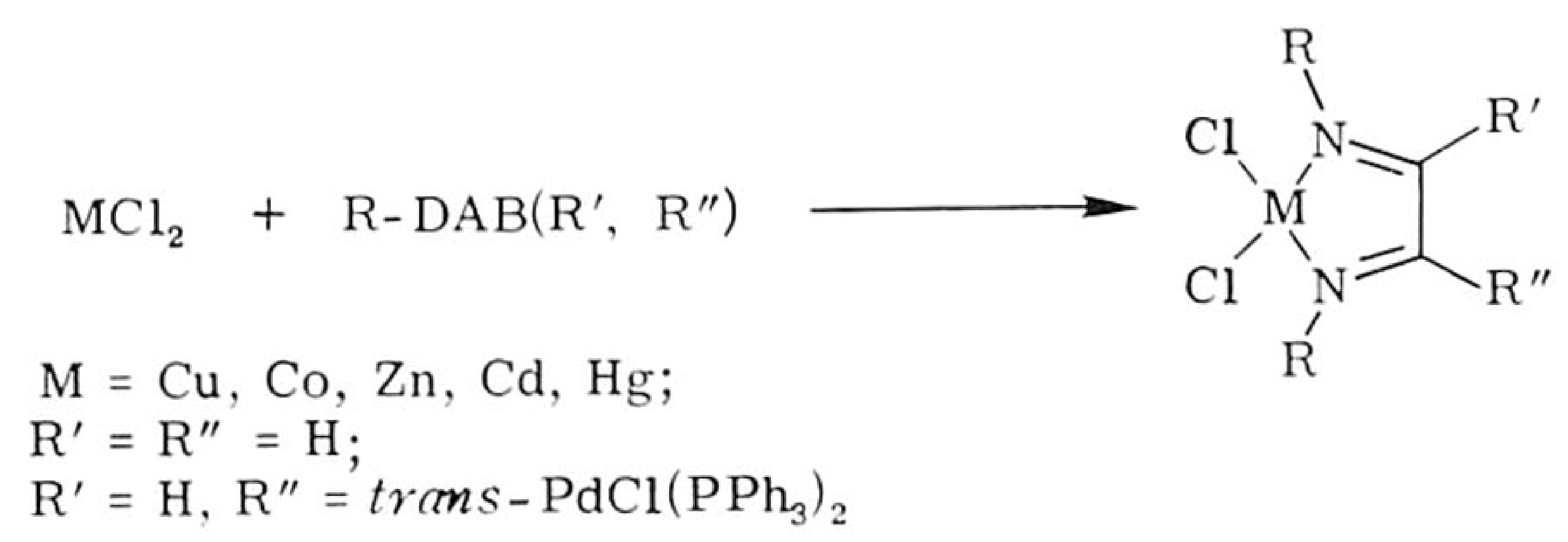


Likewise reaction of a 1,4-diaza-1,3-butadien-2-ylmetal complex with $\mathrm{CuCl}_{2}, \mathrm{CoCl}_{2}$, and $\mathrm{ZnCl}_{2}$ gives the corresponding 1:1 complexes. This route is summarized in Eq. (8) $(60,63-67)$. Diarylzinc-R-DAB complexes have been similarly prepared (68) (see Section III,D,2,g).

For the synthesis of metal carbonyl complexes various routes have been reported. Methods that are not of general applicability (being unique for a given compound) are described in Section III,D,2.

a. Thermal Reaction of the Metal Hexacarbonyl Complexes with $R$ $D A B$. Reaction of $\mathrm{Mo}(\mathrm{CO})_{6}$ with $\mathrm{Ph}-\mathrm{DAB}(\mathrm{Me}, \mathrm{Me})$ afforded at $80^{\circ} \mathrm{C}$ via a slow substitution of $\mathrm{CO}$ the corresponding $\mathrm{Mo}(\mathrm{CO})_{4}[\mathrm{Ph}-\mathrm{DAB}(\mathrm{Me}, \mathrm{Me})]$ complexes $(69,70)$.

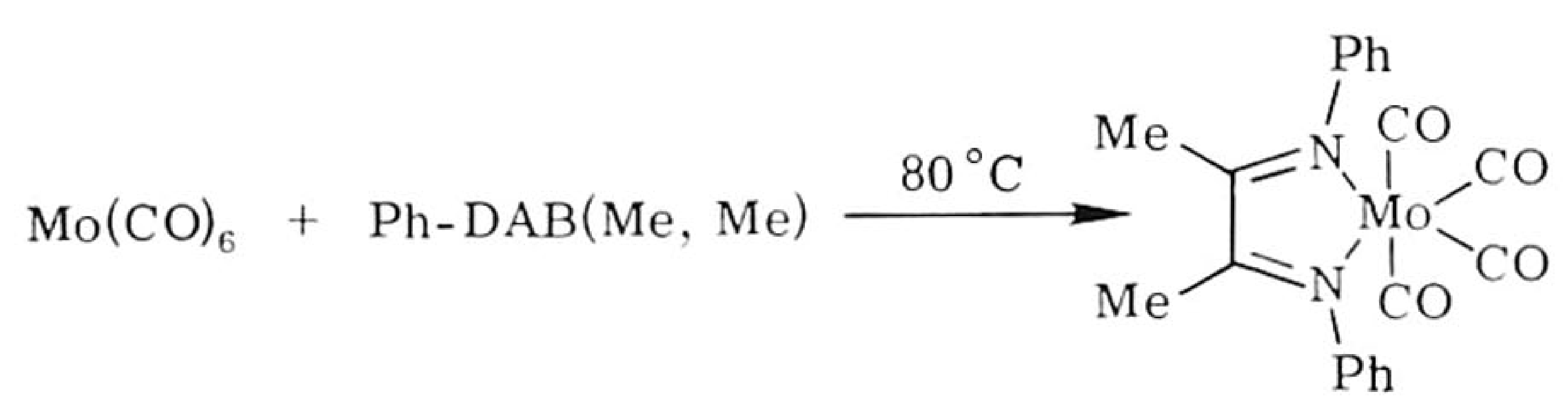

b. Ligand Substitution of Metal Carbonyl Derivatives. Since reaction (9) at elevated temperatures often leads to side reactions a better procedure involves the use of metal carbonyl derivatives containing at least one ligand that is weakly bonded. Two such reactions are shown in Eqs. (10) (71) and (11) (55).

$$
\mathrm{MX}\left(\eta^{3}-\mathrm{C}_{3} \mathrm{H}_{4} \mathrm{R}^{\prime}\right)(\mathrm{CO})_{2}(\mathrm{MeCN})_{2}+\mathrm{R}-\mathrm{DAB}
$$


It has been shown that the conversion of the $\sigma-\mathrm{N}$ to a $\sigma, \sigma-\mathrm{N}, \mathrm{N}^{\prime}$ bonded $\mathrm{Ph}-\mathrm{DAB}$ ligand in Eq. (11) is a fast reaction.

c. Substitution in the Ligand Sphere of a Metal. Some R-DAB ligands are either not known as free molecules or have only a very limited stability. For these ligands the synthesis of complexes by an in situ preparation is a well-known approach and are illustrated in Eqs. (12) $(11,69)$ and (13) (72).

$$
2 \mathrm{Aryl}-\mathrm{NH}_{2}+\mathrm{O}=\mathrm{C}(\mathrm{Me}) \mathrm{C}(\mathrm{Me})=\mathrm{O}+\mathrm{Mo}(\mathrm{CO})_{6} \frac{-2 \mathrm{CO}}{-2 \mathrm{H}_{2} \mathrm{O}}
$$

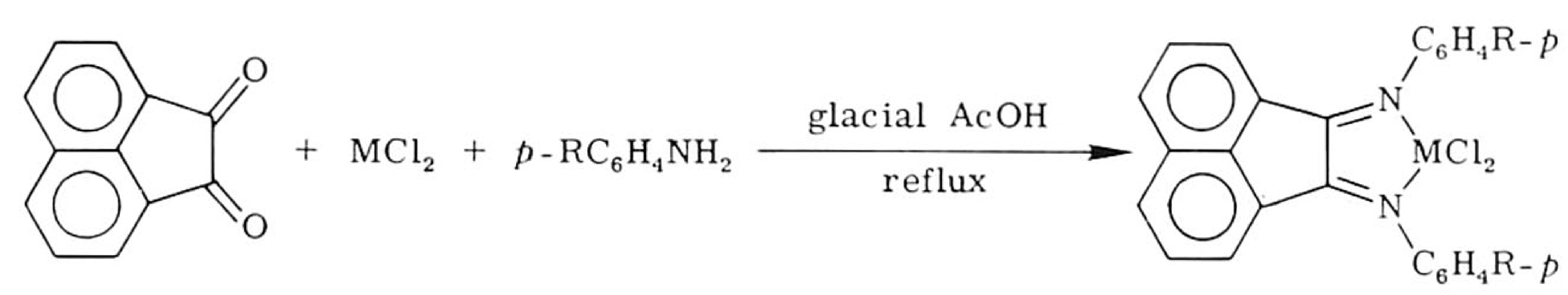

$\mathrm{R}=$ e.g., $\mathrm{Me}, \mathrm{NO}_{2}$

$\mathrm{M}=\mathrm{Zn}, \mathrm{Co}, \mathrm{Ni}$, or $\mathrm{Cu}$

Another interesting reaction involves the exchange of an amino for a benzyl group as illustrated in Eq. (14) (69).<smiles>Cc1c([NH2+]Cc2ccccc2)n(C(=O)[O-])[n+](N)c1C</smiles>

d. Via Reduction of Metal Halides in the Presence of $R-D A B$. A large number of zerovalent metal 1,4-diaza-1,3-butadiene complexes are accessible via reactions of R-DAB with zerovalent metal-ligand complexes, or via reduction of metal-ligand complexes with Grignard or aluminum compounds in the presence of R-DAB. Examples are shown in Eqs. (15)-(18).

$$
\begin{gathered}
\mathrm{Ni}(\mathrm{COD})_{2}+2 \mathrm{R}-\mathrm{DAB} \rightarrow \mathrm{Ni}(\mathrm{R}-\mathrm{DAB})_{2}+2 \mathrm{COD}(9,10,73,74) \\
\mathrm{Pt}(\mathrm{COD})_{2}+\mathrm{R}-\mathrm{DAB} \rightarrow \mathrm{Pt}(\mathrm{COD})(\mathrm{R}-\mathrm{DAB})+\mathrm{COD}(75) \\
\mathrm{Pd}(\mathrm{DBA})_{2}+\mathrm{R}-\mathrm{DAB}+\text { olefin } \rightarrow \mathrm{Pd}(\mathrm{R}-\mathrm{DAB})\left(\eta^{2} \text {-olefin }\right)(58)
\end{gathered}
$$




$$
\mathrm{Cr}(\mathrm{acac})_{3}+2 \mathrm{R}-\mathrm{DAB} \underset{\mathrm{THF}}{\stackrel{3 \mathrm{e}^{-}}{\longrightarrow}} \mathrm{Cr}(\mathrm{R}-\mathrm{DAB})_{2}(73)
$$

\section{Structural and Bonding Aspects}

a. Groups IIIA-VA. Only limited information is available concerning the complex formation of R-DAB ligands with the early transition metals. Some work has been done directed to the synthesis of $\mathrm{TiCl}_{4}(\mathrm{R}-\mathrm{DAB})(\mathrm{R}$ $=$ e.g., $i$ - $\left.\mathrm{Pr}, t-\mathrm{Bu}, c-\mathrm{Hex}, \mathrm{C}_{6} \mathrm{H}_{4} \mathrm{OMe}-p\right)$ complexes. These are insoluble in apolar solvents and decompose upon attempted recrystallization from polar solvents such as $\mathrm{Me}_{2} \mathrm{SO}$ and DMF (76). $\sigma, \sigma-\mathrm{N}, \mathrm{N}^{\prime}$ chelate bonding for the $\mathrm{R}-\mathrm{DAB}$ in these complexes has been proposed but IR data could not unambiguously preclude the fact that these complexes could be oligomers rather than monomers.

Unsuccessful attempts were undertaken to reduce these $\mathrm{TiCl}_{4}(\mathrm{R}-\mathrm{DAB})$ complexes to $\mathrm{Ti}^{0}(\mathrm{R}-\mathrm{DAB})_{2}$. In contrast, blue-green colored $\mathrm{V}(i \text {-Pr-DAB })_{3}$, which appeared to be relatively stable, was obtained from the reaction of $\mathrm{VCl}_{3}$ with $i$-Pr-DAB and sodium in THF (76).

b. Group VIA. Complexes of the $d^{6}$ metals $\mathrm{Cr}$, Mo, and $\mathrm{W}$ containing exclusively R-DAB ligands have been reported for $\mathrm{Cr}(74,76)$. The number of R-DAB ligands bonded to $\mathrm{Cr}$ is dependent on the type of substituents present, e.g., tetracoordinate $\mathrm{Cr}(\mathrm{R}-\mathrm{DAB})_{2}$ was obtained for $\mathrm{R}=i-\mathrm{Pr}_{2} \mathrm{CH}$ and $t-\mathrm{Bu}$, and hexacoordinate $\mathrm{Cr}(\mathrm{R}-\mathrm{DAB})_{3}$ for $\mathrm{R}=i$-Pr. Analogous complexes of zerovalent Mo have not been isolated although some evidence for the synthesis of $\mathrm{Mo}\left(i-\mathrm{Pr}_{2} \mathrm{CH}-\mathrm{DAB}\right)_{2}(\mathrm{MeCN})_{2}$ containing cis-positioned $\mathrm{MeCN}$ ligands was obtained (76).

Stable R-DAB-metal carbonyl complexes were obtained starting from hexacarbonyls [cf. Eq. (9)] and complexes with $\mathrm{M}(\mathrm{CO})_{4}(\mathrm{R}-\mathrm{DAB})$ stoichiometry have been reported for all three metals (Cr: 55, 77-80; Mo: 55, $69,77-91 ; \mathrm{W}: 55,77-80,88)$. These compounds have the symmetry properties of the $C_{2 v}$ point group, they are strongly colored and the bidentate nitrogen donor ligand shows strong $\pi$-bonding interaction with the group VIA metal (vide infra). The molecular geometry of $\mathrm{Mo}(\mathrm{CO})_{4}(\mathrm{R}-\mathrm{DAB})$ $\left(\mathrm{R}=i\right.$ - $\mathrm{Pr}$ and $\left.2,6-(i-\mathrm{Pr})_{2} \mathrm{C}_{6} \mathrm{H}_{3}\right)(37)$ has been established by $\mathrm{X}$-ray structural determinations (see Table II).

Thermally stable $\mathrm{Mo}(\mathrm{CO})_{4}(\mathrm{R}-\mathrm{DAB})$ undergoes single $\mathrm{CO}$ substitution with tertiary phosphines in boiling benzene leading to $\mathrm{Mo}(\mathrm{CO})_{3^{-}}$ $\left(\mathrm{PR}_{3}^{\prime}\right)(\mathrm{R}-\mathrm{DAB})\left(\mathrm{R}^{\prime}=\mathrm{Ph}, \mathrm{Bu}(70,78,81,84,86-88,92,93) \mathrm{R}=\right.$ alkyl or aryl).

In the case of thermally less stable complexes the route shown in Eq. (19) can be followed (94). 


$$
\mathrm{Mo}(\mathrm{CO})_{3}(\mathrm{MeCN})_{3}+\mathrm{R}-\mathrm{DAB} \frac{2{ }^{\circ} \mathrm{C}}{\mathrm{C}_{6} \mathrm{H}_{6}}
$$

The interesting point of this synthesis is that exclusively the cis product is formed. In Eq. (20) the synthesis of a bisphosphine complex is shown that likewise occurs with high stereospecificity (95).

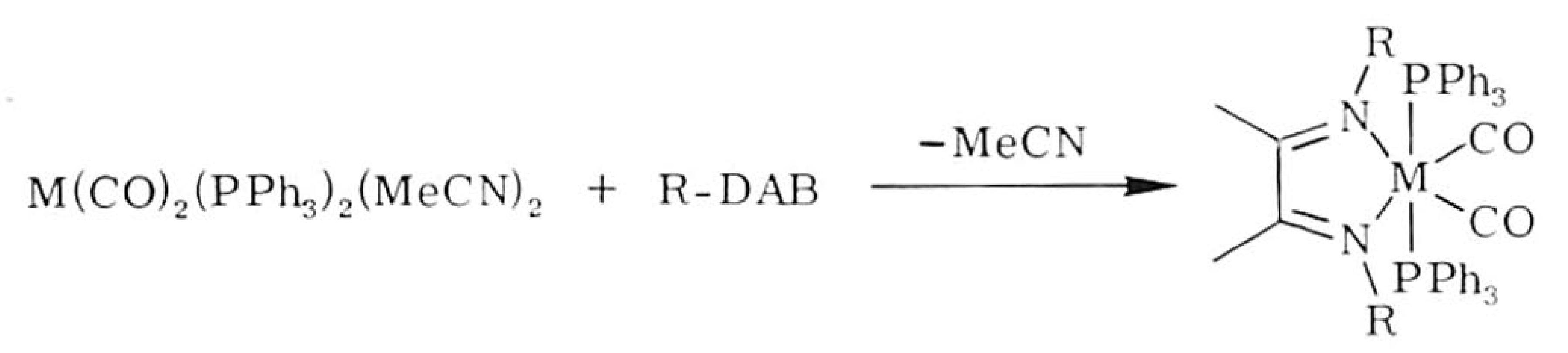

Other $\mathrm{Mo}(\mathrm{CO})_{2}\left(\mathrm{PR}_{3}^{\prime}\right)_{2}(\mathrm{R}-\mathrm{DAB})$ complexes where $\mathrm{R}^{\prime}=\mathrm{Bu}(81,93), \mathrm{Ph}$ (85), and Et (87) have been reported.

The $\mathrm{Cr}$ and Mo complexes $\mathrm{M}(\mathrm{CO})_{4}(\mathrm{R}-\mathrm{DAB})$, in which $\mathrm{R}=i-\mathrm{Pr}$, have a sufficiently high photoreactivity to form the monosubstituted $\mathrm{M}(\mathrm{CO})_{3}\left[\mathrm{P}(\mathrm{OMe})_{3}\right](i$-Pr-DAB $)$ complexes in the presence of $\mathrm{P}(\mathrm{OMe})_{3}$ upon irradiation within the MLCT (metal-to-ligand charge transfer) band (80). In contrast no photosubstitution is observed for the $\mathrm{W}$ compound when $\mathrm{R}$ is $p$-tolyl.

$\mathrm{MX}\left(\mathrm{R}^{\prime}-\mathrm{All}\right)(\mathrm{CO})_{2}(\mathrm{R}-\mathrm{DAB})$ complexes of the $d^{6}$ metal-R-DAB complexes are obtained by treating the acetonitrile complexes $\operatorname{MX}\left(\eta^{3}-\right.$ $\left.\mathrm{C}_{3} \mathrm{H}_{4} \mathrm{R}^{\prime}\right)(\mathrm{CO})_{2}(\mathrm{MeCN})_{2}\left(\mathrm{M}=\mathrm{Mo}, \mathrm{W} ; \mathrm{R}^{\prime}=\mathrm{H}\right.$ or $\mathrm{Me}$ and $\mathrm{X}=\mathrm{Cl}$ or $\left.\mathrm{Br}\right)$ with R-DAB ( $\mathrm{R}=$ alkyl or aryl) according to Eq. (10) (7l). The oxidative addition reaction of $f a c-\mathrm{M}(\mathrm{CO})_{3} \mathrm{~L}_{2} \mathrm{~L}^{\prime}(\mathrm{M}=\mathrm{Mo}, \mathrm{W})$ with $\mathrm{R}^{\prime} \mathrm{C}_{3} \mathrm{H}_{4} \mathrm{X}$, which was shown to be successful when $\mathrm{L}_{2}$ is phenanthroline or 2,2'-bipyridine (96), does not proceed when $\mathrm{L}_{2}$ is R-DAB (71).

The structures of $\mathrm{MoCl}\left(\eta^{3}-\mathrm{C}_{3} \mathrm{H}_{4} \mathrm{Me}\right)(\mathrm{CO})_{2}(c-\mathrm{Hex}-\mathrm{DAB})(38)$ and of $\mathrm{WBr}\left(\eta^{3}-\mathrm{C}_{3} \mathrm{H}_{5}\right)(\mathrm{CO})_{2}(\mathrm{c}-\mathrm{Hex}-\mathrm{DAB})(39)$ have been solved by X-ray structure determinations (see Table II) and these are schematically shown in Eq. (10). The observation that the cis positioned $\mathrm{Cl}$ atom can be exchanged 
for $\mathrm{Br}$, I, or $\mathrm{SCN}$ whereas no reaction was observed with, for example, $\mathrm{HgCl}_{2}$ was ascribed to steric hindrance imposed by the $\mathrm{N}$ substituents $(71)$.

$\operatorname{MoX}\left(\eta^{3}-\mathrm{C}_{3} \mathrm{H}_{5}\right)(\mathrm{CO})_{2}(c-\mathrm{Hex}-\mathrm{DAB})$ can be converted to cationic complexes with $\mathrm{Ag}^{\mathrm{I}}$ or $\mathrm{Tl}^{\mathrm{I}} \mathrm{BF}_{4}$ in the presence of a suitable ligand such as pyridine (71). An interesting aspect of these complexes is their structural similarity to the corresponding 2,2'-bipyridine and phenanthroline complexes but the reactivity of the R-DAB complexes is far less.

A stable trinuclear molybdenum-mercury compound was obtained via the reaction shown in Eq. (21) (97).

$$
\begin{gathered}
2 \mathrm{~K}^{+}\left[\mathrm{Mo}(\mathrm{CO})_{4}(\mathrm{R}-\mathrm{DAB})\right]+\mathrm{HgCl}_{2} \longrightarrow 2 \mathrm{KCl}+2 \mathrm{CO}+\left[\mathrm{Mo}(\mathrm{CO})_{3}(\mathrm{R}-\mathrm{DAB})\right]_{2} \mathrm{Hg} \\
\mathrm{R}=t-\mathrm{Bu}, i-\mathrm{Pr}
\end{gathered}
$$

The bonding of the $\mathrm{M}(\mathrm{CO})_{4}(\mathrm{R}-\mathrm{DAB})(\mathrm{M}=\mathrm{Cr}$, Mo, W) complexes has been extensively investigated. These studies were induced in particular by the intense colors they exhibit in solution ranging from purple to orange. Indeed all compounds have an absorption in the visible region with an $\epsilon$ value of 7.000-17.500 liters $\mathrm{mol}^{-1} \mathrm{~cm}$ in cyclohexane (69). This absorption originated from a metal-to-ligand charge transfer (MLCT) transition, i.e., electron transfer from filled metal $d$ orbitals into the empty $\pi^{*}$ orbital of the ligand $(69,84,98)$. This transfer is possible because the planarity of the five-membered metallocycle allows overlap of metal $d$ and $\pi^{*}$ orbitals.

Combined data from resonance Raman spectra, magnetic circular dichroism measurements, and UV spectra showed that the CT band comprised four separate electronic transitions $(55,78,99)$. The relevant part of a tentative $\mathrm{MO}$ scheme for the five allowed $\mathrm{CT}$ transitions is shown in Fig. 4 together with their polarization characteristics. Apart from the five symmetry allowed transitions there is one symmetry forbidden $\left(a_{2} \leftarrow a_{1}\right)$ while $\left(b_{2} \leftarrow a_{1}\right)$ is overlap forbidden (55).

The maximum of the $\mathrm{CT}$ band of the $\mathrm{Mo}(\mathrm{CO})_{4}(\mathrm{R}-\mathrm{DAB})$ complexes shifts with changing polarity of the solvent $\left(69,83-86,{ }^{4} 91,100,101\right)$, socalled solvatochromism, which is due to the fact that the ground state molecule is polar. This dependence is illustrated by Table III and has been used to quantify the polarity of a series of solvents (86).

Strong solvatochromism only occurs for electronic transitions in which electron transfer takes place along the dipole moment vector that for $\mathrm{Mo}(\mathrm{CO})_{4}(\mathrm{R}$-DAB $)$ coincides with the $z$-vector shown in Fig. 4. This was indicated by the observation that the resonance Raman effect is more

\footnotetext{
${ }^{4}$ In Ref. 85 the term negative is erroneously used when positive solvatochromism is meant. The latter refers to a shift of the maximum to shorter wavelength on going from apolar to polar solvent.
} 
a

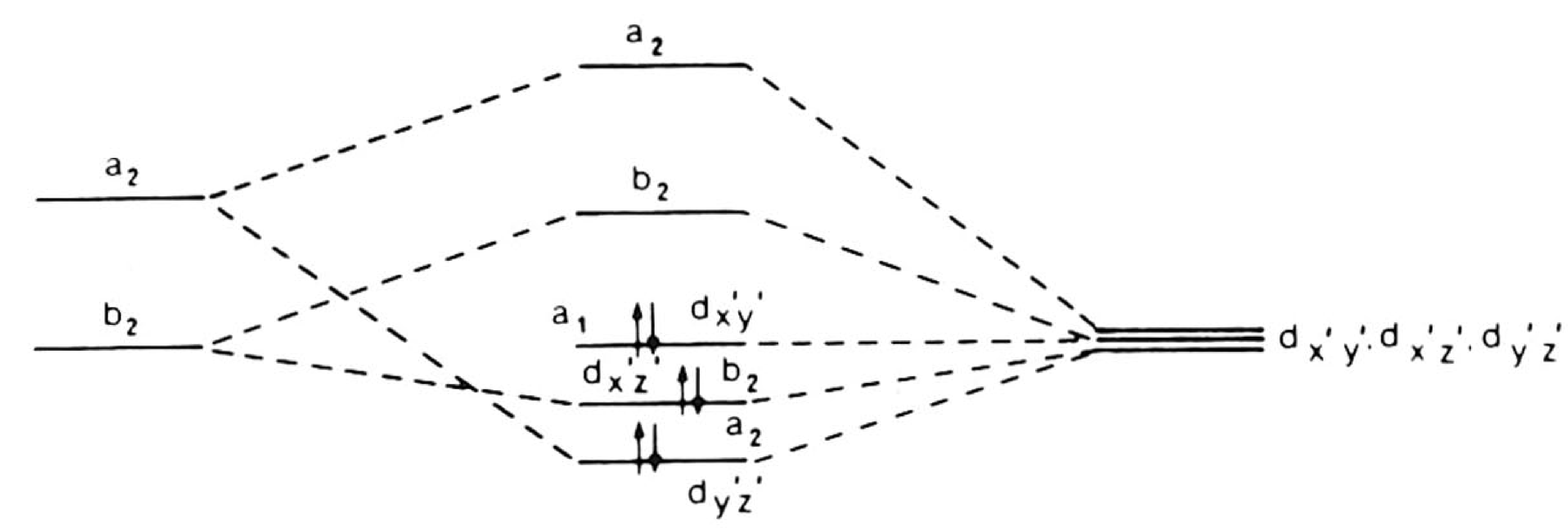

b
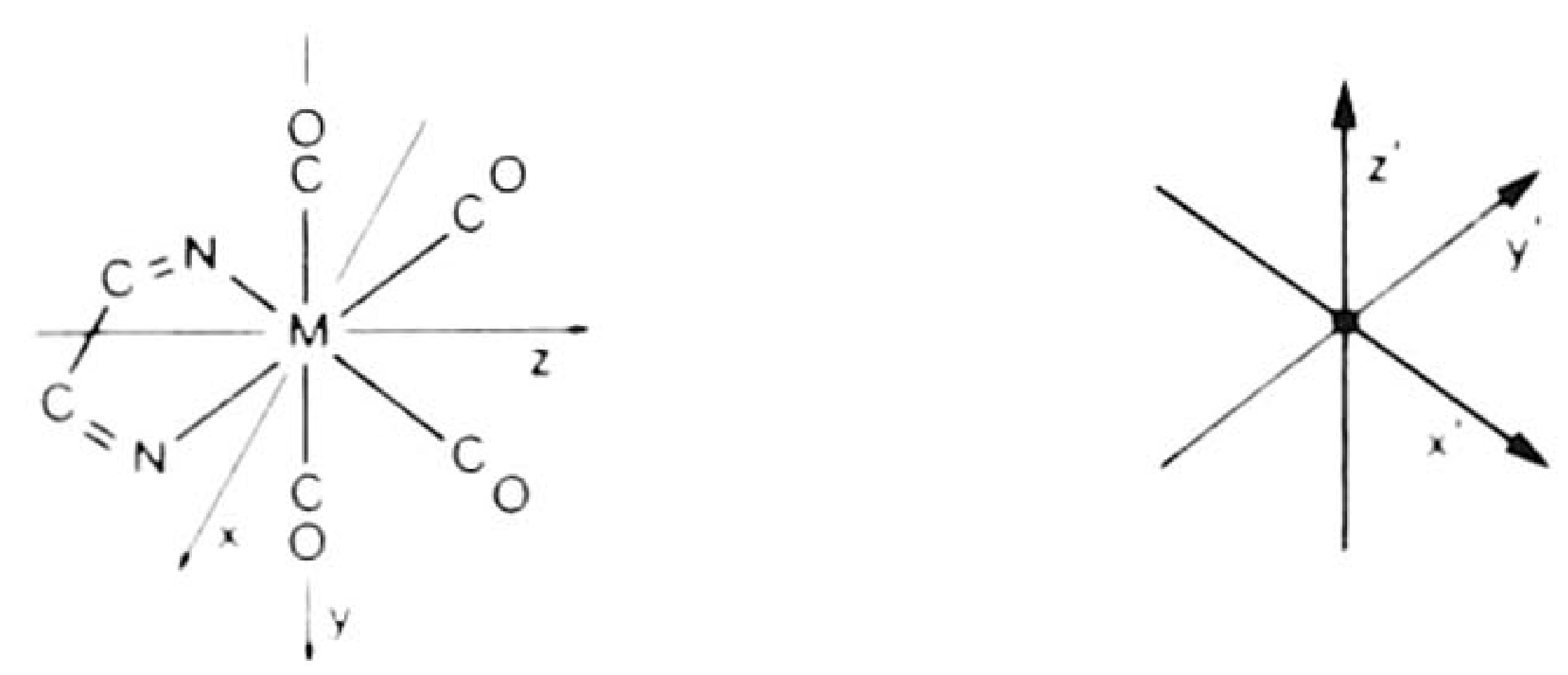

Fig. 4. (a) Part of a tentative MO scheme relevant to the $\mathrm{CT}$ transtions between the metal and the R-DAB ligand in $\mathrm{M}(\mathrm{CO})_{4}(\mathrm{R}-\mathrm{DAB})$ complexes together with the metal-to-R-DAB $\mathrm{CT}$ transitions and their polarization direction (55). (b) Applied coordinate transformation for obtaining symmetry adapted orbitals.

pronounced in the $z$-polarized transition $\mathrm{b}_{2} \leftarrow \mathrm{b}_{2}$ for the more polar solvents, i.e., in polar solvents the electrons are more localized on the metal and this involves a shift of negative charge along the dipole moment vector. This conclusion was also supported by the results of ${ }^{1} \mathrm{H}$ and ${ }^{13} \mathrm{C}$ NMR studies involving the use of ${ }^{15} \mathrm{~N}$-enriched $\mathrm{Mo}(\mathrm{CO})_{4}(\mathrm{Me}-\mathrm{DAB})(55)$.

Since the solvatochromism effect depends on the degree of stabilization of the ground state and destabilization of the excited state the R substituents are of much importance because they are responsible for the $\pi$-accepting properties of the R-DAB ligand. It has been found that a decrease in $\pi$-accepting ability is paralleled by an enhanced solvatochromic effect (84) (see Table IV).

Extensive resonance Raman studies of $\mathrm{Mo}(\mathrm{CO})_{4}(t-\mathrm{Bu}-\mathrm{DAB})$ (55) showed that the CT transitions are not purely metal-to-R-DAB in character, as has previously been assumed $(69,100)$, but that orbitals of the cis carbonyl groups appear to be mixed in the first excited states of the complex (55). This is rationalized by Fig. 5 which shows the $\pi^{*} \mathrm{R}-\mathrm{DAB}$ orbital overlap with the cis- $\mathrm{CO} \pi^{*}$ orbitals (cf. solvatochromic effect of cis and trans $\nu$ COs). On the basis of this orbital scheme the selective photosubstitution of the cis $\mathrm{CO}$ for phosphine ligands in $\mathrm{M}(\mathrm{CO})_{4}(\mathrm{R}-\mathrm{DAB})$ complexes could also be explained (vide supra). The decreasing reactivity 
TABLE III

Solvent Dependence (Solvatochromy) of the CT Absorption and $\nu(\mathrm{CO})$ $\left(\mathrm{cm}^{-1}\right)$ OF $\mathrm{Mo}(\mathrm{CO})_{4}(t-\mathrm{Bu}-\mathrm{DAB})^{a}$

\begin{tabular}{|c|c|c|c|c|c|}
\hline \multirow[b]{2}{*}{ Solvent } & \multirow[b]{2}{*}{$\mathrm{CT}$ absorption ${ }^{b}$} & \multicolumn{2}{|c|}{$\nu(\mathrm{CO})^{\mathrm{cis}}$} & \multicolumn{2}{|c|}{$\nu(\mathrm{CO})^{\operatorname{trans}}$} \\
\hline & & $A_{1}$ & $\mathrm{~B}_{1}$ & $A_{1}$ & $\mathrm{~B}_{1}$ \\
\hline Dimethyl sulfoxide & 21,120 & 1878 & 1828 & 2023 & 1908 \\
\hline Dimethylformamide & 20,960 & 1880 & 1832 & 2024 & 1908 \\
\hline Acetone & 20,400 & 1887 & 1836 & 2024 & 1912 \\
\hline Methanol & 19,880 & 1887 & 1838 & 2024 & 1913 \\
\hline Dioxane & 19,230 & 1892 & 1842 & 2022 & $\mathrm{sh}$ \\
\hline Chloroform & 18,930 & 1890 & 1838 & 2924 & 1915 \\
\hline Tetrachloromethane & 18,020 & 1910 & 1855 & 2024 & 1915 \\
\hline Cyclohexane & 17,745 & 1914 & 1864 & 2024 & 1923 \\
\hline
\end{tabular}

${ }^{a}$ Data taken from Ref. 85 .

${ }^{b} \nu_{\mathrm{m}}\left(\mathrm{cm}^{-1}\right)$.

going from $\mathrm{Cr}$ to $\mathrm{W}$ is due to a decrease of delocalization of the MLCT excited state over the cis COs as the central metal atom becomes larger (extent of overlap decreases) $(80,102)$.

Similar studies have been carried out for $\mathrm{M}(\mathrm{CO})_{4-n} \mathrm{~L}_{n}(\mathrm{R}-\mathrm{DAB})$ complexes (92). One of the more general conclusions is that, when comparing the complexes with $n=0,1$, and 2 with $\mathrm{L}=\mathrm{PPh}_{3}$, the effect of the solvent on the maximum of the $\mathrm{CT}$ band increases, thus pointing to decreasing $\pi$-accepting properties of the ligand systems $(81,87,94)$ (cf. Table IV). Accordingly, there is a question as to whether the central metal atom in $\mathrm{M}(\mathrm{CO})_{2} \mathrm{~L}_{2}(\mathrm{R}-\mathrm{DAB})$ complexes is oxidized to some extent $(92,94,95)$.

TABLE IV

Relationship Between Solvatochromic EFFECT AND $\pi$-ACCEPTING ABILITY OF THE R-DAB LIGAND IN $\mathrm{Mo}(\mathrm{CO})_{4}(\mathrm{R}-\mathrm{DAB})^{a}$

\begin{tabular}{lccr}
\hline \multicolumn{1}{c}{$\mathrm{R}$} & $\begin{array}{c}\nu_{\mathrm{m}}(\mathrm{DMF})^{b} \\
\left(\mathrm{~cm}^{-1}\right)\end{array}$ & $\begin{array}{c}\nu_{\mathrm{m}}\left(\mathrm{C}_{6} \mathrm{H}_{6}\right)^{b} \\
\left(\mathrm{~cm}^{-1}\right)\end{array}$ & $\begin{array}{c}\Delta \nu \\
\left(\mathrm{cm}^{-1}\right)\end{array}$ \\
\hline$c-\mathrm{Hex}$ & 21,275 & 18,553 & 2722 \\
$i-\mathrm{Pr}$ & 20,325 & 18,622 & 1703 \\
$c-\mathrm{Pr}$ & 20,100 & 18,553 & 1547 \\
$\mathrm{Me}$ & 20,000 & 18,762 & 1238 \\
$\mathrm{Ph}$ & 17,606 & 16,570 & 1036 \\
$\mathrm{C}_{6} \mathrm{H}_{4} \mathrm{Me}-O$ & 18,215 & 17,391 & 824 \\
\hline
\end{tabular}

${ }^{a}$ Data taken from Ref. 84.

${ }^{b}$ Maximum of the CT absorption. 

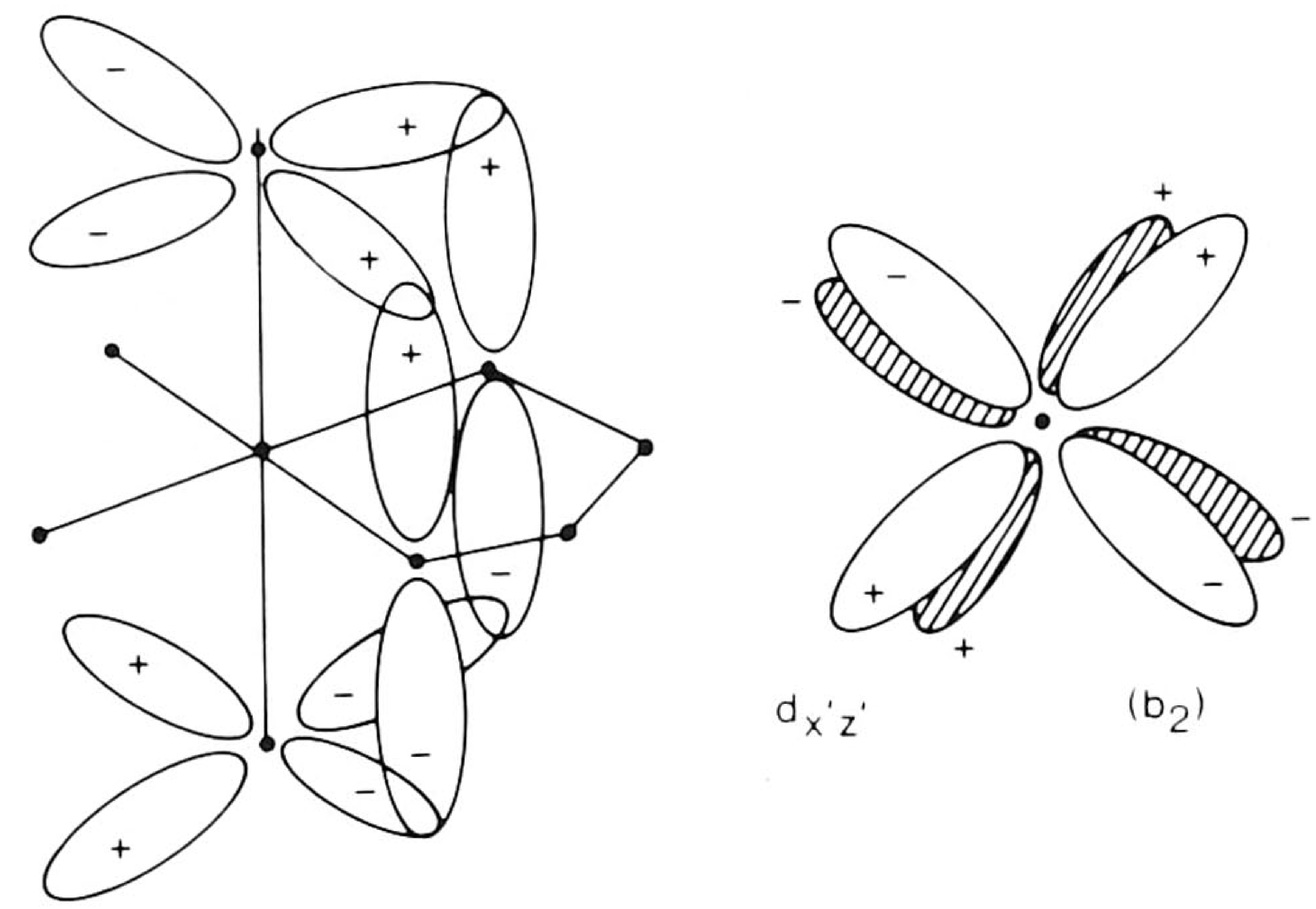

$d_{x^{\prime} z^{\prime}} \quad\left(b_{2}\right)$
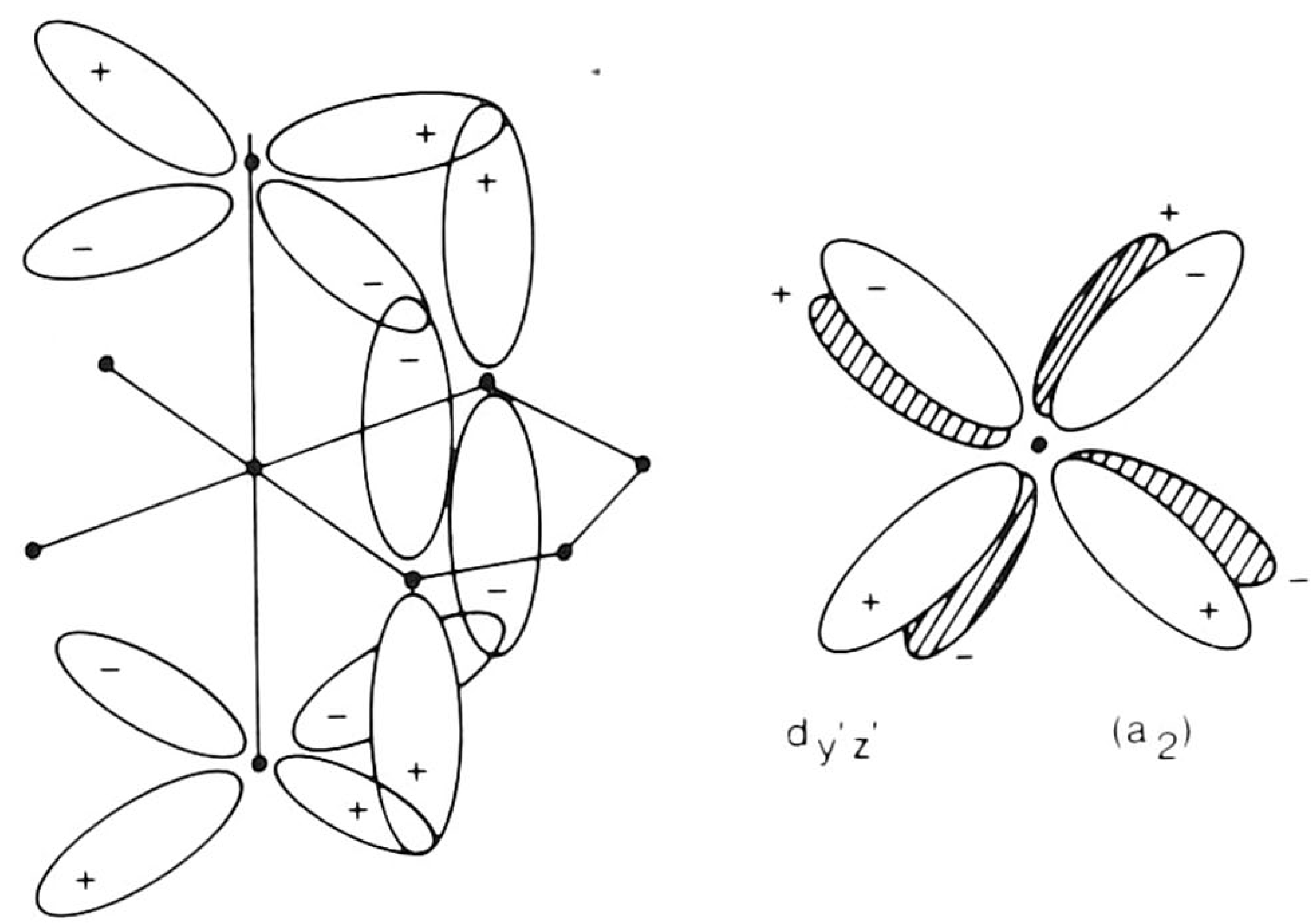

$d_{y^{\prime} z^{\prime}} \quad\left(a_{2}\right)$

FIG. 5. Overlap of $\pi^{*}$ orbitals of the cis CO groups and the $\pi^{*}$ orbitals of the R-DAB ligand. The metal $d$-orbital combinations which give $\pi$ back bonding with these $\pi^{*}$ orbitals are shown on the right (55).

IR, UV, and ${ }^{1} \mathrm{H},{ }^{13} \mathrm{C}$ and ${ }^{31} \mathrm{P}$ NMR studies of a series of $\mathrm{Mo}(\mathrm{CO})_{4-n}\left(\mathrm{PR}_{3}^{\prime}\right)_{n} \mathrm{~L}_{2}\left(n=0,1 ; \mathrm{R}^{\prime}=\mathrm{OMe}, \mathrm{Ph}\right.$, Et, $t$-Bu, $c$-Hex, and $n$ $=2 ; \mathrm{R}^{\prime}=\mathrm{Et}, \mathrm{L}=i$-Pr-DAB, $i$-PrPyca and 2,2'-bipyridine) showed that the $\pi$-back bonding between $\mathrm{Mo}$ and $\mathrm{L}$ is strongest for $i$-Pr-DAB (87). This conclusion concerning the better $\pi$-accepting properties of the R-DAB ligands was also obtained from comparison of these neutral complexes with their paramagnetic monoanions (81) (see Section V). 
Finally, attention has been paid to the conformational stability of $\mathrm{Mo}(\mathrm{CO})_{4}(\mathrm{R}-\mathrm{DAB})$. Using ${ }^{13} \mathrm{C}$ NMR spectroscopy (79) cis-trans exchange of the $\mathrm{CO}$ ligands was found while absorption and resonance Raman spectra (83) indicated a distortion of the $C_{2 v}$ conformation at $77 \mathrm{~K}$. CO exchange takes place via a transition state with pseudo $C_{4 v}$ symmetry (see Section $\mathrm{IV}, \mathrm{B}, 3$ for the influence of $\mathrm{R}$ on the activation barrier for this process).

The interesting trinuclear molybdenum-mercury compound shown in Eq. (21), which has been used for the $\mathrm{C}-\mathrm{C}$ coupling reaction of two RDAB ligands (Section VI,C) has been proposed to have the structure shown below; a linear $\mathrm{Mo}-\mathrm{Hg}-\mathrm{Mo}$ arrangement with the R-DAB ligands $\sigma, \sigma-\mathrm{N}, \mathrm{N}^{\prime}$ chelate bonded to $\mathrm{Mo}(97)$ [cf. structure of $\mathrm{Mn}(\mathrm{CO})_{5} \mathrm{M}^{\prime}(\mathrm{CO})_{3}(\mathrm{R}-$ DAB), Section III,D,2,c].

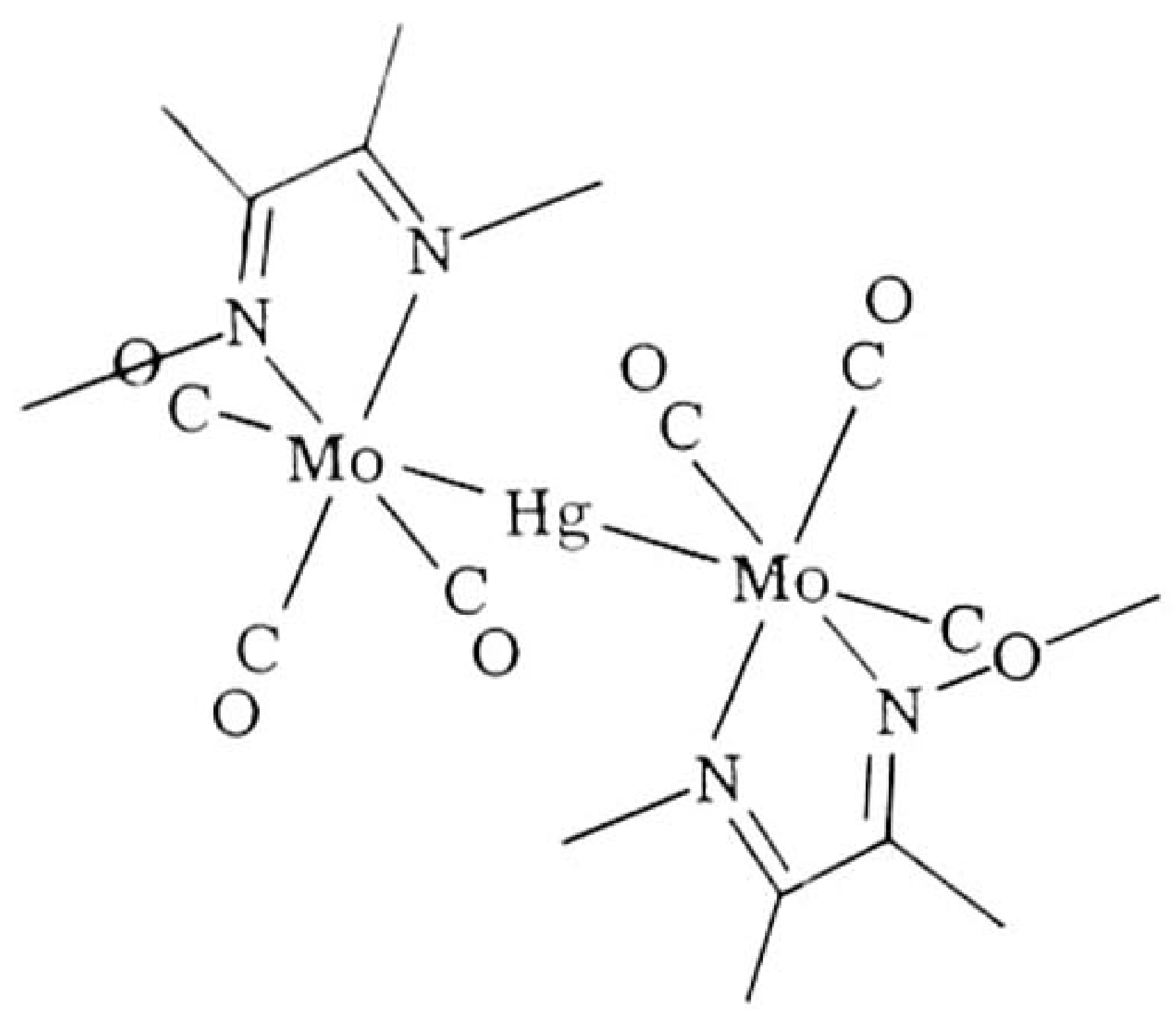

c. Group VIIA. The reaction of $(t-\mathrm{Bu}-\mathrm{DAB}) \mathrm{Na}$ with manganese acetylacetonate affords in excellent yields the 15-electron $\mathrm{Mn}(t \text {-Bu-DAB })_{2}$ complexes (42).

Carbonyl complexes of $d^{7}$ metals with R-DAB are formed via the ligand substitution reaction shown in Eq. (22).

$$
\begin{aligned}
& \mathrm{MX}(\mathrm{CO})_{5}+\mathrm{R}-\mathrm{DAB}\left(\mathrm{R}^{\prime}, \mathrm{H}\right) \longrightarrow 2 \mathrm{CO} \\
& (\mathrm{M}=\mathrm{Re}, \mathrm{X}=\mathrm{Cl}, \mathrm{R}=i-\mathrm{Pr}, c-\mathrm{Hex}, p \text {-tolyl; } \\
& \left.\mathrm{M}=\mathrm{Mn}, \mathrm{X}=\mathrm{Br}, \mathrm{R}=i-\mathrm{Pr}, t-\mathrm{Bu}\left(\mathrm{R}^{\prime}=\mathrm{H} \text { or } \mathrm{Me}\right), \mathrm{Ph}, p-\mathrm{ClC}_{6} \mathrm{H}_{4}, p-\mathrm{MeOC}_{6} \mathrm{H}_{4}\right)
\end{aligned}
$$

The complexes of $\mathrm{Mn}$ are formed more easily than those of Re. Whereas complex formation occurs readily at $30^{\circ} \mathrm{C}$ with alkyl-DAB ligands in ether the synthesis of aryl-DAB complexes requires prolonged heating in tolueneheptane (77). The exchange of chloride for iodide in the Mn and Re complexes was possible via reaction with KI (77). Similarly other X groups, e.g., $\mathrm{CN}^{-}$and $\mathrm{MeCO}_{2}^{-}$can be exchanged (77). 
$\mathrm{MnX}(\mathrm{CO})_{3}(t-\mathrm{Bu}-\mathrm{DAB})$ reacts with $\mathrm{AgBF}_{4}$ under a $\mathrm{CO}$ atmosphere (1.5 atm ) to give the cationic complex $\left[\mathrm{Mn}(\mathrm{CO})_{4}(t-\mathrm{Bu}-\mathrm{DAB})\right] \mathrm{BF}_{4}(77)$ which is isoelectronic with the corresponding $d^{6}$ metal complexes (see Section III,D, 2,b).

Dinuclear complexes $\mathrm{Mn}(\mathrm{CO})_{5} \mathrm{M}^{\prime}(\mathrm{CO})_{3}(\mathrm{R}-\mathrm{DAB})\left(\mathrm{M}^{\prime}=\mathrm{Mn}, \mathrm{Re}\right)$ are formed according to Eq. (23). In view of the high yields, it is assumed that these complexes are formed via a nucleophilic mechanism (103). The formation of $\mathrm{Mn}_{2}(\mathrm{CO})_{10}$ can be explained by a redistribution reaction involving $\mathrm{Mn}(\mathrm{CO})_{5}^{-}$and $\mathrm{Mn}(\mathrm{CO})_{5} \mathrm{M}^{\prime}(\mathrm{CO})_{3}(\mathrm{R}-\mathrm{DAB})$.

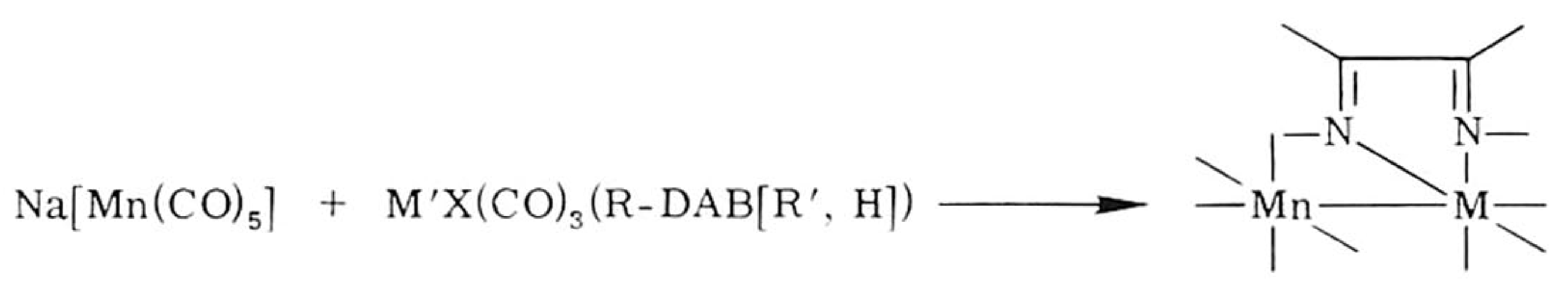

$\left(\mathrm{M}^{\prime}=\mathrm{Re}, \mathrm{R}=i-\mathrm{Pr}, c-\mathrm{Hex}, p\right.$-tolyl; $\mathrm{M}^{\prime}=\mathrm{Mn}, \mathrm{R}=i-\mathrm{Pr}$,

$\mathrm{R}^{\prime}=\mathrm{H}$ or $\mathrm{Me}, p$-tolyl, $\left.\mathrm{C}_{6} \mathrm{H}_{4} \mathrm{OMe}-p\right)$

$\mathrm{Mn}(t-\mathrm{Bu}-\mathrm{DAB})_{2}$ has a tetrahedral structure containing two $\sigma, \sigma-\mathrm{N}, \mathrm{N}^{\prime}$ chelate bonded $t$-Bu-DAB ligands (see Table II) (42). The dihedral angle $(\theta)$ between the two almost planar $\mathrm{MnN}=\mathrm{C}-\mathrm{C}=\mathrm{N}$ chelate rings being $90^{\circ}$.

$\mathrm{MnBr}(\mathrm{CO})_{3}(c-\mathrm{Hex}-\mathrm{DAB})(40)$ and $\operatorname{ReCl}(\mathrm{CO})_{3}(i-\mathrm{Pr}-\mathrm{DAB})(41)$ are isostructural as regards the direct metal-coordination sphere and are also isostructural with $\mathrm{MnBr}(\mathrm{CO})_{3} \mathrm{~L}$ complexes in which $\mathrm{L}$ is $2,2^{\prime}$-bipyridine or 1,10-phenanthroline (77). The fac configuration of the $\mathrm{X}$ and $\mathrm{N}$ ligands in these complexes is schematically shown in Eq. (22).

${ }^{1} \mathrm{H}$ and ${ }^{13} \mathrm{C}$ NMR spectroscopic data pointed to a structure for the $\mathrm{Mn}(\mathrm{CO})_{5} \mathrm{M}^{\prime}(\mathrm{CO})_{3}(\mathrm{R}-\mathrm{DAB})$ complexes consisting of a $\mathrm{Mn}-\mathrm{M}^{\prime}$ bond with the R-DAB ligand $\sigma, \sigma-\mathrm{N}, \mathrm{N}^{\prime}$ bonded to $\mathrm{M}^{\prime}$ and the chelate plane perpendicular to the $\mathrm{Mn}-\mathrm{M}^{\prime}$ axis [see structure in Eq. (23)]. This structure is closely related to the homodinuclear $\mathrm{M}_{2}(\mathrm{CO})_{8} \mathrm{~L}(\mathrm{M}=\mathrm{Mn}, \mathrm{Re} ; \mathrm{L}=1,10$ phenanthroline, 2,2'-biquinoline) complexes (103). It is assumed that steric factors are more important for the stability of the $\mathrm{MM}^{\prime}(\mathrm{CO})_{8}(\mathrm{R}-\mathrm{DAB})$ complexes than electronic factors on the basis of the much greater stability of the complex with $\mathrm{R}=i$ - $\mathrm{Pr}$ over the $\mathrm{R}=t$ - $\mathrm{Bu}$ analog (103).

The fact that in the $\mathrm{MM}^{\prime}(\mathrm{CO})_{8}(\mathrm{R}-\mathrm{DAB})$ complexes intramolecular attack of one of the $\mathrm{C}=\mathrm{N}$ bonds on the $\mathrm{Mn}$ center does not occur contrasts with instability of the intermediate $\mathrm{MnCo}(\mathrm{CO})_{7}(\mathrm{R}-\mathrm{DAB})$ formed in the reaction of $\mathrm{Co}(\mathrm{CO})_{4}^{-}$with $\mathrm{MnBr}(\mathrm{CO})_{3}(\mathrm{R}-\mathrm{DAB})$. In this $\mathrm{Mn}-\mathrm{Co}$ dinuclear species intramolecular attack occurs converting the initially $\sigma, \sigma-\mathrm{N}, \mathrm{N}^{\prime}$ chelate bonded R-DAB ligand to a $\sigma-\mathrm{N}, \mu^{2}-\mathrm{N}^{\prime}, \eta^{2}-\mathrm{CN}^{\prime}$ bridge bonded ligand (see Section IV,A,3). Like the $d^{6}$ metal complexes the $\mathrm{MX}(\mathrm{CO})_{3}(\mathrm{R}-\mathrm{DAB})$ and $\mathrm{Mn}(\mathrm{CO})_{5} \mathrm{M}^{\prime}(\mathrm{CO})_{3}(\mathrm{R}-\mathrm{DAB})$ complexes are all highly colored in so- 
lution and have complex electronic absorption spectra in the visible and near UV (103). The $\mathrm{MX}(\mathrm{CO})_{3}(\mathrm{R}-\mathrm{DAB})$ complexes show positive solvatochromism (77) which indicates that there is a strong resultant dipole moment from the R-DAB ligand to the metal and that the electron transfer during the $\mathrm{CT}$ transition is antiparallel to it. Extensive resonance Raman investigations of a series of $\mathrm{ReCl}(\mathrm{CO})_{3}(p$-Tol-DAB $)$ complexes showed that upon excitation within both MLCT and intraligand transitions resonance enhancement of a cis-carbonyl stretching mode also occurs (104).

d. Group VIII; $\mathrm{d}^{8}$ Metals Fe, Ru and Os. Of the $d^{8}$ metals only for Fe has a series of zerovalent R-DAB complexes been reported and the synthetic route is outlined in Eq. (24) (105).

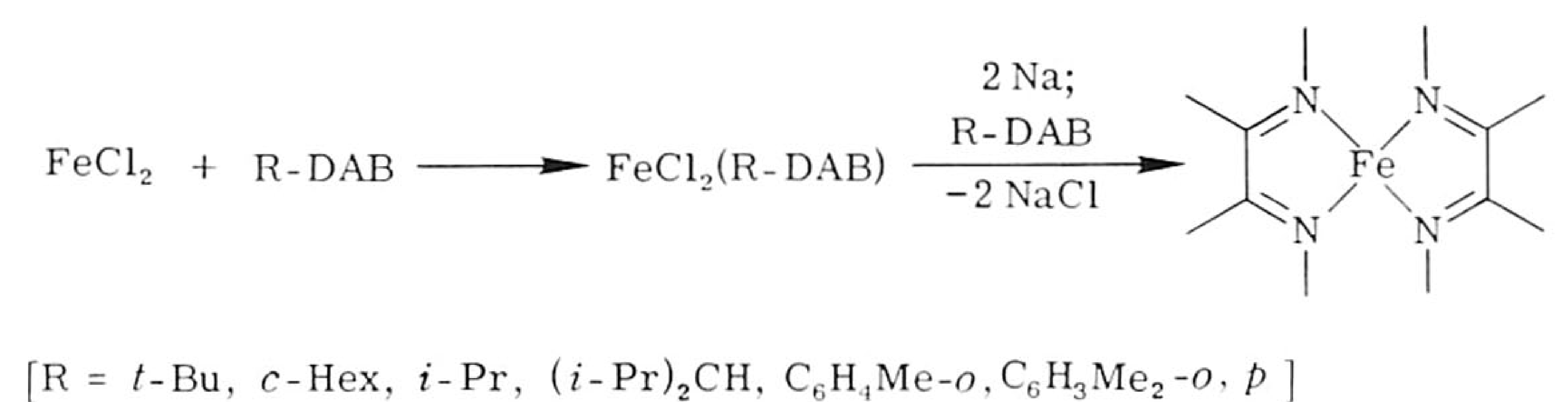

$\mathrm{Fe}(\mathrm{R}-\mathrm{DAB})_{2}$ complexes are very soluble in apolar solvents and take up $\mathrm{CO}$ reversibly to give $\mathrm{Fe}(\mathrm{CO})(\mathrm{R}-\mathrm{DAB})_{2}$ which is stable only in solution in a $\mathrm{CO}$ atmosphere $(105,106)$. Excess $\mathrm{CO}$ irreversibly generates $\mathrm{Fe}(\mathrm{CO})_{3}(\mathrm{R}-\mathrm{DAB})$ and free R-DAB (105). Likewise, the reaction with $(\mathrm{CN})_{2}$ giving rise to formation of $\mathrm{Fe}^{\mathrm{Il}}(\mathrm{CN})_{2}(\mathrm{R}-\mathrm{DAB})_{2}$ is irreversible ( $\mathrm{R}$ = small alkyl grouping) (107). No reaction is observed for $\mathrm{R}=t$ - Bu.

Much effort has been put into the study of $\mathrm{Fe}_{2}(\mathrm{CO})_{9}$ and $\mathrm{Fe}(\mathrm{CO})_{5}$ with $\mathrm{R}-\mathrm{DAB}(30,105,106,108,109)$. According to a reinvestigation $(110)$ the thermal reaction of $\mathrm{Fe}_{2}(\mathrm{CO})_{9}$ with $t$ - $\mathrm{Bu}$-DAB forms $\mathrm{Fe}(\mathrm{CO})_{3}(t$-Bu-DAB$)$, $t$ - Bu- $\mathrm{NC}(\mathrm{H})=\mathrm{C}(\mathrm{H}) \mathrm{N}(t-\mathrm{Bu}) \mathrm{C}=\mathrm{O}$ (2-imidazolinone) and $\mathrm{Fe}(\mathrm{CO})_{5}$ in equimolar amounts (Fig. 22 in Section VI,A,1). Fe(CO) $)_{3}(\mathrm{R}-\mathrm{DAB})$ can also be prepared via the photochemical reaction of $\mathrm{Fe}(\mathrm{CO})_{5}$ in the presence of the R-DAB ligand (30). In this reaction dinuclear products $\mathrm{Fe}_{2}(\mathrm{CO})_{6}(\mathrm{R}$ $\mathrm{DAB}$ ), which can be isolated, are also formed (see Section III,E).

$\mathrm{Fe}(\mathrm{NO})_{2}(\mathrm{R}-\mathrm{DAB})(\mathrm{R}=i$-Pr or $\mathrm{Ph})$ has been reported without any comment concerning its preparation (107).

Photolysis of $\mathrm{Fe}(\mathrm{CO})_{3}(\mathrm{R}-\mathrm{DAB})$ in the presence of 1,3-dienes affords complexes of the type $\mathrm{Fe}(\mathrm{CO})\left(\eta^{4}-1,3\right.$-diene $)(\mathrm{R}-\mathrm{DAB})$ liberating two moles of $\mathrm{CO}$. This conversion occurs in two steps of which the first is thermally reversible. Only for 1,3-dienes with weak $\pi$-acceptor properties could such complexes be obtained (111). 


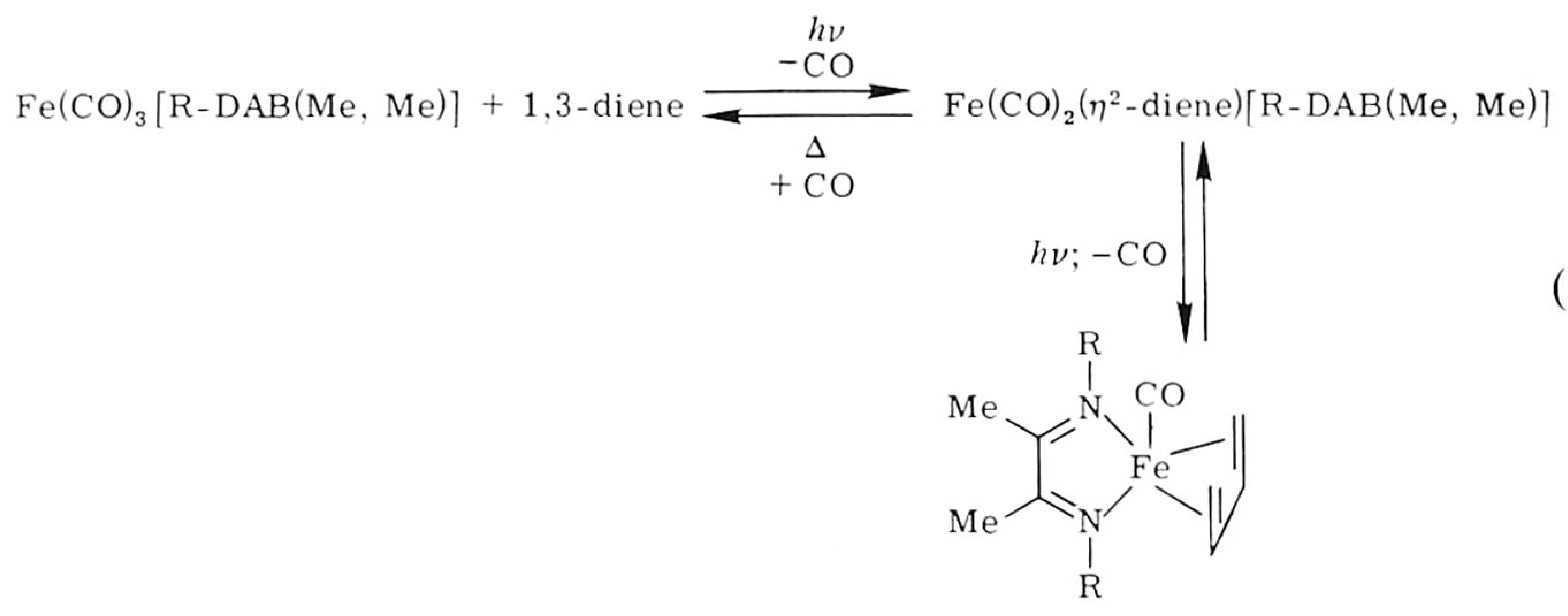

$\mathrm{R}=i-\mathrm{Pr}, c-\mathrm{Hex}, \mathrm{C}_{6} \mathrm{H}_{4} \mathrm{OMe}-p$

Mononuclear $\mathrm{Ru}$ and Os derivatives of the type $\mathrm{M}(\mathrm{CO})_{3}(\mathrm{R}-\mathrm{DAB})$ have been reported only for $\mathrm{Ru}$ with special sterically demanding $\mathrm{R}$ groups (112) (see Scheme 6 in Section IV,A,2).

A zerovalent $\mathrm{Ru}\left(p-\mathrm{MeOC}_{6} \mathrm{H}_{4}-\mathrm{DAB}\right)_{3}$ has been reported as the product from the reaction of $p$ - $\mathrm{MeOC}_{6} \mathrm{H}_{4}-\mathrm{DAB}$ with either $\mathrm{RuH}_{2}\left(\mathrm{PPh}_{3}\right)_{4}$ or $\mathrm{RuH}\left(\mathrm{C}_{6} \mathrm{H}_{4} \mathrm{PPh}_{2}\right)\left(\mathrm{PPh}_{3}\right)_{2}\left(\mathrm{C}_{2} \mathrm{H}_{4}\right)$ in toluene at $80^{\circ} \mathrm{C}(43)$. So far analogous Os compounds are not known.

One of the most thoroughly investigated classes of compounds are those of general formula $\left[\mathrm{Fe}^{\mathrm{II}}(\mathrm{R}-\mathrm{DAB})_{3}\right] \mathrm{X}_{2}(28,89,90,107,113-131)$. The complexes with $\mathrm{R}=\mathrm{Me}$ are generally made by the condensation reaction of methylamine with glyoxal in the presence of the Fe ${ }^{11}$ salt [cf. Eqs. (12) and (13)].

$\mathrm{Ru}^{\mathrm{II}}$ complexes were obtained from reactions of $\mathrm{RuHCl}\left(\mathrm{PPh}_{3}\right)_{3}$ with $i$ Pr-DAB affording $\mathrm{RuHCl}\left(\mathrm{PPh}_{3}\right)_{2}(i$-Pr-DAB) (132). The latter compound reacts in $\mathrm{MeOH}$ at $50^{\circ} \mathrm{C}$ to give $\mathrm{RuH}_{2}\left(\mathrm{PPh}_{3}\right)_{2}(i$-Pr-DAB $)$ which could also be prepared via the reaction of $\mathrm{RuH}_{4}\left(\mathrm{PPh}_{3}\right)_{3}$ with $i$-Pr-DAB. In Scheme 1 the other products that have been obtained are summarized.

$\left[\mathrm{Ru}^{\mathrm{II}}(\mathrm{R}-\mathrm{DAB})_{3}\right] \mathrm{X}_{2}$ is produced quantitatively and isolated readily as the $\mathrm{Cl}^{-}, \mathrm{BPh}_{4}^{-}$, or $\mathrm{PF}_{6}^{-}$salt by oxidation of $\mathrm{Ru}(\mathrm{R}-\mathrm{DAB})_{3}$ with molecular oxygen, $\mathrm{I}_{2}, \mathrm{HCl}$, or even excess R-DAB (43).

Reduction of $\mathrm{RuCl}_{3} \cdot 3 \mathrm{H}_{2} \mathrm{O}$ by metallic zinc in the presence of $i$-Pr-DAB afforded $\mathrm{RuCl}_{2}(i$-Pr-DAB) 2 (13l). The corresponding low-spin complex $\mathrm{Fe}(\mathrm{SCN})_{2}(c-\mathrm{Hex}-\mathrm{DAB})_{2}$ was obtained from the reaction of $\mathrm{FeCl}_{2}$ with $c$ Hex-DAB in the presence of $\mathrm{KSCN}$ (131).

$\mathrm{Fe}(\mathrm{R}-\mathrm{DAB})_{2}$ are 16 -electron tetrahedral species that are paramagnetic ( $\mathrm{R}=t$ - $\mathrm{Bu} ; 2.98 \mathrm{BM}$ in benzene) and very sensitive to oxygen (105). Ru( $\mathrm{R}$ $\mathrm{DAB})_{3}$ has been formulated on the basis of an X-ray structure determination (see Table II) as a formally 20-electron octahedral complex. This 


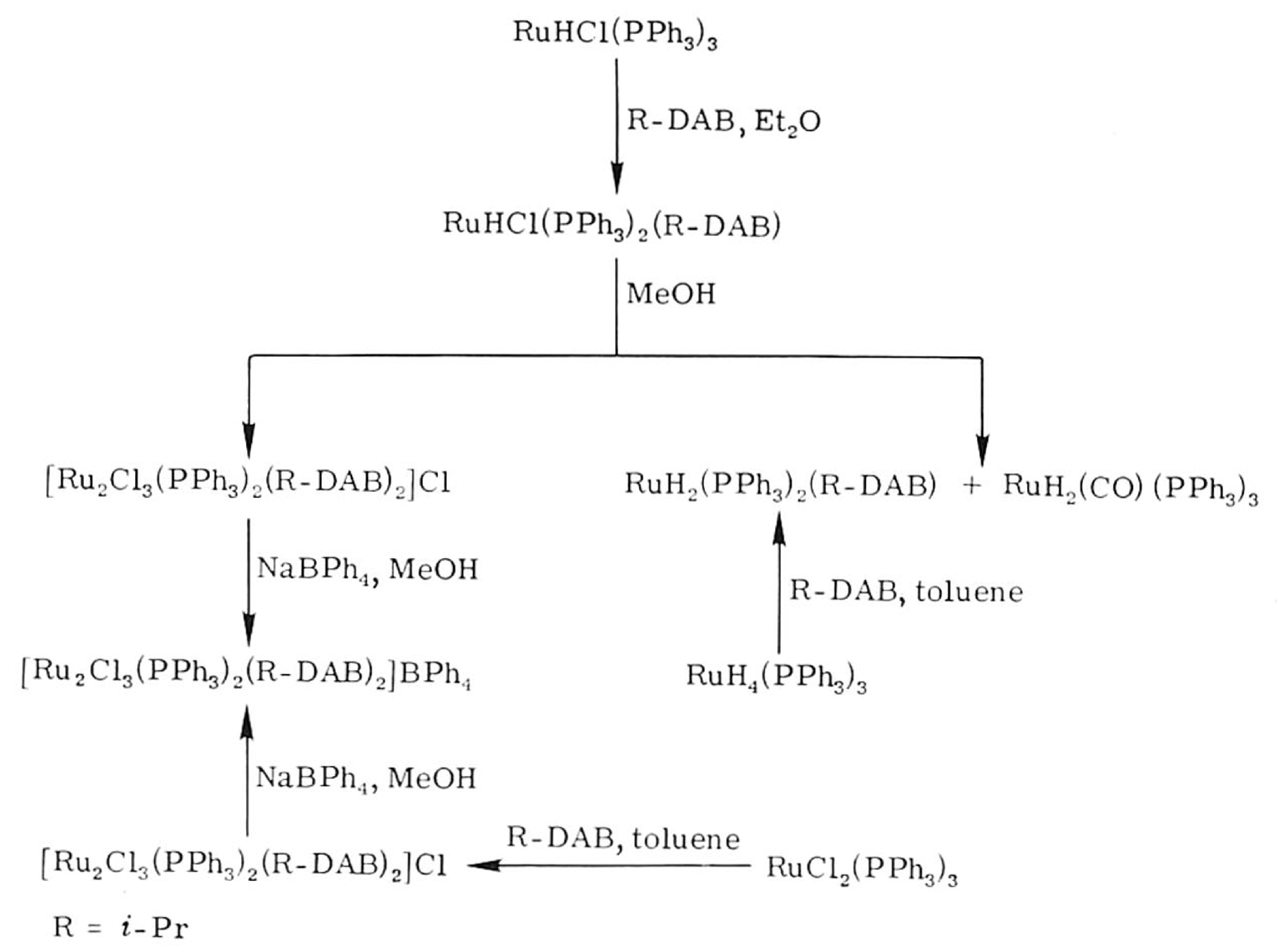

SCHEME 1. Various related reactions of $\mathrm{RuHCl}\left(\mathrm{PPh}_{3}\right)_{3}, \mathrm{RuCl} 2\left(\mathrm{PPh}_{3}\right)_{3}$, and $\mathrm{RuH}_{4}\left(\mathrm{PPh}_{3}\right)_{3}$ $(132,133)$.

complex, contrary to expectations, is diamagnetic (43), the analogous $\mathrm{Fe}(\mathrm{Bipy})_{3}$ complex being paramagnetic (134). It is proposed that the ruthenium compound has a temperature-dependent spin-free spin-paired equilibrium with a small population of the paramagnetic state (43).

For $\mathrm{Fe}(\mathrm{CO})_{3}(\mathrm{R}-\mathrm{DAB})$ it was assumed that, depending on the substituents, the R-DAB ligand was bonded either in the $\sigma, \sigma-\mathrm{N}, \mathrm{N}^{\prime}$ chelate mode or in a $\sigma-\mathrm{N}, \eta^{2}-\mathrm{C}=\mathrm{N}^{\prime}$ fashion $(106,109)$. However, later it was shown that all mononuclear $\mathrm{M}(\mathrm{CO})_{3}(\mathrm{R}-\mathrm{DAB})$ complexes, as was earlier suggested (108), contain $\sigma, \sigma-\mathrm{N}, \mathrm{N}^{\prime}$ chelate bonded R-DAB ligands (110). A recent $\mathrm{X}$-ray structure determination of $\mathrm{Fe}(\mathrm{CO})_{3}\left(2,6-i-\mathrm{Pr}_{2} \mathrm{C}_{6} \mathrm{H}_{3}\right.$-DAB) (see Table II) revealed that the $\mathrm{Fe}$ center is square pyramidally surrounded. The basal plane contains two $\mathrm{CO}$ and the $\sigma, \sigma-\mathrm{N}, \mathrm{N}^{\prime}$ chelate bonded R-DAB ligand while the third $\mathrm{CO}$ ligand resides in apical position. An interesting feature is the position of the aryl group perpendicular to the chelate plane (110b).

The $\mathrm{Fe}(\mathrm{CO})\left(\eta^{4}\right.$-1,3-diene)(R-DAB) complexes have, based on ${ }^{1} \mathrm{H}$ and ${ }^{13} \mathrm{C}$ NMR, IR, and UV-visible spectra, square-pyramidal structures with basal-basal coordination of the R-DAB and 1,3-diene ligands [see structure in Eq. (25)] (111). This has been established by the structure in the solid of $\mathrm{Fe}(\mathrm{CO})(i-\mathrm{Pr}-\mathrm{DAB})\left(2,3-\mathrm{Me}_{2} \mathrm{C}_{4} \mathrm{H}_{4}\right)(111 b)$. 
Structural information concerning $\mathrm{Fe}(\mathrm{NO})_{2}(\mathrm{R}-\mathrm{DAB})$ and $\mathrm{Fe}(\mathrm{CN})_{2}(\mathrm{R}$ DAB) (107) is not available.

The octahedral $\mathrm{Fe}^{\mathrm{II}}$ complexes $\left[\mathrm{Fe}(\mathrm{R}-\mathrm{DAB})_{3}\right] \mathrm{X}_{2}$ were some of the first R-DAB-metal complexes to be studied. In particular Krumholz and coworkers established the stability of the chelate ring in these spin-paired complexes $(125,135)$. The IR spectra, normal coordinate analysis (136), resonance Raman spectra, and excitation profiles (114) have all been subjects of interest.

For the $\mathrm{Ru}$ complexes shown in Scheme 1 the R-DAB ligands are proposed to be $\sigma, \sigma-\mathrm{N}, \mathrm{N}^{\prime}$ chelate bonded. Recently a $\eta^{2}, \eta^{2}$-bonded R-DAB ligand in the $E$ - $s$-cis- $E$ conformation was considered as a possibility in trans- $\mathrm{Ru}\left(\mathrm{PPh}_{3}\right)_{2}(\mathrm{H})_{2}\left(p-\mathrm{OMeC}{ }_{6} \mathrm{H}_{4}-\mathrm{DAB}\right)(137)$. This structure is unlikely in view of the unfavorable interaction of the lone pairs of the $\mathrm{N}$ atoms (see Section III,A).

Finally, the structure in the solid state of $\mathrm{RuCl}_{2}(i \text {-Pr-DAB) })_{2}$ (see Table II) shows a $c i s$ arrangement of the two $\sigma, \sigma-\mathrm{N}, \mathrm{N}^{\prime}$ chelate bonded $i$-Pr-DAB ligands in agreement with that deduced from ${ }^{1} \mathrm{H}$ NMR experiments (131).

e. Group VIII; $\mathrm{d}^{9}$ Metals Co, Rh and Ir. To date R-DAB complexes of Ir have not been reported and the number of complexes containing Co and $\mathrm{Rh}$ is still very limited. Calculations have been carried out on cobalt complexes $\mathrm{CoL}_{3}^{3+}(\mathrm{L}=1,10$-phenanthroline, 2,2'-bipyridine, Me-DAB $)$ show that aliphatic diimines, which have the better $\pi$-acceptor ability in comparison to $2,2^{\prime}$-bipy, cause a higher net charge on the metal and a stronger stabilization of the combining $\pi$ orbitals $(138,139)$. This conclusion is in agreement with results of earlier spectroscopic studies (cf. Section III,D, 2,b).

Up to now the known isolated complexes of Co are homo- or heterodinuclear species of which the former contain $\sigma, \sigma-\mathrm{N}, \mathrm{N}^{\prime}$ chelate bonded RDAB ligands $(51,140)$. The heterodinuclear complexes, which have 6electron R-DAB ligands bridging the metal pair, are discussed in Section III,E.

Complexes of the type $\mathrm{Co}_{2}(\mathrm{CO})_{6}(\mathrm{R}-\mathrm{DAB})$ have been obtained from the reaction of $\mathrm{CO}_{2}(\mathrm{CO})_{8}$ with $\mathrm{R}-\mathrm{DAB}$. Reaction of $\mathrm{Co}_{2}(\mathrm{CO})_{6}(p$-Tol-DAB) with $p$-Tol-DAB in ether resulted in further substitution of $\mathrm{CO}$ while heating the complex in hexane caused dimerization (140) [Eq. (26)].

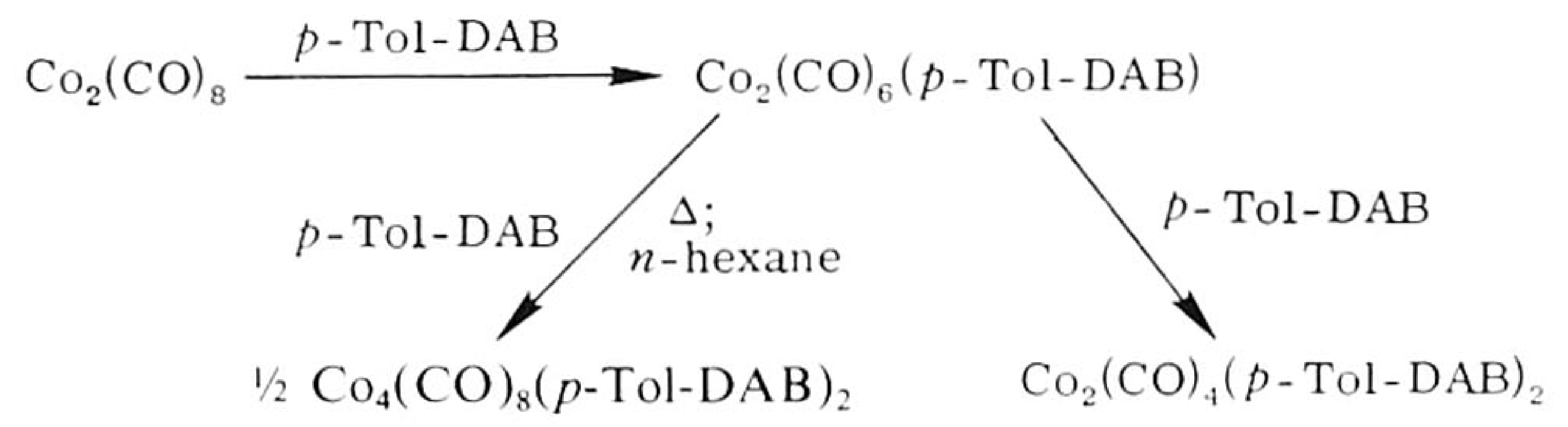


${ }^{1} \mathrm{H}$ and ${ }^{13} \mathrm{C}$ NMR spectroscopy of $\mathrm{Co}_{2}(\mathrm{CO})_{6}(\mathrm{R}-\mathrm{DAB})$ revealed the characteristic chemical shifts of $\sigma, \sigma-\mathrm{N}, \mathrm{N}^{\prime}$ chelate bonded R-DAB ligands (cf. Section IV, B, 2) while the resonance pattern, furthermore, showed isochronous signals for the two $\mathrm{R}-\mathrm{N}=\mathrm{CH}$ halves of the $\mathrm{R}-\mathrm{DAB}$ ligand in agreement with the schematic structure shown below. A series of $\mathrm{Co}_{2}(\mathrm{CO})_{6} \mathrm{~L}$ complexes (in which $\mathrm{L}$ is a bidentate $\mathrm{N}$ donor ligand) (14l) as well as $\mathrm{Fe}_{2}(\mathrm{CO})_{7}\left(2,2^{\prime}\right.$-bipy) (142) are known to have this structure. The nature of the $2 \mathrm{e}-2 \mathrm{c} \mathrm{Co}-\mathrm{Co}$ bond has been studied by UV-visible and resonance Raman spectroscopy [observation of band at $145 \mathrm{~cm}^{-1}$ assigned to $\nu(\mathrm{Co}-\mathrm{Co})](51)$. In contrast to the pronounced solvatochromic shifts observed for $d^{6}$ and $d^{7}$ metal carbonyl R-DAB complexes such shifts were not found for $\mathrm{Co}_{2}(\mathrm{CO})_{6}(\mathrm{R}-\mathrm{DAB})(51)$.

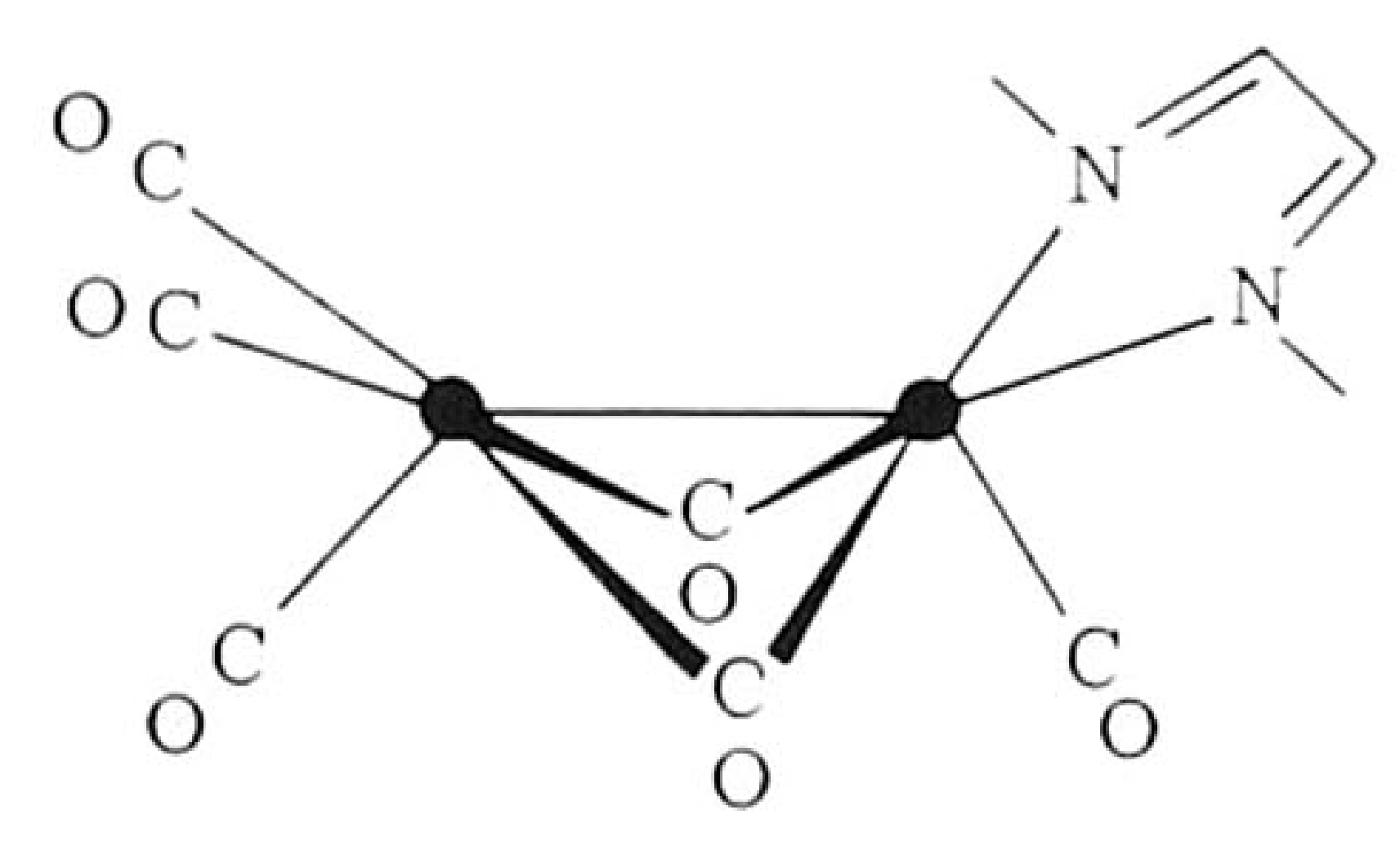

The striking difference of the coordination mode of the R-DAB ligand in the homo- and heterodinuclear complexes ( $4 \mathrm{e} \sigma, \sigma-\mathrm{N}, \mathrm{N}^{\prime}$ versus $6 \mathrm{e} \sigma-\mathrm{N}, \mu^{2}$ $\mathrm{N}^{\prime}, \eta^{2}-\mathrm{C}=\mathrm{N}^{\prime}$ ), which can be explained on the basis of the different geometries in the coordination polyhedra, is discussed in Section IV,A,3.

Finally, entirely different heterodinuclear Co-Pd complexes have been derived from the reaction of the (1,4-diaza-3-methyl-1,3-butadien-2yl)palladium(II) complexes with $\mathrm{CoCl}_{2}$ [see Eq. (8)]. In these complexes the Pd-substituted R-DAB ligands are also $\sigma, \sigma-\mathrm{N}, \mathrm{N}^{\prime}$ bonded $(63,143)$.

The R-DAB-to-Rh interaction has been found to be vary between $\sigma$-N monodentate, $\sigma-\mathrm{N}, \sigma-\mathrm{N}^{\prime}$ bridging and $\sigma, \sigma-\mathrm{N}, \mathrm{N}^{\prime}$ chelate coordination modes depending on the nature of $\mathrm{R}(29,34,59,61)$. The former two have been discussed in Section III,B and C.

Complexes with $\sigma, \sigma-\mathrm{N}, \mathrm{N}^{\prime}$ bonded R-DAB ligands are encountered when the $\mathrm{R}$ group is doubly or triply branched at $\mathrm{C}^{\alpha}$ in combination with substitution at the imino- $\mathrm{C}$ atoms [ $\mathrm{R}^{\prime}$ is $\mathrm{Me}$ or $\mathrm{PdCl}\left(\mathrm{Ph}_{2} \mathrm{PCH}_{2} \mathrm{CH}_{2} \mathrm{PPh}_{2}\right)$ [see Eq. (27)]. 


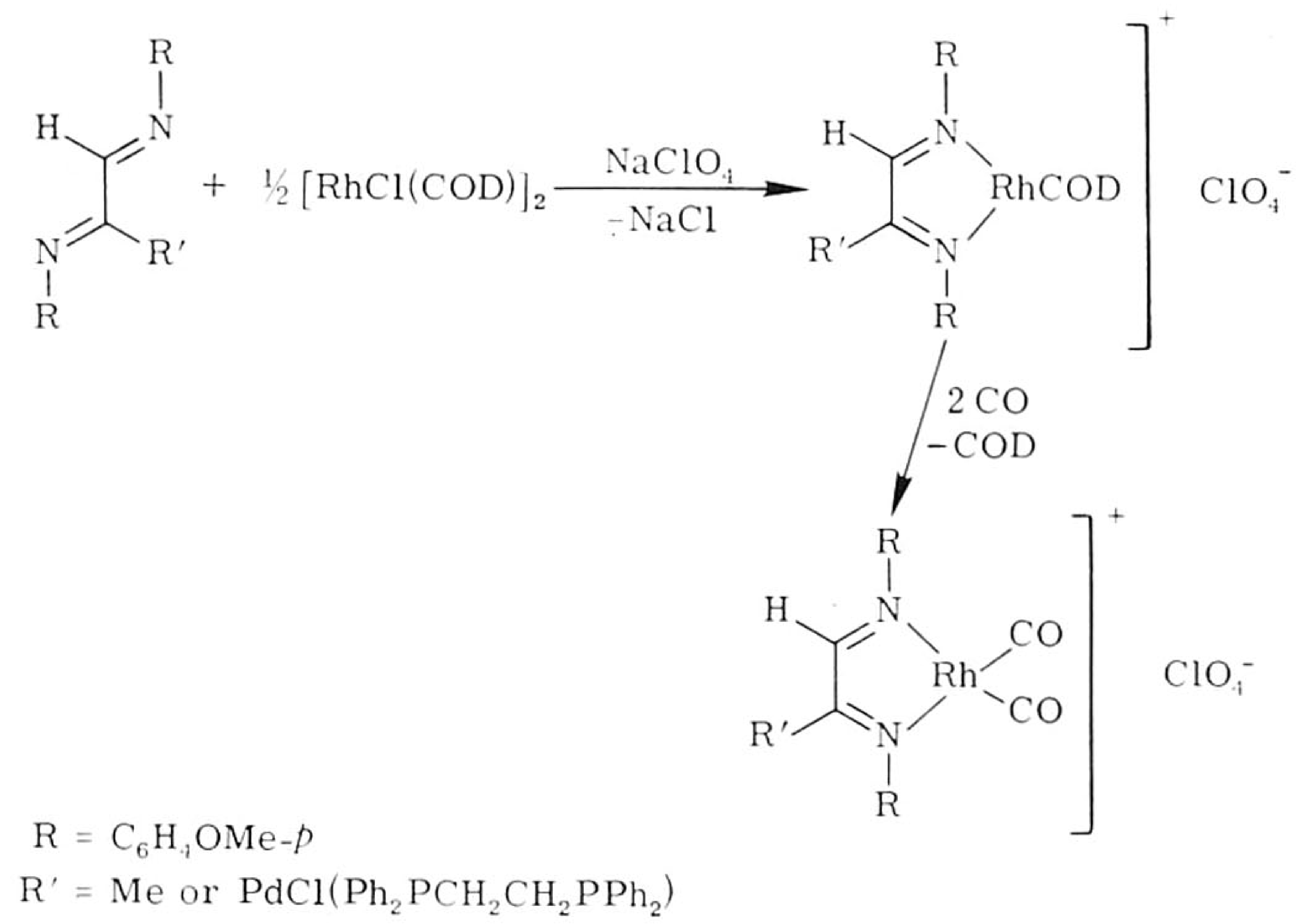

The X-ray structure of $\left[\mathrm{Rh}(\mathrm{CO})_{2}\left(i-\mathrm{Pr}_{2} \mathrm{CH}\right.\right.$-DAB) $]\left[\mathrm{RhCl}_{2}(\mathrm{CO})_{2}\right]$ (see Table II) contains a stable Rh-cationic species with a $\sigma, \sigma-\mathrm{N}, \mathrm{N}^{\prime}$ chelate bonded $i$ - $\mathrm{Pr}_{2} \mathrm{CH}-\mathrm{DAB}$ ligand (45) in agreement with earlier expectations $(34,59,61)$.

Violet $\mathrm{RhCl}(\mathrm{CO})\left(\eta^{2}-\mathrm{C}_{2} \mathrm{H}_{4}\right)(\mathrm{R}-\mathrm{DAB})\left(\mathrm{R}=t\right.$ - Bu and $\left.\mathrm{EtMe}_{2} \mathrm{C}\right)$ have been isolated according to the bridge splitting reactions [see Eq. (28)] or by a ligand substitution reaction (see Scheme 2) (61). Extensive ${ }^{1} \mathrm{H}$ and ${ }^{13} \mathrm{C}$ NMR spectroscopic studies revealed a structure for this complex type analogous to that found for $\mathrm{PtCl}_{2}\left(\eta^{2}\right.$-olefin)(R-DAB) (Section III,D,2,f): i.e., a trigonal bipyramidal array with the $\sigma, \sigma-\mathrm{N}, \mathrm{N}^{\prime}$ chelate bonded R-DAB and the olefin residing in the equatorial plane (61).

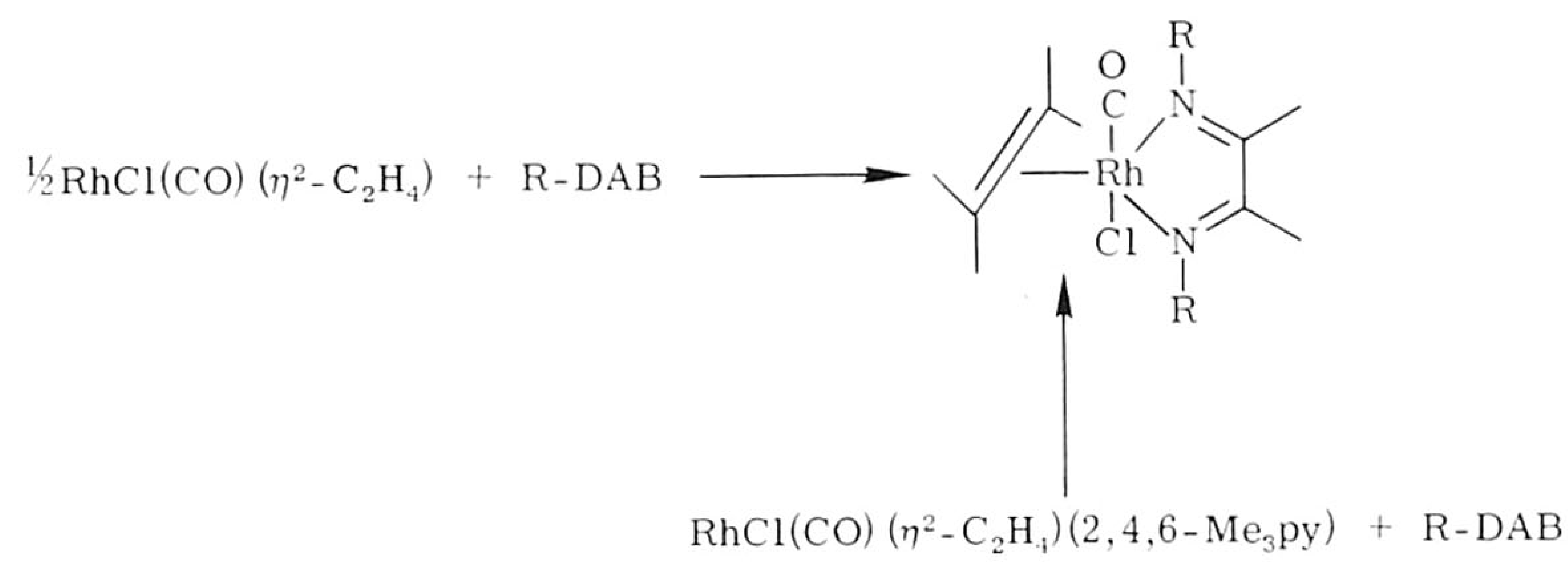

$\mathrm{RhCl}(\mathrm{CO})\left(\eta^{2}-\mathrm{C}_{2} \mathrm{H}_{4}\right)(\mathrm{R}-\mathrm{DAB})$ readily loses ethylene thus providing fourcoordinate $\mathrm{RhCl}(\mathrm{CO})(\mathrm{R}-\mathrm{DAB})\left(\mathrm{R}=t-\mathrm{Bu}, \mathrm{EtMe}_{2} \mathrm{C}\right)$ in which the $\mathrm{R}-\mathrm{DAB}$ is $\sigma, \sigma-\mathrm{N}, \mathrm{N}^{\prime}$ bonded (see Scheme 2). The dissymmetry in the square plane 
was clearly reflected by the anisochronous ${ }^{1} \mathrm{H}$ and ${ }^{13} \mathrm{C}$ resonances of the two $\mathrm{R}-\mathrm{N}=\mathrm{CH}$ halves $(61)$.

Addition of another equivalent of R-DAB to $\mathrm{Rh}_{2} \mathrm{Cl}_{2}(\mathrm{CO})_{4}(\mathrm{R}-\mathrm{DAB})$ or the bridge splitting reaction of $\mathrm{R}-\mathrm{DAB}$ with $[\mathrm{RhCl}(\mathrm{CO})]_{2}$ in hexane resulted in formation of $\mathrm{RhCl}(\mathrm{CO})_{2}(\mathrm{R}-\mathrm{DAB})\left(\mathrm{R}=t-\mathrm{Bu}, \mathrm{EtMe}_{2} \mathrm{C}\right)$ which, however, cannot be isolated (61). In solution a trigonal bipyramidal structure is proposed containing $\sigma, \sigma-\mathrm{N}, \mathrm{N}^{\prime}$ bonded R-DAB but the geometry of this complex could not be conclusively established.

Spin saturation experiments on mixtures of $\mathrm{RhCl}(\mathrm{CO})\left(\eta^{2}-\mathrm{C}_{2} \mathrm{H}_{4}\right)(\mathrm{R}$ $\mathrm{DAB}$ ) with $\mathrm{R}-\mathrm{DAB}$ (involving ${ }^{1} \mathrm{H}$ resonances of free and coordinated $\mathrm{R}$ $\mathrm{DAB}$ ) showed that intermolecular exchange of R-DAB occurs (61). The $\mathrm{RhCl}(\mathrm{CO})_{2}(\mathrm{R}-\mathrm{DAB})$ species are less stable in solution than in the solid state. Exchange reactions for these five coordinate Rh-R-DAB species are shown in Scheme 2.

f. Group VIII; $\mathrm{d}^{\prime O}$ Metals Ni, Pd, and Pt. In contrast to the relatively few metal $d^{9}$ species, the complex chemistry of $d^{10}$ metals with R-DAB is rather developed. The synthesis of zerovalent $\mathrm{Ni}$ complexes has been extensively investigated. The most important synthetic routes are given in Scheme 3. The synthesis starting from $\mathrm{Ni}(\mathrm{CO})_{4}$ occurs at elevated temperatures and cannot be used for thermally unstable R-DAB ligands (144). Furthermore, these reactions sometimes stop at the stage of $\mathrm{Ni}(\mathrm{CO})_{2}(\mathrm{R}$ $\mathrm{DAB})$ as has been shown for $\mathrm{R}=i-\mathrm{Pr}_{2} \mathrm{CH}(9,100)$. Ni(COD) $)_{2}$ is a better

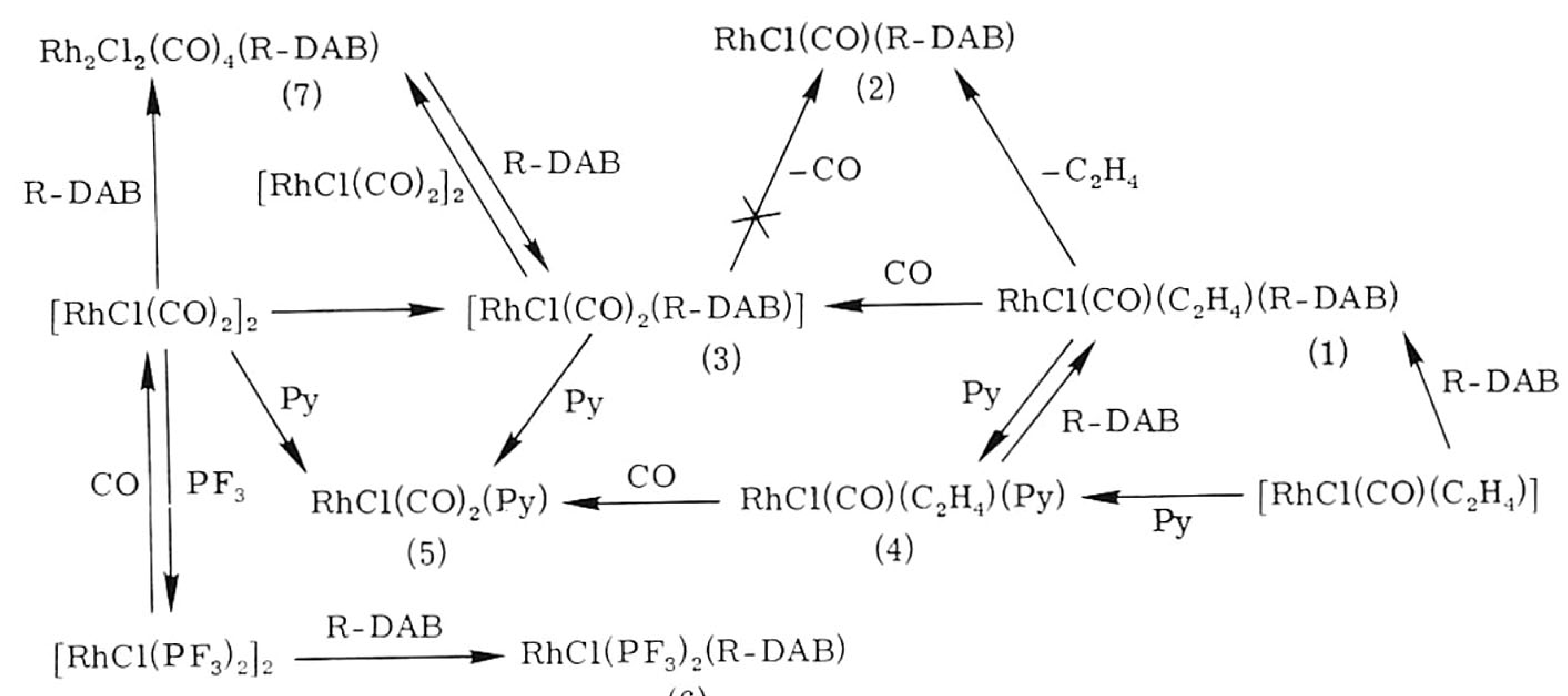

(6)

SCHEME 2. Reactions of rhodium(I)-R-DAB $[\mathrm{R}=t$-Bu ( $1 \mathrm{a}-3 \mathrm{a}, 6 \mathrm{a}, 7 \mathrm{a})$ or $\mathrm{EtMe}_{2} \mathrm{C}(1 \mathrm{~b}-$ $3 \mathrm{~b}, 6 \mathrm{~b}$, and 7b)] complexes in $\mathrm{CHCl}_{3}$ or hexane (61). 


\section{Ligand substitution}

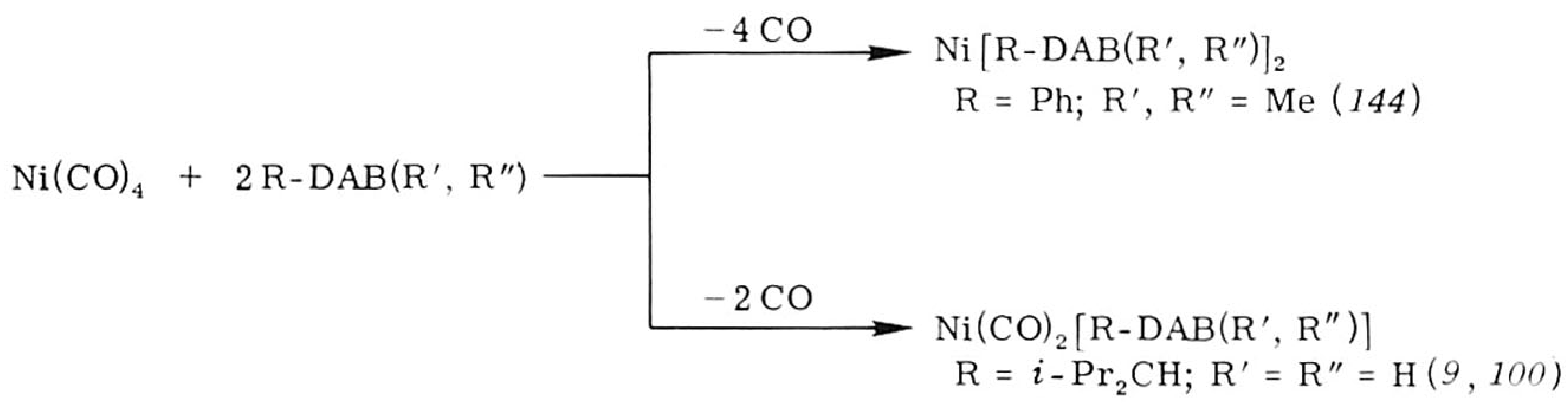

$$
\begin{aligned}
& \mathrm{Ni}(\mathrm{COD})_{2}+2 \mathrm{R}-\mathrm{DAB}\left(\mathrm{R}^{\prime}, \mathrm{R}^{\prime \prime}\right) \stackrel{-2 \mathrm{COD}}{\longrightarrow} \mathrm{Ni}\left[\mathrm{R}-\mathrm{DAB}\left(\mathrm{R}^{\prime}, \mathrm{R}^{\prime \prime}\right)\right]_{2} \\
& \mathrm{R}=\text { variety of alkyl or aryl groups } \\
& (9,10,100)
\end{aligned}
$$

Reduction in the presence of $\mathrm{R}-\mathrm{DAB}\left(\mathrm{R}^{\prime}, \mathrm{R}^{\prime \prime}\right)$

$$
\begin{aligned}
& \begin{aligned}
\mathrm{NiBr}_{2}\left[R-D A B\left(R^{\prime}, R^{\prime \prime}\right)\right] & +\mathrm{R}-\mathrm{DAB}\left(\mathrm{R}^{\prime}, \mathrm{R}^{\prime \prime}\right) \frac{\mathrm{RT}, \mathrm{THF}(9,10)}{-2 \mathrm{NaBr}} \\
& +2 \mathrm{Na}
\end{aligned} \\
& \mathrm{Ni}(\text { Acac })_{2}+2 \mathrm{R}-\mathrm{DAB}\left(\mathrm{R}^{\prime}, \mathrm{R}^{\prime \prime}\right)+2 \mathrm{Na} \frac{\mathrm{RT}, \operatorname{THF}(9,10)}{-2 \mathrm{NaAcac}} \\
& \mathrm{NiBr}_{2} \mathrm{DME}+2 \mathrm{R}-\mathrm{DAB}\left(\mathrm{R}^{\prime}, \mathrm{R}^{\prime \prime}\right)+2 \mathrm{Na} \frac{\mathrm{RT}, \mathrm{THF}(9,10)}{-2 \mathrm{NaBr}} \\
& \mathrm{NiBr}_{2} \mathrm{DME}+\mathrm{Na}\left[\mathrm{R}-\mathrm{DAB}\left(\mathrm{R}^{\prime}, \mathrm{R}^{\prime \prime}\right)\right] \\
& \frac{-2 \mathrm{NaBr}}{-\mathrm{DME}(145)} \\
& \mathrm{Ni}(\text { Acac })_{2}+\mathrm{Ph}_{2} \mathrm{AlOPh}+2 \mathrm{R}-\mathrm{DAB}\left(\mathrm{R}^{\prime}, \mathrm{R}^{\prime \prime}\right) \frac{-\mathrm{PhPh} ;}{-\mathrm{Acac}_{2} \mathrm{AlOPh}} \mathrm{Ni}\left[\mathrm{R}-\mathrm{DAB}\left(\mathrm{R}^{\prime}, \mathrm{R}\right)\right]_{2} \\
& \mathrm{R}=\mathrm{R}^{\prime}=\mathrm{R}^{\prime \prime}=\mathrm{Ph} \text { and } \mathrm{R}=p \text { - Tol }\left(\mathrm{R}^{\prime}=\mathrm{R}^{\prime \prime}=\mathrm{H}\right) \text {; } \\
& \mathrm{R}=\mathrm{PH}\left(\mathrm{R}^{\prime}=\mathrm{R}^{\prime \prime}=\mathrm{C}_{6} \mathrm{H}_{4} \mathrm{OMe}-p\right)(145)
\end{aligned}
$$

Scheme 3. Reactions leading to $\mathrm{Ni}^{0}-\mathrm{R}-\mathrm{DAB}$ complexes.

starting material although also in this case with sterically hindered groups (e.g., $\left.\mathrm{R}=i-\mathrm{Pr}_{2} \mathrm{CH}\right)$ substitution beyond the $\mathrm{Ni}(\mathrm{COD})(\mathrm{R}-\mathrm{DAB})$ stage is not possible (9). The preferred method appears to be one of the reductive routes shown in Scheme $3(9,47,70,145,146)$. Following such a route the interesting tetra(organyl)cyclobutadienenickel complex shown in Eq. (29) has been synthesized. 


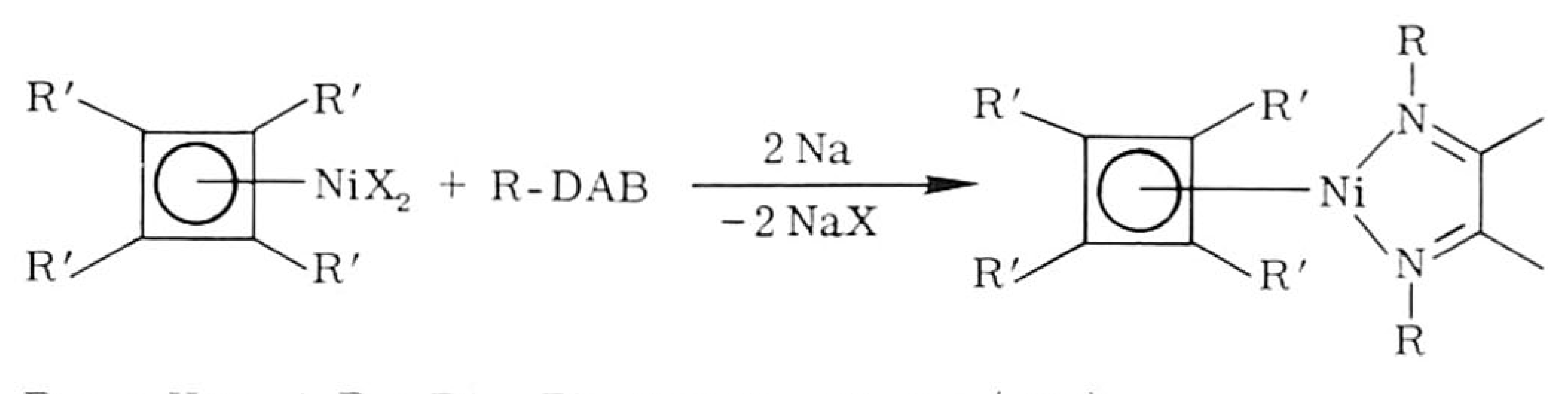

$\mathrm{R}=c-\mathrm{Hex}, i-\mathrm{Pr} ; \mathrm{R}^{\prime}=\mathrm{Ph}, \mathrm{Me} ; \mathrm{X}=\mathrm{Cl}, \mathrm{Br}(146)$

A combined ligand substitution-reductive elimination reaction of $\mathrm{NiEt}_{2}\left(2,2^{\prime}\right.$-bipy $)$ complexes in the presence of $\mathrm{Ph}-\mathrm{DAB}(\mathrm{Ph}, \mathrm{Ph})$ resulted in formation of $\mathrm{Ni}[\mathrm{Ph}-\mathrm{DAB}(\mathrm{Ph}, \mathrm{Ph})]_{2}$ (145). The complex Ni[Ph-DAB$(\mathrm{Ph}, \mathrm{Ph})]\left(\mathrm{PPh}_{3}\right)_{2}$ can be isolated from the 1:1 reaction of $\mathrm{R}-\mathrm{DAB}$ with $\mathrm{Ni}\left(\mathrm{PPh}_{3}\right)_{2}\left(\mathrm{C}_{2} \mathrm{H}_{4}\right)$. However, this complex readily undergoes further substitution of the $\mathrm{PPh}_{3}$ ligands $(70,73)$.

$\mathrm{NiX}_{2}(\mathrm{R}-\mathrm{DAB})$ complexes that are obtained from the $1: 1$ reaction of $\mathrm{NiX}_{2}$ with R-DAB (47) are good starting materials for zerovalent Ni-RDAB species (see Scheme 3).

Reaction of $\mathrm{NiBr}_{2}\left(i-\mathrm{Pr}_{2} \mathrm{CH}\right.$-DAB $)$ with $o$-tolylmagnesium bromide results (probably via an $O$-tolylnickel intermediate from which toluene is eliminated) in formation of a new $\mathrm{Ni}-\mathrm{C}$ bond (Eq. 30) $(47,147)$.
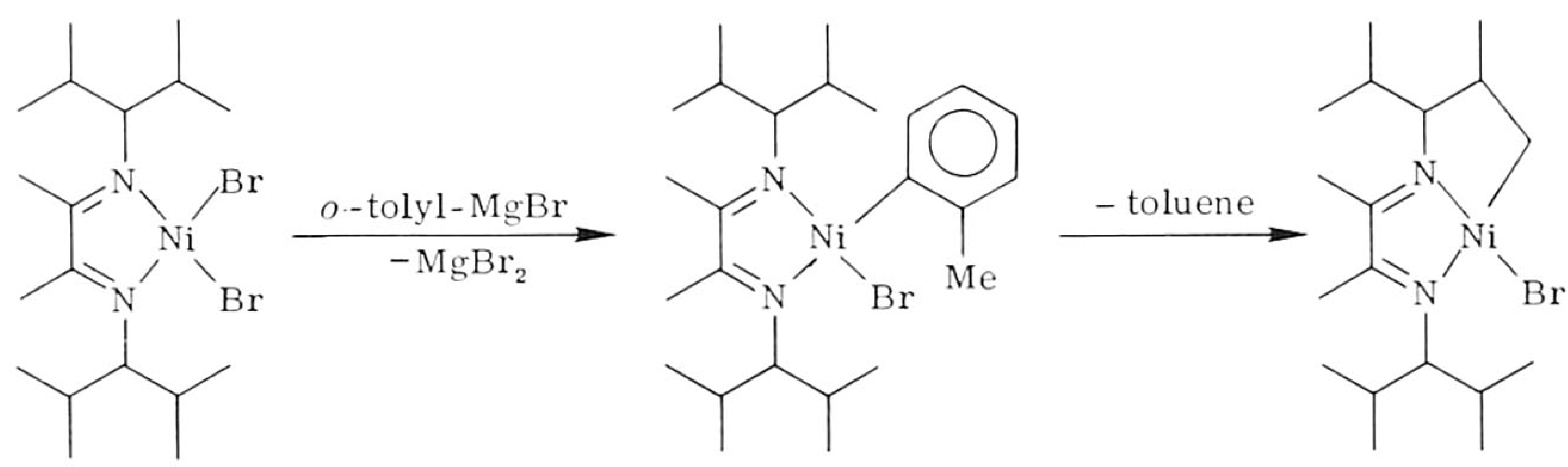

In the $O$-tolylnickel intermediate one of the $\mathrm{CH}_{3}$ groups of the $i$ - $\mathrm{Pr}_{2} \mathrm{CH}$ substituent in the $\sigma, \sigma-\mathrm{N}, \mathrm{N}^{\prime}$ bonded $i$ - $\mathrm{Pr}_{2} \mathrm{CH}$-DAB ligand is brought into close proximity with the reactive $\mathrm{Ni}-O$-tolyl bond, thus facilitating the intramolecular elimination reaction (147).

The R-DAB analogs of the $\mathrm{NiR}_{2}\left(2,2^{\prime}\right.$-bipy) complexes are only stable when $\mathrm{R}$ is a 2,6-disubstituted aryl group, in particular 2,6-i- $\mathrm{Pr}_{2} \mathrm{C}_{6} \mathrm{H}_{3}(148)$, and can be prepared via routes shown in Eq. (31).

$$
\begin{aligned}
& \mathrm{NiBr}_{2}(\mathrm{R}-\mathrm{DAB})+2 \mathrm{R}^{\prime} \mathrm{MgBr} \frac{\mathrm{Et}_{2} \mathrm{O}}{-80^{\circ} \mathrm{C}}-\mathrm{NiR}_{2}^{\prime}(\mathrm{R}-\mathrm{DAB})+2 \mathrm{MgXBr} \\
& \mathrm{Ni}(\mathrm{Acac})_{2}+\mathrm{R}-\mathrm{DAB}+\left.2 \mathrm{R}_{2} \mathrm{O}\right|_{-8{ }^{\circ} \mathrm{C}} \\
& \mathrm{Xr} \text {, Acac }
\end{aligned}
$$


The lower stability of the $\mathrm{NiMe}_{2}(\mathrm{R}-\mathrm{DAB})$ complexes compared to the 2,2'bipy analogs is ascribed to a destabilization of the $\mathrm{Ni}-\mathrm{C}$ bond brought about by a distortion from the square planar geometry as a result of steric interaction of the Me groups and the bulky R substituents (148). However, electronic factors may also contribute to a destabilization of the $\mathrm{NiR}_{2}(\mathrm{R}$ DAB) complexes.

Selective reduction of $\mathrm{NiBr}_{2}\left(i-\mathrm{Pr}_{2} \mathrm{CH}-\mathrm{DAB}\right)$ with sodium in ether affords the $\mathrm{Ni}^{1}$ dimer $\left[\mathrm{NiBr}\left(i-\mathrm{Pr}_{2} \mathrm{CH}-\mathrm{DAB}\right)\right]_{2}(47)$. Three further routes to this product are available as shown in Scheme 4.

$\mathrm{X}$-Ray structure determinations of $\mathrm{Ni}(\mathrm{R}-\mathrm{DAB})_{2}[\mathrm{R}=c$-Hex (9) and 2,6- $\mathrm{Me}_{2} \mathrm{C}_{6} \mathrm{H}_{3}(10)$ ] (see Table II) have been carried out and revealed structures containing $\sigma, \sigma-\mathrm{N}, \mathrm{N}^{\prime}$ bonded R-DAB ligands. However, the structures differ with respect to the angle between the two chelate rings. For the compound with $\mathrm{R}=c$-Hex this angle is $88.3^{\circ}$ whereas a value of $44.5^{\circ}$ is found for $\mathrm{R}=2,6-\mathrm{Me}_{2} \mathrm{C}_{6} \mathrm{H}_{3}$. This difference has been explained on the basis of the tendency of $\mathrm{Ni}$ to favor a planar diamagnetic (i.e., a formally $\mathrm{Ni}^{\mathrm{II}}$ ) arrangement with 1,4-heterodienes which leads for the sterically smaller 2,6- $\mathrm{Me}_{2} \mathrm{C}_{6} \mathrm{H}_{3}$ groupings to an intermediate square planar-tetrahedral arrangement. In this respect it is interesting that isoelectronic $\mathrm{Ni}\left[\left(3,5-\mathrm{Me}_{2} \mathrm{C}_{6} \mathrm{H}_{3}\right)_{2} \mathrm{~N}_{4}\right]_{2}$ has a corresponding angle $\theta$ of $90^{\circ}$. Since the tetraazadiene ligand is an even better $\pi$-electron acceptor than the diazabutadiene ligand $(75,148 a)$ this suggests that other factors may be operative. Both structures are shown in Fig. 6.

An attempt has been made to classify the $\mathrm{Ni}(\mathrm{R}-\mathrm{DAB})_{2}$ complexes with various $\mathrm{R}$ groups according to the formal oxidation state on the $\mathrm{Ni}$ center by ESCA spectroscopy (149). However, the $\mathrm{Ni}(2 p 3 / 2)$ data do not appear to provide reliable information, in contrast to the $\mathrm{Pt}(4 f 7 / 2)$ data for

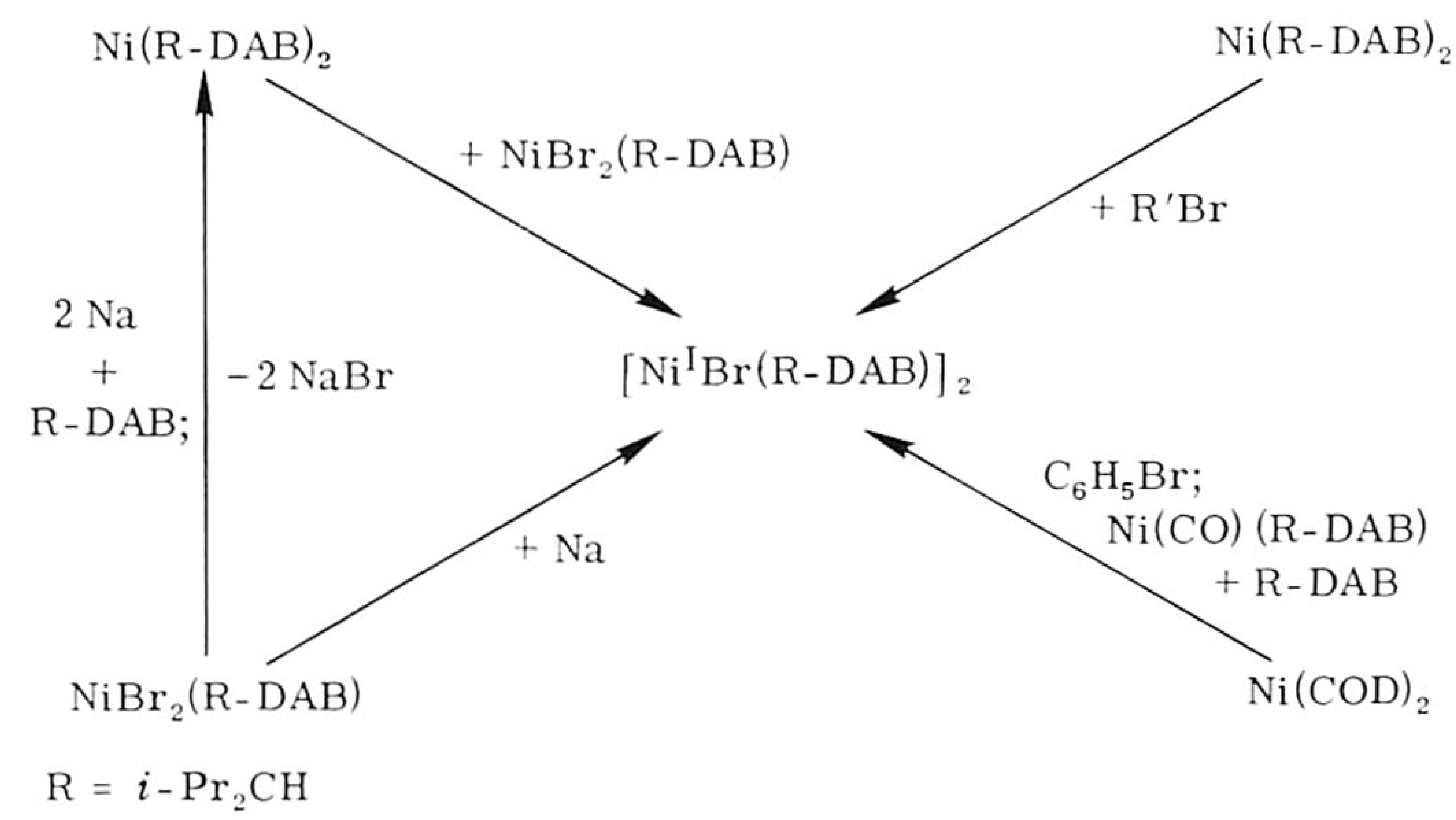

SCHEme 4. Routes to $\left[\mathrm{Ni}{ }^{1} \mathrm{Br}(\mathrm{R}-\mathrm{DAB})\right]_{2}$ (47). 

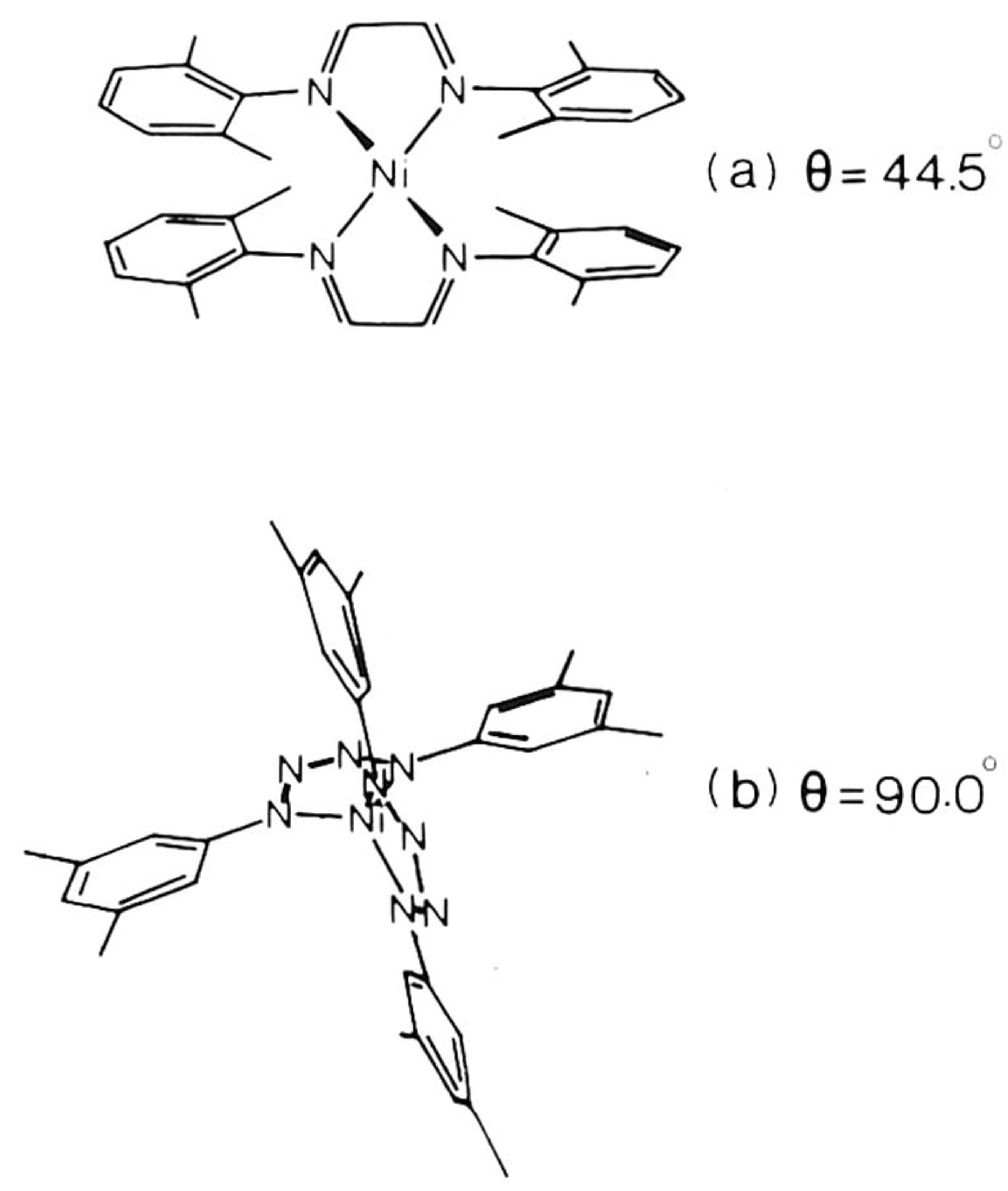

(b) $\theta=90.0^{\circ}$

FIG. 6. Structure (a) of isoelectronic nickel-R-DAB $(9,10)$ and (b) nickeltetraazadiene (148a) complexes; $\theta$ is the angle between the chelate planes.

which such classification in ranges for $\mathrm{Pt}^{0}, \mathrm{Pt}^{\mathrm{Il}}$, and $\mathrm{Pt}^{\mathrm{IV}}$ seems meaningful (150).

The structure of $\left[\mathrm{NiBr}\left(i-\mathrm{Pr}_{2} \mathrm{CH}-\mathrm{DAB}\right)\right]_{2}$ has been established by an $\mathrm{X}$ ray diffraction study (see Table II and Scheme 4).

The structures of $\mathrm{Ni}(\mathrm{CO})_{2}(\mathrm{R}-\mathrm{DAB})$ complexes can be deduced from the crystal structure of a corresponding diacetyl(bis-dimethylhydrazon)nickel complex which is shown in Fig. 7 (46). Apart from the tetrahedral geometry around $\mathrm{Ni}$ and the $\sigma, \sigma-\mathrm{N}, \mathrm{N}^{\prime}$ bonded $\alpha$-diimine ligand this structure shows the influence of the methyl substituents on the imino- $\mathrm{C}$ atoms on the ro-

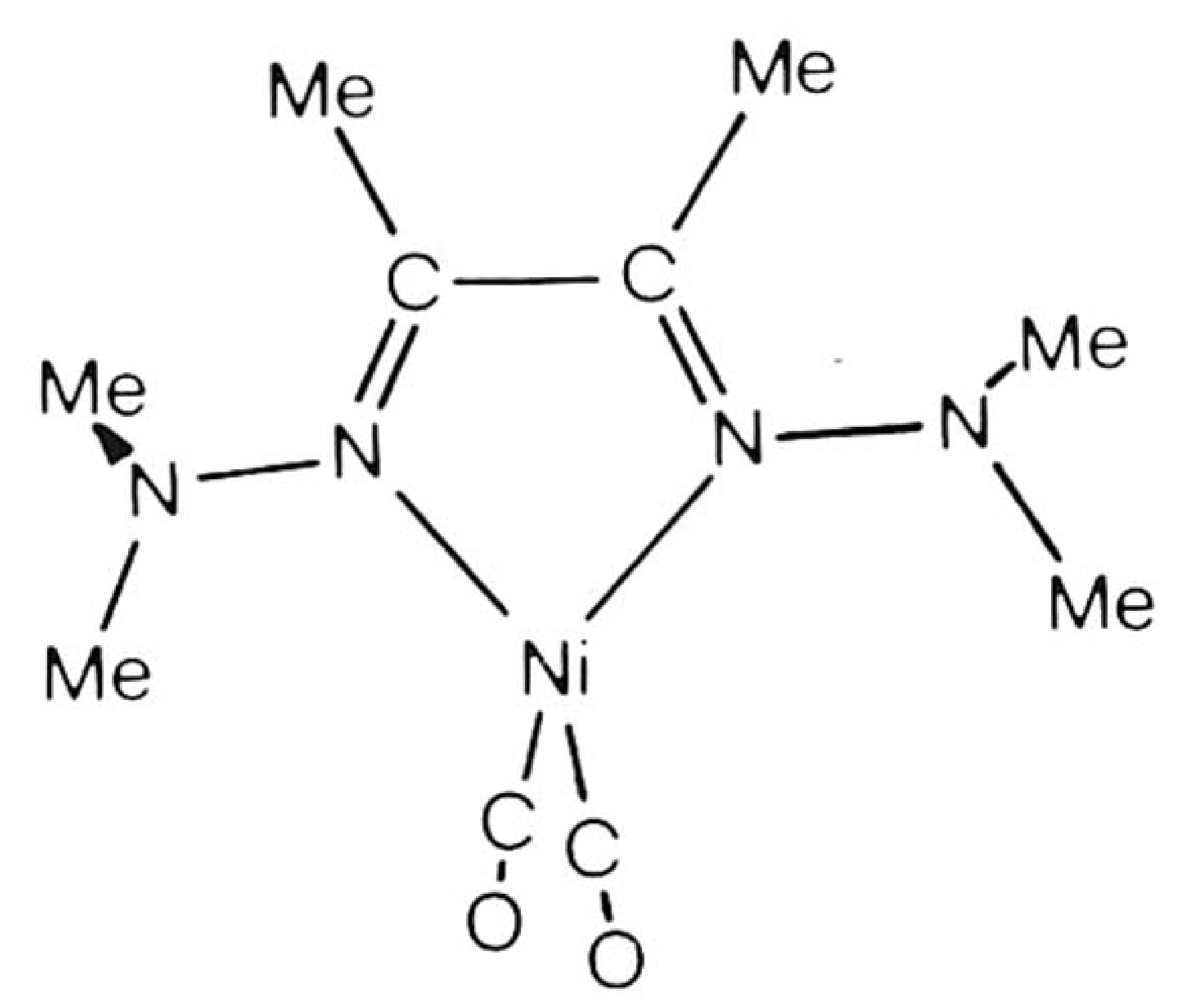

Fig. 7. Molecular geometry of $\mathrm{Ni}(\mathrm{CO})_{2}\left[\mathrm{Me}_{2} \mathrm{~N}-\mathrm{DAB}(\mathrm{Me}, \mathrm{Me})\right]_{2}(46)$. 
tamer conformation of the $\mathrm{Me}_{2} \mathrm{~N}$ groups (both methyl groups of the $\mathrm{Me}_{2} \mathrm{~N}$ grouping being directed away).

Zerovalent complexes of palladium containing $\sigma, \sigma-\mathrm{N}, \mathrm{N}^{\prime}$ bonded R-DAB have been obtained by the simultaneous reaction of activated olefins and a R-DAB ligand with $\mathrm{Pd}_{3}(\mathrm{TTAA})_{3}$ [cf. (58)] as the preferred source of $\mathrm{Pd}^{0}$ [Eq. (32)].

$$
\frac{1}{3} \mathrm{Pd}_{3}(\text { TTAA })_{3}+\text { olefin }+t \text {-Bu-DAB } \underset{- \text { TTAA }}{\longrightarrow} \operatorname{Pd}\left(\eta^{2}-\text { olefin }\right)(t \text {-Bu-DAB })
$$

olefin $=$ e.g., Dmf

Stable combinations of the $\eta^{2}$-olefin and R-DAB ligands are formed with strong $\sigma$-donating $\mathrm{R}$ groups and a strong $\pi$-electron density accepting olefin (58).

$\mathrm{Pt}(\mathrm{COD})_{2}$ reacts with $\mathrm{R}-\mathrm{DAB}$ to give tetrahedral $\mathrm{Pt}(\mathrm{COD})-(\mathrm{R}-\mathrm{DAB})$ (15l) complexes that are strikingly similar to the $\operatorname{Pt}(\mathrm{COD})\left(\mathrm{R}_{2} \mathrm{~N}_{4}\right)\left(\mathrm{R}_{2} \mathrm{~N}_{4}\right.$ $=\operatorname{aryl} \mathrm{N}=\mathrm{N}-\mathrm{N}=\mathrm{Naryl}$ ) complexes for which ESCA measurements indicate a $\mathrm{Pt}^{\mathrm{II}}$ formal oxidation state (150). However, ${ }^{13} \mathrm{C}$ NMR measurements reveal ' $J(\mathrm{Pt}-\mathrm{C})$ values comparable with those of $\mathrm{Pt}(\mathrm{COD})(\mathrm{R}$ $\mathrm{DAB})$ and other known zerovalent platinum cyclooctadiene complexes $(150,151)$.

Divalent Pd- and Pt-R-DAB complexes with $\sigma, \sigma-\mathrm{N}, \mathrm{N}^{\prime}$ bonded R-DAB ligands have been reported for the (1,4-diaza-3-methyl-1,3-butadien-2yl)palladium(II) ligands as shown below (60).

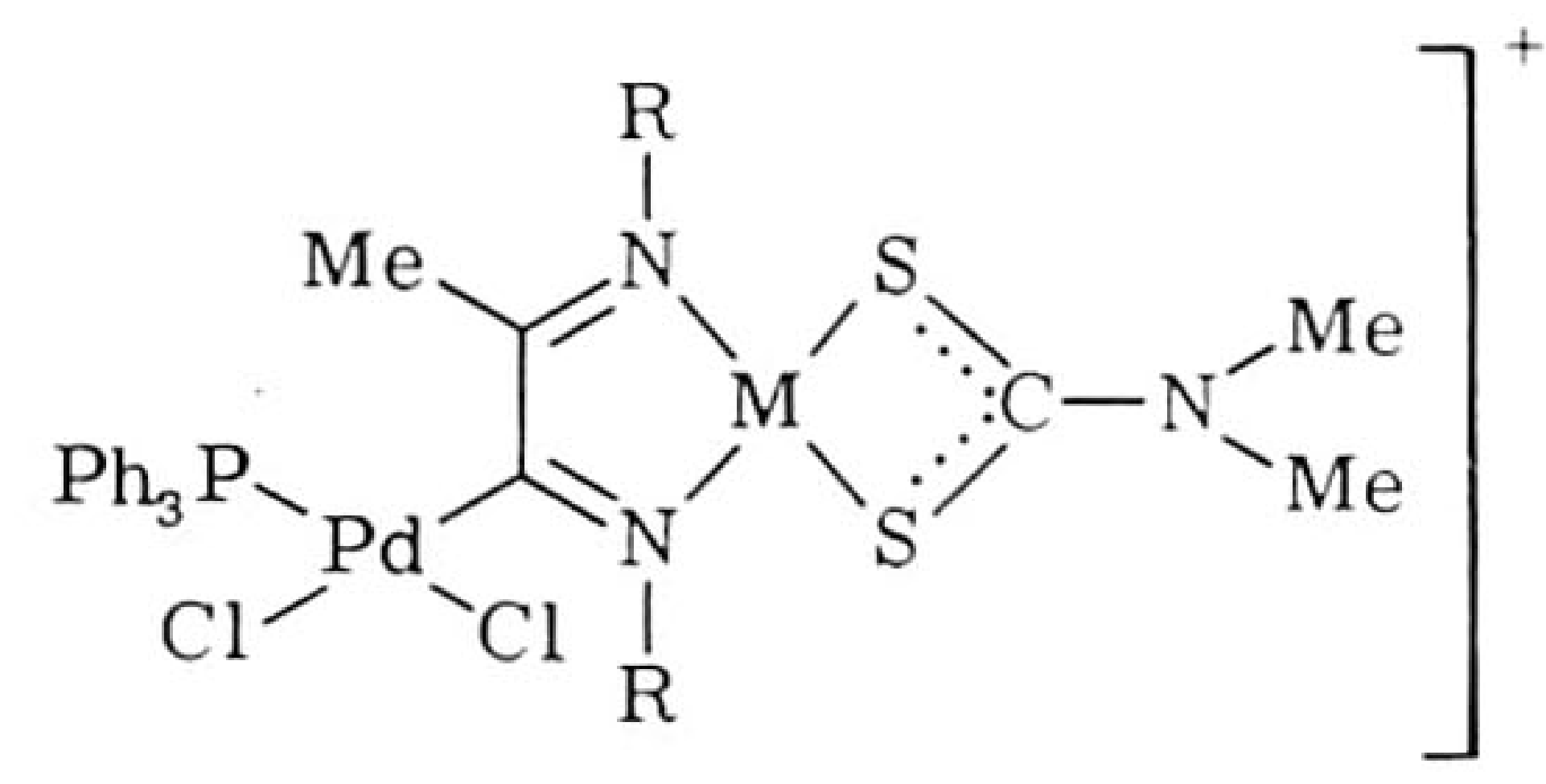

$\mathrm{R}=\mathrm{C}_{6} \mathrm{H}_{4} \mathrm{OMe}-p ; \mathrm{M}=\mathrm{Pt}, \mathrm{Pd}$

Cis $-\mathrm{MCl}_{2}(\mathrm{R}-\mathrm{DAB})$ can exclusively be obtained for $\mathrm{M}=\mathrm{Pd}$ starting from trans- $\mathrm{MCl}_{2}(\mathrm{PhCN})_{2}$ with $\mathrm{R}-\mathrm{DAB}\left(\mathrm{R}=t\right.$ - $\left.\mathrm{Bu}, \mathrm{EtMe}_{2} \mathrm{C}\right)$ (29). The corresponding $\mathrm{Pt}$ compounds are accessible via olefin dissociation from the fivecoordinate $\mathrm{PtCl}_{2}\left(\eta^{2}\right.$-olefin $)(\mathrm{R}-\mathrm{DAB})$ complexes (29) that can be obtained according to Eq. (32) (48).<smiles>[R7]C[P+]1(Cl)(Cl)N=C([R7])N([R7])C(C)=C1C</smiles> 
${ }^{1} \mathrm{H}$ and ${ }^{13} \mathrm{C}$ NMR measurements confirmed the five-coordinate structure for these compounds which is schematically shown in Eq. (32b). When styrene is the $\eta^{2}$-coordinated olefin, the ground state structure in the solid state (see Table II) established that the $\mathrm{C}=\mathrm{C}$ skeleton is in the trigonal plane $(48,56)$. This in-plane conformation is a reflection of the stabilizing metal back bonding capability of the olefin on the $\sigma, \sigma-\mathrm{N}, \mathrm{N}^{\prime}$ chelate bonding mode. Complexes containing a phosphine instead of an $\eta^{2}$-olefin undergo $\sigma$-N $\rightleftarrows \sigma$ - $\mathrm{N}^{\prime}$ fluxional processes (see Fig. 3 ) in which the five-coordinate situation is an intermediate or transition state $(30,35)$.

Stabilization of $\mathrm{Pt}$-olefin and $\mathrm{Pt}$-alkyne bonds due to effective back bonding from the metal to empty $\pi^{*}$ orbitals of the unsaturated hydrocarbon in electron-rich five-coordinate complexes have been demonstrated in a number of cases: e.g., $\mathrm{PtCl}_{2}\left(\eta^{2}-\mathrm{C}_{2} \mathrm{H}_{4}\right)[\mathrm{Ph}(\mathrm{Me}) \mathrm{N}-\mathrm{DAB}(\mathrm{Me}, \mathrm{Me})]$ (49, 152) $\mathrm{PtMeCl}\left(\eta^{2}-\mathrm{RC} \equiv \mathrm{CR}\right)\left(2,2^{\prime}\right.$-bipy) (153), $\mathrm{PtCl}_{2}\left(\eta^{2}-\mathrm{C}_{2} \mathrm{H}_{4}\right)[(\mathrm{RN}-$ $\left.\left.(\mathrm{H}) \mathrm{CH}_{2}\right)_{2}\right](48,153 a)$ and $\mathrm{PtCl}_{2}\left(\eta^{2}-\mathrm{C}_{2} \mathrm{H}_{4}\right)(2-\mathrm{RN}=\mathrm{C}(\mathrm{H})$ py $)(154)$.

The structural aspects and reactivity of the five-coordinate $\mathrm{PtX}_{2}\left(\eta^{2}\right.$-olefin) (R-DAB) and analogous $\mathrm{RhX}(\mathrm{CO})\left(\eta^{2}-\mathrm{C}_{2} \mathrm{H}_{4}\right)(\mathrm{R}-\mathrm{DAB})$ complexes have been studied in detail since they represent model compounds for the fivecoordinate intermediates (activated complexes) found in ligand displacement reactions from four-coordinate complexes: i.e., trans- $\mathrm{MX}_{2} \mathrm{~A}\left(\eta^{2}\right.$-olefin $)+\mathrm{B} \rightleftarrows$ trans $-\mathrm{MX}_{2} \mathrm{~B}\left(\eta^{2}\right.$-olefin $)+\mathrm{A}(48,155)$. Moreover, the barrier to rotation of the olefin around the olefin-Pt axis in $\mathrm{PtX}_{2}\left(\eta^{2}\right.$-olefin $)(\mathrm{R}$ DAB) was studied (48) and found to be similar to that observed in square planar Pt-olefin complexes. This has been attributed to the planarity of the five-membered chelate ring, which lowers the barrier for bending of the $\mathrm{Cl}$ atoms toward the $\mathrm{R}-\mathrm{DAB}$ ligand when the olefin passes through an upright conformation (see Fig. 8). It is interesting that the above-mentioned $\mathrm{Pt}^{0}(\mathrm{COD})(\mathrm{R}-\mathrm{DAB})$ and $\mathrm{Pt}^{0}\left(\eta^{2}\right.$-olefin $)(\mathrm{R}-\mathrm{DAB})$ complexes, which lack the two axial ligands, have the same stereochemistry in the trigonal plane as has been found for the five-coordinate $\mathrm{Pt}^{\mathrm{II}}$ and $\mathrm{Rh}^{\mathrm{I}}$ complexes.
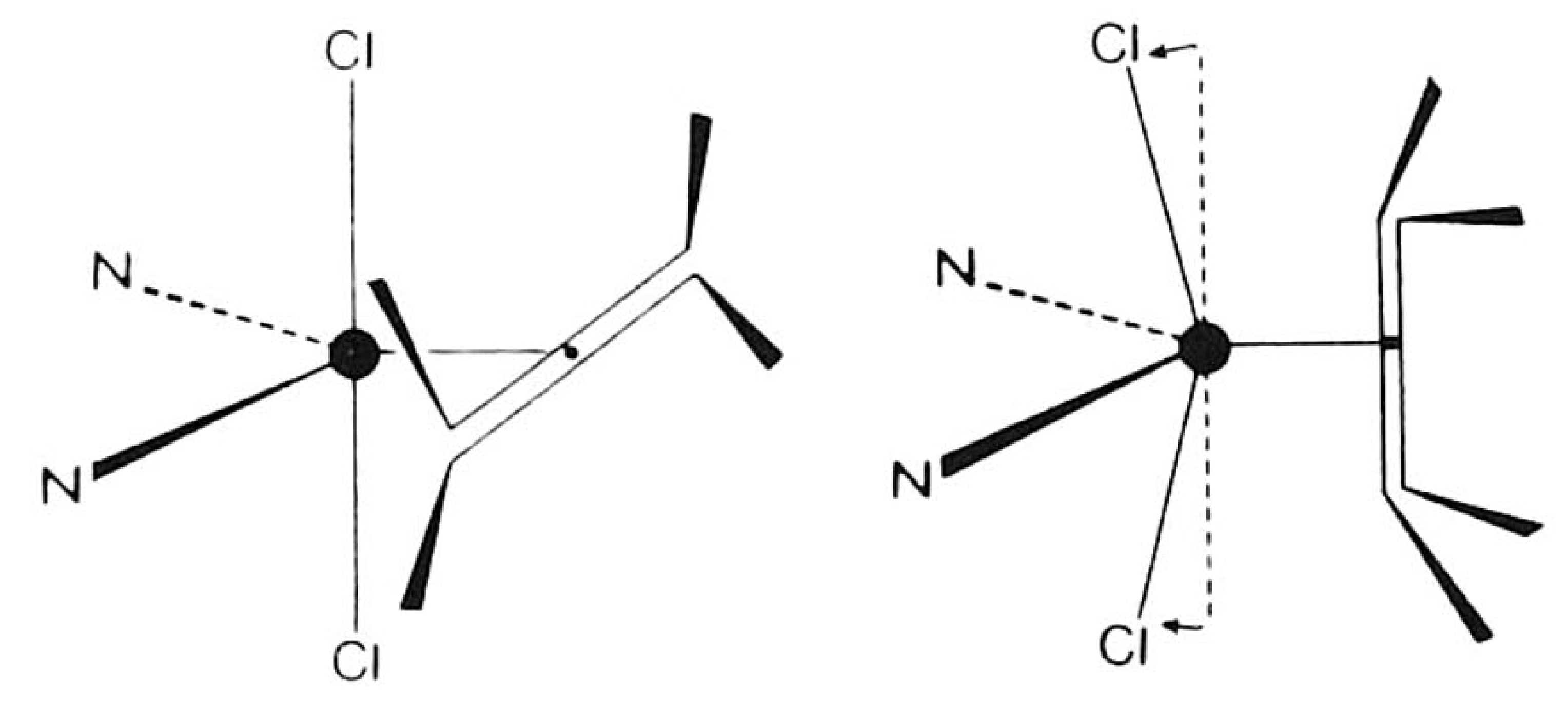

- $\mathrm{Pt}$

Fig. 8. Bending back of the $\mathrm{Cl}$ atoms in the TBP structure of $\mathrm{PtCl}_{2}\left(\eta^{2}\right.$-olefin)(R-DAB) when the olefin passes the upright conformation during the rotation process (48). 
In $\mathrm{PtCl}_{2}\left(\eta^{2}\right.$-olefin $)\left(6-\mathrm{R}^{\prime}\right.$-py-2-CH=NR) the $\mathrm{N}$-coordination sites of the bidentate ligand are dissimilar (154). Owing to the resulting asymmetry in the equatorial plane of the trigonal bipyramidal structure of these complexes it was possible to use ${ }^{13} \mathrm{C}$ NMR spectroscopy to establish the ground state structure with an in-plane $\mathrm{C}=\mathrm{C}$ olefinic moiety. Furthermore, it was shown that changing the 6- $\mathrm{H}$ for a 6 -Me group introduced a considerable increase of the steric constraints in the equatorial plane. This can explain the increased stability of the 6-Me complexes with respect to $\mathrm{Pt}$-olefin bond dissociation: a process that would afford cis- $\mathrm{PtCl}_{2}\left(6-\mathrm{R}^{\prime}-\mathrm{py}-2-\right.$ $\mathrm{CH}=\mathrm{NR})$. In the latter square planar complex the 6- $\mathrm{R}^{\prime}$ substituent comes much closer to one of the cis- $\mathrm{Cl}$ groups (154).

Finally, the above observations were confirmed by studying the ${ }^{15} \mathrm{~N}$ labeled compounds $\mathrm{PtCl}_{2}\left(\eta^{2}\right.$-styrene $)\left(t\right.$-Bu-DAB- $\left.{ }^{15} \mathrm{~N}_{2}\right)(35)$.

An important aspect of these five-coordinate $\mathrm{PtX}_{2}\left(\eta^{2}\right.$-olefin $)(\mathrm{R}-\mathrm{DAB})$ complexes is that the axial halogen atoms as well as the equatorial $\eta^{2}$-olefin (e.g., $\mathrm{C}_{2} \mathrm{H}_{4}$ ) and $\sigma, \sigma-\mathrm{N}, \mathrm{N}^{\prime}$ chelate bonded R-DAB ligands can be replaced with retention of the trigonal bipyramidal structure (see Scheme 5) (155, 156). Halogen exchange is initiated by formation of an ionic intermediate $\left[\mathrm{PtX}\left(\eta^{2}-\mathrm{C}_{2} \mathrm{H}_{4}\right)(\mathrm{R}-\mathrm{DAB})\right] \mathrm{X}$. The reversible exchange of the equatorial ligands with olefins, R-DAB, or 1,2-diaminoethane ligands is proposed to proceed via five-coordinate intermediates containing a $\sigma-\mathrm{N}$ monodentate bonded R-DAB or 1,2-diaminoethane ligand $(155,156)$ (see Fig. 9).

It was argued on the basis of stereochemical and electronic grounds that the R-DAB and 1,2-diaminoethane ligands are better suited to this reversible $\sigma-\mathrm{N} \rightleftarrows \sigma, \sigma-\mathrm{N}, \mathrm{N}^{\prime}$ bonding than py-2-CH=NR or $2,2^{\prime}-$ bipyridine (156).

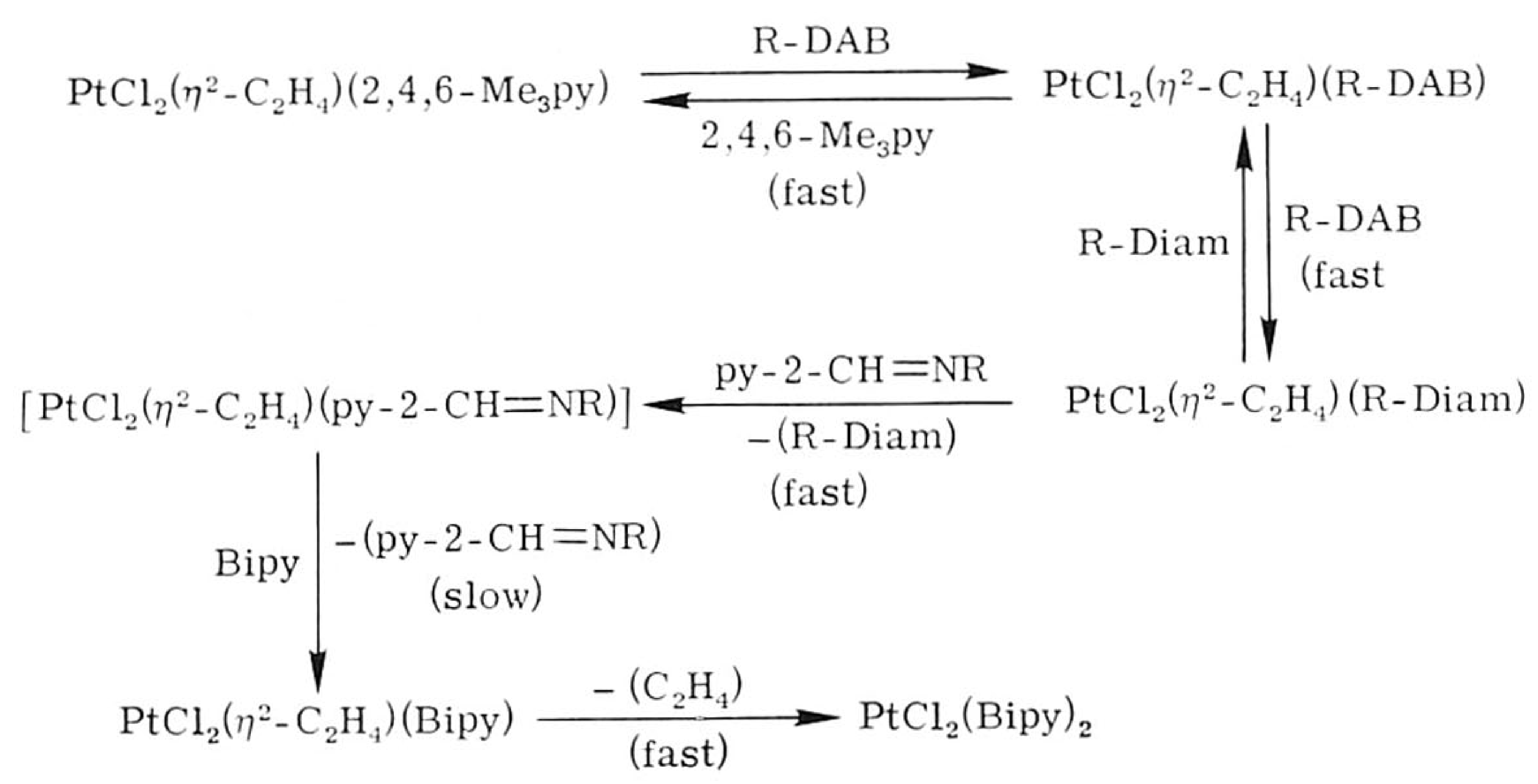

SCHEME 5. Ligand substitution in five-coordinate platinum(II) complexes [R-Diam is $\left.\mathrm{RN}(\mathrm{H}) \mathrm{CH}_{2} \mathrm{CH}_{2} \mathrm{~N}(\mathrm{H}) \mathrm{R}\right](156)$. 


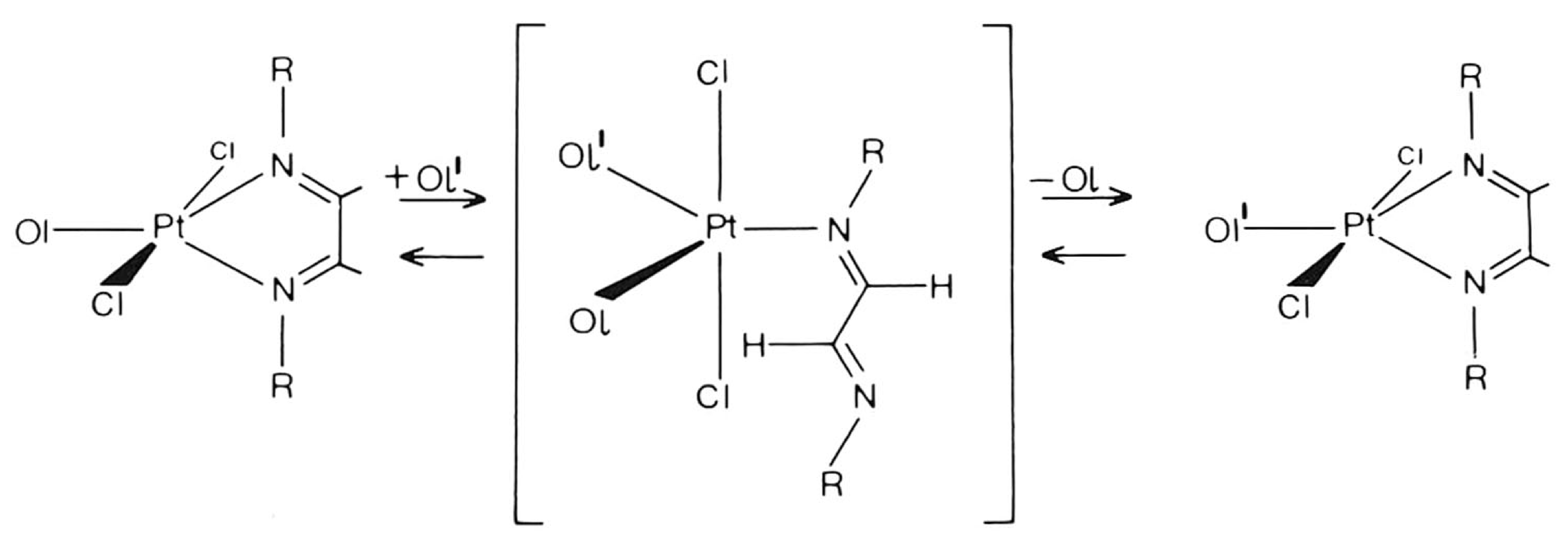

FIG. 9. Mechanism proposed for olefin exchange in $\mathrm{PtCl}_{2}\left(\eta^{2}\right.$-olefin $) \mathrm{L}_{2}$ complexes. Similar intermediates are proposed for the bidentate $\mathrm{N}$-donor ligand exchange: replace in the figure ol' by $\mathrm{L}_{2}^{\prime}$ for the incoming ligand and ol by R-DAB as leaving group (156).

g. Groups IB and IIB. Reactions of copper(I) halides with R-DAB $\left(\mathrm{R}^{\prime}, \mathrm{R}^{\prime \prime}\right)$ $\left(\mathrm{R}=t\right.$ - $\mathrm{Bu}, c$-Hex, $\mathrm{C}_{6} \mathrm{H}_{4} \mathrm{Y}$ - $p$ with $\mathrm{Y}=\mathrm{H}, \mathrm{OH}, \mathrm{NMe}_{2}$, or $\mathrm{Me} ; \mathrm{R}^{\prime}=\mathrm{R}^{\prime \prime}$ $=\mathrm{H}$ or $\mathrm{Me}$ ) afford highly colored monomeric (in nitrobenzene) $\mathrm{CuX}[\mathrm{R}$ $\left.\operatorname{DAB}\left(\mathrm{R}^{\prime}, \mathrm{R}^{\prime \prime}\right)\right]$ complexes. It has been put forward that the trigonal coordination at copper is reflected in spectroscopic measurements (14). A UVvisible spectroscopic study using various solvents showed that for these complexes the typical solvatochromic behavior and high intensity of the long-wavelength absorption (MLCT band) found for $\mathrm{Mo}^{0}$ (see Section III,D, 2,b) is absent. This is explained by extensive participation of metal $d$ and ligand $\pi^{*}$ orbitals in the ground state, which removes the typical CT character in the case of $\mathrm{Cu}^{1}(14)$.

Later the reaction of copper(I) perchlorate with $t$-Bu-DAB in acetonitrile was studied (157). It was shown that in this solvent the reaction proceeds in two steps involving first formation of $\mathrm{Cu}(\mathrm{t}-\mathrm{Bu}-\mathrm{DAB})^{+}$(in which the $\mathrm{Cu}^{+}$ center is probably further coordinated by two $\mathrm{MeCN}$ ligands) and in the second a four-coordinate species $\mathrm{Cu}(\mathrm{t}-\mathrm{Bu}-\mathrm{DAB})_{2}^{+}$. On the basis of a comparison of the optical spectra, Zelewsky et al. suggest that the above-mentioned $\mathrm{CuX}(\mathrm{R}-\mathrm{DAB})$ complexes can be better formulated as being $\left[\mathrm{CuX}{ }_{2}\right]\left[\mathrm{Cu}(\mathrm{R}-\mathrm{DAB})_{2}\right]$ species $(157)$.

The $\mathrm{CuX}(\mathrm{R}-\mathrm{DAB})$ complexes have been used in reactions directed to formation of pure K(R-DAB) (see Section V).

Reaction of tetranuclear $\mathrm{Cu}_{4}\left(\mathrm{C}_{6} \mathrm{H}_{4} \mathrm{Me}-p\right)_{4}(158)$ with $t$-Bu-DAB afforded a stable red-colored complex with $\mathrm{Cu}_{3}\left(\mathrm{C}_{6} \mathrm{H}_{4} \mathrm{Me}-p\right)_{3}(t$-Bu-DAB $)$ stoichiometry, the structure of which is under study (159). In contrast, reaction of $\mathrm{Cu}_{2} \mathrm{Li}_{2}\left(\mathrm{C}_{6} \mathrm{H}_{4} \mathrm{Me}-p\right)_{4}\left(\mathrm{Et}_{2} \mathrm{O}\right)_{2}(160)$ with $t$ - $\mathrm{Bu}-\mathrm{DAB}$ forms at low temperature a $\mathrm{Cu}_{2} \mathrm{Li}_{2}\left(\mathrm{C}_{6} \mathrm{H}_{4} \mathrm{Me}-p\right)_{4}(t-\mathrm{Bu}-\mathrm{DAB})_{2}$ complex that decomposes at room temperature into a variety of products (159). 
So far R-DAB complexes of $\mathrm{Ag}^{\mathrm{I}}$ and $\mathrm{Au}^{\mathrm{I}}$ or $\mathrm{Au}^{\mathrm{III}}$ have not been reported. That $\alpha$-diimine and also R-DAB complexes for these metals are feasible is indicated by the stable tetrahedral cations formed with 6-R'-py-2$\mathrm{CH}=\mathrm{NR}$ ligands [see Eq. (33)] (161).

$\mathrm{AgO}_{3} \mathrm{SCF}_{3}+2$
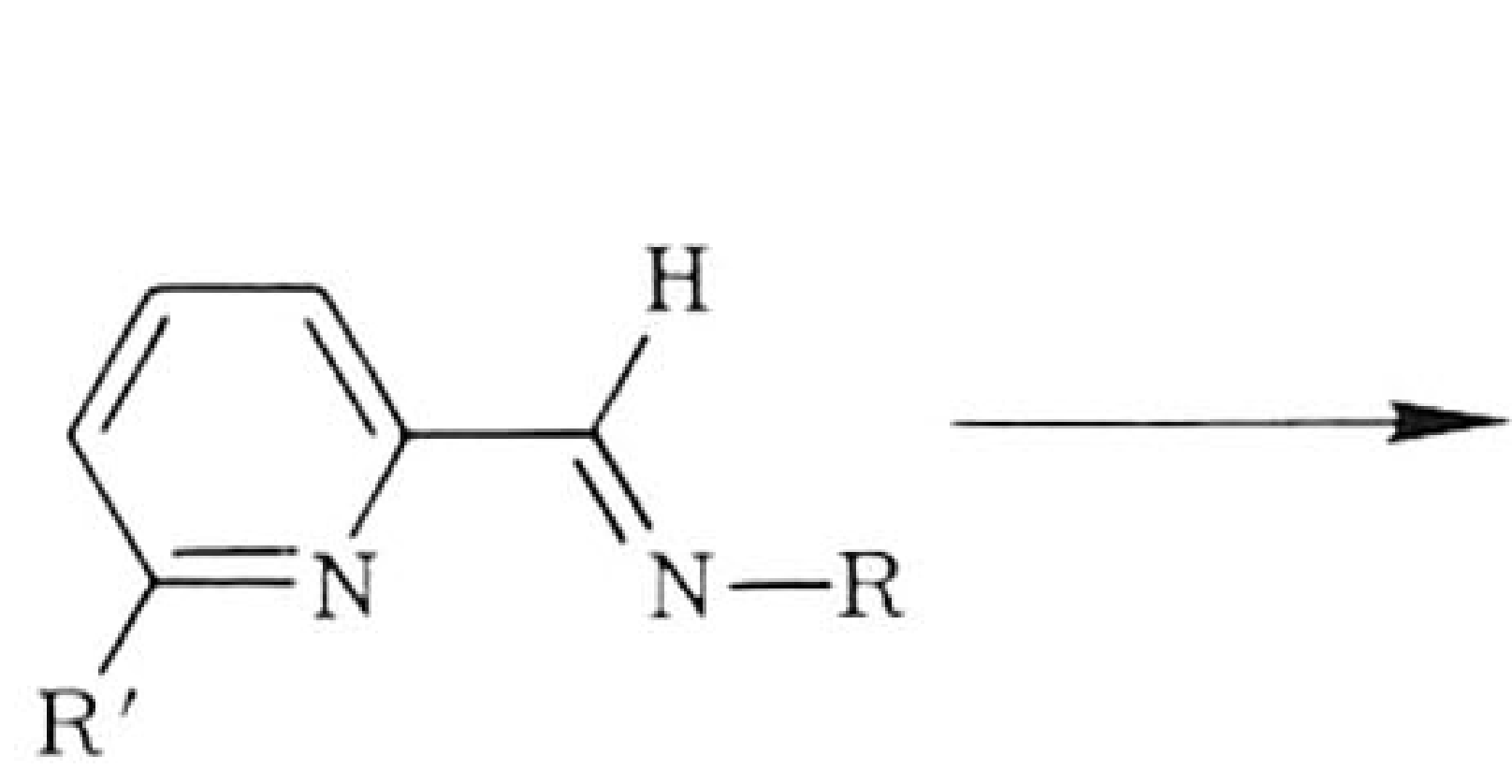

$\mathrm{R}^{\prime}=\mathrm{Me}, \mathrm{H} ; \mathrm{R}=t-\mathrm{Bu},(S)-\mathrm{C}(\mathrm{H}) \mathrm{MePh}$

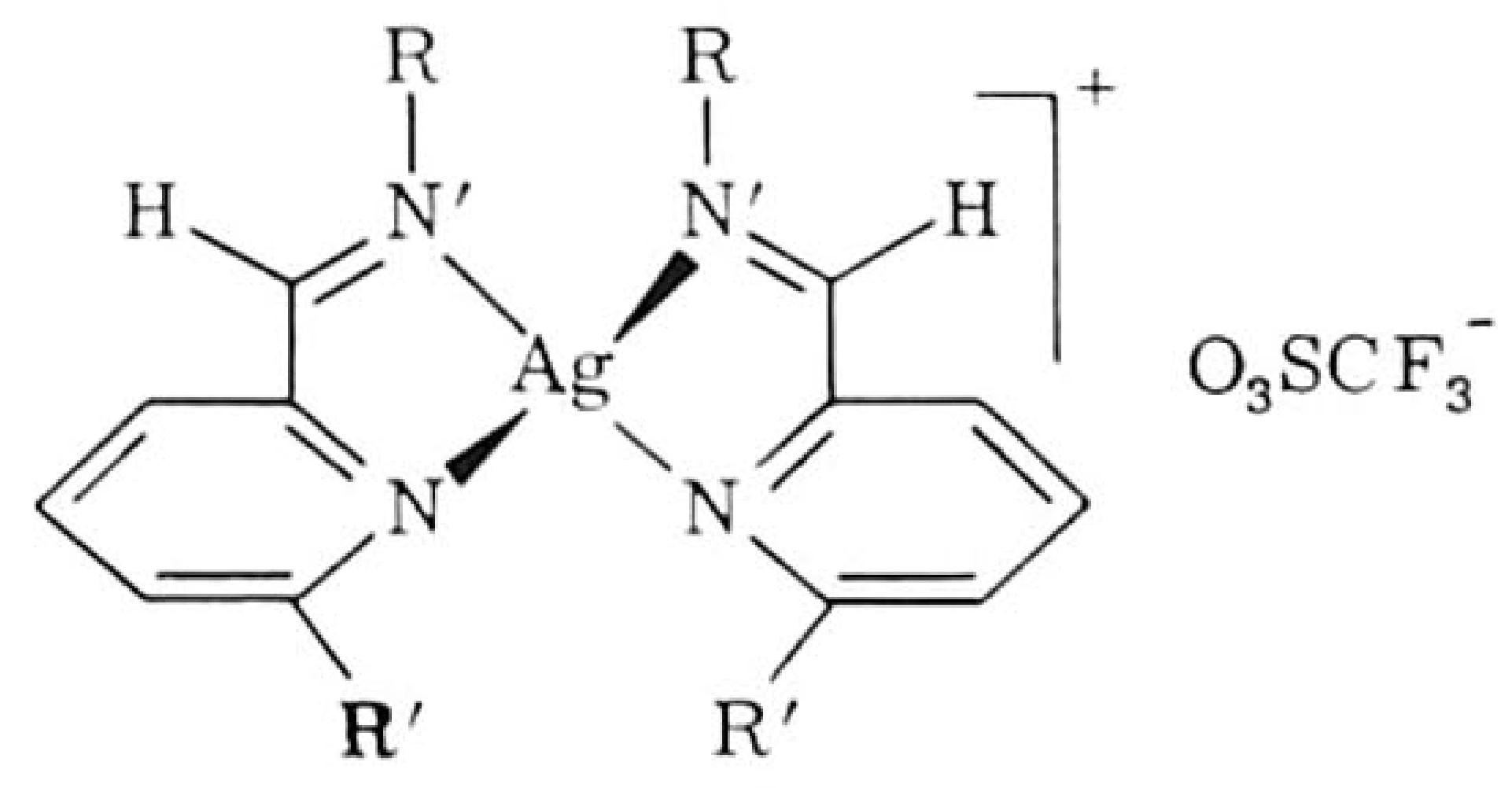

The stereochemistry of these complexes in methanol solutions has been studied by ${ }^{109} \mathrm{Ag}$ INEPT NMR spectroscopy $(161 a)$ and ${ }^{15} \mathrm{~N}$ NMR of ${ }^{15} \mathrm{~N}$ labeled complexes $(161,161 a)$.

A series of $\mathrm{MX}_{2}(\mathrm{R}-\mathrm{DAB})$ complexes where $\mathrm{M}$ is $\mathrm{Zn}, \mathrm{Hg}$, and $\mathrm{Cd}$ have been prepared [see Eq. (8)] containing $\sigma, \sigma-\mathrm{N}, \mathrm{N}^{\prime}$ chelate bonded R-DAB $(\mathrm{R}=\mathrm{Ph}$ and the central $\mathrm{C}-\mathrm{C}$ bond is part of a camphor skeleton (162) or $\mathrm{R}=c$-Hex, $p$ - $\mathrm{MeOC}_{6} \mathrm{H}_{4}, t$-Bu (62).

The radical complexes $[\mathrm{M}(\mathrm{R}-\mathrm{DAB})] \mathrm{X}(\mathrm{M}=\mathrm{Zn}, \mathrm{Mg}, \mathrm{Ca})$ will be discussed in Section V.

Organozinc complexes show a remarkable variance in stability. Whereas $\mathrm{Zn}\left(\mathrm{C}_{6} \mathrm{H}_{4} \mathrm{Me}-p\right)_{2}(t-\mathrm{Bu}-\mathrm{DAB})$ is stable up to $130^{\circ} \mathrm{C}, \mathrm{ZnEt}_{2}(t-\mathrm{Bu}-\mathrm{DAB})$ is stable only below $-50^{\circ} \mathrm{C}$ and above this temperature a selective ethyl transfer from $\mathrm{Zn}$ to $\mathrm{N}$ occurs [see Section V and VI,B (e.g., Fig. 23)] (68).

\section{E. Complexes Containing Bridging $\sigma-N, \mu^{2}-N^{\prime}, \eta^{2}-C=N^{\prime}(6 e)$ Bonded 1,4-Diaza-1,3-butadiene Ligands}

There are relatively few examples of compounds containing the R-DAB ligand bonded in a $\sigma-\mathrm{N}, \mu^{2}-\mathrm{N}^{\prime}, \eta^{2}-\mathrm{C}=\mathrm{N}^{\prime}$ (6e) fashion. Frühauf et al. (30) reported the first examples of such a bonding mode for a number of compounds $\mathrm{Fe}_{2}(\mathrm{CO})_{6}(\mathrm{R}$-DAB $)$. The structure of $\mathrm{Fe}_{2}(\mathrm{CO})_{6}(t$-Bu-DAB $)$ shows that two electrons donated by one $\sigma-\mathrm{N}$ bonded $\mathrm{N}=\mathrm{C}$ group [1.260(5) $\AA$ ] and four electrons via the other $\mathrm{N}=\mathrm{C}$ group $[1.397(4) \AA]$ that bridges the two Fe atoms. Formally the last $\mathrm{N}=\mathrm{C}$ group donates two electrons through the bridging $\mathrm{N}$ atom and two electrons by $\eta^{2}$-bonding to one Fe center (30) (see Fig. 10 and Table II). It has now been shown on the basis of crystallographic and/or spectroscopic evidence that this 6e-donor mode of $\mathrm{R}-\mathrm{DAB}$, which is then always in the $E-s$-cis- $E$ conformation, exists for $\mathrm{Fe}_{2}(\mathrm{CO})_{6}(\mathrm{R}-\mathrm{DAB})[\mathrm{R}=t-\mathrm{Bu}(30,50,112,163), c-\operatorname{Hex}(30,163), i-\operatorname{Pr}$ 


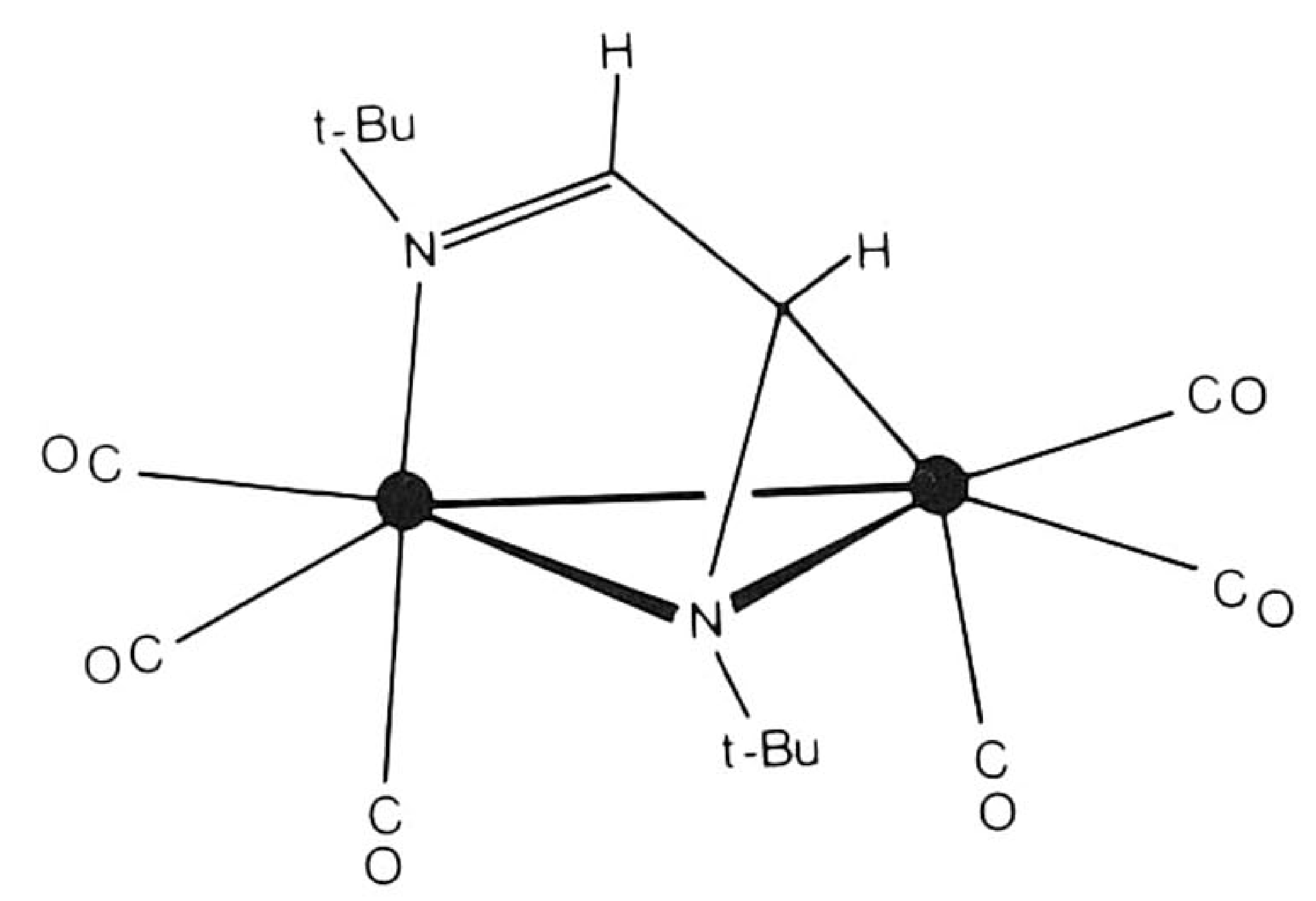

FIG. 10. Schematic structure of $\mathrm{M}_{2}(\mathrm{CO})_{6}(t-\mathrm{Bu}-\mathrm{DAB})(30)$. (๑) Fe, Ru, Os.

$(112,163)], \mathrm{Ru}_{2}(\mathrm{CO})_{6}(\mathrm{R}-\mathrm{DAB})[\mathrm{R}=t-\mathrm{Bu}(50,112,163), c-\mathrm{Hex}(50$, $163), i-\operatorname{Pr}(50,112,163)]$, and $\mathrm{Os}_{2}(\mathrm{CO})_{6}(\mathrm{R}-\mathrm{DAB})[\mathrm{R}=t-\mathrm{Bu}, i-\operatorname{Pr}(112)]$.

An analogous structure has been reported for $\mathrm{Fe}_{2}(\mathrm{CO})_{6}[\mathrm{PhCH}$ $(\mathrm{Me}) \mathrm{NC}(\mathrm{H}) \mathrm{C}(\mathrm{OEt})=\mathrm{O}](164)$ (Fig. 11). The $N$ - $\alpha$-methylbenzyl iminoacetate donates two electrons via the $\mathrm{O}$-atom $[\mathrm{C}=\mathrm{O}=1.326(8) \AA]$ and four electrons via the $\mathrm{C}=\mathrm{N}$ moiety $[1.417(7) \AA]$. The $\mathrm{Fe}^{\prime}-\mathrm{C}, \mathrm{Fe}^{\prime}-\mathrm{N}$, and $\mathrm{C}-\mathrm{C}$ bond lengths are 2.055(6), 1.927(5), and 1.435(10) $\AA$, respectively. These data together with the $\mathrm{Fe}-\mathrm{Fe}$ bond lengths of 2.551(1) $\AA$ are very similar indeed to those of $\mathrm{Fe}_{2}(\mathrm{CO})_{6}(c-\mathrm{Hex}-\mathrm{DAB})$ (Table II) (30). Mixed complexes $\mathrm{MM}^{\prime}(\mathrm{CO})_{6}-(\mathrm{R}-\mathrm{DAB})$ have been obtained for $\mathrm{M}=\mathrm{Fe}$ and $\mathrm{M}^{\prime}$ $=\mathrm{Ru}$ [prepared by the reaction of $\mathrm{Fe}(\mathrm{CO})_{3}(t-\mathrm{Bu}-\mathrm{DAB})$ with $\mathrm{Ru}_{3}(\mathrm{CO})_{12}$ in a three to one molar ratio (165)] and for $\mathrm{M}=\mathrm{Mn}, \mathrm{Re}$ and $\mathrm{M}^{\prime}=\mathrm{Co}$ with $\mathrm{R}=t$ - $\mathrm{Bu}, i-\mathrm{Pr}$, and $c$-Hex (5l). Binuclear ruthenium complexes $\mathrm{Ru}_{2}(\mathrm{CO})_{4}(\mathrm{R}-\mathrm{DAB})_{2}$ containing two $\sigma-\mathrm{N}, \mu^{2}-\mathrm{N}^{\prime}, \eta^{2}-\mathrm{C}=\mathrm{N}^{\prime}(6 \mathrm{e})$ bonded R-

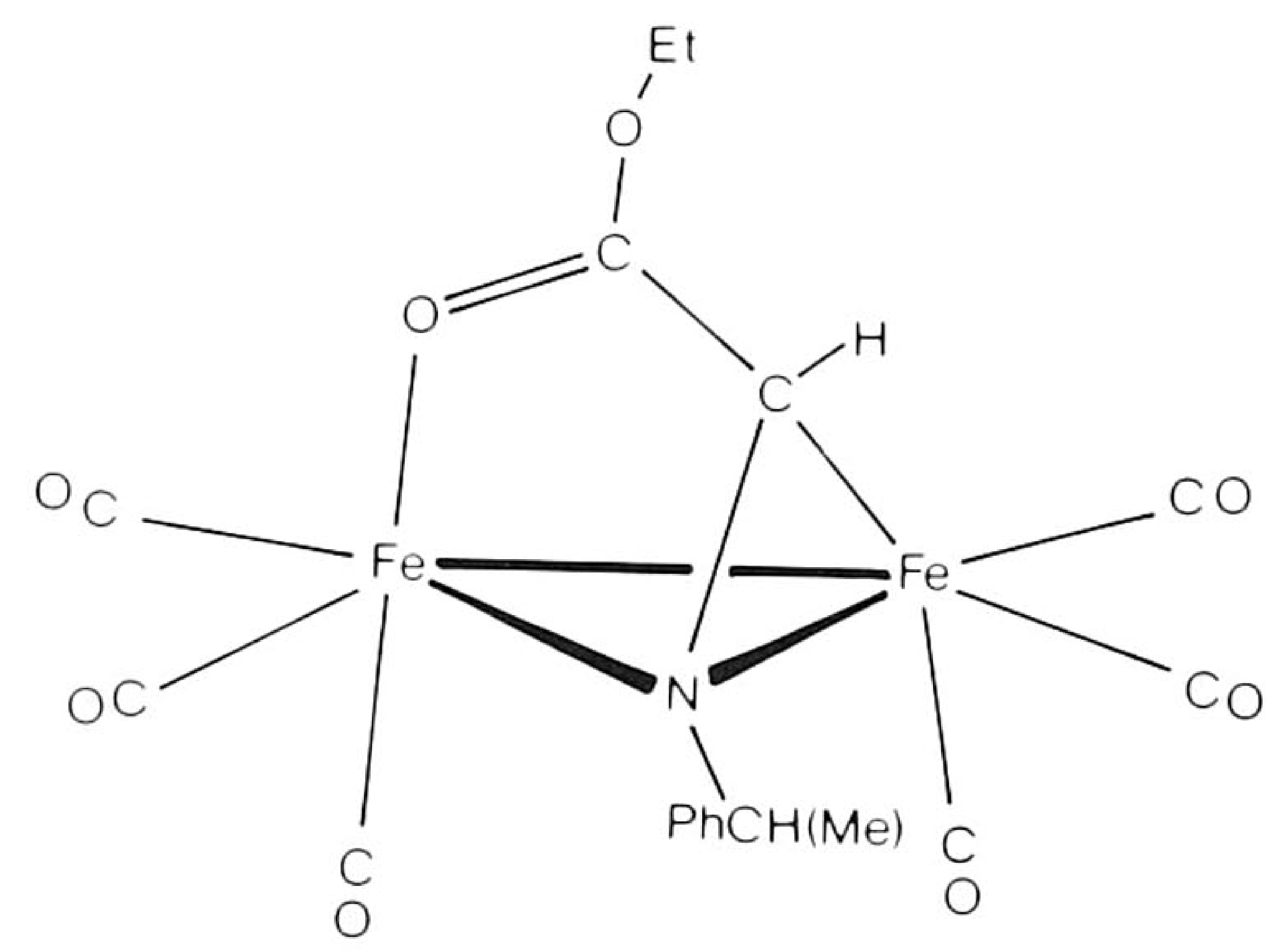

Fig. 11. Schematic structure of $\mathrm{Fe}_{2}(\mathrm{CO})_{6}[\mathrm{PhCH}(\mathrm{Me}) \mathrm{NCHC}(\mathrm{OEt})=\mathrm{O}](164)$. 
DAB groups $[\mathrm{R}=i-\operatorname{Pr}, c-\operatorname{Hex}, p-\mathrm{Tol}(50,163)]$ bridging a nonbonded $\mathrm{Ru}_{2}$ pair have been reported. The $\sigma-\mathrm{N}, \mu^{2}-\mathrm{N}^{\prime}, \eta^{2}-\mathrm{C}=\mathrm{N}^{\prime}$ bonding mode has also been realized for asymmetric R-DAB $(\mathrm{H}, \mathrm{Me})$ groups e.g., in $\mathrm{Fe}_{2}(\mathrm{CO})_{6}(\mathrm{R}$ $\mathrm{DAB})(\mathrm{H}, \mathrm{Me}) \quad(50, \quad 163), \mathrm{Ru}_{2}(\mathrm{CO})_{6}(\mathrm{R}-\mathrm{DAB})(\mathrm{H}, \mathrm{Me}) \quad(50,163)$ and $\mathrm{MnCo}(\mathrm{CO})_{6}(\mathrm{R}-\mathrm{DAB})(\mathrm{H}, \mathrm{Me})(51,163)$.

A common feature of all these compounds is that the $\mathrm{C}=\mathrm{N}$ group, which is $\eta^{2}$-bonded to the metal atom, carries a $\mathrm{H}$ atom on the imino- $\mathrm{C}$ atom. It has not been possible as yet, except for one compound, to bind R-DAB ligands containing two $\mathrm{Me}$ groups on the imino- $\mathrm{C}$ atoms in a 6e-bonding mode. The single exception is $\mathrm{MnCo}(\mathrm{CO})_{6}(c-\mathrm{Pr}-\mathrm{DAB})(\mathrm{Me}, \mathrm{Me})(5 l)$. The methyl group clearly destabilizes $\eta^{2}-\mathrm{C}=\mathrm{N}$ bonding as is also indicated by the fact that this 6e R-DAB compound is the only fluxional one. At ambient temperatures the two $(\mathrm{Me}) \mathrm{C}=\mathrm{N}$ groups exchange their points of attachment intramolecularly (Fig. 12). This movement, which probably proceeds via an intermediate containing the $c-\operatorname{Pr}-\mathrm{DAB}(\mathrm{Me}, \mathrm{Me})$ group $\sigma, \sigma-\mathrm{N}, \mathrm{N}^{\prime}(4 \mathrm{e})$ chelated to $\mathrm{Mn}$, suggests that metal $-\eta^{2}-\mathrm{C}=\mathrm{N}$ bonding is here less strong than for the $\eta^{2}-\mathrm{HC}=\mathrm{N}$ bonded groups.

Typical of the $\sigma-\mathrm{N}, \mu^{2}-\mathrm{N}^{\prime}, \eta^{2}-\mathrm{C}=\mathrm{N}^{\prime}(6 \mathrm{e})$ bonding mode is the bond lengthening of the $\eta^{2}-\mathrm{C}=\mathrm{N}$ bonded imine group to about $1.40 \AA$, this is appreciably longer than the $\sigma$ - $\mathrm{N}$ coordinated $\mathrm{N}=\mathrm{C}$ group (about $1.28 \AA$ ). In Table II various relevant details are given for $\mathrm{Fe}_{2}(\mathrm{CO})_{6}(t$-Bu-DAB) (30). $\mathrm{MnCo}(\mathrm{CO})_{6}(t-\mathrm{Bu}-\mathrm{DAB})(51)$ and $\mathrm{Ru}_{2}(\mathrm{CO})_{4}(i-\mathrm{Pr}-\mathrm{DAB})_{2}(50)$. Furthermore, the ${ }^{1} \mathrm{H}$ and ${ }^{13} \mathrm{C}$ NMR chemical shifts of the $\eta^{2}$-bonded $\mathrm{N}=\mathrm{C}$ lie at much higher fields than the signals of the $\sigma-\mathrm{N}$ bonded $\mathrm{N}=\mathrm{C}$ group (Table $\mathrm{V})$. These crystallographic and NMR aspects, returned to later in Section IV.B, clearly indicate intensive $\pi$-back donation into the $\pi^{*}$ - $\mathrm{N}=\mathrm{C}$ levels and negative charge density increase on the $\eta^{2}-\mathrm{N}=\mathrm{C}(\mathrm{H})$ bonded groups.

An outline of the preparations of the various types of $6 \mathrm{e}$ R-DAB complexes now completes this Section with the mechanistic aspects being discussed in detail in Section IV, A.

In the first preparation such a complex was reported by Frühauf et al. (30) and involved the reaction of $\mathrm{Fe}(\mathrm{CO})_{3}(\mathrm{R}-\mathrm{DAB})$ with $\mathrm{Fe}(\mathrm{CO})_{5}$ or $\mathrm{Fe}_{2}(\mathrm{CO})_{9}(101)$ (Eq. 34):

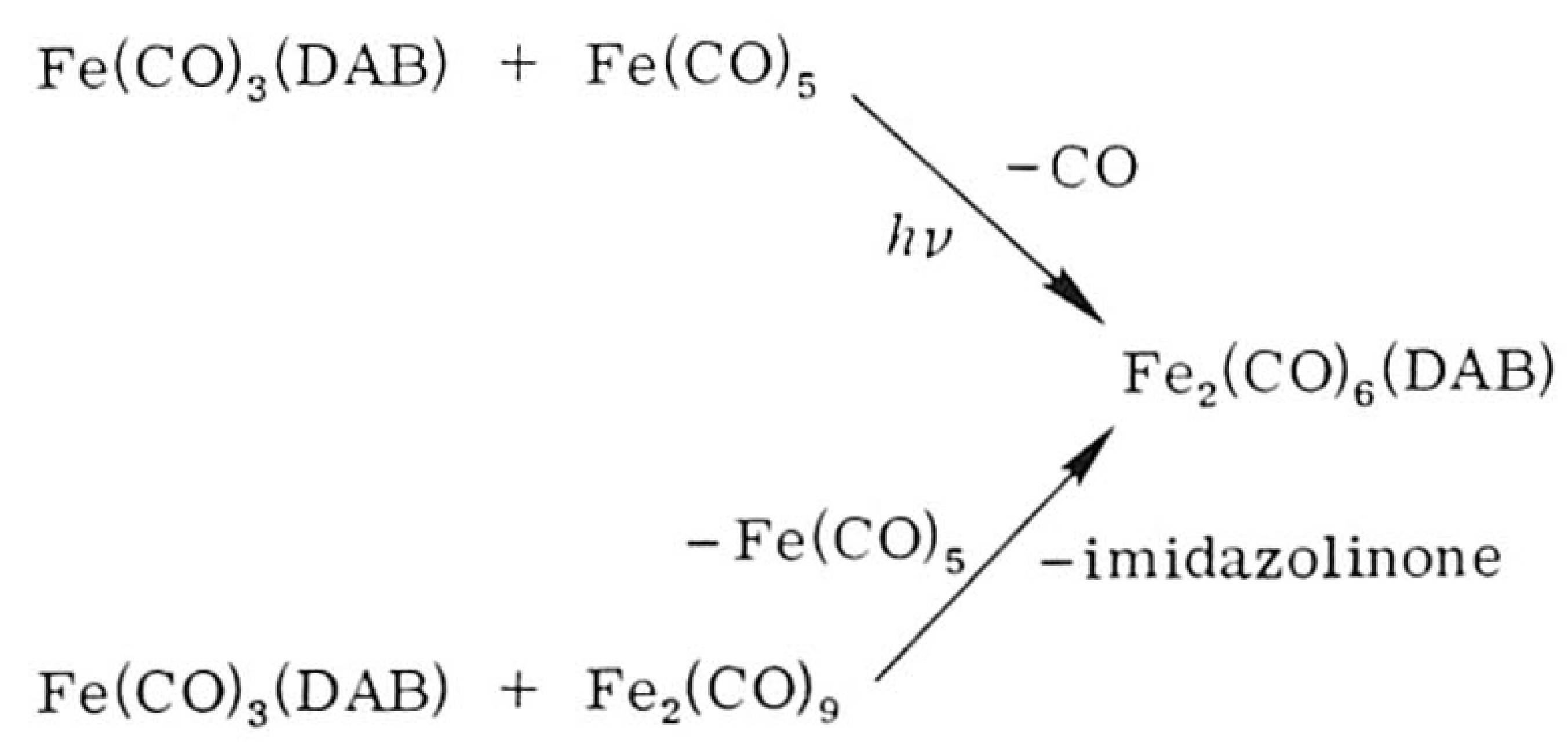



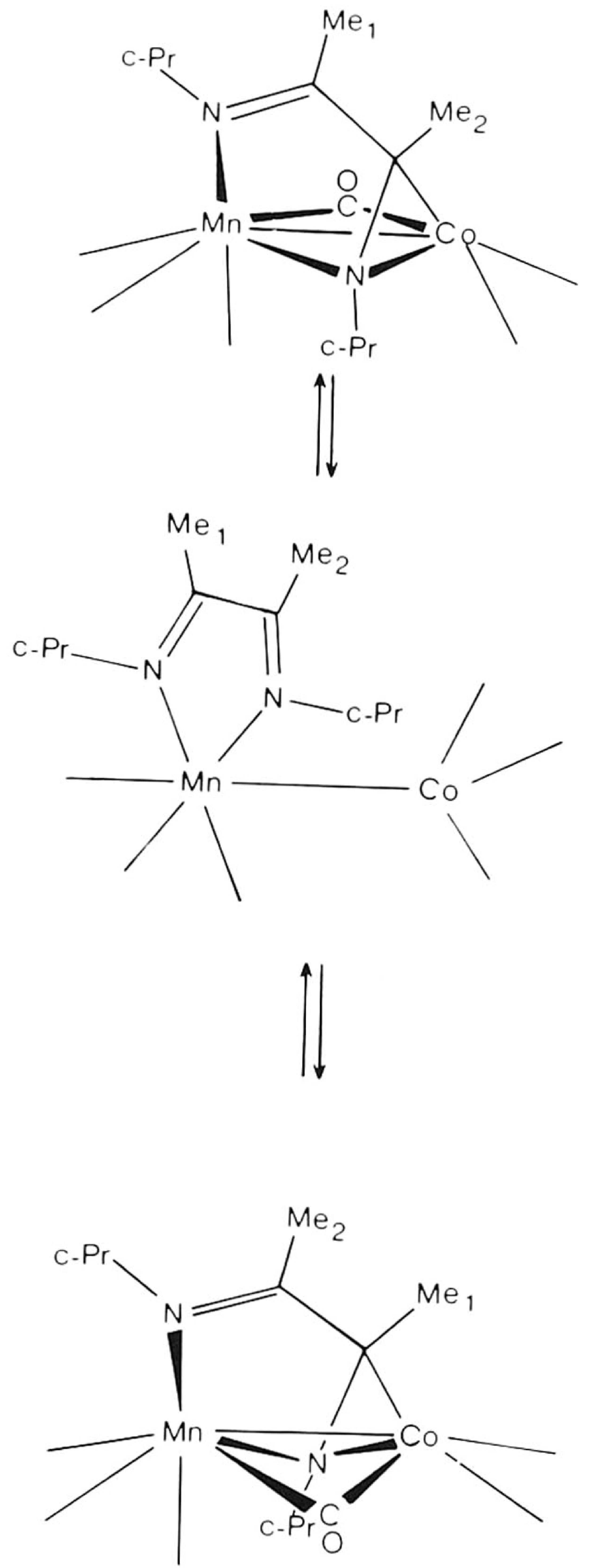

Fig. 12. Proposed route showing the fluxional behavior of $\mathrm{MnCo}(\mathrm{CO})_{6}[c-\mathrm{Pr}-\mathrm{DAB}-$ $(\mathrm{Me}, \mathrm{Me})](5 l)$.

The mixed complex containing an $\mathrm{Fe}-\mathrm{Ru}$ bond was prepared similarly (165) [Eq. (35)]:

$$
\mathrm{Fe}(\mathrm{CO})_{3}(\mathrm{DAB})+1 / 3 \mathrm{Ru}_{3}(\mathrm{CO})_{12} \rightarrow \mathrm{FeRu}(\mathrm{CO})_{6}(\mathrm{DAB})+\mathrm{CO}
$$

The preparation of $\mathrm{Ru}_{2}(\mathrm{CO})_{6}(\mathrm{R}-\mathrm{DAB})(\mathrm{R}=i$-Pr, $t-\mathrm{Bu}, c-\mathrm{Hex})$ involves 
TABLE $\mathrm{V}$

Relevant ${ }^{1} \mathrm{H}$ AND ${ }^{13} \mathrm{C}$ NMR Parameters of $\left(\sigma-\mathrm{N}, \mu^{2}-\mathrm{N}^{\prime}, \eta^{2}-\mathrm{C}=\mathrm{N}^{\prime} ; 6 \mathrm{e}\right)$ Bonded R-DAB GROUPS IN COMPLEXES $\left[\mathrm{M}_{2}(\mathrm{CO})_{6}(\mathrm{R}-\mathrm{DAB})\right]$ AND $\left[\mathrm{Ru}_{2}(\mathrm{CO})_{4}(\mathrm{R}-\mathrm{DAB})_{2}\right]^{a, b}$

\begin{tabular}{|c|c|c|c|c|}
\hline Complex & $\begin{array}{l}\text { Amino }{ }^{\prime} \mathrm{H} \\
(J \simeq 2 \mathrm{~Hz})\end{array}$ & Imino ${ }^{\prime} \mathrm{H}$ & Amino ${ }^{13} \mathrm{C}$ & Imino ${ }^{13} \mathrm{C}$ \\
\hline $\mathrm{Fe}_{2}(\mathrm{CO})_{6}(t-\mathrm{Bu}-\mathrm{DAB})$ & 3.33 & 7.63 & 60.1 & 175.1 \\
\hline $\mathrm{Ru}_{2}(\mathrm{CO})_{6}(t-\mathrm{Bu}-\mathrm{DAB})$ & 3.41 & 7.79 & 56.3 & 173.5 \\
\hline $\mathrm{Os}_{2}(\mathrm{CO})_{6}(t-\mathrm{Bu}-\mathrm{DAB})$ & 4.06 & 8.12 & 49.3 & 176.1 \\
\hline $\mathrm{MnCo}(\mathrm{CO})_{6}(t-\mathrm{Bu}-\mathrm{DAB})$ & 4.76 & 7.89 & 74.4 & 171.3 \\
\hline $\operatorname{ReCo}(\mathrm{CO})_{6}(t-\mathrm{Bu}-\mathrm{DAB})$ & 5.48 & 8.06 & 75.5 & 172.4 \\
\hline $\mathrm{Fe}_{2}(\mathrm{CO})_{6}(i-\mathrm{Pr}-\mathrm{DAB})$ & 3.30 & 7.52 & 58.9 & 173.3 \\
\hline $\mathrm{Ru}_{2}(\mathrm{CO})_{6}(i-\mathrm{Pr}-\mathrm{DAB})$ & 3.24 & 7.70 & - & - \\
\hline $\mathrm{Os}_{2}(\mathrm{CO})_{6}(i-\mathrm{Pr}-\mathrm{DAB})$ & 3.98 & 8.17 & - & - \\
\hline $\mathrm{MnCo}(\mathrm{CO})_{6}(i-\mathrm{Pr}-\mathrm{DAB})$ & 4.85 & 7.79 & 75.8 & 170.5 \\
\hline $\mathrm{Ru}_{2}(\mathrm{CO})_{4}(i-\mathrm{Pr}-\mathrm{DAB})_{2}$ & 4.08 & $8.23,8.25$ & 63.8 & 172.1 \\
\hline $\mathrm{Fe}_{2}(\mathrm{CO})_{6}(c-\mathrm{Hex}-\mathrm{DAB})$ & - & - & 63.7 & 173.6 \\
\hline $\mathrm{Ru}_{2}(\mathrm{CO})_{6}(c-\mathrm{Hex}-\mathrm{DAB})$ & 3.27 & 7.74 & 61.5 & 173.5 \\
\hline $\mathrm{MnCo}(\mathrm{CO})_{6}(c-\mathrm{Hex}-\mathrm{DAB})$ & 4.84 & 7.80 & 76.6 & 170.7 \\
\hline $\mathrm{ReCo}(\mathrm{CO})_{6}(c-\mathrm{Hex}-\mathrm{DAB})$ & 5.54 & 7.97 & 78.6 & 173.6 \\
\hline $\mathrm{Ru}_{2}(\mathrm{CO})_{4}(c-\mathrm{Hex}-\mathrm{DAB})_{2}$ & 4.31 & 8.43 & - & - \\
\hline $\mathrm{MnCo}(\mathrm{CO})_{6}(c-\mathrm{Pr}-\mathrm{DAB})$ & 4.88 & 7.65 & 79.6 & 172.1 \\
\hline $\mathrm{MnCo}(\mathrm{CO})_{6}[c-\operatorname{Pr}-\mathrm{DAB}(\mathrm{Me}, \mathrm{Me})]$ & - & - & 96.7 & 186.5 \\
\hline
\end{tabular}

${ }^{a}$ From Refs. 50, 5l, 112 , and 163 .

${ }^{b} \mathrm{Ppm}$ from TMS $(\delta)$ in $\mathrm{CDCl}_{3}$.

the treatment of $\mathrm{Ru}_{3}(\mathrm{CO})_{12}$ with $\mathrm{R}-\mathrm{DAB}$ and a similar reaction (92) was used for $\mathrm{Os}_{2}(\mathrm{CO})_{6}(\mathrm{R}-\mathrm{DAB})(50,112)[\mathrm{Eq} .(36)]$.

$$
2 / 3 \mathrm{M}_{3}(\mathrm{CO})_{12}+\mathrm{R}-\mathrm{DAB} \stackrel{\mathrm{M}=\mathrm{Ru}, \mathrm{Os}}{\longrightarrow} \mathrm{M}_{2}(\mathrm{CO})_{6}(\mathrm{DAB})+2 \mathrm{CO}
$$

Finally, the formation of $\mathrm{MnCo}(\mathrm{CO})_{6}(\mathrm{R}-\mathrm{DAB})$ proceeds via two steps. The first step involves a nucleophilic substitution of $\mathrm{Br}^{-}$in $\mathrm{MnBr}(\mathrm{CO})_{3}(\mathrm{R}$ $\mathrm{DAB})$ by $\mathrm{Co}(\mathrm{CO})_{4}^{-}$to form the $\mathrm{Mn}-\mathrm{Co}$ bonded $\mathrm{MnCo}(\mathrm{CO})_{7}(\mathrm{R}-\mathrm{DAB})$, which contains an R-DAB $\sigma, \sigma-\mathrm{N}, \mathrm{N}^{\prime}$ (4e) bonded to Mn. Subsequently there occurs an intramolecular substitution of one cobalt $\mathrm{CO}$ group by one $\mathrm{HC}=\mathrm{N}$ group which then becomes $\eta^{2}-\mathrm{C}=\mathrm{N}$ bonded to $\mathrm{Co}(51)$ [Eqs. (37a) and $(37 b)]$.

$$
\begin{gathered}
\mathrm{MnBr}(\mathrm{CO})_{3}(\mathrm{R}-\mathrm{DAB})+\mathrm{Co}(\mathrm{CO})_{4}^{-} \rightarrow \mathrm{MnCo}(\mathrm{CO})_{7}(\mathrm{R}-\mathrm{DAB})+\mathrm{Br}^{-} \\
\mathrm{MnCo}(\mathrm{CO})_{7}(\mathrm{R}-\mathrm{DAB}) \rightarrow \mathrm{MnCo}(\mathrm{CO})_{6}(\mathrm{R}-\mathrm{DAB})+\mathrm{CO}
\end{gathered}
$$



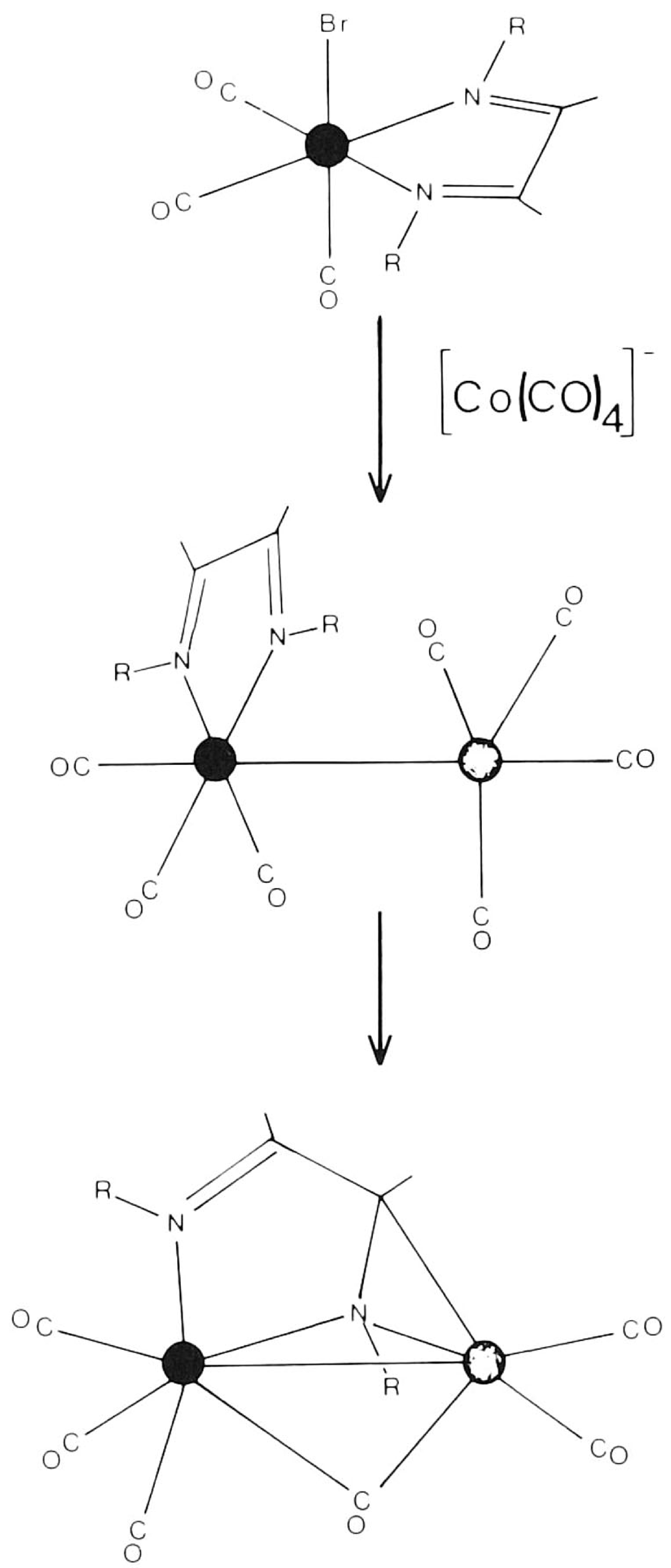

FIG. 13. Reaction to give $\mathrm{MnCo}(\mathrm{CO})_{6}(\mathrm{R}-\mathrm{DAB})(87)$.

This two step reaction (87) is shown in Fig. 13. Of interest is that in the final product one $\mathrm{CO}$ group is semibridging, as indicated by the structure determination of $\mathrm{MnCo}(\mathrm{CO})_{6}(t-\mathrm{Bu}-\mathrm{DAB})$ and suggested by the $\nu(\mathrm{CO})$ $\left(1880-2000 \mathrm{~cm}^{-1}\right)$ (Table VI), being in the range between terminal and bridging $\mathrm{CO}$ groups. 
$\nu(\mathrm{CO})$ Stretching Frequencies of $\mathrm{M}_{2}(\mathrm{CO})_{6}(\mathrm{R}-\mathrm{DAB})^{a, b}$

\begin{tabular}{ll}
\hline \multicolumn{1}{c}{ Complex } & \multicolumn{1}{c}{$v(\mathrm{CO})$} \\
$\left(\mathrm{cm}^{-1}\right)$
\end{tabular}

${ }^{a}$ From Refs. $5 /$ and $/ / 2$.

${ }^{b}$ In $n$-pentane.

'Semibridging CO.

\section{F. Complexes Containing Bridging $\sigma-N, \sigma-N^{\prime}, \eta^{2}-C=N, \eta^{2}-C=N^{\prime}$ (8e) Bonded 1,4-Diaza-1,3-butadiene Ligands}

Very recently examples of complexes in which the R-DAB ligand functions as a $\sigma-\mathrm{N}, \sigma-\mathrm{N}^{\prime}, \eta^{2}-\mathrm{C}=\mathrm{N}, \eta^{2}-\mathrm{C}=\mathrm{N}^{\prime}(8 \mathrm{e})$ donor ligand have come to light. Firm crystallographic evidence was provided by the structures of $\mathrm{Ru}_{4}(\mathrm{CO})_{8}(i-\mathrm{Pr}-\mathrm{DAB})_{2}(31,52)$ (Fig. 14a) and of $\mathrm{Ru}_{2}(\mathrm{CO})_{4}\left(\mu^{2}-\mathrm{HC}_{2} \mathrm{H}\right)(i-$ Pr-DAB) $(31,33,166)$ (Fig. 14b) and of $\mathrm{Mn}_{2}(\mathrm{CO})_{6}[\mathrm{Me}-\mathrm{DAB}(\mathrm{Me}, \mathrm{Me})]$ (53) (Fig. 15). The relevant 'H NMR shifts are shown in Table VII. The

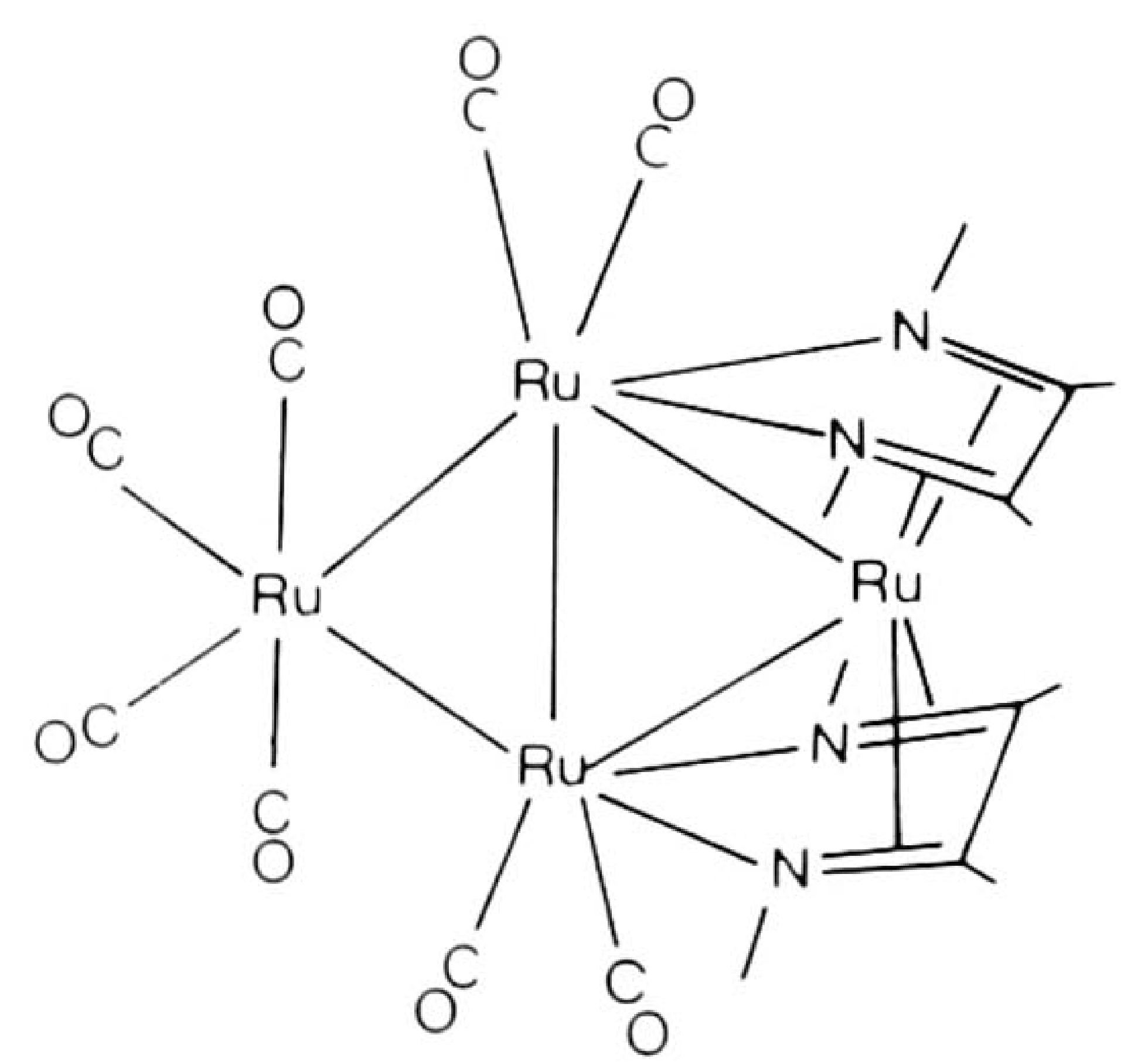

(a)

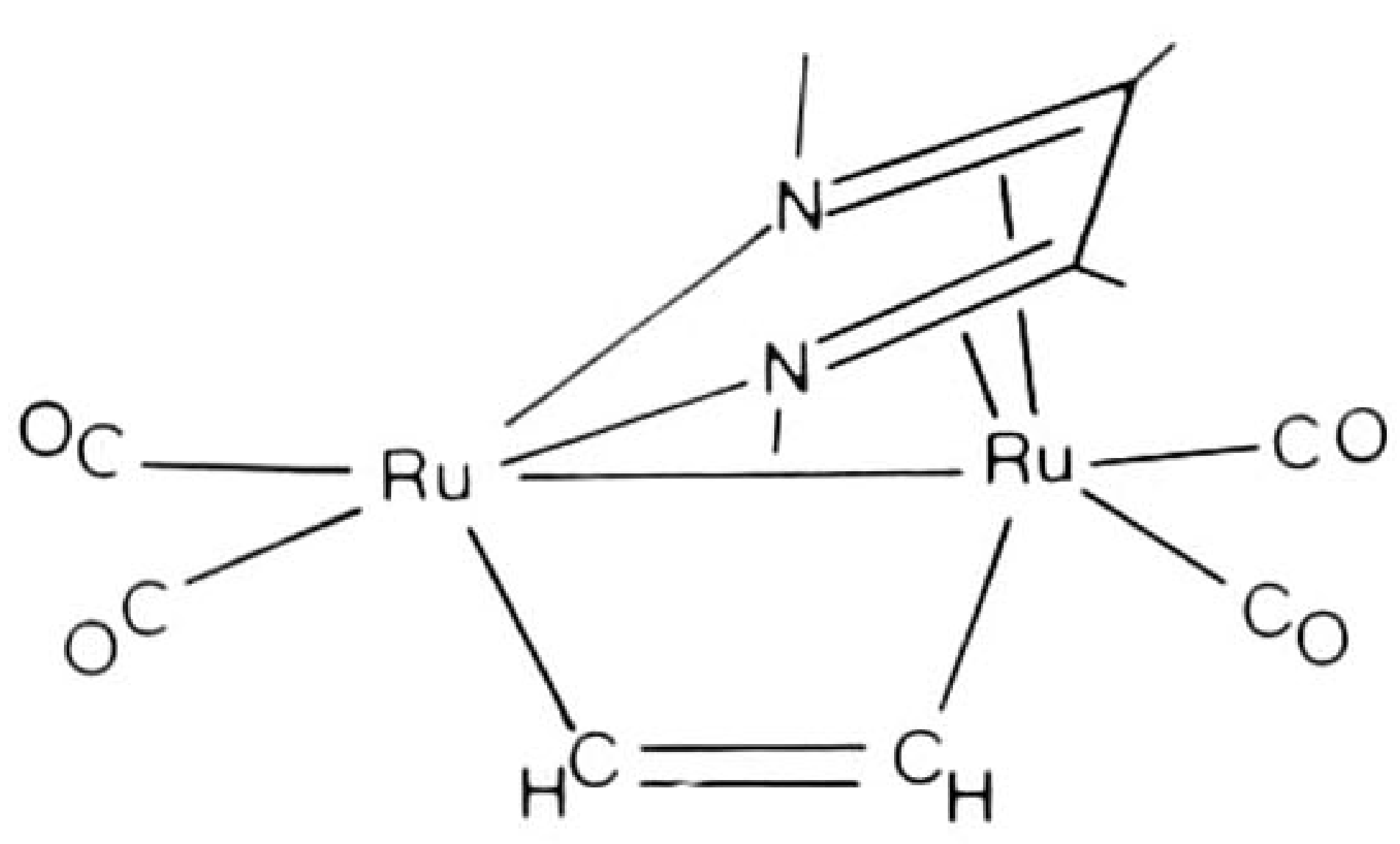

(b)

Fig. 14. Schematic structures (a) of $\mathrm{Ru}_{4}(\mathrm{CO})_{8}(i-\mathrm{Pr}-\mathrm{DAB})_{2}(52)$ and (b) of $\mathrm{Ru}_{2}(\mathrm{CO})_{4}\left(\mu^{2}-\right.$ $\left.\mathrm{HC}_{2} \mathrm{H}\right)(i$-Pr-DAB) $(166)$. 


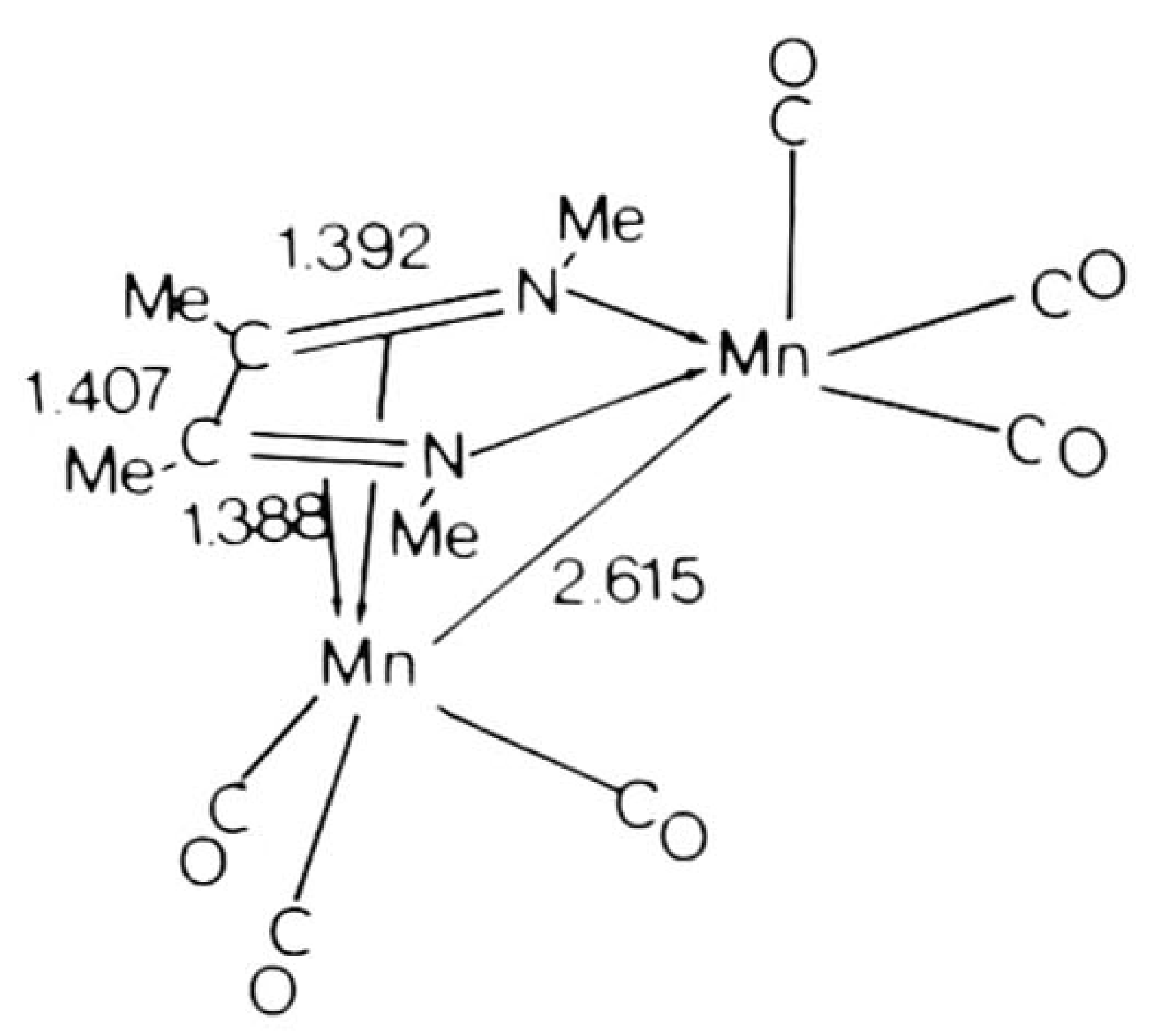

Fig. 15. Schematic structure of $\mathrm{Mn}_{2}(\mathrm{CO})_{6}[\mathrm{Me}-\mathrm{DAB}(\mathrm{Me}, \mathrm{Me})]$ (53).

overall reactions, which will be more extensively discussed in Section IV,A, are shown in Eqs. (38) and (39).

$$
\begin{array}{r}
2 \mathrm{Ru}_{2}(\mathrm{CO})_{6}(\mathrm{R}-\mathrm{DAB}) \stackrel{\mathrm{N}_{2}}{\rightarrow} \mathrm{Ru}_{4}(\mathrm{CO})_{8}(\mathrm{R}-\mathrm{DAB})_{2}+4 \mathrm{CO} \quad \mathrm{R}=i-\operatorname{Pr}, c-\mathrm{Hex} \\
\mathrm{Ru}_{2}(\mathrm{CO})_{6}(\mathrm{R}-\mathrm{DAB}) \stackrel{\mathrm{HC} 2 \mathrm{H}}{\longrightarrow} \mathrm{Ru}_{2}(\mathrm{CO})_{4}\left(\mu^{2}-\mathrm{HC}_{2} \mathrm{H}\right)(\mathrm{R}-\mathrm{DAB})+2 \mathrm{CO} \quad \mathrm{R}=i-\operatorname{Pr}, c-\mathrm{Hex}
\end{array}
$$

To prepare the manganese compound $\mathrm{Mn}_{2}(\mathrm{CO})_{6}[\mathrm{Me}-\mathrm{DAB}(\mathrm{Me}, \mathrm{Me})]$ an unusual reaction was used involving the treatment of $\mathrm{Mn}(\mathrm{CO})_{4}(\mathrm{CNMe})^{-}$ with MeI and the resultant yield was low (7\%) (53). The diimine is formed on the metal atom(s) by $\mathrm{C}-\mathrm{C}$ coupling of the isonitrile units and by addition of methyl groups (53).

Relevant 'H NMR Parameters of $\left(\sigma-\mathrm{N}, \sigma-\mathrm{N}^{\prime}, \eta^{2}-\mathrm{C}=\mathrm{N}, \eta^{2}-\mathrm{C}=\mathrm{N}^{\prime} ; 8 \mathrm{e}\right)$ BONDED R-DAB LIGANDS ${ }^{a, b}$

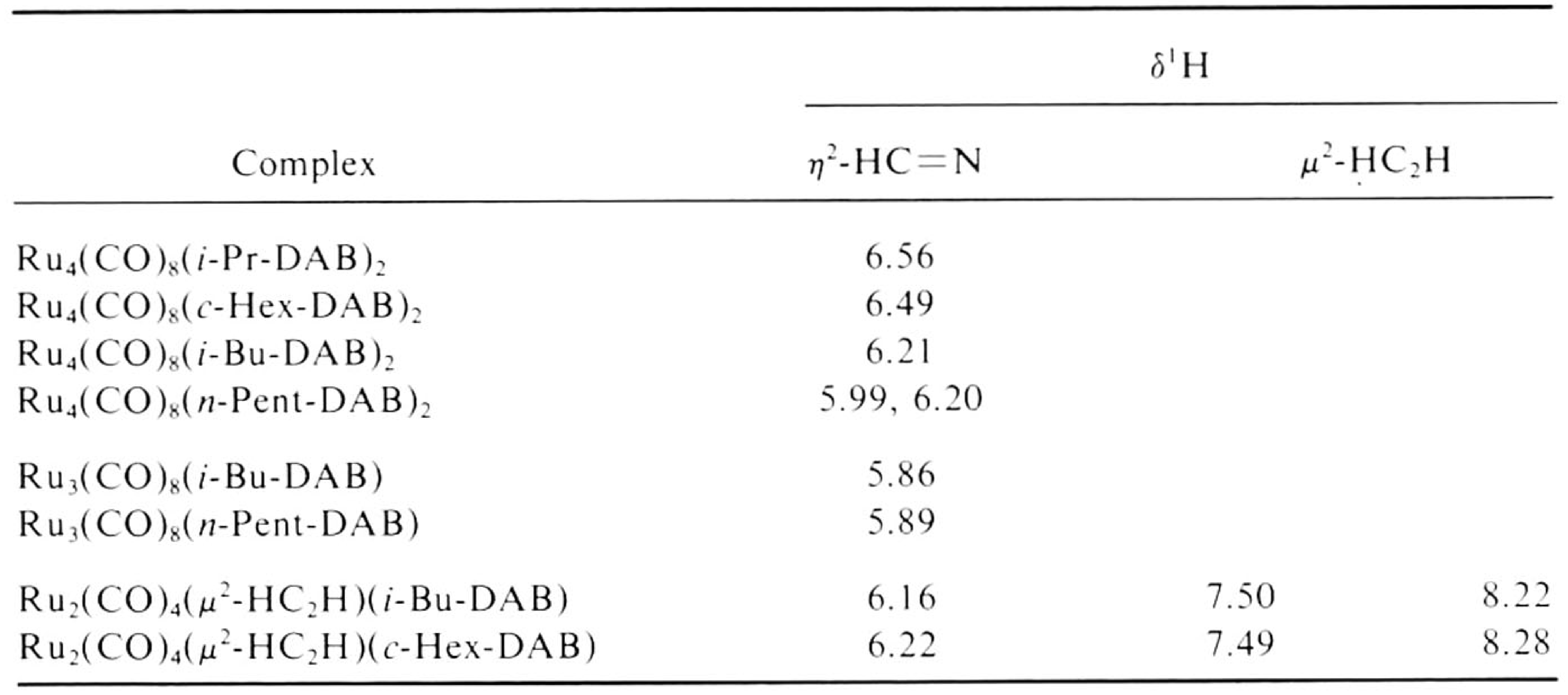

${ }^{a}$ From Refs. 33 and 52.

${ }^{b}$ In toluene- $d_{8}$ at RT. 
The structural features of all three compounds clearly involve the presence of 8e-bonded R-DAB ligands (Table II). The $\mathrm{N}=\mathrm{C}$ bond lengths (between 1.39 and $1.45 \AA$ ) indicate an appreciable bond lengthening of the $\mathrm{C}=\mathrm{N}$ bonds in analogy to the $\eta^{2}-\mathrm{C}=\mathrm{N}$ bonded imine groups of $\sigma$ $\mathrm{N}, \mu^{2}-\mathrm{N}^{\prime}, \eta^{2}-\mathrm{C}=\mathrm{N}^{\prime}$ linked R-DAB groups. Meanwhile there is shortening of the central $\mathrm{C}-\mathrm{C}$ bond of the R-DAB group (1.40-1.42 $\AA$ ). While the diimine is symmetrically bonded in $\mathrm{Mn}_{2}(\mathrm{CO})_{6}[\mathrm{Me}-\mathrm{DAB}(\mathrm{Me}, \mathrm{Me})]$, there appears to be some asymmetry in the two $\mathrm{Ru}$ complexes, since the $\mathrm{N}=\mathrm{C}$ bond lengths differ (Table II). Interesting is the bonding in $\mathrm{Ru}_{4}(\mathrm{CO})_{8}(i-$ $\mathrm{Pr}-\mathrm{DAB})_{2}$ in which one of the $\mathrm{Ru}$ atoms does not possess $\mathrm{CO}$ groups, but is exclusively bonded to the $\pi$ system of the two five-membered $\mathrm{R}-\mathrm{N}=\mathrm{C}-\mathrm{C}=\mathrm{N}$ chelate rings resembling therefore a $\mathrm{M}\left(\mathrm{C}_{5} \mathrm{H}_{5}\right)_{2}$ complex (52). The complex has a butterfly structure, which makes the two imino halves of each $\mathrm{M}-\mathrm{N}=\mathrm{C}-\mathrm{C}=\mathrm{N}$ skeleton nonequivalent. This was indeed confirmed by ' $\mathrm{H}$ NMR at low temperatures of the imino ${ }^{1} \mathrm{H}$ signals. At higher temperatures these signals coalesce due to a flying movement of this butterfly (52).

In $\mathrm{Ru}_{2}(\mathrm{CO})_{4}\left(\mu^{2}-\mathrm{HC}_{2} \mathrm{H}\right)(i-\mathrm{Pr}-\mathrm{DAB})$ one of the $\mathrm{Ru}$ atoms is coordinated to the $\pi$ system of one $\mathrm{Ru}-\mathrm{N}=\mathrm{C}-\mathrm{C}=\mathrm{N}$ ring (Fig. 14b) (52). A similar situation is encountered in the manganese compound (53) that is isoelectronic and isostructural with $\mathrm{Fe}_{2}(\mathrm{CO})_{6}[\mathrm{C}(\mathrm{R})=\mathrm{C}(\mathrm{R})-\mathrm{C}(\mathrm{R})=\mathrm{C}(\mathrm{R})]$ $(167-170)$.

In the iron complex one of the $\mathrm{Fe}$ atoms is linked to the $\pi$ system of the $\mathrm{C}_{4}$ part of the $\mathrm{Fe}-\mathrm{C}=\mathrm{C}-\mathrm{C}=\mathrm{C}$ ring. Furthermore, the iron compound contains a semibridging carbonyl group in order to relieve the charge separation in the complex caused by the $\mathrm{Fe} \rightarrow \mathrm{Fe}$ donor bond. Although such a donor bond is not strictly necessary the manganese compound (53) indicated structural features not in disagreement with the presence of a semibridging $\mathrm{CO}$ group.

Recently a very interesting structure was found for $\mathrm{Ru}_{3}(\mathrm{CO})_{9}(c$-Hex$\mathrm{DAB})$ isolated as a probable intermediate in the preparation of $\mathrm{Ru}_{2}(\mathrm{CO})_{6}(c-$ Hex-DAB) (17).

The structural features are shown in Fig. 16a. On the basis of simple electron counting one would expect the R-DAB ligand to be bonded as a $\sigma-\mathrm{N}, \mu^{2}-\mathrm{N}^{\prime}, \eta^{2}-\mathrm{C}=\mathrm{N}^{\prime}(6 \mathrm{e})$ bonded group in the way shown in Fig. 16b with two $\mathrm{CO}$ groups on the $\mathrm{Ru}$ atom with the $\mu^{2}-\mathrm{N}$ bonded imine group and three $\mathrm{CO}$ groups on the $\mathrm{Ru}$ atom bonded to the $\eta^{2}-\mathrm{C}=\mathrm{N}$ unit. However, this is not the case; instead one observes that, (Fig. 16a) although the diimine is clearly asymmetrically bonded, the ligand appears to be bonded approximately as an $\sigma-\mathrm{N}, \sigma-\mathrm{N}^{\prime}, \eta^{2}-\mathrm{C}=\mathrm{N}, \eta^{2}-\mathrm{C}=\mathrm{N}^{\prime}(8 \mathrm{e})$ bonded ligand bridging a $\mathrm{Ru}-\mathrm{Ru}$ pair with a $\mathrm{Ru}-\mathrm{Ru}$ distance of $3.02 \AA$ and $\mathrm{C}=\mathrm{N}$ bond lengths of 1.33 and $1.45 \AA$. The bond length of $1.45 \AA$ indicates extensive 

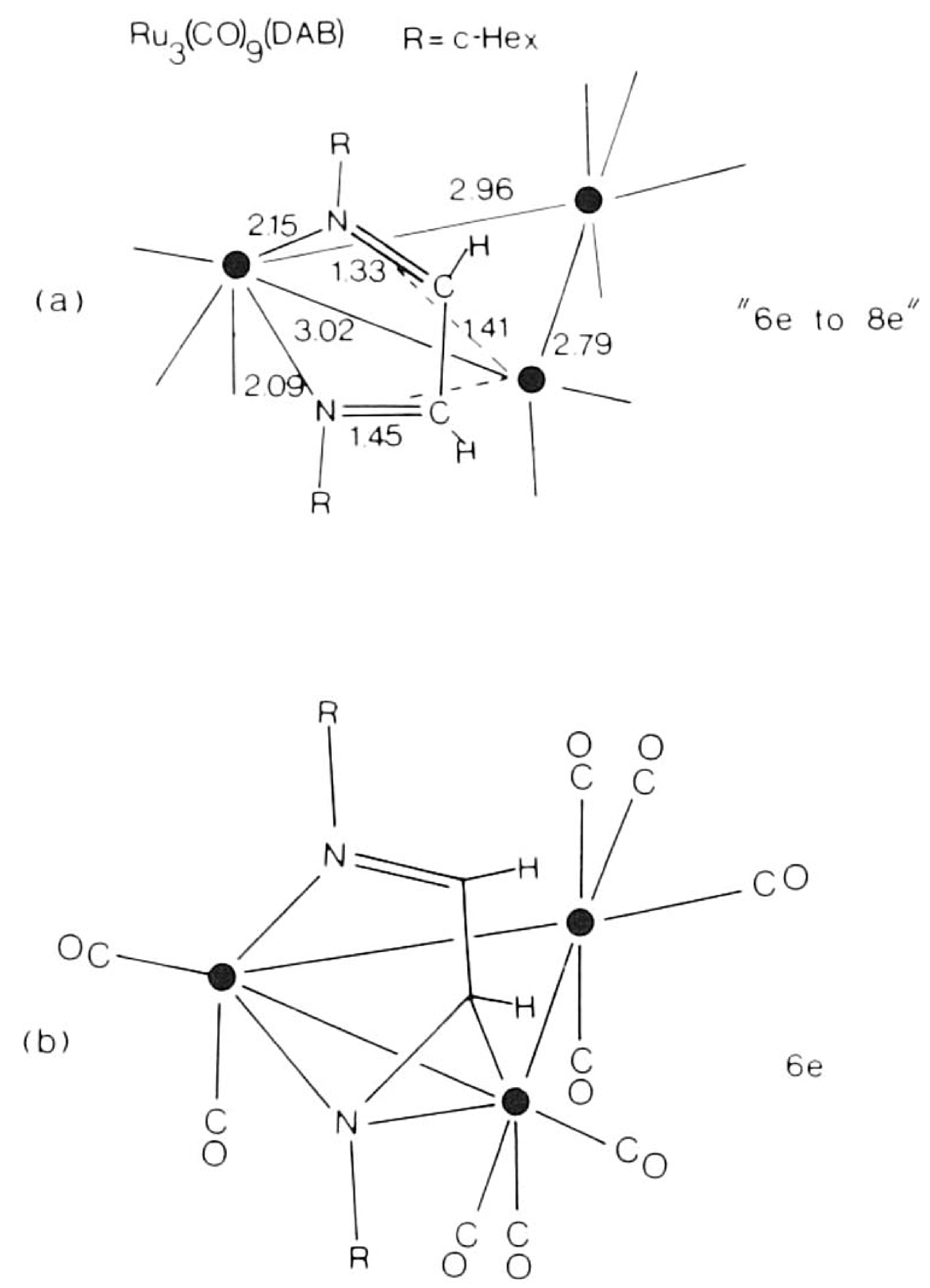

Fig. 16. Structural features of $\mathrm{Ru}_{3}(\mathrm{CO})_{9}(c-\mathrm{Hex}-\mathrm{DAB})$, (a) as found by X-ray crystallography (17) and (b) as expected on the basis of electron counting.

back donation into the $\pi^{*} \mathrm{C}=\mathrm{N}$ orbital. The $\mathrm{C}=\mathrm{N}$ bond length of 1.33 $\AA$ is close to that of the $\eta^{2}-\mathrm{C}=\mathrm{N}$ bonded imine group in $\mathrm{MnCo}(\mathrm{CO})_{6}(t$ $\mathrm{Bu}-\mathrm{DAB})$ and the $\sigma-\mathrm{N}$ bonded $\mathrm{C}=\mathrm{N}$ groups found in $\mathrm{Ni}(\mathrm{R}-\mathrm{DAB})_{2}(\mathrm{R}$ $=c$-Hex, $\mathrm{Xyl})$ and $\mathrm{Mn}(t-\mathrm{Bu}-\mathrm{DAB})_{2}$ i.e., for electron-rich metal complexes containing $\sigma, \sigma-\mathrm{N}, \mathrm{N}^{\prime}$ chelated R-DAB groups (Table II). This length of $1.33 \AA$ is therefore consistent with $\pi$-back bonding to the $\mathrm{C}=\mathrm{N}$ group, though this is, however, not so pronounced as for the other $\mathrm{C}=\mathrm{N}$ bond. Other features are the metal-metal bond lengths, which vary from 3.02 $\AA$ for the bridged $\mathrm{Ru}-\mathrm{Ru}$ pair to $2.96 \AA$ and $2.79 \AA$ for the other $\mathrm{Ru}-\mathrm{Ru}$ pairs. Note for comparison that the $\mathrm{Ru}-\mathrm{Ru}$ bond length in $\mathrm{Ru}_{3}(\mathrm{CO})_{12}$ is 2.854(4) $\AA(171)$.

According to the rules of Wade (172) addition of two electrons to a triangular cluster with 48 electrons (i.e., containing the 6e R-DAB ligand) should lead to the rupture of one of the three metal-metal bonds. For $\mathrm{Ru}_{3}(\mathrm{CO})_{9}(\mathrm{R}-\mathrm{DAB})$ it is possible to describe an intermediate type of bonding situation with the R-DAB ligand between a $6 \mathrm{e}$ and $8 \mathrm{e}$ donor type of 
binding. As a result the LUMO situation on the $\mathrm{Ru}_{3}$ triangle is sufficiently populated to cause the bond lengthening of two $\mathrm{Ru}_{2}$ pairs as actually observed.

A point that is not clear is why the R-DAB ligand is not symmetrically bonded in an $8 \mathrm{e}$ fashion with relatively short $\mathrm{C}=\mathrm{N}$ bonds, instead of here with one very long one and one relatively short one. Further theoretical investigations are currently under way to help answer this question.

A final point to make here is that Adams (53) has clearly shown, albeit by a completely different reaction, that $\mathrm{Me}-\mathrm{DAB}(\mathrm{Me}, \mathrm{Me})$ can bond as an $\sigma-\mathrm{N}, \sigma-\mathrm{N}^{\prime}, \eta^{2}-\mathrm{C}=\mathrm{N}, \eta^{2}-\mathrm{C}=\mathrm{N}^{\prime}(8 \mathrm{e})$ donor ligand. On the other hand it is almost impossible to prepare $6 \mathrm{e} \mathrm{R}-\mathrm{DAB}$ complexes with the $\eta^{2}-\mathrm{N}=\mathrm{C}$ bonded imino group having a methyl group on the $\mathrm{C}$ atom (vide infra). In our view it might therefore be possible to use $\mathrm{R}-\mathrm{DAB}(\mathrm{Me}, \mathrm{Me})$ ligands to prepare metal complexes containing 8e-bonded diimines.

\section{IV}

\section{STRUCTURAL ASPECTS}

\section{A. The Influence of Steric and Electronic Factors on the Type of Products Formed}

It is obvious that factors such as the substituents $\mathrm{R}$ and $\mathrm{R}^{\prime}$, the metal atom, and the other ligands bonded to the metal atom will influence the type of coordination of the R-DAB $\left(R^{\prime}, R\right)$ ligands. In the following we shall discuss these aspects for various examples.

\section{The Relative Importance of $\sigma-N(2 e), \sigma-N, \sigma-N^{\prime}(4 e)$ and $\sigma, \sigma-N, N^{\prime}$ (4e) Bonding}

The first case in hand is the observation that stable five-coordinate complexes $\mathrm{PtCl}_{2}\left(\eta^{2}\right.$-olefin $)(\mathrm{R}-\mathrm{DAB})$ containing $\sigma, \sigma-\mathrm{N}, \mathrm{N}^{\prime}$ chelated R-DAB can be prepared in which the $\mathrm{N}=\mathrm{C}-\mathrm{C}=\mathrm{N}$ plane is coplanar with the $\mathrm{Pt}-\eta^{2}$ olefin unit $(35,48,154-156)$. However, if the olefin is replaced by $\mathrm{PPh}_{3}$, for example, a complex is formed of the composition trans- $\mathrm{PtCl}_{2}\left(\mathrm{PPh}_{3}\right)(\mathrm{R}-$ DAB) (29) in which the R-DAB ligand is $\sigma-\mathrm{N}$ (2e) monodentate bonded. This latter complex is fluxional by a process that involves an intramolecular change of the point of attachment from $\sigma-\mathrm{N}$ to $\sigma-\mathrm{N}^{\prime}$ and vice versa via a five-coordinate intermediate with a chelate $\sigma, \sigma-\mathrm{N}, \mathrm{N}^{\prime} \mathrm{R}-\mathrm{DAB}$ ligand (see Fig. 3). 
The rationalization is that the greater electron-accepting properties of the olefin allows more extensive back bonding from the relevant Pt orbitals into the $\pi^{*}$ orbital of the olefin than is possible for the phosphine. The better $\pi$-back-bonding ability of the olefin compensates then for the increased charge density if one goes from $2 \mathrm{e}$ - to $4 \mathrm{e}$-donation by the R-DAB ligand.

A case in which several species are in equilibrium is presented by the five-coordinate complex $\mathrm{RhCl}(\mathrm{CO})_{2}(\mathrm{R}-\mathrm{DAB})$ that in solution is in equilibrium with free R-DAB, four-coordinate ionic $\left[\mathrm{Rh}(\mathrm{CO})_{2}(\mathrm{R}-\mathrm{DAB})\right]$ $\left[\mathrm{RhCl}_{2}(\mathrm{CO})_{2}\right]$, and with the dinuclear $\left[\mathrm{RhCl}(\mathrm{CO})_{2}\right]_{2}(\mathrm{R}-\mathrm{DAB})$ complex, which contains four-coordinate $\mathrm{Rh}^{\mathrm{I}}$ and a bridging R-DAB ligand in the $E$ - $s$-trans- $E$ conformation $(61)$. In this system the influence of $\mathrm{R}$ was studied extensively. It was found that the five-coordinate compound with a $\sigma, \sigma-\mathrm{N}, \mathrm{N}^{\prime}$ chelated R-DAB ligand is most stable for R containing a triply branched $\mathrm{C}^{\alpha}$ (e.g., $t$-Bu). The stability most probably arises through an increased kinetic stability. A similar situation was found for the five-coordinate compounds $\mathrm{PtCl}_{2}\left(\eta^{2}\right.$-olefin)(R-DAB) for which the kinetic stability also increased on going from double to triple branching at $\mathrm{C}^{\alpha}$ and from single to double branching at $\mathrm{C}^{\beta}(48)$.

Further research in the case of the $\mathrm{Rh}$ complexes showed that fourcoordinate complexes with an ionic structure are favored if the imino- $\mathrm{C}$ atoms carry substituents and furthermore when the $\mathrm{R}$ groups on $\mathrm{N}$ are doubly or singly branched at $\mathrm{C}^{\alpha}$. When $\mathrm{C}^{\alpha}$ is triply branched $(t-\mathrm{Bu}$ or $\mathrm{EtMe}_{2} \mathrm{C}$ ) dinuclear complexes of four-coordinate $\mathrm{Rh}^{\prime}$ with an $\sigma-\mathrm{N}, \sigma-\mathrm{N}^{\prime}$ bridging R-DAB ligand appear to dominate (34). Models show that while the $t$ - $\mathrm{Bu}$ group interacts strongly with the cis- $\mathrm{CO}$ groups of $\mathrm{Rh}(\mathrm{CO})_{2}(t$ $\mathrm{Bu}-\mathrm{DAB})^{+}$for the dimer one of the methyl groups interacts only slightly with the $\mathrm{Rh}^{1}$ atom (Fig. 17).
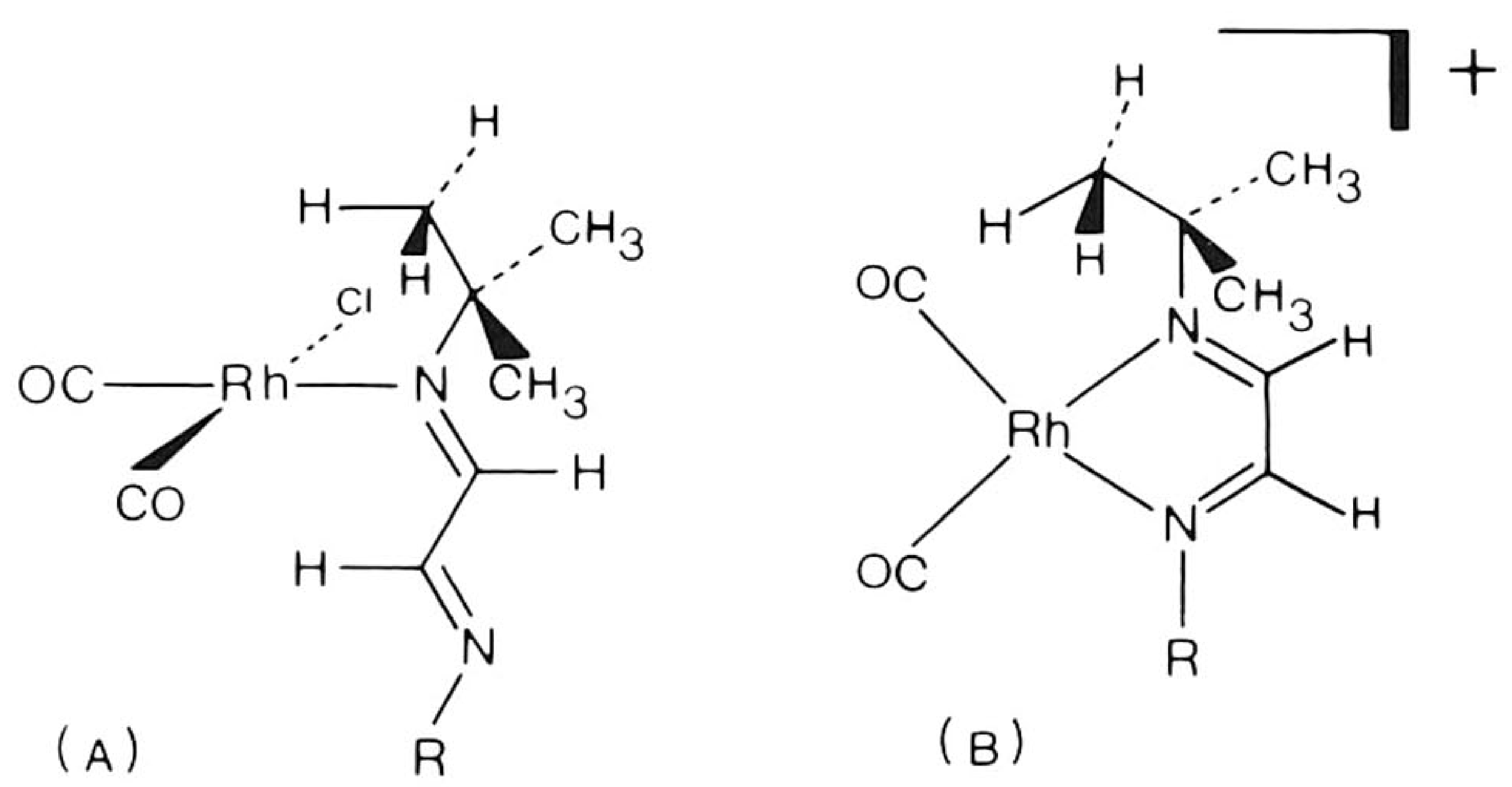

Fig. 17. Steric interactions of the $t$-Bu substituents in the $t$-Bu-DAB ligand with the metal and the co-ligands; (A) $\sigma-\mathrm{N}$ monodentate $t$-Bu-DAB and (B) $\sigma, \sigma-\mathrm{N}, \mathrm{N}^{\prime}$ chelate $t$-Bu-DAB $(61)$. 
2. The Relative Importance of $\sigma, \sigma-N, N^{\prime}$ (4e) versus $\sigma-N, \mu^{2}-N^{\prime}, \eta^{2}-C=N^{\prime}$ (6e) and $\sigma-N, \sigma-N^{\prime}, \eta^{2}-C=N, \eta^{2}-C=N^{\prime}(8 e)$ Bonding

In Section III,E we have already discussed the reactions leading to $\mathrm{MnCo}(\mathrm{CO})_{6}(\mathrm{R}-\mathrm{DAB})$ and have made the observation that the introduction of methyl groups appears to destabilize the 6e type of bonding relative to the $\sigma, \sigma-\mathrm{N}, \mathrm{N}^{\prime}(4 \mathrm{e})$ bonding type (5l). Only for the very special R substituent $c-\operatorname{Pr} \mathrm{MnCo}(\mathrm{CO})_{6}[c-\operatorname{Pr}-\mathrm{DAB}(\mathrm{Me}, \mathrm{Me})]$ was obtained, which at present cannot be properly explained. One expects that the methyl groups decrease the $\pi$-acceptor capacity of the heteroolefinic bond in analogy to similar observations for olefins. If so, it is then not immediately clear why the $8 \mathrm{e}$ donor type of bonding can be stabilized as found in the case of $\mathrm{Mn}_{2}(\mathrm{CO})_{6}[\mathrm{Me}-\mathrm{DAB}(\mathrm{Me}, \mathrm{Me})]$ (53). In the last case it is, however, clear that we have a small methyl group, which is an example of an unbranched substituent. Also, there is only $\pi$ back bonding from one $\mathrm{Mn}$ atom to the $\pi$ system of the $\mathrm{Mn}-\mathrm{N}=\mathrm{C}-\mathrm{C}=\mathrm{N}$ ring, while in the $6 \mathrm{e}$ case of $\mathrm{Ru}_{2}(\mathrm{CO})_{6}(\mathrm{R}-\mathrm{DAB})$ the $\mathrm{Ru}$ atom has only $\pi$ back bonding to about half of the five-membered $\mathrm{R}-\mathrm{N}=\mathrm{C}-\mathrm{C}=\mathrm{N}$ ring.

The influence of the $\mathrm{R}$ group is further strikingly demonstrated by the reactions of $\mathrm{Ru}_{3}(\mathrm{CO})_{12}$ with $\mathrm{R}-\mathrm{DAB}(52)$. A very tentative reaction scheme of the various reaction routes is shown in Scheme 6.

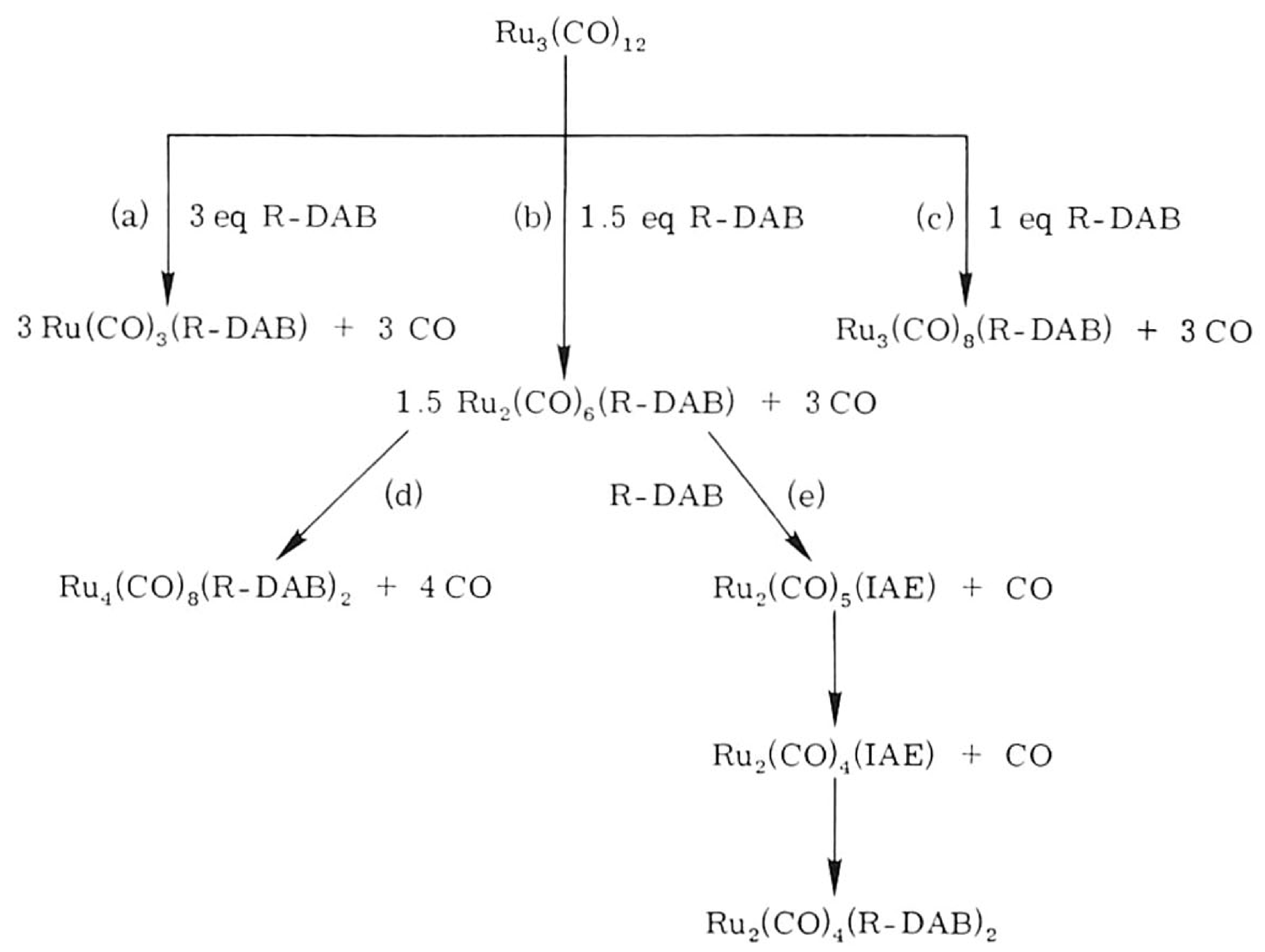

SCheme 6. Reactions of $\mathrm{Ru}_{3}(\mathrm{CO})_{12}$ with $\mathrm{R}-\mathrm{DAB}$, (a) for $\mathrm{R}=\mathrm{Mes}, \mathrm{Xyl}$, (b) for $\mathrm{R}=i$ $\operatorname{Pr}, c$-Hex, (c) for $\mathrm{R}=i$-Bu, $n$-Pent, (d) for $\mathrm{R}=i$ - $\operatorname{Pr}, c$-Hex (traces for $\mathrm{R}=i$ - $\mathrm{Bu}, n$-Pent), and $(\mathrm{e})$ for $\mathrm{R}=i-\mathrm{Pr}, c-\mathrm{Hex}\left[\mathrm{N}\right.$. B. $\mathrm{Ru}_{2}(\mathrm{CO})_{4}(\mathrm{R}-\mathrm{DAB})_{2}$ for $\mathrm{R}=\mathrm{Ar}$ is formed directly from $\left.\mathrm{Ru}_{3}(\mathrm{CO})_{12}\right]$ (52). 
The type of product is strongly dependent on the bulkiness of $\mathrm{R}$ and in particular on the branching at $C^{\alpha}$ and at $C^{\beta}(52)$. If we assume that in the reaction of $\mathrm{Ru}_{3}(\mathrm{CO})_{12}$ with $\mathrm{R}-\mathrm{DAB}$ one of the first products will contain a $\sigma, \sigma-\mathrm{N}, \mathrm{N}^{\prime}$ chelated R-DAB group, we may then consider several possibilities. When the $\mathrm{R}$ group is doubly branched at $\mathrm{C}^{\alpha}$ and at $\mathrm{C}^{\beta}$ (e.g., $\mathrm{R}$ $=2,4,6-\mathrm{Mes} ; 2,6-\mathrm{Xyl} ; i$ - $\mathrm{Pr}_{2} \mathrm{CH}$ ) the $\mathrm{N}=\mathrm{C} \pi$ bonds are blocked on both sides of the $\mathrm{M}-\mathrm{N}=\mathrm{C}-\mathrm{C}=\mathrm{N}$ skeleton, in which the $\mathrm{R}-\mathrm{DAB}$ ligand is in the $E$-s-cis- $E$ conformation. Therefore, it is impossible for another metal atom to reach the $\pi$ system of the R-DAB ligand and as a consequence $\mathrm{Ru}(\mathrm{CO})_{3}(\mathrm{R}-\mathrm{DAB})$ is the final product if sufficient $\mathrm{R}-\mathrm{DAB}$ is present (route a of Scheme 6). On the other hand, for $\mathrm{R}=n$-Pent or $i$-Bu, which are singly branched at $\mathrm{C}^{\alpha}$ and doubly branched at $\mathrm{C}^{\beta}$, the $\pi$ system at one side of the $\mathrm{M}-\mathrm{N}=\mathrm{C}-\mathrm{C}=\mathrm{N}$ ring is open and as a result the R-DAB ligand may use more coordination sites which then leads to the preferential formation of $\mathrm{Ru}_{3}(\mathrm{CO})_{8}(\mathrm{R}-\mathrm{DAB})$ (route $\mathrm{c}$ of Scheme 6) in which the diimine is bonded as an $8 \mathrm{e} \sigma-\mathrm{N}, \sigma-\mathrm{N}^{\prime}, \eta^{2}-\mathrm{C}=\mathrm{N}, \eta^{2}-\mathrm{C}=\mathrm{N}^{\prime}$ ligand. Indeed, the R-DAB ligand in $\mathrm{Ru}_{3}(\mathrm{CO})_{8}(\mathrm{R}-\mathrm{DAB})$ appears to act as a symmetrically bonded ligand, since the imino $\mathrm{H}$-substituents are equivalent and absorb at 5.86 and $5.89 \mathrm{ppm}$ for $\mathrm{R}=i$-Bu and $n$-Pent, respectively (52). These chemical shifts lie in the range observed for 8e-bonded R-DAB ligands (see Table VII). However, there is evidence that there are two isomers at lower temperatures of which the ratio is temperature dependent. The proposed equilibrium is shown in Fig. 18.

When $\mathrm{R}$ is doubly branched at $\mathrm{C}^{\alpha}$ and singly branched at $\mathrm{C}^{\beta}$ (e.g., $i$ - $\mathrm{Pr}$, $c$-Hex, $c$ - $\mathrm{Pr}, \mathrm{Ar}$ ) it was found that $\mathrm{Ru}_{2}(\mathrm{CO})_{6}(\mathrm{R}-\mathrm{DAB})$ (6e bonding mode) is the favored product (route b of Scheme 6). There is still sufficient room for the 8e-bonding mode, as demonstrated by the virtually quantitative conversion of $\mathrm{Ru}_{2}(\mathrm{CO})_{6}(\mathrm{R}-\mathrm{DAB})$ to $\mathrm{Ru}_{4}(\mathrm{CO})_{8}(\mathrm{R}-\mathrm{DAB})_{2}$ upon heating $(33,52)$, (see Section III,F and Table II for details). Finally, for $\mathrm{R}=t$ $\mathrm{Bu}$, i.e., triply branched at $\mathrm{C}^{\alpha}$ there is only room for $6 \mathrm{e}$ bonding as indicated by the exclusive formation of thermally stable $\mathrm{Ru}_{2}(\mathrm{CO})_{6}(\mathrm{R}-\mathrm{DAB})(52)$.

After having discussed the various products as a function of the steric form of $\mathrm{R}$ it is of interest to consider in more detail the possible mechanisms
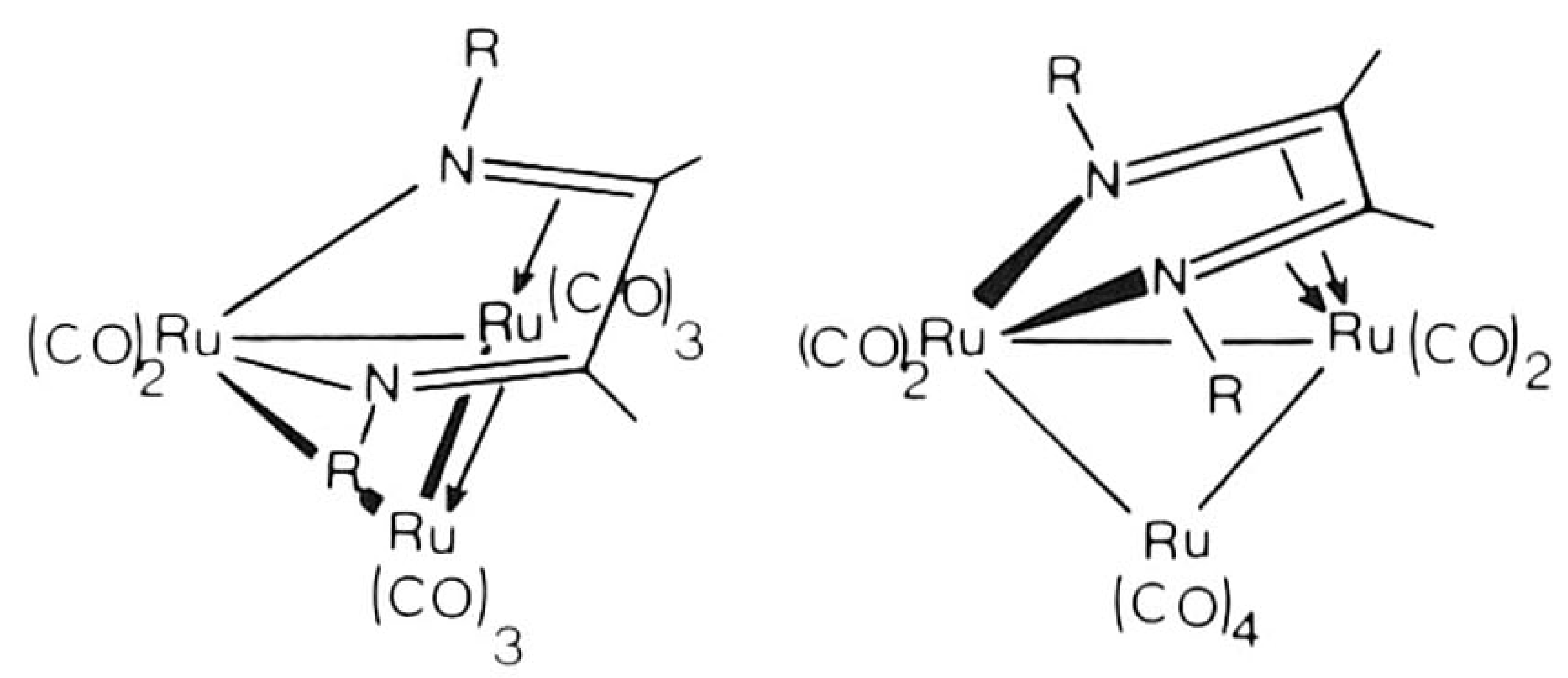

Fig. 18. The two proposed isomers of $\mathrm{Ru}_{3}(\mathrm{CO})_{8}(\mathrm{R}-\mathrm{DAB})(52)$. 
occurring in the various routes. Such a discussion is of course highly speculative, since it is very difficult to study the several chemical steps.

The first step, i.e., the reaction of $\mathrm{Ru}_{3}(\mathrm{CO})_{12}$ with $\mathrm{R}-\mathrm{DAB}$ has been studied kinetically by means of HPLC measurements (173). It was shown that this reaction with $i$-Pr-DAB is first order in metal carbonyl and first order in R-DAB ligand, while the overall reaction is of order two. The reaction with $t$ - $\mathrm{Bu}-\mathrm{DAB}$ is also of order two, but is much slower than for $i$-Pr-DAB. The rate determining step is the formation of an unstable intermediate, which might be $\mathrm{Ru}_{3}(\mathrm{CO})_{11}(\mathrm{R}-\mathrm{DAB})$ or more probably $\mathrm{Ru}_{3}(\mathrm{CO})_{10}(\mathrm{R}-\mathrm{DAB})$. Further kinetic evidence for the following steps could not be obtained (173). Of great interest is therefore the formation of $\mathrm{Ru}_{3}(\mathrm{CO})_{9}(c-\mathrm{Hex}-\mathrm{DAB})$ during the preparation of $\left.\mathrm{Ru}_{2}(\mathrm{CO})_{6}(c-\mathrm{Hex}-\mathrm{DAB})\right]$, the structure of which has been discussed in Section III,F. Another look at the $\mathrm{Ru}_{3}$ compound (Fig. 16a), in which the metal cluster has already been partially ruptured, shows in fact the coordination of a $\mathrm{Ru}(\mathrm{CO})_{3}(c$ Hex-DAB) moiety to a $\mathrm{Ru}_{2}(\mathrm{CO})_{6}$ entity. It can be easily seen that movement of one $\mathrm{CO}$ from one metal atom to the other and loss of $\mathrm{Ru}(\mathrm{CO})_{3}$ would rationalize the formation of $\mathrm{Ru}_{2}(\mathrm{CO})_{6}(\mathrm{R}-\mathrm{DAB})$ (route b). On the other hand, loss of one $\mathrm{CO}$ from $\mathrm{Ru}_{3}(\mathrm{CO})_{9}(\mathrm{R}-\mathrm{DAB})$ would just give stable $\mathrm{Ru}_{3}(\mathrm{CO})_{8}(\mathrm{R}-\mathrm{DAB})$ (route c) (Fig. 18). On present evidence, it seems unlikely that $\mathrm{Ru}_{2}(\mathrm{CO})_{6}(\mathrm{R}-\mathrm{DAB})$ is formed from $\mathrm{Ru}_{3}(\mathrm{CO})_{8}(\mathrm{R}-\mathrm{DAB})$, since these two species are clearly formed in competing reaction pathways (52).

A completely different possibility is that $\mathrm{Ru}(\mathrm{CO})_{3}(\mathrm{R}-\mathrm{DAB})$ is always formed first and, for suitable $\mathrm{R}$, this unstable monomer then reacts with $\mathrm{Ru}_{3}(\mathrm{CO})_{12}$ to give $\mathrm{Ru}_{2}(\mathrm{CO})_{6}(\mathrm{R}-\mathrm{DAB})$ and $\mathrm{Ru}_{3}(\mathrm{CO})_{9}(\mathrm{R}-\mathrm{DAB})$ and thereafter $\mathrm{Ru}_{3}(\mathrm{CO})_{8}(\mathrm{R}-\mathrm{DAB})$. Again it should be noted that the species ultimately formed depend on the branching at $\mathrm{C}^{\alpha}$ and at $\mathrm{C}^{\beta}$ as discussed previously.

In the case of $\mathrm{Os}_{3}(\mathrm{CO})_{12}$ the reactions are much slower than for $\mathrm{Ru}$ and $\mathrm{Os}_{2}(\mathrm{CO})_{6}(\mathrm{R}-\mathrm{DAB})$ could be unambiguously characterized (1/2). In addition, $\mathrm{Os}_{3}(\mathrm{CO})_{9}(\mathrm{R}-\mathrm{DAB})$ was isolated, and on the basis of its molecular formula was suggested to possess a 6e-donor diimine ligand (112), i.e., as shown in Fig. 16b. However, a structure analogous to $\mathrm{Ru}_{3}(\mathrm{CO})_{9}(c$-HexDAB) (Fig. 16a) might also be possible.

Also it is worthwhile to note again that $\mathrm{Fe}_{2}(\mathrm{CO})_{6}(\mathrm{R}-\mathrm{DAB})$ is prepared from $\mathrm{Fe}(\mathrm{CO})_{3}(\mathrm{R}-\mathrm{DAB})$ with $\mathrm{Fe}_{2}(\mathrm{CO})_{9}$ [N.B. Under the reaction conditions employed the same synthesis from $\mathrm{Fe}(\mathrm{CO})_{5}$ also proceeds via $\mathrm{Fe}_{2}(\mathrm{CO})_{9}$, see reaction (39) in Section III,D]. This reaction seems rather strange, but on closer inspection would become understandable, if $\mathrm{Fe}(\mathrm{CO})_{3}(\mathrm{R}-\mathrm{DAB})$ coordinates to $\mathrm{Fe}_{2}(\mathrm{CO})_{n}$, with the possible intermediate formation of $\mathrm{Fe}_{3}(\mathrm{CO})_{9}(\mathrm{R}-\mathrm{DAB})$, after which $\mathrm{Fe}_{2}(\mathrm{CO})_{6}(\mathrm{R}-\mathrm{DAB})$ is formed through loss of $\mathrm{Fe}(\mathrm{CO})_{3}$. Another pathway is the equilibrium shown in reaction (40). 


$$
\mathrm{Fe}_{2}(\mathrm{CO})_{6}(\mathrm{R}-\mathrm{DAB})+\mathrm{R}-\mathrm{DAB} \leftrightarrows 2 \mathrm{Fe}(\mathrm{CO})_{3}(\mathrm{R}-\mathrm{DAB})
$$

This equilibrium lies far to the right in the case of Fe $(110,112)$. In the case of $\mathrm{Ru}$ a similar equilibrium might exist, as was tentatively suggested on the basis of kinetic HPLC measurements (173), but this equilibrium lies then far to the left due to the greater $\mathrm{M}-\mathrm{M}$ bond strength for $\mathrm{Ru}$.

An unexplained point is the rather astonishing virtually quantitative formation of $\mathrm{Ru}_{4}(\mathrm{CO})_{8}(\mathrm{R}-\mathrm{DAB})_{2}$ from $\mathrm{Ru}_{2}(\mathrm{CO})_{6}(\mathrm{R}-\mathrm{DAB})$ (52), which points to a relatively simple, kinetically easily available pathway (route $\mathrm{d}$ of Scheme 6). Bearing in mind the reaction conditions, it seems likely that reactive species $\mathrm{Ru}_{2}(\mathrm{CO})_{5}(\mathrm{R}-\mathrm{DAB})$ and also $\mathrm{Ru}_{2}(\mathrm{CO})_{4}(\mathrm{R}-\mathrm{DAB})$ may be formed through successive loss of $\mathrm{CO}$ from $\mathrm{Ru}_{2}(\mathrm{CO})_{6}(\mathrm{R}-\mathrm{DAB})$. Subsequent dimerization to a tetranuclear $\mathrm{Ru}_{4}$ intermediate compound accompanied by migration of $\mathrm{CO}$ and of $\mathrm{R}-\mathrm{DAB}$ may then lead to the formation of $\mathrm{Ru}_{4}(\mathrm{CO})_{8}(\mathrm{R}-\mathrm{DAB})_{2}$ when, as mentioned above, suitable $\mathrm{R}$ substituents are present.

\section{The Influence of Geometric and Metal-Carbonyl Bond Strength \\ Factors on the Formation of $\sigma-N, \mu^{2}-N^{\prime}, \eta^{2}-C N^{\prime}(6 e)$ Bonding}

Because of the facile formation of $\mathrm{MnCo}(\mathrm{CO})_{6}(\mathrm{R}-\mathrm{DAB})(6 \mathrm{e})$ from $\mathrm{MnCo}(\mathrm{CO})_{7}(\mathrm{R}-\mathrm{DAB})(4 \mathrm{e})$ an attempted was made to prepare similar homobinuclear complexes of $\mathrm{Mn}$ and $\mathrm{Co}$ and the compounds $\mathrm{Mn}_{2}(\mathrm{CO})_{8}(\mathrm{R}$ $\mathrm{DAB}), \mathrm{Co}_{2}(\mathrm{CO})_{6}(\mathrm{R}-\mathrm{DAB}), \mathrm{Cr}_{2}(\mathrm{CO})_{4}(\mathrm{R}-\mathrm{DAB})_{2}$, and $\mathrm{CO}_{4}(\mathrm{CO})_{8}(\mathrm{R}-\mathrm{DAB})_{2}$ were isolated $(103,140)$. However, they all contain $\sigma, \sigma-\mathrm{N}, \mathrm{N}^{\prime}$ chelated $\mathrm{R}$ DAB ligands $(103,140)$ and neither heating nor irradiation led to $\mathrm{CO}$ substitution by a $C=N$ group of the $R-D A B$ ligand. In the case of $\mathrm{Co}_{2}(\mathrm{CO})_{6}(\mathrm{R}-\mathrm{DAB})$ this might be due to the fact that the R-DAB ligand is in a noninteractive position, since the five-membered $\mathrm{Co}-\mathrm{N}=\mathrm{C}-\mathrm{C}=\mathrm{N}$ ring is not perpendicular to but bent away from

the $\mathrm{Co}-\mathrm{Co}$ bond. In the case of $\mathrm{Mn}_{2}(\mathrm{CO})_{8}(\mathrm{R}-\mathrm{DAB})$ the $\mathrm{Mn}-\mathrm{N}=\mathrm{C}-\mathrm{C}=\mathrm{N}$ ring is now in a position perpendicular to the $\mathrm{Mn}-\mathrm{Mn}$ bond. However, intramolecular attack of one $\mathrm{C}=\mathrm{N} \pi$ bond on the $\mathrm{Mn}(\mathrm{CO})_{5}$ unit does not occur, possibly due to the strength of the $\mathrm{Mn}-\mathrm{CO}$ bond. It is clear that more experimental work is needed to understand the formation of the $6 \mathrm{e}-\mathrm{R}-\mathrm{DAB}$ bonding mode.

\section{B. Structural and Fluxional Features}

\section{X-Ray Structural Features}

The various structures for the $\sigma-\mathrm{N}(2 \mathrm{e}), \sigma-\mathrm{N}, \sigma-\mathrm{N}^{\prime}(4 \mathrm{e}), \sigma, \sigma-\mathrm{N}, \mathrm{N}^{\prime}(4 \mathrm{e})$, $\sigma-\mathrm{N}, \mu^{2}-\mathrm{N}^{\prime}, \eta^{2}-\mathrm{C}=\mathrm{N}^{\prime}(6 \mathrm{e})$, and $\sigma-\mathrm{N}, \sigma-\mathrm{N}^{\prime}, \eta^{2}-\mathrm{C}=\mathrm{N}, \eta^{2}-\mathrm{C}=\mathrm{N}^{\prime}(8 \mathrm{e})$ bonded $\mathrm{R}-$ 
DAB complexes have been discussed fairly broadly in the previous sections, while relevant details have been given in Table II.

Some important aspects that interest us here include the conformation of the R-DAB ligands and the $\mathrm{C}=\mathrm{N}$ and $\mathrm{C}-\mathrm{C}$ bond lengths. In all compounds the $\mathrm{N}=\mathrm{C}-\mathrm{C}=\mathrm{N}$ skeleton, whether in the $E$-s-trans- $E$ conformation found for the monodentate and bridging situations, or in the $E$-scis- $E$ conformation (chelate, 6e-bridging, 8e-bridging) is approximately planar. No doubt this is due to the fact that by virtue of this planarity the skeleton is better able to use its electron donating and accepting capabilities. Furthermore, steric factors also play a role, as has been pointed out before for the $\sigma$-N monodentate and $\sigma-\mathrm{N}, \sigma-\mathrm{N}^{\prime}$ bridging conformations.

In the last two bonding types the $\mathrm{N}=\mathrm{C}$ and central $\mathrm{C}-\mathrm{C}$ bond lengths are scarcely different. However, this situation changes for the other bonding modes. In the case of the $\sigma, \sigma-\mathrm{N}, \mathrm{N}^{\prime}$ chelate bonding there are small but significant differences between the $\mathrm{N}=\mathrm{C}$ and $\mathrm{C}-\mathrm{C}$ bond lengths. It is clear from Table II that generally speaking the low-valent electron-rich metal atoms have longer $\mathrm{C}=\mathrm{N}$ bond lengths and a shorter $\mathrm{C}-\mathrm{C}$ bond lengths due to population of the LUMO, which is antibonding in $\mathrm{C}-\mathrm{N}$ and bonding in $\mathrm{C}-\mathrm{C}(26)$. Larger changes, as have already been noted, occur in the case of $\eta^{2}-\mathrm{C}=\mathrm{N}$ bonding both for 6e- and 8e-bonding types, since the central $\mathrm{C}$ atoms of the R-DAB skeleton are also directly bonded to the metal atom. The $\eta^{2}-\mathrm{C}=\mathrm{N}$ bond length is somewhat shorter for $\mathrm{MnCo}(\mathrm{CO})_{6}(t-\mathrm{Bu}-\mathrm{DAB})[1.358(16) \AA ; 6 \mathrm{e}]$ than for $\mathrm{Fe}_{2}(\mathrm{CO})_{6}(c$-Hex$\mathrm{DAB})[1.397(4) \AA ; 6 \mathrm{e}]$ and for $\mathrm{Ru}_{2}(\mathrm{CO})_{4}(i \text {-Pr-DAB })_{2}[1.43(1) \AA ; 6 \mathrm{e}]$. This might indicate less $\eta^{2}$-bonding interaction to $\mathrm{Co}$ than to $\mathrm{Fe}$ or $\mathrm{Ru}$, which could change the bonding (formally) from $\sigma-\mathrm{N}, \mu^{2}-\mathrm{N}^{\prime}, \eta^{2}-\mathrm{C}=\mathrm{N}^{\prime}$ to $\sigma-\mathrm{N}, \sigma-\mathrm{N}^{\prime}, \eta^{2}-\mathrm{C}=\mathrm{N}^{\prime}$ ( see also Section III,E).

\section{NMR Aspects}

Most of the relevant NMR data have been dealt with in Section III but some observations should be made here. An important point is always the investigation into the correlation of NMR parameters with, e.g., charge density on ligands. Such systematic studies have, generally speaking, not given much insight since, for example, ${ }^{1} \mathrm{H}$ and certainly ${ }^{13} \mathrm{C}$ NMR are also dependent on other factors $(3,9,10,89,120)$. In the case of diimine complexes relatively little systematic work has been carried out, though a large number of $\mathrm{Ni}\left[\mathrm{R}-\mathrm{DAB}\left(\mathrm{R}^{\prime}, \mathrm{R}^{\prime \prime}\right)\right]$ complexes $(\mathrm{R}=$ alkyl or aryl $)$ have been studied in detail $(9,10)$. In general it was found that the ${ }^{1} \mathrm{H}$ signals of the imine-H substituents (2,3 positions) are downfield with respect to the free diimine and these shifts increase when the $\mathrm{R}$ groups show increased branching at $C^{\alpha}(9)$. However, the interpretation of these results remains difficult, since for $\mathrm{Ni}^{0}$ complexes an energetically low-lying triplet level 
may strongly influence the shifts, with the added complication that the $\mathrm{Ni}(\mathrm{R}-\mathrm{DAB})_{2}$ complexes may have variable coordination geometries $(9,10)$.

Change of the electron configuration of the metal clearly has an influence on the ${ }^{1} \mathrm{H}$ NMR chemical shifts of the imine-H atoms, as is shown in Table VIII for a number of $\sigma, \sigma-\mathrm{N}, \mathrm{N}^{\prime}$ chelated diimines bonded to metal carbonyl fragments. It is clear that there is a high field shift on going to higher electronic configuration i.e., from $d^{6} \rightarrow d^{7} \rightarrow d^{8} \rightarrow d^{9}$. In the case of the carbonyl free $d^{10}$ complexes $\mathrm{Ni}(\mathrm{R}-\mathrm{DAB})_{2}$ a low field shift is again observed, no doubt due partly to an energetically low lying triplet state. Also the change in solvent may play a role by specific solvent-solute interactions, since the Ni compound (Table VIII) is the only compound in this series that was measured in $\mathrm{C}_{6} \mathrm{D}_{6}$. The trend in the high field shift of the carbonyl complexes might be due to increasing donation to the R-DAB ligand, but one should be particularly careful when comparing different geometries (120).

Much stronger upfield shifts for both the ${ }^{1} \mathrm{H}$ and ${ }^{13} \mathrm{C}$ resonances of imine$\mathrm{H}$ and imine- $\mathrm{C}$ atoms, respectively, have been observed for $\eta^{2}-\mathrm{C}=\mathrm{N}$ bonded groups. The ${ }^{1} \mathrm{H}$ shifts lie in the range of 3.3 to $5.5 \mathrm{ppm}$ for $\sigma-\mathrm{N}, \mu^{2}-\mathrm{N}^{\prime}, \eta^{2}-$ $\mathrm{C}=\mathrm{N}^{\prime}(6 \mathrm{e})$ bonding and in the range of 5.9 to $6.6 \mathrm{ppm}$ for $\sigma-\mathrm{N}, \sigma-\mathrm{N}^{\prime}, \eta^{2}$ $\mathrm{C}=\mathrm{N}, \eta^{2}-\mathrm{C}=\mathrm{N}^{\prime}(8 \mathrm{e})$ bonding $(52,163,166)$. The smaller shifts for the $8 \mathrm{e}-$ compared to the $6 \mathrm{e}$ - bonding situation might be due to the fact that in the first case there is only one metal atom back donating to two $\mathrm{C}=\mathrm{N}$ groups of the $\mathrm{M}-\mathrm{N}=\mathrm{C}-\mathrm{C}=\mathrm{N}$ ring instead of to one $\mathrm{C}=\mathrm{N}$ group as for the $6 \mathrm{e}-$ bonding mode (Table $\mathrm{V}$ and Table VII).

Among the $\sigma-\mathrm{N}, \mu^{2}-\mathrm{N}^{\prime}, \eta^{2}-\mathrm{C}=\mathrm{N}^{\prime}$ bonded R-DAB groups there are some interesting but unexplained differences in the Fe column, since the ${ }^{1} \mathrm{H}$ NMR chemical shifts go upfield from Fe to Os, while the corresponding ${ }^{13} \mathrm{C}$ shifts go downfield (163) (Table V). The analogous chemical shifts for the $\mathrm{MCo}(\mathrm{CO})_{6}(\mathrm{R}-\mathrm{DAB})(\mathrm{M}=\mathrm{Mn}, \mathrm{Re})$ (Table $\left.\mathrm{V}\right)$ are downfield from these of the complexes of the Fe-triad metals and may be due to the smaller metal $-\eta^{2}-\mathrm{C}=\mathrm{N}$ interaction for cobalt, as was suggested in Section IV, B,1, on the basis of the shorter $\mathrm{C}=\mathrm{N}$ bond length of $\mathrm{MnCo}(\mathrm{CO})_{6}(t-\mathrm{Bu}$ DAB) (51).

\section{Fluxional Processes Involving Carbonyl Groups}

Fluxional processes connected, e.g., with olefin rotation in metal olefin complexes, with intramolecular exchange of $\sigma-\mathrm{N}(2 \mathrm{e})$ bonded R-DAB groups and with cluster movements taking place for $\mathrm{Ru}_{4}(\mathrm{CO})_{8}(\mathrm{R}-\mathrm{DAB})_{2}$ have been discussed in previous sections. Here we shall restrict ourselves to $\mathrm{CO}$ scrambling processes. 


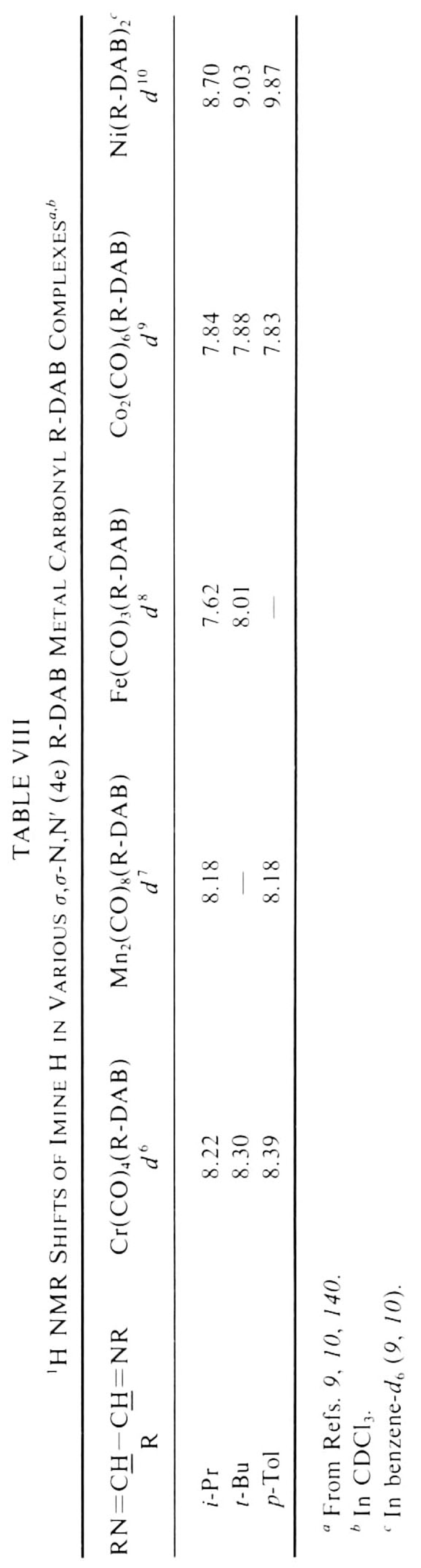


Majunke et al. (79) discovered by means of stereospecific ${ }^{13} \mathrm{CO}$ labeling (i.e., one ${ }^{13} \mathrm{CO}$ cis to the $\sigma, \sigma-\mathrm{N}, \mathrm{N}^{\prime}$-chelated R-DAB ligand) that an equilibrium exists between an axial and equatorial substituted tetracarbonyl. This equilibrium is fast on the NMR time scale for $\mathrm{R}=\mathrm{Ar}$ at room temperature but slow for $\mathrm{R}=t$-Bu. In the case of the aryl groups the $\Delta G \ddagger$ values for $\mathrm{M}=\mathrm{Mo}$ increased in the order $p$-Tol $<o$-Tol $<2,6-\mathrm{Xyl}<2,4,6$ tri- $i$ - $\mathrm{Pr}-\mathrm{C}_{6} \mathrm{H}_{2}$ (79). The interchange process proceeds according to an "umbrella mechanism" (79) $\left(C_{2 v} \rightleftarrows C_{4 v}\right)$. This is relatively easy for aryl groups, since these groups can minimize the steric interaction with the equatorial $\mathrm{CO}$ groups by turning to a position perpendicular to the chelate plane.

These conformational interchanges have also been studied by Staal et al. (83) by means of electronic absorption spectra and resonance Raman spectroscopy in solutions or glasses at temperatures below $-73^{\circ} \mathrm{C}$ for compounds $\mathrm{M}(\mathrm{CO})_{4}(\mathrm{R}$-DAB $)(\mathrm{M}=\mathrm{Cr}, \mathrm{Mo}, \mathrm{W} ; \mathrm{R}=t$-Bu, $c$-Hex, $n$-Pent $)$. It appeared that at low temperatures both conformations exist and interchange in a temperature dependent equilibrium.

Intramolecular $\mathrm{CO}$ exchange in five-coordinate complexes $\mathrm{Fe}(\mathrm{CO})_{3}(\mathrm{R}$ $\mathrm{DAB}$ ) have been studied for $\mathrm{R}=t$ - Bu and $i$-Pr by ${ }^{13} \mathrm{C} \mathrm{NMR}$. The energy barrier for the process, which may be a Berry pseudorotation or a turnstile movement, is low, but is higher for $t$-Bu than for $i-\operatorname{Pr}$, while both have lower energy barriers than measured for $\mathrm{Fe}(\mathrm{CO})_{3}\left(\eta^{4}\right.$-butadiene) (106).

Intramolecular $\mathrm{CO}$ site exchange processes have also been observed for $\mathrm{M}_{2}(\mathrm{CO})_{6}(\mathrm{R}-\mathrm{DAB})(51,163)$. In the case of $\mathrm{MnCo}(\mathrm{CO})_{6}[c-\mathrm{Pr}-$ $\mathrm{DAB}(\mathrm{Me}, \mathrm{Me})]$ the fluxional process involving the change of point of attachment of the R-DAB(Me,Me) ligand from $\eta^{2}-\mathrm{C}=\mathrm{N}^{\prime}$ to $\eta^{2}-\mathrm{C}=\mathrm{N}$ and vice versa in the temperature range -40 to $+20^{\circ} \mathrm{C}$ has been discussed in Section III,D (51, 163) (Fig. 12). Independently, there is also an intramolecular site exchange, between the semibridging carbonyl group and the two terminal $\mathrm{C}^{\alpha}$ carbonyl groups, which even at $-50^{\circ} \mathrm{C}$ is already fast on the NMR time scale. The terminal $\mathrm{CO}$ groups on $\mathrm{Mn}$, however, remain rigid even at $+50^{\circ} \mathrm{C}$. Pseudorotational $\mathrm{CO}$ site exchange processes occurring at both metal centers have been observed for $\mathrm{M}_{2}(\mathrm{CO})_{6}(\mathrm{R}-\mathrm{DAB})(\mathrm{M}$ $=\mathrm{Fe}, \mathrm{Ru}(163)$.

For the $\mathrm{Ru}_{2}(\mathrm{CO})_{6}(\mathrm{R}-\mathrm{DAB})$ complexes the intramolecular site exchanges on each $\mathrm{Ru}$ atom are fast even at low temperatures $\left(-70^{\circ} \mathrm{C}\right)$. In the case of $\mathrm{Fe}_{2}(\mathrm{CO})_{6}(t-\mathrm{Bu}-\mathrm{DAB})$ it could be shown that the $\mathrm{CO}$ groups on the $\mathrm{Fe}$ atom containing the $\sigma-\mathrm{N}$ bonded $\mathrm{N}=\mathrm{C}$ moiety already exchange locally at $-50^{\circ} \mathrm{C}$. However, the local scrambling of the $\mathrm{CO}$ groups on the other Fe atom containing the $\eta^{2}-\mathrm{C}=\mathrm{N}$ bonded unit began on the NMR time scale at about room temperature. Obviously $\sigma-\mathrm{N}=\mathrm{C}$ and $\eta^{2}-\mathrm{C}=\mathrm{N}$ bonding types have a strong influence on the energy barriers of the intramolecular site exchange. No intermolecular site exchange was observed (163). 


\section{V \\ METAL-1,4-DIAZA-1,3-BUTADIENE RADICALS: ESR SPECTROSCOPY AND REACTIVITY}

Like 2,2'-bipyridine (174) the R-DAB ligands can be readily converted to stable paramagnetic radical anions by potassium in 1,2-dimethoxyethane (175) or THF (176). The radical anion $t$-Bu-DAB ${ }^{-}$exists, like the free molecule (see Section II,B) in the $E$-s-trans-E conformation (Fig. 19a) and displays a highly resolved ESR spectrum in which the two equivalent ${ }^{14} \mathrm{~N}$ nuclei $(5.62 \mathrm{G})(I=1)$, the imino hydrogens $(4.37 \mathrm{G})$, the 18 equivalent $t$-Bu hydrogen nuclei $(0.15 \mathrm{G})(I=1 / 2)$ and the two pairs of ${ }^{13} \mathrm{C}$ nuclei $(I=1 / 2)(176)$ couple. The absence of any further coupling indicates that no association with potassium occurs in solution $(175,176)$.

Direct treatment of complexes containing the R-DAB ligand in the $E$ $s$-cis- $E$ conformation (i.e., $\sigma, \sigma-\mathrm{N}, \mathrm{N}^{\prime}$ bonded) such as $\mathrm{CuCl}(t-\mathrm{Bu}-\mathrm{DAB})$ (177) or $\operatorname{MoBr}\left(\eta^{3}-\mathrm{C}_{3} \mathrm{H}_{5}\right)(\mathrm{CO})_{2}(t-\mathrm{Bu}-\mathrm{DAB})(178)$ with potassium again generates $\mathrm{R}-\mathrm{DAB}^{-}$in the $E$-s-trans- $E$ conformation. However, the radical anion of $\operatorname{MoBr}\left(\eta^{3}-\mathrm{C}_{3} \mathrm{H}_{5}\right)(\mathrm{CO})_{2}(t-\mathrm{Bu}-\mathrm{DAB})$ reacts with free $t$-Bu-DAB to
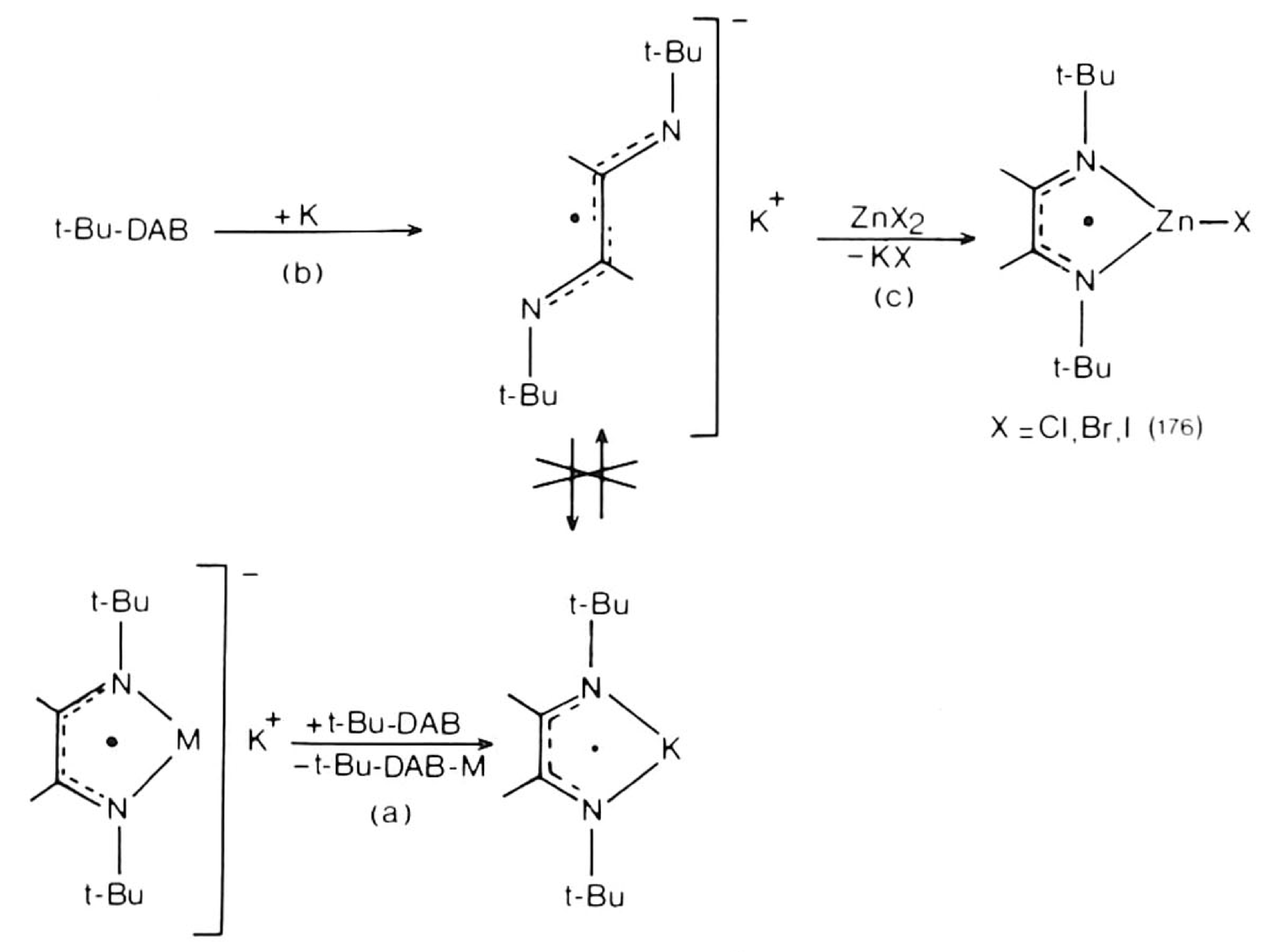

$\mathrm{M}=\mathrm{CuCl}$ or $\operatorname{MoBr}\left(\eta^{3}-\mathrm{C}_{3} \mathrm{H}_{5}\right)(\mathrm{CO})_{2}$

Fig. 19. Reaction (a) of $\mathrm{K}[\mathrm{M}(t-\mathrm{Bu}-\mathrm{DAB})]$ with $t$-Bu-DAB $\left[\mathrm{M}=\mathrm{CuCl}\right.$ or $\operatorname{MoBr}\left(\eta^{3}-\right.$ $\left.\left.\mathrm{C}_{3} \mathrm{H}_{5}\right)(\mathrm{CO})_{2}\right]$, (b) of potassium with $t$-Bu-DAB, and (c) of $\mathrm{ZnX}_{2}(\mathrm{X}=\mathrm{Cl}, \mathrm{Br}, \mathrm{I})$ with $\mathrm{K}^{+}(\mathrm{R}-$ $\mathrm{DAB})^{-}$. 
give the $(t-\mathrm{Bu}-\mathrm{DAB}) \mathrm{K}$ complex in which the $s$-cis conformation of the $\mathrm{N}=\mathrm{C}-\mathrm{C}=\mathrm{N}$ skeleton is retained and coordination of $\mathrm{K}^{+}(I=3 / 2)$ is reflected in the ESR spectrum (175). No evidence was found for conversion of the $s$-trans to $s$-cis conformation (see Fig. 19) of the radical anionic species at temperatures up to $+30^{\circ} \mathrm{C}(175)$ (see Fig. 19a, b).

The blocked conversion between the $s$-cis and $s$-trans conformations has been explained $(175,176)$ by occupation in the radical ion of a molecular orbital that has bonding interactions between the central $\mathrm{C}$ atoms (see Fig. 20) and hence an increased barrier to rotation around this central $\mathrm{C}-\mathrm{C}$ bond. However, it is not clear yet to what extent the $\mathrm{K}-\mathrm{N}$ interaction between $\mathrm{K}^{+}$and the $s$-cis conformer plays a stabilizing role. Reaction of $t$-Bu-DAB ${ }^{-}$with $\mathrm{ZnX}_{2}$ affords an ESR spectrum in agreement with $\mathrm{ZnX}(t-$ $\mathrm{Bu}-\mathrm{DAB})$ radical revealing coupling with both the $\mathrm{N}$ nuclei $(5.6 \mathrm{G})$, the imino hydrogens $(5.6 \mathrm{G}$ ), and the chlorine nucleus (mean $0.58 \mathrm{G}$ ). Even using ${ }^{67} \mathrm{Zn}$ enriched samples the satellites arising from coupling with ${ }^{67} \mathrm{Zn}$ $(4.4 \mathrm{G})$ could be established (176). The zinc atom in $\mathrm{ZnX}(t-\mathrm{Bu}-\mathrm{DAB})$ is stable three-coordinate when $X=$ halide (Fig. 19c). When $X=C N$ or $\mathrm{NCS}, \mathrm{ZnX}_{2}(t-\mathrm{Bu}-\mathrm{DAB})^{-}$is obtained directly (176). Analogous $\mathrm{MgX}(t-$ $\mathrm{Bu}-\mathrm{DAB})$ was not only accessible via the $t-\mathrm{Bu}_{-} \mathrm{DAB}^{-}-\mathrm{MgX}_{2}$ route but also by reaction of $\mathrm{MgCl}_{2}$ with $t$-Bu-DAB in the presence of metallic magnesium as the reducing reagent (176).

Reaction of $[t-\mathrm{Bu}-\mathrm{DAB}] \mathrm{K}$ with $\mathrm{Et} \mathrm{ZnCl}$ formed in quantitative yield the corresponding $\mathrm{ZnEt}(t$-Bu-DAB) radical which, however, is in equilibrium with its $C-C$ coupled dimer [see Eq. (41)].

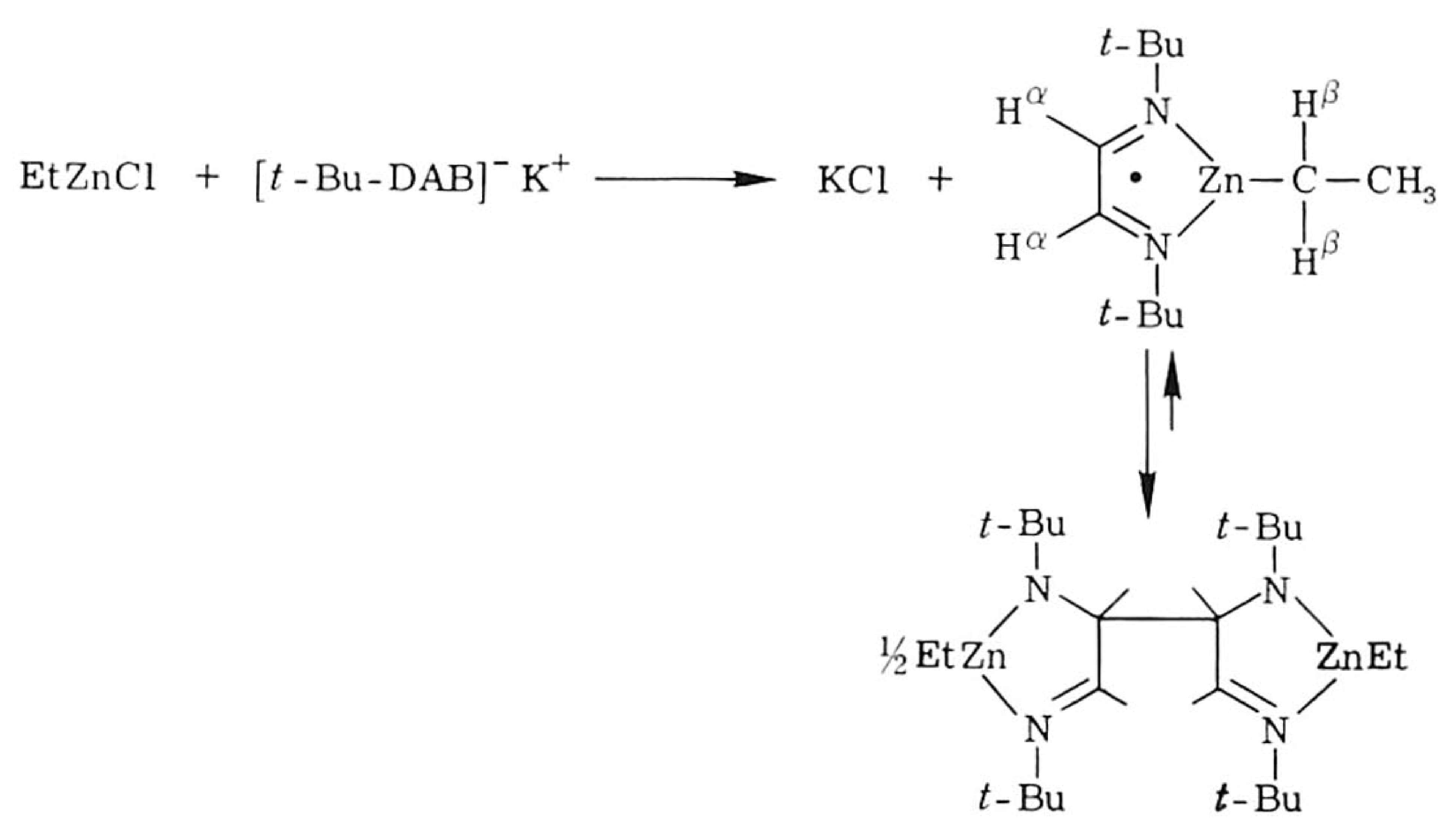

At low temperatures $\left(<-50^{\circ} \mathrm{C}\right)$ the concentration of the radical is too low to be detected by ESR, indicating that the equilibrium is shifted completely to the side of the dimer. Above $-50^{\circ} \mathrm{C}$ the solution displays a highly resolved ESR spectrum $\left(a_{\mathrm{N}} 4.87, a_{\mathrm{H}^{\alpha}} 5.87, a_{\mathrm{H}^{\beta}} 0.48 \mathrm{G}\right)$, indicatirg a com- 

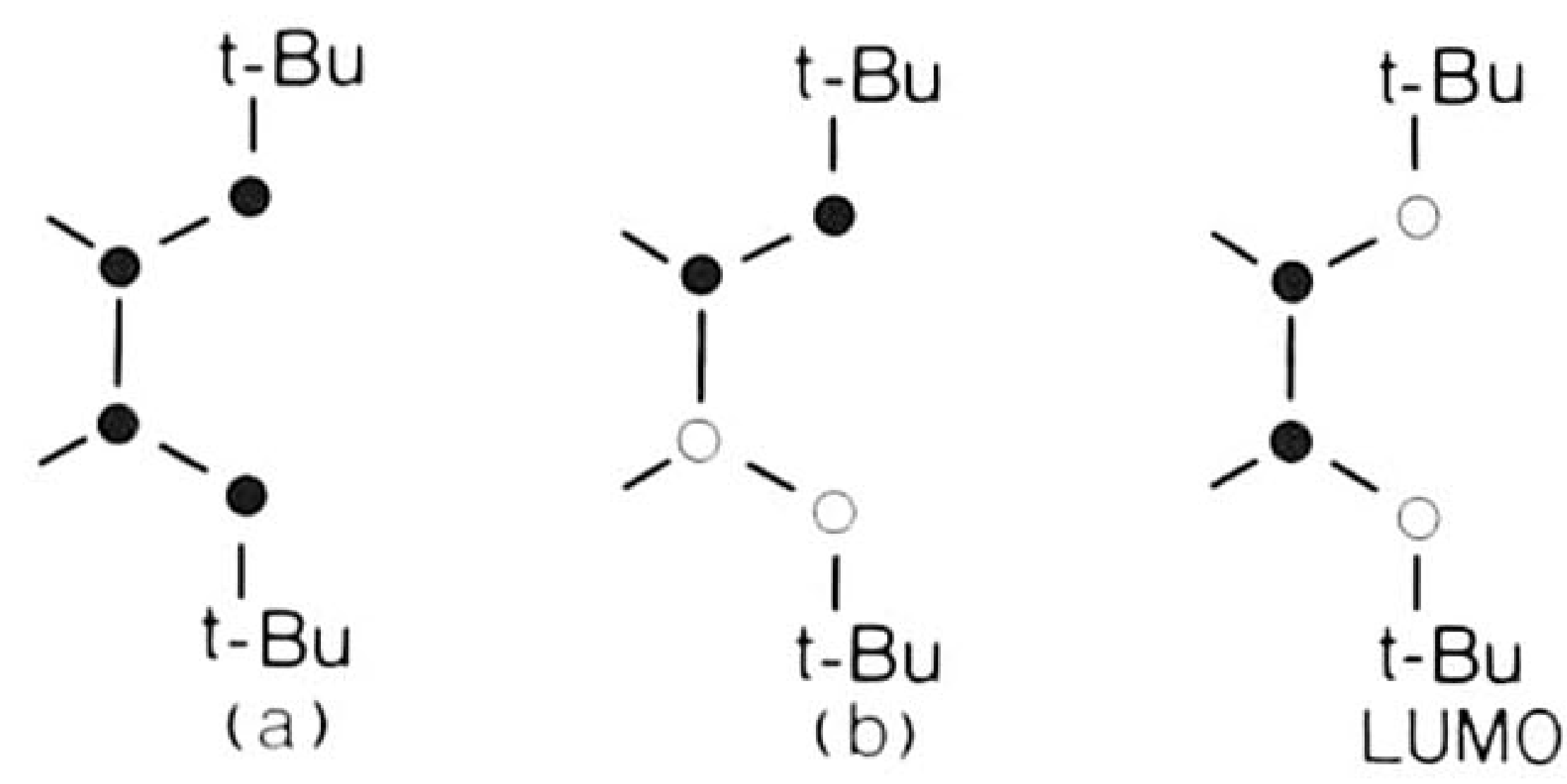

Fig. 20. Molecular orbitals, (a) and (b), of the free $t$-Bu-DAB ( $s$-cis conformation shown) and the LUMO, which become partly occupied in the $t$-Bu-DAB radical anion.

plete delocalization of the unpaired electron density over the metallocycle and the neighboring nuclei $(2,68)$, see Fig. 21 . NMR spectra reveal that the $\mathrm{C}-\mathrm{C}$ coupling must occur with high stereospecificity while the fact that a sharp NMR resonance pattern was observed points to a low rate for the monomer association-dimer dissociation processes. Other $\mathrm{ZnR}^{\prime}(\mathrm{R}$ $\mathrm{DAB})(\mathrm{R}=\mathrm{Me}, i$-Pr, $t$-Bu $)$ radicals have also been prepared according to Eq. (41) (see Fig. 21 for the ESR patterns).

Also in the reaction of $\mathrm{R}_{2} \mathrm{Zn}$ with $t$-Bu-DAB $\mathrm{ZnR}(t$-Bu-DAB) radicals are formed, although in minor amounts, for $\mathrm{R}$ is a primary alkyl group (Et, $n$ - $\mathrm{Bu}$, or $\mathrm{CH}_{2}-t-\mathrm{Bu}$ ) (68). In these reactions the organo group does

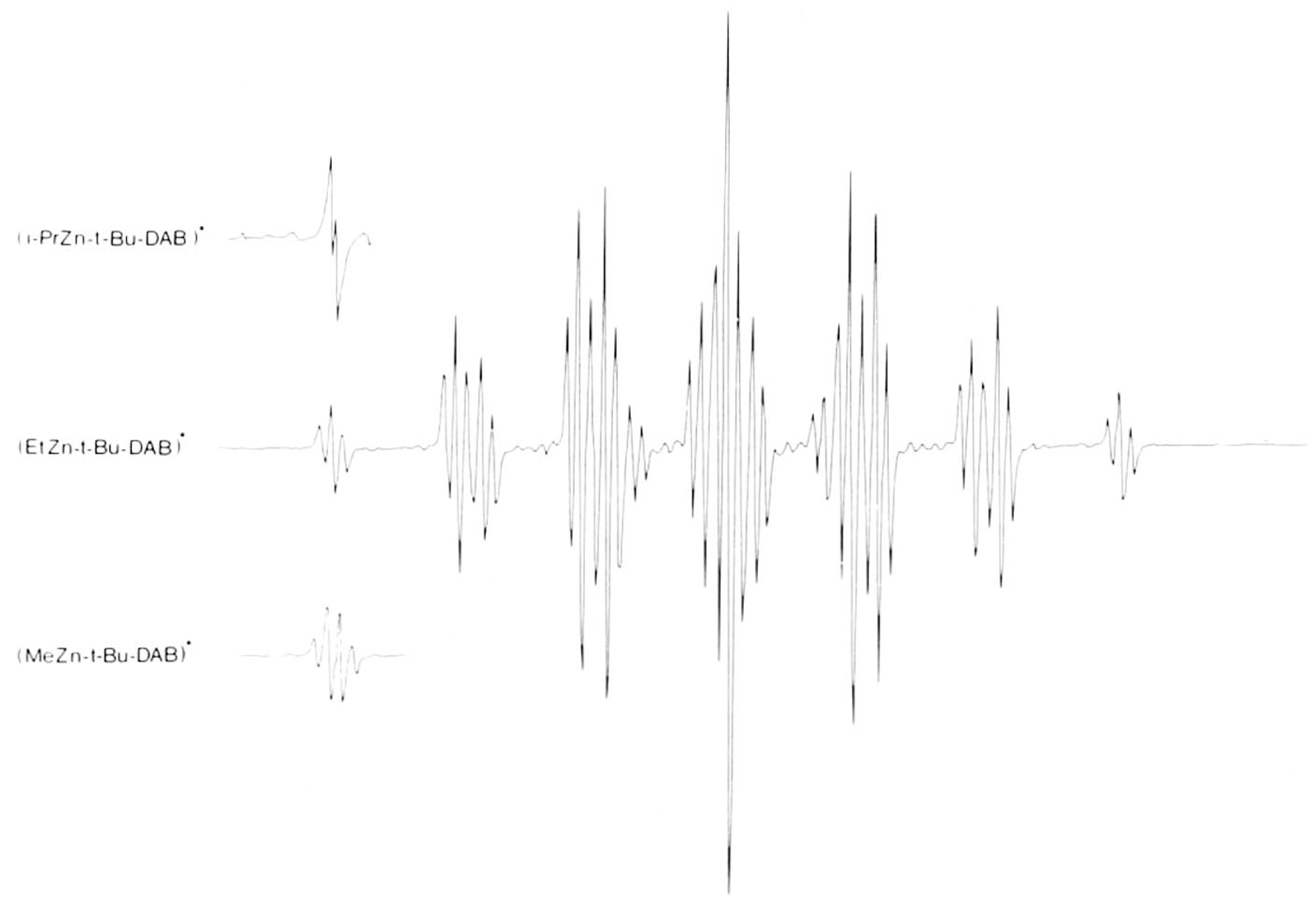

Fig. 21. ESR spectra for $\mathrm{R}^{\prime} \mathrm{Zn}(t-\mathrm{Bu}-\mathrm{DAB})$ radicals: $\mathrm{R}^{\prime}=\mathrm{Me}$, Et (fully shown) and $i-\mathrm{Pr}$. Note the multiplicity of the outer multiplet arising from coupling with the $\mathrm{R}^{\prime}$ group $\alpha$ protons. 
not escape from the $\mathrm{ZnR}_{2}(t-\mathrm{Bu}-\mathrm{DAB})$ intermediate as a radical but is transferred either completely to the imino- $\mathrm{N}$ (for primary alkyls) or to the imino- $\mathrm{C}$ atoms (tertiary alkyl) or in some instances partially to the imino$\mathrm{N}$ and the imino-C atom, see Section VI,C (179). An exception is the reaction for $\mathrm{Me}_{2} \mathrm{Zn}$ with $t$-Bu-DAB which results in formation of the stable $1: 1$ complex $\mathrm{Me}_{2} \mathrm{Zn}(t$-Bu-DAB). Above room temperature this complex is converted according to Eq. (42) to the $\operatorname{MeZn}(t-\mathrm{Bu}-\mathrm{DAB})$ radical (50\%). Similarly, reaction of $\mathrm{Et}_{2} \mathrm{Zn}$ with $\mathrm{C}_{5} \mathrm{H}_{4} \mathrm{NC}(\mathrm{H})=\mathrm{N}-t$ - Bu afforded the equilibrium mixture of the three-coordinate radical and the $\mathrm{C}-\mathrm{C}$ coupled dimer [Eq. (43)] via the four-coordinate $\mathrm{ZnEt}_{2}\left[\mathrm{C}_{5} \mathrm{H}_{4} \mathrm{NC}(\mathrm{H})=\mathrm{N}-t\right.$-Bu] complex (68). This equilibrium is shifted more to the side of the dimer than in the case of the $t$-Bu-DAB derivative in Eq. (41). Recently the structure of $\left[\mathrm{ZnEt}\left\{\mathrm{C}_{5} \mathrm{H}_{4} \mathrm{NC}(\mathrm{H}) \mathrm{N}-t-\mathrm{Bu}\right\}\right]_{2}$ was established by an $\mathrm{X}$-ray structure determination (179). Remarkable is the resemblance of this structure [schematically shown in Eq. (43)] to the structure of the C-C coupling product $\mathrm{Ru}_{2}(\mathrm{CO})_{5}(\mathrm{IAE})$ (see Fig. 26; Section IV,C).
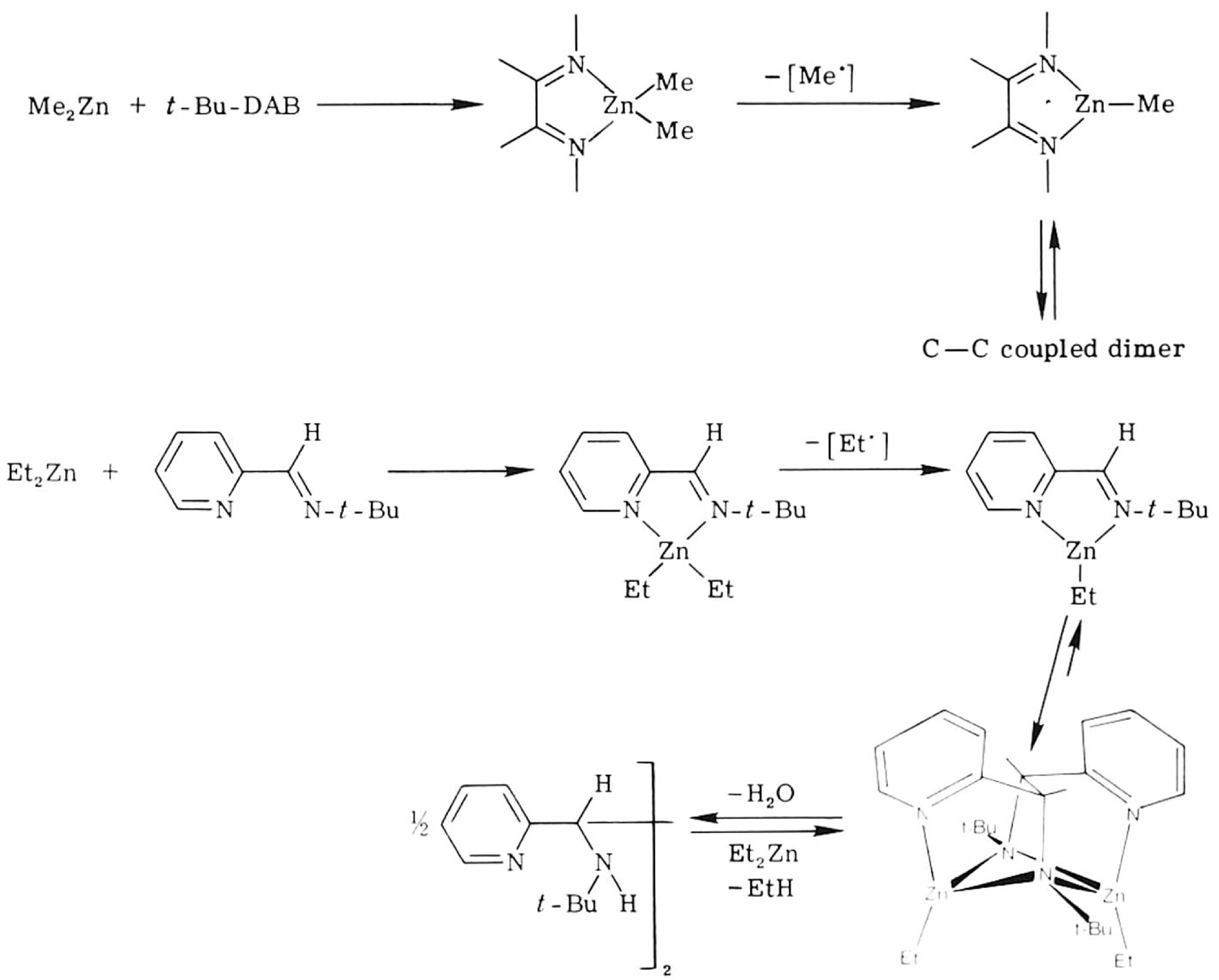

These $\mathrm{C}-\mathrm{C}$ coupling reactions (41) and (42) are in a sense very similar to the ones occurring during the formation of $\mathrm{Mo}_{2}(\mathrm{CO})_{6}(\mathrm{IAE})$ and $\mathrm{Ru}_{2}(\mathrm{CO})_{n}(\mathrm{IAE})(n=4,5)$ (see Section VI,C). 
Extensive ESR investigations have been carried out on the radicals obtained by treating $\mathrm{M}(\mathrm{CO})_{4-n} \mathrm{~L}_{n}\left[\mathrm{R}-\mathrm{DAB}\left(\mathrm{R}^{\prime}, \mathrm{R}^{\prime \prime}\right)\right]$ with potassium in 1,2-dimethoxyethane or THF $(81,88,145,180)$ in which $\mathrm{M}=\mathrm{Cr}$, Mo, W and $\mathrm{R}=\mathrm{Me}, \mathrm{CH}_{2} \mathrm{Ph}, i-\mathrm{Pr}, c-\mathrm{Hex}, c-\mathrm{Pr}$ for $\mathrm{R}^{\prime}=\mathrm{R}^{\prime \prime}=\mathrm{H}$ or $\mathrm{Me}$, and $\mathrm{L}=\mathrm{PBu}_{3}$ with $n=0,1$, or 2. Comparison of the ESR spin density at the coordination sites as well as the coupling data (in case of $n=1$ or 2) for these complexes with those obtained for the corresponding 2,2'-bypyridine complexes showed that the $\pi$-acceptor capacity of 2,2'-bypyridine is about half that of the R-DAB ligand. This result corresponds with the higher stability of the zerovalent metal-R-DAB complexes and the lower reduction potential of many of these complexes as compared to those of the zerovalent metal2,2 '-bipyridine analogs $(84,94)$.

\section{VI}

\section{CHEMICAL ACTIVATION OF METAL COORDINATED 1,4-DIAZA- 1,3-BUTADIENE LIGANDS}

Earlier we have mentioned the strong electron accepting properties of $\mathrm{R}-\mathrm{DAB}$ ligands when coordinated in the $\sigma, \sigma-\mathrm{N}, \mathrm{N}^{\prime}(4 \mathrm{e})$ and particularly in the $\sigma-\mathrm{N}, \mu^{2}-\mathrm{N}^{\prime}, \eta^{2}-\mathrm{C}=\mathrm{N}^{\prime}(6 \mathrm{e})$ and $\sigma-\mathrm{N}, \sigma-\mathrm{N}^{\prime}, \eta^{2}-\mathrm{C}=\mathrm{N}, \eta^{2}-\mathrm{C}=\mathrm{N}^{\prime}(8 \mathrm{e})$ bonding modes. In the latter two types one and two $\mathrm{C}=\mathrm{N}$ groups are $\eta^{2}$-bonded, respectively. As a consequence one would expect chemical activation of the diimine itself, and also of the metal to which the diimine is coordinated.

First, we shall discuss activation by $\sigma$-bonded R-DAB groups and subsequently reactions involving the $\eta^{2}-\mathrm{C}=\mathrm{N}$ metal linkages.

\section{A. Complexes with (Intermediate) $\sigma-N(2 e)$ Bonded 1,4-Diaza- 1,3-butadiene Ligands}

An example is the stoichiometric reaction of $\mathrm{Fe}_{2}(\mathrm{CO})_{9}$ with $t$-Bu-DAB which gives $\mathrm{Fe}(\mathrm{CO})_{5}, \mathrm{Fe}(\mathrm{CO})_{3}(\mathrm{DAB})$, and 2-imidazolinone in a $1: 1: 1$ ratio $(30,110)$. A fairly detailed study of this formation of imidazolinone which, as far as we know, has not been observed for other metal carbonyl R-DAB complexes, showed that the reaction can be made catalytic (110). The proposed mechanism for both the stoichiometric and catalytic reactions (Fig. 22) starts with the attack of $t$ - $\mathrm{Bu}-\mathrm{DAB}$ on $\mathrm{Fe}_{2}(\mathrm{CO})_{9}$ giving $\mathrm{Fe}(\mathrm{CO})_{5}$ and $\mathrm{Fe}(\mathrm{CO})_{4}(t-\mathrm{Bu}-\mathrm{DAB})$ in which the t-Bu-DAB is $\sigma-\mathrm{N}(2 \mathrm{e})$ bonded to $\mathrm{Fe}$ and probably in the $E$ - $s$-trans- $E$ conformation. Rotation about the cen- 


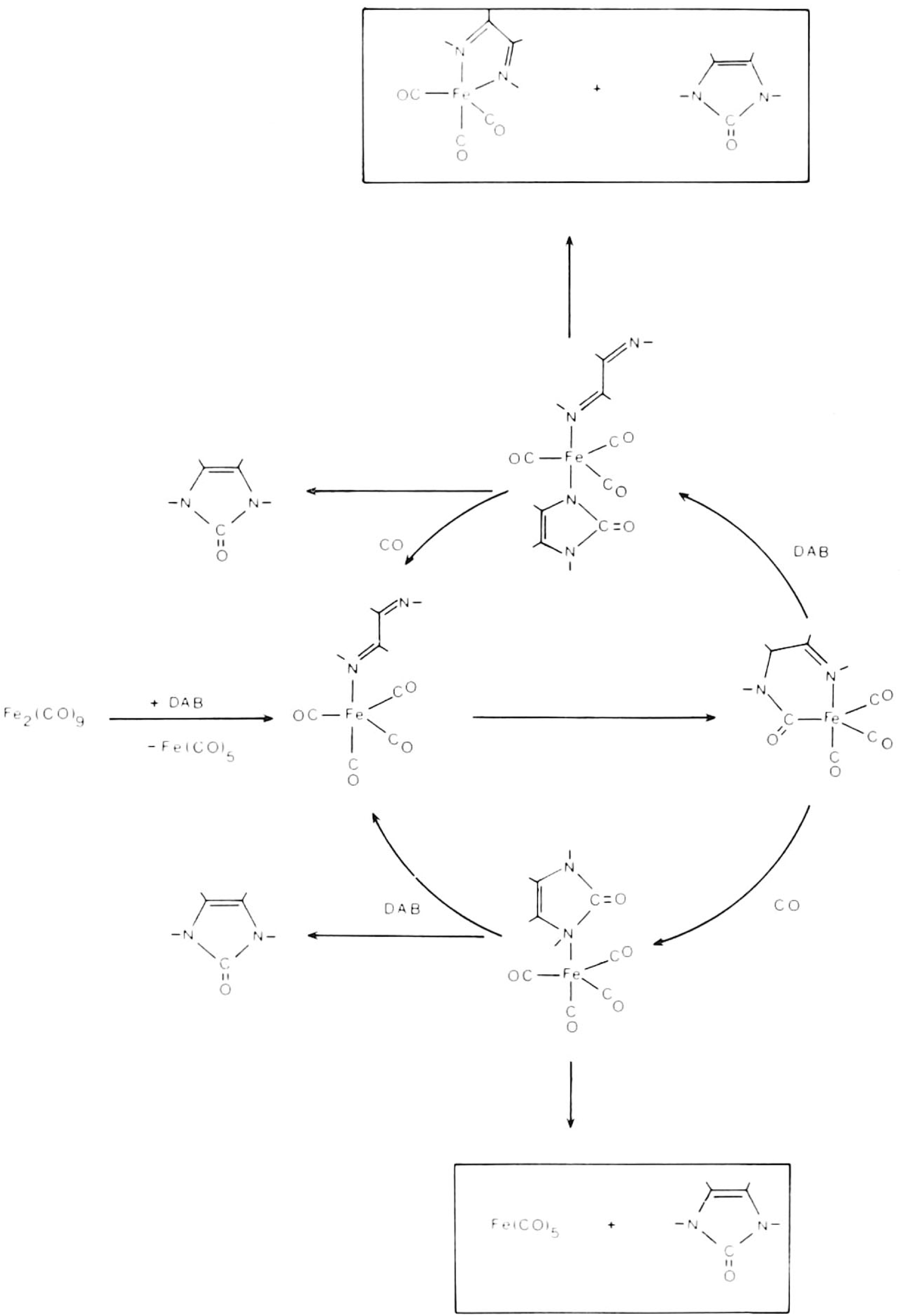

FIG. 22. Suggested (catalytic) reaction scheme for the formation of imidazolinone in the reaction of $\mathrm{Fe}_{2}(\mathrm{CO})_{9}$ with $t$-Bu-DAB and $\mathrm{CO}(/ 10)$. 
tral $\mathrm{C}-\mathrm{C}$ bond brings the diimine in this intermediate complex into the $E$-s-cis- $E$ conformation and therefore in the right position to bind to one of the $\mathrm{CO}$ groups on $\mathrm{Fe}$ through intramolecular nucleophilic attack. Subsequent addition of $t$-Bu-DAB and extrusion of the weakly bonding imidazolinone then gives further $\mathrm{Fe}(\mathrm{CO})_{3}(t-\mathrm{Bu}-\mathrm{DAB})$. [N.B. Recently some work was published on the possible coordination modes of imidazoline $(1,3-$ $H$ )-2-thione which is a sulfur analog of 2-imidazolinone (181) and it was shown that both $\mathrm{S}$ and $\mathrm{N}$ may be involved in metal coordination.] However, when the reaction was carried out under $\mathrm{CO}$ pressure, a catalytic process occurred possibly going via two pathways differing in the order of attack of R-DAB and CO, as is shown clearly in Fig. 22 (110). Unfortunately the catalyst was deactivated after about three cycles due to the unproductive side reactions that lead to $\mathrm{Fe}(\mathrm{CO})_{3}(\mathrm{R}-\mathrm{DAB})$ and $\mathrm{Fe}(\mathrm{CO})_{5}$.

\section{B. Complexes with $\sigma, \sigma-N, N^{\prime}$ (4e) 1,4-Diaza-1,3-butadiene Ligands}

In a series of papers Krumholz and co-workers $(28,115-117,122,130)$ studied ligand oxidation mainly on iron diimine complexes $\mathrm{Fe}[\mathrm{Me}$ $\left.\mathrm{DAB}\left(\mathrm{R}^{\prime}, \mathrm{R}^{\prime \prime}\right)\right]_{3}^{2+}$. These reactions using $\mathrm{Ce}^{\mathrm{IV}}$ in strongly acidic environments were studied by means of potentiometric, photometric $(115,116,130)$, and electrochemical techniques (117). For example $\mathrm{Fe}^{\mathrm{II}}(\mathrm{Me}-\mathrm{DAB})_{3}^{2+}$ reacted in strong sulfuric acid with $\mathrm{Ce}^{\mathrm{IV}}$ to yield $\mathrm{Fe}^{\mathrm{III}}(\mathrm{Me}-\mathrm{DAB})_{3}^{3+}$, which disproportionated further as shown below (115-117). It is thought that the first step involves the oxidation of $\mathrm{Fe}^{\mathrm{II}}(\mathrm{Me}-\mathrm{DAB})_{3}^{2+}$ [Eq. (44)]:

$$
\mathrm{Fe}(\mathrm{Me}-\mathrm{DAB})_{3}^{3+}+\mathrm{Ce}^{\mathrm{Iv}} \rightleftarrows \mathrm{Fe}(\mathrm{Me}-\mathrm{DAB})_{3}^{3+}+\mathrm{Ce}^{\mathrm{III}}
$$

Subsequently there is an intramolecular electron transfer assisted by nucleophilic attack of a water molecule [Eq. (45)]:

$2 \mathrm{Fe}(\mathrm{Me}-\mathrm{DAB})_{3}^{3+} \stackrel{\mathrm{H}_{2} \mathrm{O}}{\longrightarrow} \mathrm{Fe}(\mathrm{Me}-\mathrm{DAB})_{2}[\mathrm{MeN}=\mathrm{CH}-\mathrm{C}(\mathrm{OH})=\mathrm{NMe}]^{2+}$

$$
+\mathrm{Fe}(\mathrm{Me}-\mathrm{DAB})_{3}^{2+}+2 \mathrm{H}^{+}
$$

which is followed by a fast intramolecular electron transfer reaction [Eq. (46)]:

$\mathrm{Fe}(\mathrm{Me}-\mathrm{DAB})_{2}[\mathrm{MeN}=\mathrm{CH}-\mathrm{C}(\mathrm{OH})=\mathrm{NMe}]^{2+}+\mathrm{Fe}(\mathrm{Me}-\mathrm{DAB})_{3}^{3+} \stackrel{\text { fast }}{\rightarrow}$

$$
\mathrm{Fe}(\mathrm{Me}-\mathrm{DAB})_{2}[\mathrm{MeN}=\mathrm{CH}-\mathrm{C}(\mathrm{OH})=\mathrm{NMe}]^{3+}+\mathrm{Fe}(\mathrm{Me}-\mathrm{DAB})_{3}^{2+}
$$


Parallel to reaction (45) reaction (47) occurs:

$2 \mathrm{Fe}(\mathrm{Me}-\mathrm{DAB})_{3}^{3+} \stackrel{\mathrm{H}_{2} \mathrm{O}}{\longrightarrow} \mathrm{Fe}(\mathrm{Me}-\mathrm{DAB})_{2}\left(\mathrm{MeN}=\mathrm{CHCHNCH}_{2} \mathrm{OH}\right)^{2+}$

$$
+\mathrm{Fe}(\mathrm{Me}-\mathrm{DAB})_{3}^{2+}+2 \mathrm{H}^{+}
$$

The intramolecular electron transfer by means of a nucleophilic reaction with $\mathrm{H}_{2} \mathrm{O}$ is shown schematically [Eq. (48)]:

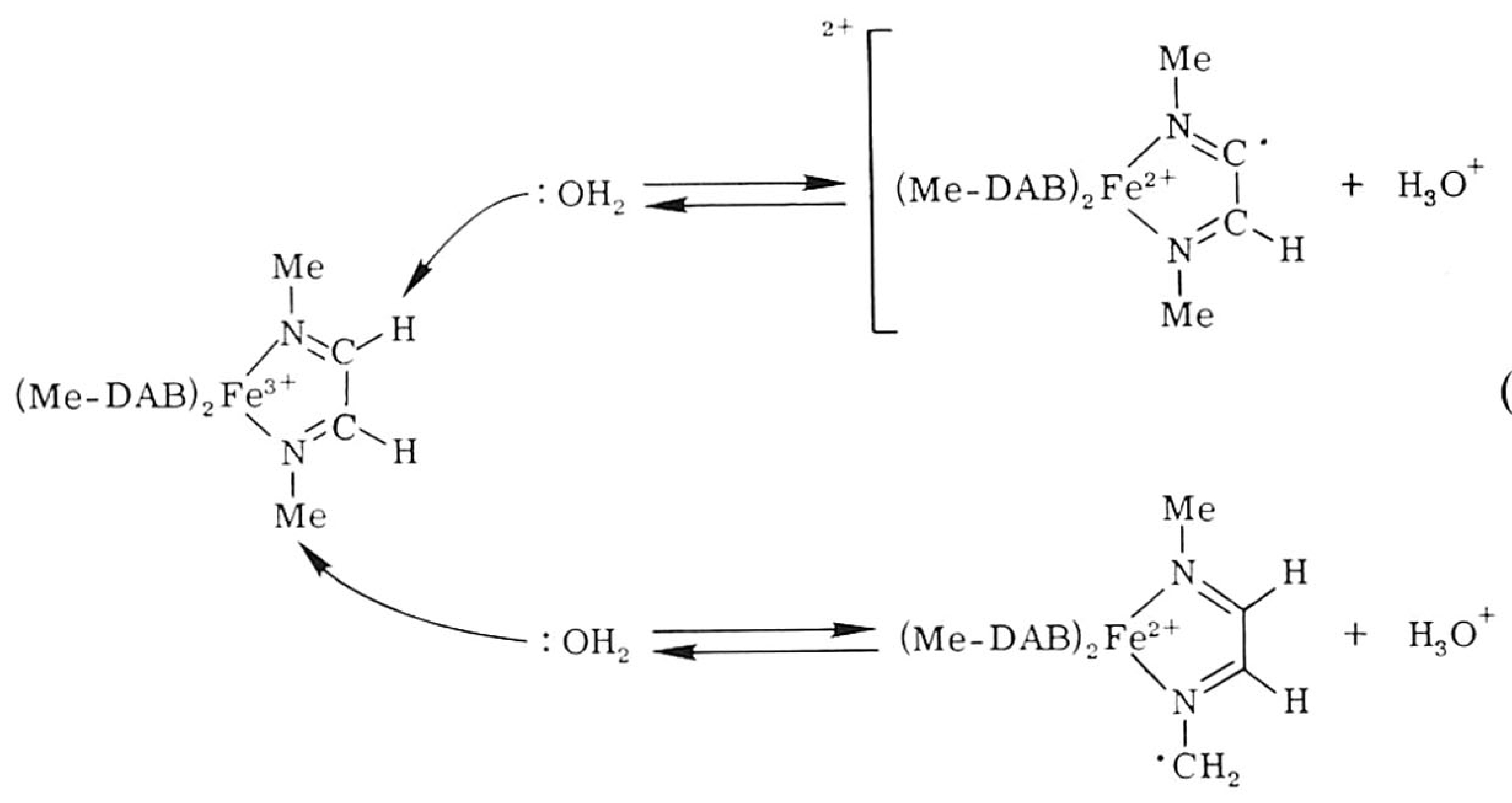

Subsequent reaction of the radical complex with water and $\mathrm{Fe}(\mathrm{Me}-$ $\mathrm{DAB})_{3}^{3+}$ gives stable two-electron oxidation products, e.g., Eq. (49):

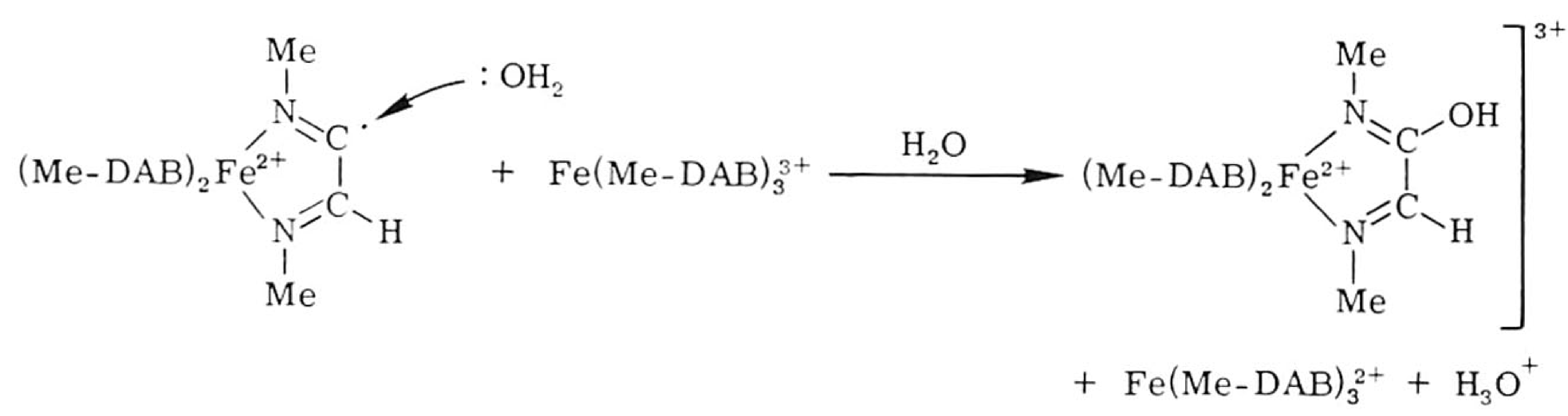

A rather similar reaction is the autoxidation of $\mathrm{Fe}[\mathrm{Me}-\mathrm{DAB}$ $(\mathrm{Me}, \mathrm{Me})]_{3}^{2+}$ in acidic aqueous media with oxygen, which was studied by spectrophotometric and NMR techniques (130). Also in this case a radical intermediate $[\mathrm{Me}-\mathrm{DAB}(\mathrm{Me}, \mathrm{Me})]_{2} \mathrm{Fe}[\mathrm{MeN}=\mathrm{C}(\mathrm{Me})-\mathrm{C}(\mathrm{Me})$ $=\mathrm{N}-\dot{\mathrm{C}} \mathrm{H}_{2}^{2+}$ was proposed. The electron is mainly localized on the deprotonated $\mathrm{Me}$ group bonded to the $\mathrm{N}$ atom.

Asymmetric R-DAB ligands $\mathrm{C}_{5} \mathrm{H}_{4} \mathrm{~N}-\mathrm{CMe}=\mathrm{NMe}$ bonded to $\mathrm{Fe}^{\mathrm{II}}$ are oxidized by $\mathrm{Ce}^{\mathrm{IV}}$ in acidic environments to give via a radical intermediate an aldehyde group formed from the Me group bonded to the imine- $\mathrm{C}$ atom (122). 
These studies therefore show that radical intermediates are of crucial importance in $\mathrm{Fe}$-diimine reactions. The electron may be localized on the imino- $\mathrm{C}$ atom, on the substituent bonded to the imino- $\mathrm{C}$ atom and also on the substituent bonded to a $\mathrm{N}$ atom.

Other examples of activation of $\sigma, \sigma-\mathrm{N}, \mathrm{N}^{\prime}$ bonded R-DAB ligands include their reactions with $\mathrm{RLi}, \mathrm{RMgX}$, and $\mathrm{R}_{2} \mathrm{CuLi}$ which gave after hydrolysis a large variety of products (159). However selective reactions were obtained between $\mathrm{R}-\mathrm{DAB}$ and $\mathrm{ZnR}_{2}$ and $\mathrm{AlR}_{3}$, respectively $(68,182,183)$. The four-coordinate complexes $\mathrm{Zn}(p-\mathrm{Tol})_{2}(\mathrm{R}-\mathrm{DAB})$ are stable, but the compounds $\mathrm{ZnEt}_{2}\left[\mathrm{R}-\mathrm{DAB}\left(\mathrm{R}^{\prime}, \mathrm{R}^{\prime \prime}\right)\right]$ are stable only at low temperatures $(\mathrm{R}$ $=t-\mathrm{Bu}, i-\mathrm{Pr}, \mathrm{CH}_{2}(t-\mathrm{Bu}), c-\mathrm{Hex}$, and $i-\mathrm{Pr}_{2} \mathrm{CH} ; \mathrm{R}^{\prime}=\mathrm{R}^{\prime \prime}=\mathrm{H}$ and $\mathrm{R}=i-\mathrm{Pr}$ with $\mathrm{R}^{\prime}=\mathrm{H}, \mathrm{R}^{\prime \prime}=$ Me and finally $\mathrm{R}=c$-Hex and $\mathrm{R}^{\prime}=\mathrm{R}^{\prime \prime}=\mathrm{Me}$ ). For example, $\mathrm{ZnEt}_{2}(t-\mathrm{Bu}-\mathrm{DAB})$ converted at $-50^{\circ} \mathrm{C}$ to $\mathrm{EtZn-N(Et)}$ $(t-\mathrm{Bu}) \mathrm{CH}=\mathrm{CHN}-t-\mathrm{Bu}$ via an intramolecular ethyl transfer from $\mathrm{Zn}^{11}$ to one of the $\sigma-\mathrm{N}$ coordinated $\mathrm{N}$ atoms (Fig. 23ab) (183). The reaction is<smiles>CCCCN1C(C)=C(C)N(C(=O)[O+])[Z]1(CC)CC</smiles>

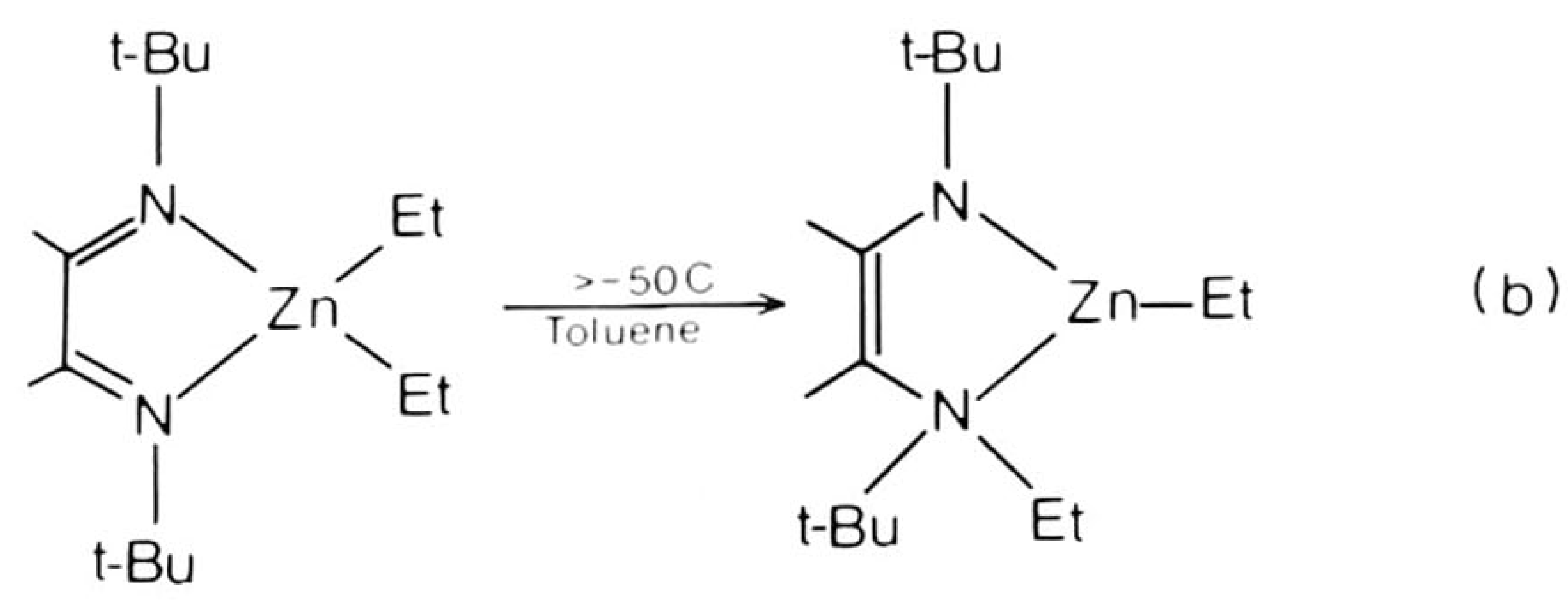

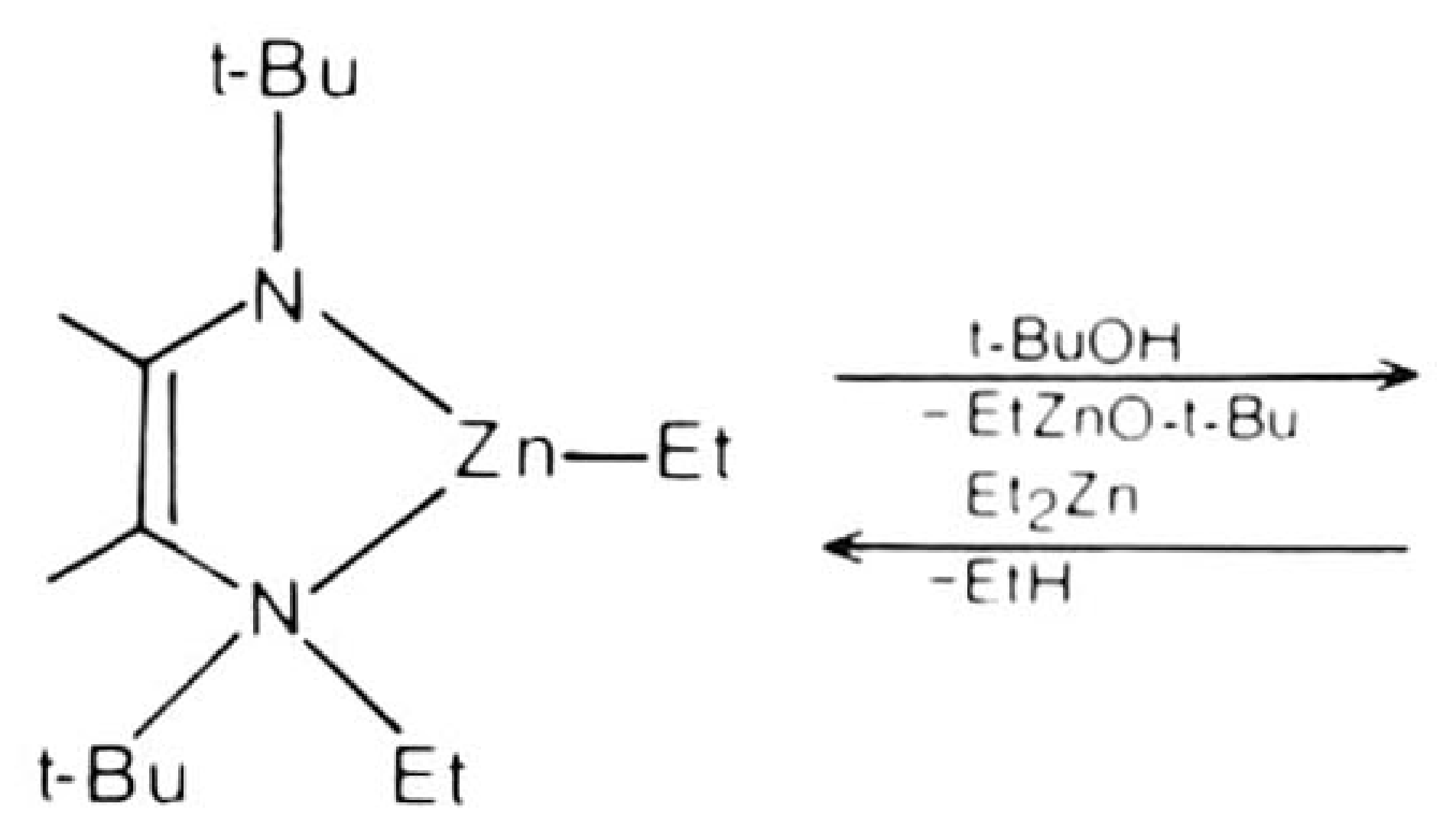<smiles>CCN(CC)/C(C)=C(/C)NC(=O)c1ccccc1</smiles><smiles>CCN(CC)C(C)(CC)C(C)=N[Ga]</smiles>

FIG. 23. Reaction (a) of $\mathrm{ZnEt}_{2}$ with $t$-Bu-DAB; formation (b) of $\mathrm{EtZnN(Et)}$ -

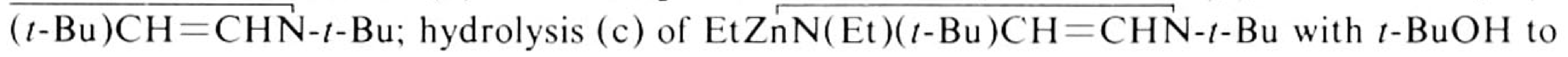
give a tautomeric mixture of enediamines (183). 
almost quantitative, but a small amount $(<2 \%)$ of a persistent three-coordinated zinc radical species $\operatorname{EtZn}(t-\mathrm{Bu}-\mathrm{DAB})^{*}$ was also obtained (see Section $\mathrm{V})$. Both molecular weight and NMR measurements indicated the monomer nature of $\mathrm{Et} Z \mathrm{nN}(\mathrm{Et})(t-\mathrm{Bu}) \mathrm{CH}=\mathrm{CHN}-t-\mathrm{Bu}$. Careful protonolysis with $t$ - $\mathrm{BuOH}$ produced EtZnO- $t$-Bu and quantitatively a $4: 1$ tautomeric mixture of the enediamine $(t-\mathrm{Bu}) \mathrm{EtNCH}=\mathrm{CHN}(\mathrm{H})-t-\mathrm{Bu}$ and an iminoaminoethane ( $t$ - Bu) Et $\mathrm{NCH}_{2} \mathrm{CH}=\mathrm{N}-t$-Bu (Fig. 23c). Reaction with $\mathrm{ZnEt}_{2}$ then gave back the starting material in quantitative yield (Fig. 23).

The protonolysis with $t$-BuOD showed that in a very fast reaction the monodeuterated enediamine is formed first, after which a slower reaction reaches equilibrium in about ten minutes and this leads to a number of monodeuterated enediamine and the monodeuterated iminoaminoethane compounds (Fig. 24) (183). After about one hour in a second process a statistical ratio of fully protonated, mono- and dideuterated enediamines and iminoaminoethanes is formed. It could be deduced from ' $\mathrm{H}$ NMR that $\mathrm{H}_{\mathrm{A}}$ in Fig. 24 is not participating in the isomerization and the $\mathrm{H}-\mathrm{D}$ exchange.

The ratio of the tautomers appeared to depend on the $\mathrm{R}-\mathrm{N}$ and $\mathrm{R}^{\prime}-\mathrm{C}$ substituents, since branching at $\mathrm{C}^{\beta}$ in $\mathrm{R}$ shifted the equilibrium away from the enediamine and $\mathrm{R}^{\prime}$ substitution of $\mathrm{H}$ for Me stabilized the enediamine tautomer (183). The mechanism of the unprecedented ethyl group transfer from $\mathrm{Zn}$ to $\mathrm{N}$ probably occurs via a mechanism involving initial homolytic cleavage of the $\mathrm{Et}-\mathrm{Zn}$ bond for which the formation of the radical $\mathrm{EtZn}(\mathrm{R}-\mathrm{DAB})^{*}$ through loss of an ethyl radical is supporting evidence. In the case where the Et radical does not escape from the solvent cage it moves to the $\mathrm{N}$ atom via an intramolecular 1,2-shift. This can be rationalized by the character of the LUMO of the $\mathrm{Zn}-\mathrm{N}=\mathrm{C}-\mathrm{C}=\mathrm{N}$ entity, which is bonding in $\mathrm{C}-\mathrm{C}$ and antibonding in $\mathrm{C}-\mathrm{N}$ (183) (see Fig. 20 in Section V). Apparently, this activation of the chelated $\mathrm{N}=\mathrm{C}-\mathrm{C}=\mathrm{N}$ skeleton is a delicately tuned process because recent results have shown that in $\mathrm{R}_{2}^{\prime} \mathrm{Zn}(\mathrm{R}-\mathrm{DAB})\left(\mathrm{R}^{\prime}=\mathrm{Me}, \mathrm{R}=t-\mathrm{Bu}\right)$ complexes the $\mathrm{ZnMe}(t-\mathrm{Bu}-$ DAB) radical is formed exclusively (50\%) [see Fig. 21 and Eq. (42) in Section V]. For $\mathrm{R}^{\prime}=$ primary alkyl a 1,2-shift is observed while for $\mathrm{R}=t$ - $\mathrm{Bu}$ or $i$ - $\mathrm{Pr}$ a 1,3 -shift to the imino- $\mathrm{C}$ atom is the predominant process.

In contrast to the $\mathrm{Zn}$ reactions, $\mathrm{Al}_{2} \mathrm{Ph}_{6}$ reacted with $p$-Tol-DAB to produce $\mathrm{Ph}_{2} \mathrm{Al}[(p-\mathrm{Tol}) \mathrm{NCH}(\mathrm{Ph}) \mathrm{CH}=\mathrm{N}(p-\mathrm{Tol})]$ via the four coordinate intermediate $\mathrm{Ph}_{2} \mathrm{Al}(p$-Tol-DAB) (182). However, now $\mathrm{C}-\mathrm{C}$ coupling occurs instead of $\mathrm{N}-\mathrm{C}$ bond formation and the corresponding iminoamine can be isolated in virtually quantitative yields upon protonolysis. Of interest is the more complicated reaction of $\mathrm{Al}_{2} \mathrm{Me}_{6}$ with $\mathrm{R}-\mathrm{DAB}$, which afforded various reaction products in very selective ways depending on the $\mathrm{R}$ group 


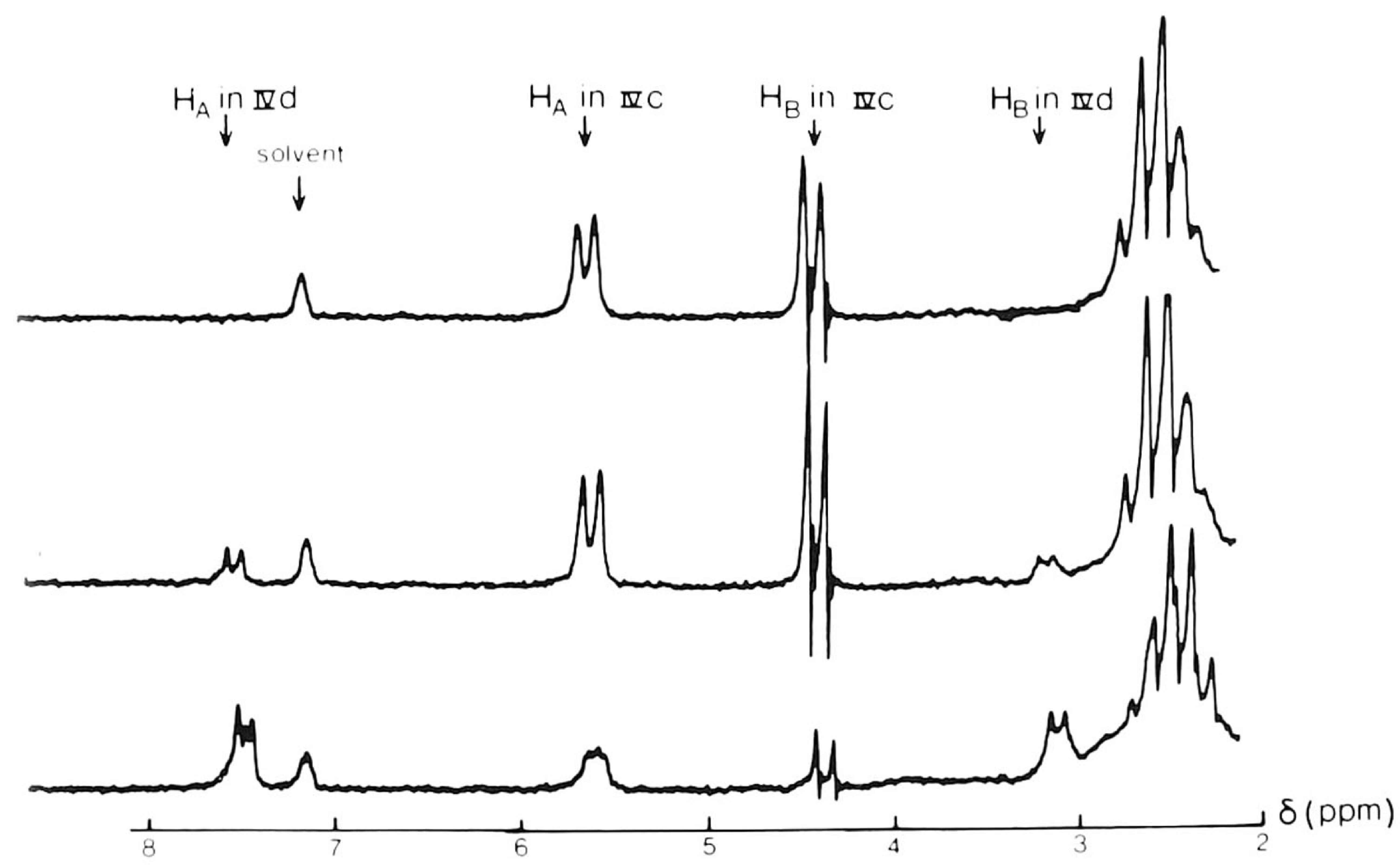

$R=c y c l o h e x y l$

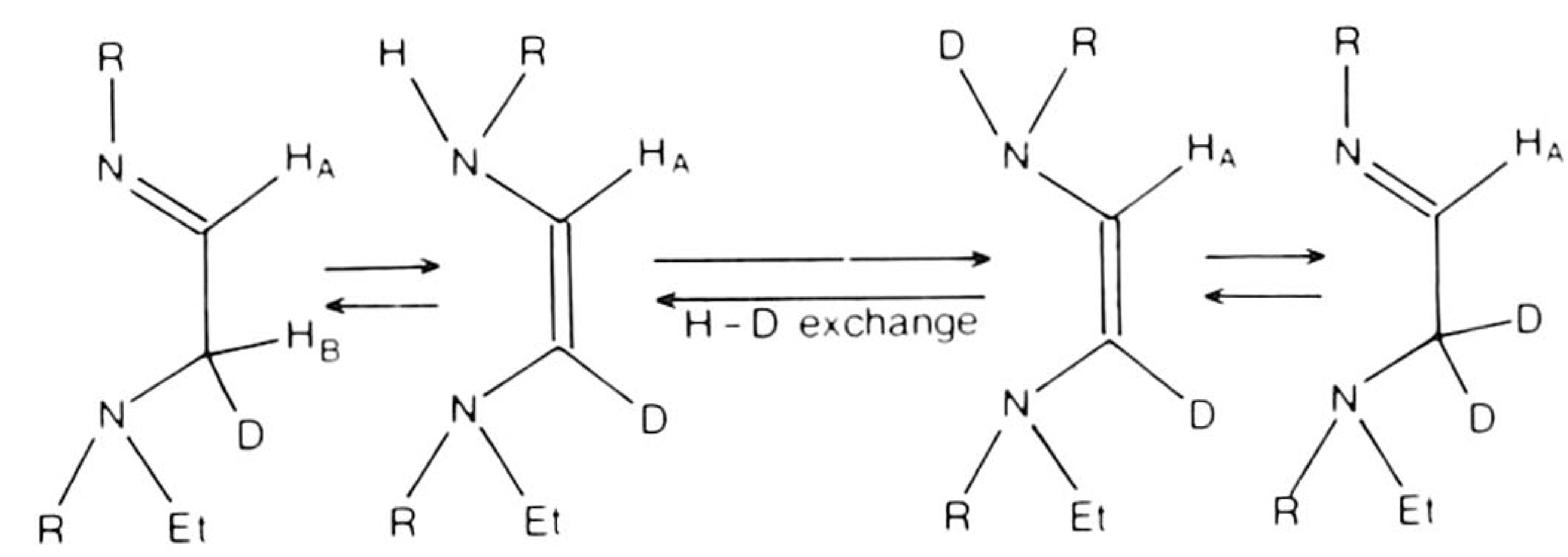

$\mathbb{\nabla d}$ $\mathbb{\nabla C}$<smiles>[CH]1CC1</smiles>

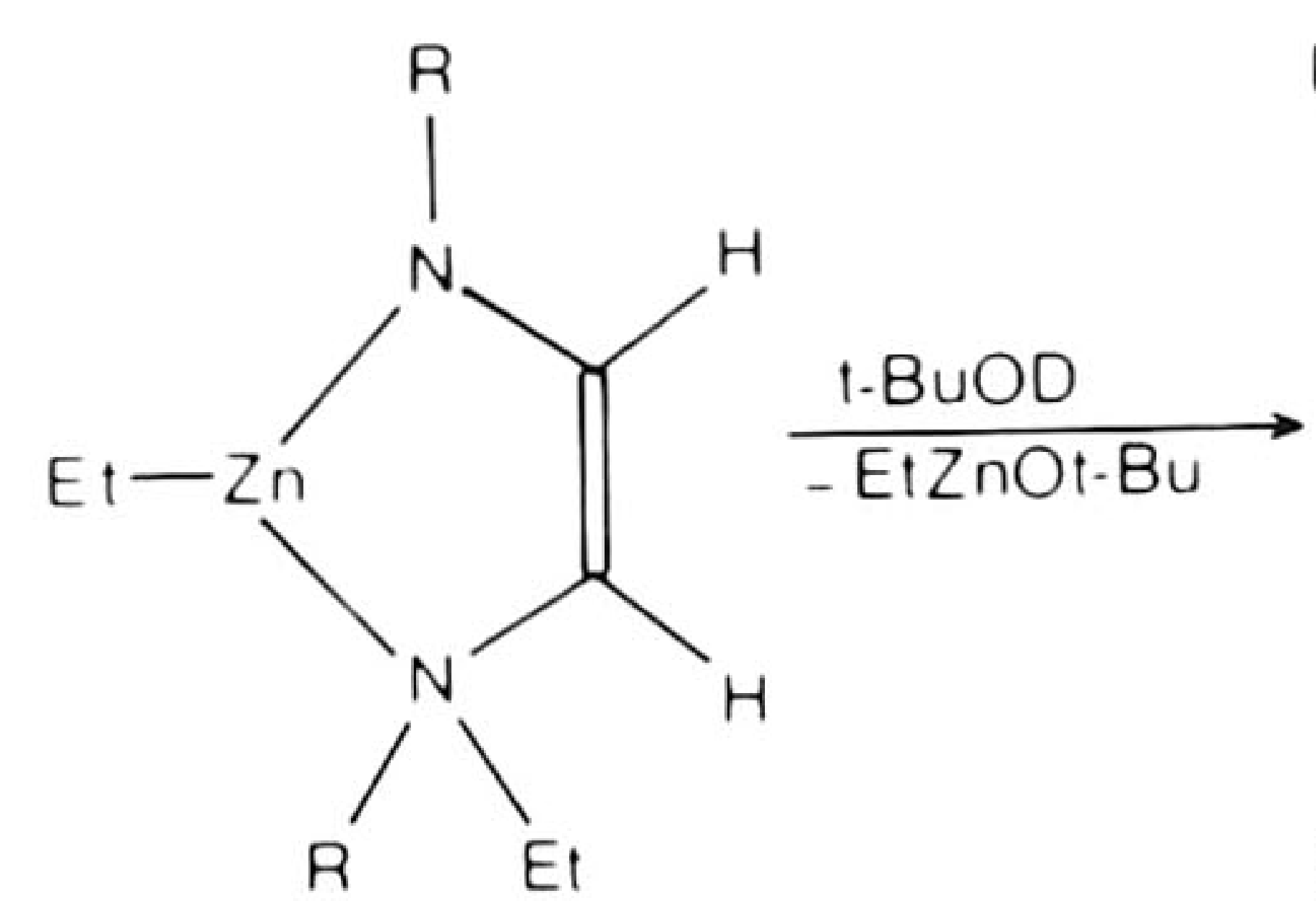

IV b
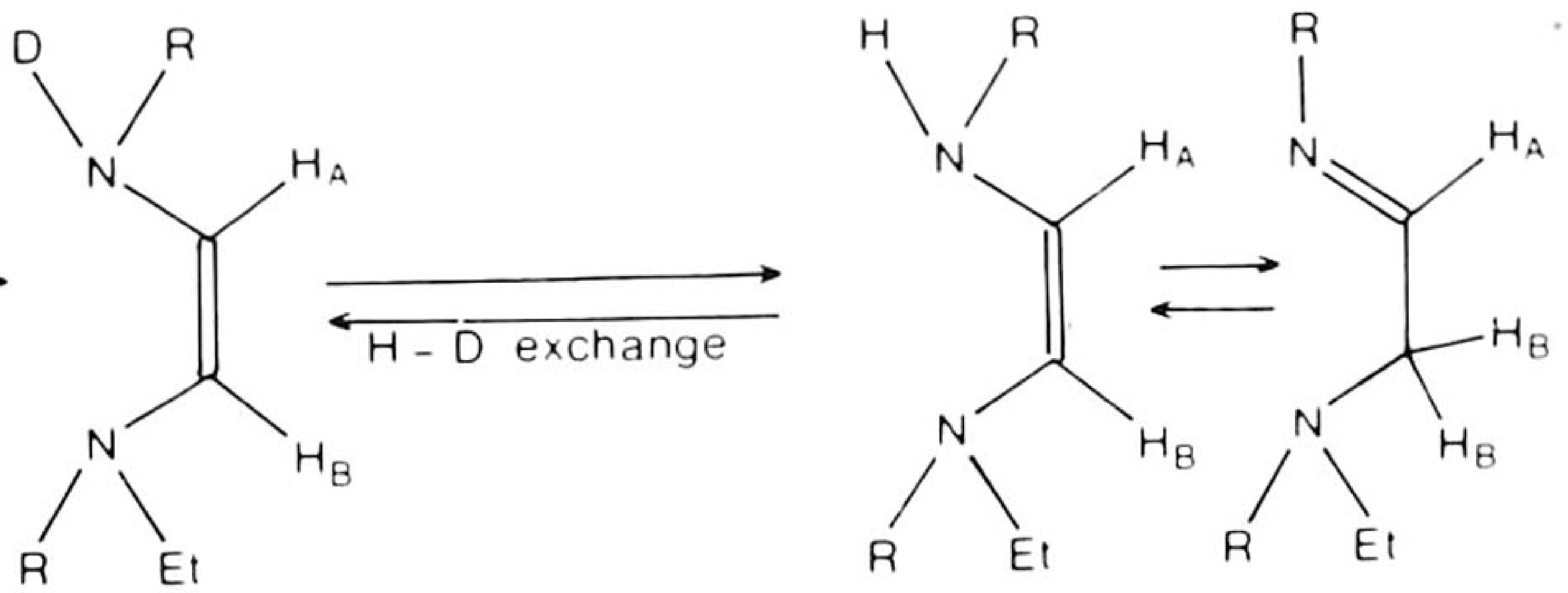

IVc

FIG. 24. The hydrolysis of $E t Z n N(E t)(R) C H=C H N R$. 

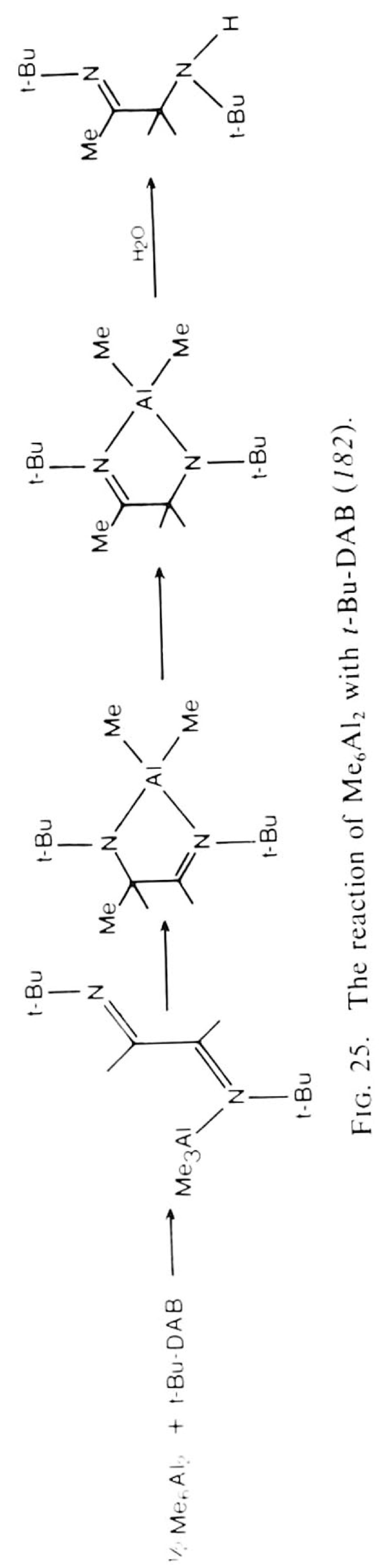
(182). The first step (Fig. 25) yielded $\mathrm{Me}_{3} \mathrm{Al}(\mathrm{R}-\mathrm{DAB})(\mathrm{R}=2,6-\mathrm{Xyl}$ and $2,4,6$-Mes) in which the R-DAB is $\sigma$-N (2e) bonded with the R-DAB probably in the $E$-s-trans- $E$ conformation. In the subsequent step one of the methyl groups of $\mathrm{Al}$ is transferred to one of the imine- $\mathrm{C}$ atoms giving $\mathrm{Me}_{2} \mathrm{Al}(\mathrm{RN}-\mathrm{CHMe}-\mathrm{CH}=\mathrm{NR})$, which could be isolated for $\mathrm{R}=p$ $\mathrm{XC}_{6} \mathrm{H}_{4}$ with $\mathrm{X}=\mathrm{Me}, \mathrm{OMe}, \mathrm{Cl}$. In the final step this compound rearranges to $\mathrm{Me}_{2} \mathrm{AlRN}=\mathrm{C}(\mathrm{Me})-\mathrm{CH}_{2}-\mathrm{NR}$ via a hydrogen migration (Fig. 25) (182). For $\mathrm{R}=2,6-\mathrm{Xyl}$ and Mes this last compound is directly formed from the first coordination product. Hydrolysis of the final product affords the particular iminoamine $\mathrm{RN}(\mathrm{H}) \mathrm{CH}_{2} \mathrm{C}(\mathrm{Me})=\mathrm{NR}$. The rate of rearrangement increased in the order $p-\mathrm{ClC}_{6} \mathrm{H}_{4}<p-\mathrm{MeC}_{6} \mathrm{H}_{4}<p-\mathrm{MeO}-\mathrm{C}_{6} \mathrm{H}_{4}$ and 2,6 -Xyl $<\mathrm{Mes} \ll t$-Bu. For $t$-Bu the reactions take place very rapidly even in the solid state at $-20^{\circ} \mathrm{C}$. The proposed mechanism for the $\mathrm{Me}$ transfer involves an intramolecular attack of the nucleophilic methyl groups on the relatively less negative imine- $\mathrm{C}$ atoms.

Recent results show that in the case of $\mathrm{Al}_{2} \mathrm{Et}_{6}$ Et transfer from both $\mathrm{Al}$ to $\mathrm{N}$ and $\mathrm{Al}$ to $\mathrm{C}$ occurs in parallel reactions, while in the first reaction also a radical species $\mathrm{Et}_{2} \mathrm{Al}(\mathrm{RN}=\mathrm{CHCH}=\mathrm{NR})^{\circ}$ was observed (179), i.e., a simple change from Me to Et may change the reaction picture completely as does also the change from $\mathrm{Zn}^{\text {II }}$ to $\mathrm{Al}^{\mathrm{III}}$.

In this respect it is of interest to mention that $\mathrm{K}(t-\mathrm{Bu}-\mathrm{DAB})$ reacts with alkyl halides $\mathrm{RX}$ to give $t$ - $\mathrm{Bu}-\mathrm{N}=\mathrm{CHC}(\mathrm{R})=\mathrm{N}-t$ - $\mathrm{Bu}$, while with $\mathrm{Me}_{3} \mathrm{SiCl}$, it produces in low yields cis-enediamines and bis- $N$-silylated trans-enediamines (42).

\section{Stoichiometric C-C Coupling Reactions Involving $\sigma-N, \mu^{2}-N^{\prime}, \eta^{2}-$ $C=N^{\prime}$ Coordinated 1,4-Diaza-1,3-butadiene Ligands}

The $\eta^{2}-\mathrm{C}=\mathrm{N}$ bonded entity in complexes $\mathrm{M}_{2}(\mathrm{CO})_{6}(\mathrm{R}-\mathrm{DAB})$ is clearly activated as indicated by the lengthened $\mathrm{C}=\mathrm{N}$ bond and the strong upfield ${ }^{1} \mathrm{H}$ and ${ }^{13} \mathrm{C}$ NMR chemical shifts of the relevant atoms (Table V). Investigations now show that it is possible to insert a number of unsaturated systems into the activated $\mathrm{Ru}-\mathrm{C}$ bond of $\mathrm{Ru}_{2}(\mathrm{CO})_{6}(\mathrm{R}-\mathrm{DAB})$, compounds which have been most extensively studied $(2,50,165,166,173)$. For example, $\mathrm{Ru}_{2}(\mathrm{CO})_{6}(\mathrm{R}-\mathrm{DAB})(\mathrm{R}=t$-Bu, $i$ - $\mathrm{Pr}, c-\mathrm{Hex})$ afforded with $\mathrm{R}-\mathrm{DAB}$ in the first instance $\mathrm{Ru}_{2}(\mathrm{CO})_{5}(\mathrm{IAE}) \quad\{\mathrm{IAE}=$ bis[(alkylimino)(alkylamino)ethane]\} (Fig. 26). This complex, which has a bridging CO group, but no metal-metal bond, contains two R-DAB ligands coupled together via one $\mathrm{C}-\mathrm{C}$ bond. The structure is similar to that of $\mathrm{Mo}_{2}(\mathrm{CO})_{6}(\mathrm{IAE})$ which shows the presence of a 10e-donating IAE ligand with a long $\mathrm{C}-\mathrm{C}$ 

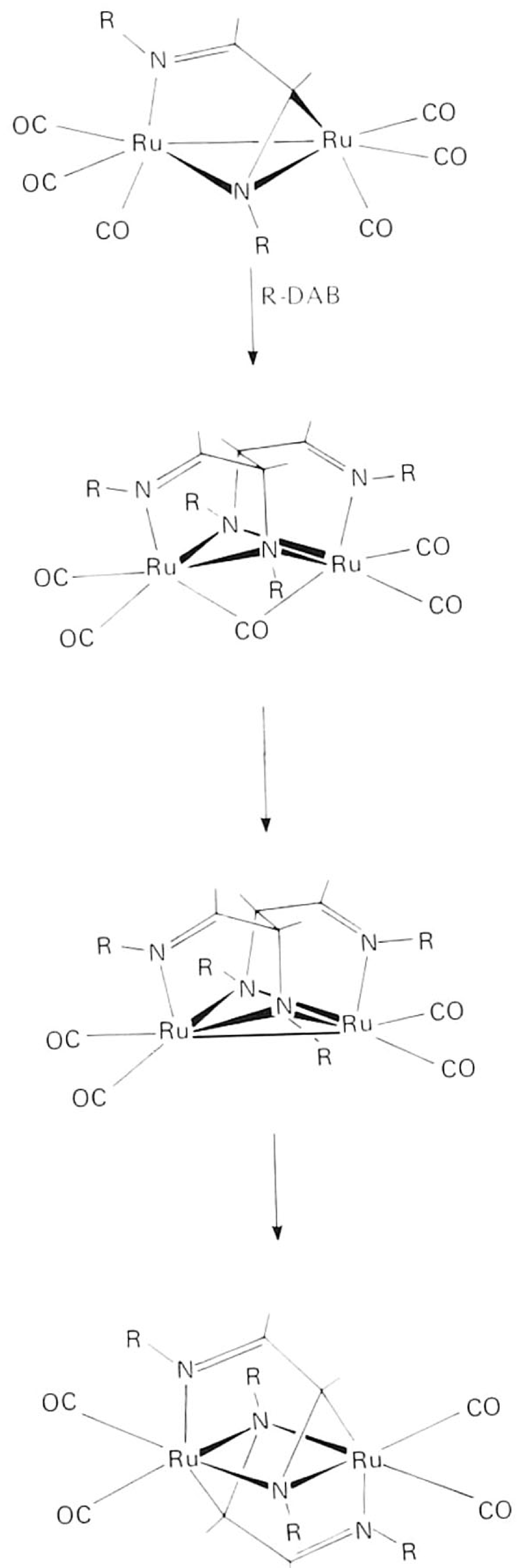

Fig. 26. The reaction of $\mathrm{Ru}_{2}(\mathrm{CO})_{6}(\mathrm{R}-\mathrm{DAB})$ with $\mathrm{R}-\mathrm{DAB}(\mathrm{R}=i$ - $\mathrm{Pr}, c-\mathrm{Hex}, t-\mathrm{Bu})$ to give via $\mathrm{Ru}_{2}(\mathrm{CO})_{5}(\mathrm{IAE})$ and via $\mathrm{Ru}_{2}(\mathrm{CO})_{4}(\mathrm{IAE})$ (only for $\mathrm{R}=i$ - $\operatorname{Pr}$ and $c$-Hex) the complex $\mathrm{Ru}_{2}(\mathrm{CO})_{4}(\mathrm{R}-\mathrm{DAB})_{2}(50)$. 
bond of 1.61(2) $\AA$ connecting the two R-DAB groups (97). The $\mathrm{C}-\mathrm{C}$ coupling reaction is completely regiospecific since in the case of asymmetric $\mathrm{R}-\mathrm{DAB}(\mathrm{H}, \mathrm{Me})$ it takes place uniquely between the $\mathrm{C}$ atoms bearing the $\mathrm{H}$ atoms $(50,165)$. The following step upon heating $\mathrm{Ru}_{2}(\mathrm{CO})_{5}(\mathrm{IAE})$ is the loss of the bridging $\mathrm{CO}$ group and formation of $\mathrm{Ru}_{2}(\mathrm{CO})_{4}(\mathrm{IAE})$. $\mathrm{Ru}_{2}(\mathrm{CO})_{4}(\mathrm{IAE})$ has a metal-metal bond, as is indicated by the presence of a strong electronic absorption band at $290 \mathrm{~nm}$ whose intensity increases appreciably at lower temperatures and which is ascribed to a $\sigma \rightarrow \sigma^{*}$ transition localized on the $\mathrm{Ru}-\mathrm{Ru}$ bond. $\mathrm{Ru}_{2}(\mathrm{CO})_{4}(\mathrm{IAE})$ was isolated only for $\mathrm{R}=i$ - $\mathrm{Pr}$ and $c$-Hex since the reaction stopped at $\mathrm{Ru}_{2}(\mathrm{CO})_{5}(\mathrm{IAE})$ for $\mathrm{R}=t$ - $\mathrm{Bu}$. Further heating of $\mathrm{Ru}_{2}(\mathrm{CO})_{4}(\mathrm{IAE})$ caused the $\mathrm{C}-\mathrm{C}$ bond originally formed to break again. A point confirmed by the crystal structure of the product $\mathrm{Ru}_{2}(\mathrm{CO})_{4}(\mathrm{R}-\mathrm{DAB})_{2}(\mathrm{R}=i$-Pr $)(50)$ (see also Section III,D). For $\mathrm{R}=\mathrm{Ar}$ the analogous compound was formed rapidly from $\mathrm{Ru}_{3}(\mathrm{CO})_{12}$ and R-DAB, although the intermediate complexes with IAE ligands could be identified in solution (50). From the above, it should be clear that $\mathrm{Ru}_{2}(\mathrm{CO})_{4}(\mathrm{R}-\mathrm{DAB})_{2}$ is not an intermediate, but the thermodynamically stable end product, while the $\mathrm{Ru}_{2}(\mathrm{CO})_{n}$ (IAE) complexes are formed in a kinetically very favorable pathway, probably by coupling of an inserting $\mathrm{R}-\mathrm{DAB}$ into the $\mathrm{Ru}-\mathrm{C}$ bond activated by $\eta^{2}-\mathrm{N}=\mathrm{C}$ bonding. In this respect it should be noted that there is a strong dependence not only on the Rgroup but on the metal too, since IAE complexes could not be formed from $\mathrm{Fe}_{2}(\mathrm{CO})_{6}(\mathrm{R}-\mathrm{DAB})$ (N.B. IAE complexes may be formed fleetingly but the $\mathrm{C}-\mathrm{C}$ bond could then quickly break again), while $\mathrm{Os}_{2}(\mathrm{CO})_{6}(\mathrm{R}-\mathrm{DAB})$ reacted sluggishly and no "coupled" products have been isolated as yet (112). Coupling of $\mathrm{C}-\mathrm{C}$ does occur in the reaction of $N$ - $\alpha$-methylbenzyl iminoacetate $\mathrm{PhCH}(\mathrm{Me}) \mathrm{N}=\mathrm{CHCO}_{2} \mathrm{Et}(=\mathrm{L})$ with $\mathrm{Fe}_{2}(\mathrm{CO})_{6} \mathrm{~L}(164)$ (see also Section III,E, Fig. 11). The resulting product $\mathrm{Fe}_{2}(\mathrm{CO})_{6} \mathrm{~L}_{2}$, which was characterized by X-ray crystallography, shows the presence of a 2,3-diaminosuccinic acid derivative to which are linked a nitrogen bridged binuclear $\mathrm{Fe}_{2}(\mathrm{CO})_{6}$ entity. Just as in IAE there is coupling between the $\eta^{2}$ $\mathrm{N}=\mathrm{C}$ bonded $\mathrm{C}$ atom and the $\mathrm{N}=\mathrm{C} \mathrm{C}$-atom of the inserting ligand (Fig. 27).

In order to obtain more information about the $\mathrm{C}-\mathrm{C}$ coupling reaction kinetic measurements [using reversed phase HPLC analysis (high performance liquid chromatography)] were carried out on mixtures of $\mathrm{Ru}_{2}(\mathrm{CO})_{6}(\mathrm{R}-\mathrm{DAB})$ with R-DAB (173).

The reaction for $\mathrm{R}=i$ - $\operatorname{Pr}$ [Eq. (50)] turned out to have an overall order of one, being first order in complex and zero order in $i$-Pr-DAB (173). The reaction for the $t$-Bu case proceeded at a much lower rate and it was confirmed that the complex $\mathrm{Ru}_{2}(\mathrm{CO})_{5}(\mathrm{IAE})$ was the end of the reaction sequence in Fig. 26. 


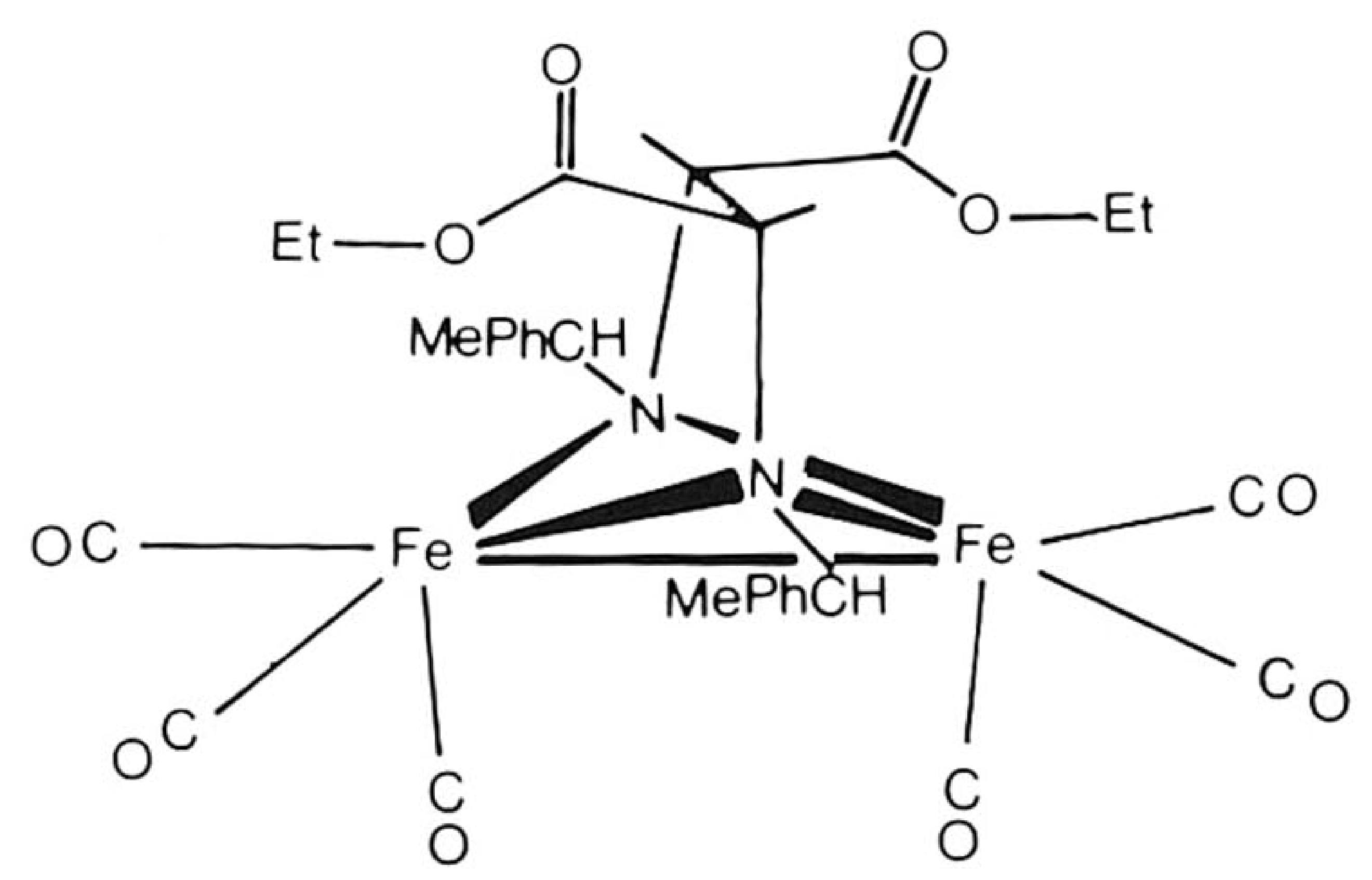

Fig. 27. Schematic structure of $\mathrm{Fe}_{2}(\mathrm{CO})_{6} \mathrm{~L}_{2} . \mathrm{L}_{2}$ is the $\mathrm{C}-\mathrm{C}$ coupled dimer of $\mathrm{PhCH}(\mathrm{Me}) \mathrm{N}=\mathrm{CHCO}_{2} \mathrm{Et}(164)$ (see also Fig. 11).

$$
\mathrm{Ru}_{2}(\mathrm{CO})_{6}(i-\mathrm{Pr}-\mathrm{DAB})+i-\mathrm{Pr}-\mathrm{DAB} \rightarrow \mathrm{Ru}_{2}(\mathrm{CO})_{5}(\mathrm{IAE})+\mathrm{CO}
$$

Somewhat more complicated reactions appeared to take place for mixtures of $\mathrm{Ru}_{2}(\mathrm{CO})_{6}(i-\mathrm{Pr}-\mathrm{DAB})$ with $t$-Bu-DAB and of $\mathrm{Ru}_{2}(\mathrm{CO})_{6}(t-\mathrm{Bu}-$ $\mathrm{DAB})$ with $i$-Pr-DAB, since different products were characterized. The former reaction gave $\mathrm{Ru}_{2}(\mathrm{CO})_{6}(t$-Bu-DAB $), \mathrm{Ru}_{2}(\mathrm{CO})_{n}(i$-Pr-IAE), and $\mathrm{Ru}_{2}(\mathrm{CO})_{4}(i-\mathrm{Pr}-\mathrm{DAB})_{2}$. However, for the second reaction mixture these last two compounds were present, but not $\mathrm{Ru}_{2}(\mathrm{CO})_{6}(i$-Pr-DAB $)$. There is some evidence that mixed IAE complexes containing $t$-Bu-DAB $\mathrm{C}-\mathrm{C}$ coupled to $i$-Pr-DAB and furthermore a mixed compound $\mathrm{Ru}_{2}(\mathrm{CO})_{4}(t-\mathrm{Bu}-\mathrm{DAB})(i-$ Pr-DAB) might also be formed (173).

These various reactions may be rationalized by the following equilibrium equation

$$
\mathrm{M}_{2}(\mathrm{CO})_{6}(\mathrm{DAB}) \underset{-\mathrm{DAB}}{\stackrel{+\mathrm{DAB}}{\rightleftarrows}} 2 \mathrm{M}(\mathrm{CO})_{3}(\mathrm{DAB})
$$

which moves to the right for $\mathrm{M}=\mathrm{Fe}$ and for $\mathrm{R}$ substituents doubly branched at $C^{\alpha}$ and $C^{\beta}$. Such a process would account for the presence of both mixed IAE and mixed R-DAB complexes. The intermediate complex $\mathrm{Ru}_{2}(\mathrm{CO})_{6}(\mathrm{DAB})$ probably consists of a R-DAB ligand $\sigma, \sigma-\mathrm{N}, \mathrm{N}^{\prime}$ chelated to one $\mathrm{M}$ atom, while the other $\mathrm{M}$ atom is coordinatively unsaturated and therefore susceptible to attack of a second R-DAB. This would also be in line with the reaction scheme proposed for the formation of $\mathrm{MnCo}(\mathrm{CO})_{6}(\mathrm{R}$ DAB) (see also Sections III,E and IV,A and Fig. 13).

The mechanism of formation of the previously mentioned $\mathrm{Mo}_{2}(\mathrm{CO})_{6}(\mathrm{IAE})$ is not very clear, since the preparations are different from those of $\mathrm{Ru}$ compounds (97). For example, the compound can be made by treating not only $\mathrm{MnBr}(\mathrm{CO})_{3}(\mathrm{R}-\mathrm{DAB})$ but also $\mathrm{MnBr}(\mathrm{CO})_{5}$, with $\left[\mathrm{Mo}(\mathrm{CO})_{4}(\mathrm{R}\right.$ DAB)]K [Eqs. (52) and (53)]: 
$2 \mathrm{MnBr}(\mathrm{CO})_{3}(\mathrm{DAB})+2\left[\mathrm{Mo}(\mathrm{CO})_{4}(\mathrm{DAB})\right] \mathrm{K} \rightarrow$

$$
\mathrm{Mo}_{2}(\mathrm{CO})_{6}(\mathrm{IAE})+2 \mathrm{DAB}+\mathrm{KBr}+\mathrm{Mn}_{2}(\mathrm{CO})_{10}
$$

$2 \mathrm{MnBr}(\mathrm{CO})_{5}+2\left[\mathrm{Mo}(\mathrm{CO})_{4}(\mathrm{DAB})\right] \mathrm{K} \rightarrow$

$$
\mathrm{Mo}_{2}(\mathrm{CO})_{6}(\mathrm{IAE})+2 \mathrm{CO}+2 \mathrm{KBr}+\mathrm{Mn}_{2}(\mathrm{CO})_{10}
$$

It was further demonstrated that even though a Mo-Mn bonded complex is an intermediate, the IAE ligand is formed exclusively from the R-DAB bonded to $\mathrm{Mo}$, indicating a bimetallic $\mathrm{Mo}_{2}$ intermediate. The method giving the highest yields of $\mathrm{Mo}_{2}(\mathrm{CO})_{6}$ (IAE) involves the treatment of $\mathrm{Hg}\left[\mathrm{Mo}(\mathrm{CO})_{3}(\mathrm{R}-\mathrm{DAB})\right]_{2}$ with acids [Eq. (54)].

$$
\mathrm{Hg}\left[\mathrm{Mo}(\mathrm{CO})_{3}(\mathrm{R}-\mathrm{DAB})\right]_{2}+2 \mathrm{H}^{+} \rightarrow \mathrm{Mo}_{2}(\mathrm{CO})_{6}(\mathrm{IAE})+\mathrm{H}_{2}+\mathrm{Hg}^{2+}
$$

Using a similar reaction, only a few percent yield of $\mathrm{Cr}_{2}(\mathrm{CO})_{6}$ (IAE) could be obtained, while the analogous tungsten complex could not be prepared. Use of asymmetric R-DAB(H,Me) gave quantitatively a regiospecific reaction in which only the $\mathrm{C}$ atoms bearing the $\mathrm{H}$ atoms were linked together. All these observations indicate a kinetically favorable pathway that is very sensitive to the various factors. The preferred reaction mechanism involves a dimerization of two coordinatively unsaturated $\mathrm{Mo}(\mathrm{CO})_{3}(\mathrm{R}-\mathrm{DAB})$ ( R $=t$ - $\mathrm{Bu}, i-\operatorname{Pr}, c-\mathrm{Hex})$ units to form an $\mathrm{Mo}_{2}$ intermediate on which the $\mathrm{R}$ $\mathrm{DAB}$ ligands are held close together. Because of the observed regiospecificity and in view of the $\mathrm{R}$ groups that could be used [i.e., those also typical for the stabilization of $\left.\mathrm{Ru}_{2}(\mathrm{CO})_{6}(\mathrm{R}-\mathrm{DAB})\right]$ it seems likely that at least one $\mathrm{R}-\mathrm{DAB}$ is $\sigma-\mathrm{N}, \mu^{2}-\mathrm{N}^{\prime}, \eta^{2}-\mathrm{C}=\mathrm{N}^{\prime}(6 \mathrm{e})$ bonded to the $\mathrm{Mo}_{2}$ pair. Whether the subsequent $\mathrm{C}-\mathrm{C}$ coupling reaction both here and with the $\mathrm{Ru}$ complexes proceeds via a radical mechanism [ $\mathrm{cf}$. the $\mathrm{C}-\mathrm{C}$ coupling reactions found for $\mathrm{Zn}$-Eqs. (42) and (43)] or via, e.g., a polar mechanism is open to question.

The molecular structure of $\mathrm{Mo}_{2}(\mathrm{CO})_{6}(\mathrm{IAE})$ with $\mathrm{R}=i-\operatorname{Pr}$ shows a $\mathrm{Mo}_{2}-$ unit $[2.813(2) \AA]$ bridged by the 10e-IAE ligand with $\mathrm{C}=\mathrm{N}, \mathrm{C}-\mathrm{N}$ and $\mathrm{C}-\mathrm{C}$ bond lengths of $1.28(2), 1.39(2)$ and $1.62(2) \AA$, respectively (97). The long $\mathrm{C}-\mathrm{C}$ bond is a result of steric strain, and it is therefore not surprising that both heat and light lead to cleavage of this bond.

\section{Catalytic C-C Coupling Reactions Involving $\sigma-N, \mu^{2}-N^{\prime}, \eta^{2}-$ $C=N^{\prime}$ Coordinated 1,4-Diaza-1,3-butadiene Ligands}

A good example of $\mathrm{C}-\mathrm{C}$ coupling with other substrates is the reaction of $\mathrm{Ru}_{2}(\mathrm{CO})_{6}(\mathrm{R}-\mathrm{DAB})(\mathrm{R}=i$ - $\mathrm{Pr}, t-\mathrm{Bu}, c$-Hex $)$ with acetylene, and monoand disubstituted alkynes $\mathrm{R}^{\prime} \mathrm{C}_{2} \mathrm{R}^{\prime \prime}\left(\mathrm{R}^{\prime}=\mathrm{R}^{\prime \prime}=\mathrm{CH}_{3} \mathrm{O}_{2} \mathrm{C}-, \mathrm{CD}_{3} \mathrm{O}_{2} \mathrm{C}-\right.$; $\mathrm{R}^{\prime}$ 
$=\mathrm{R}^{\prime \prime}=\mathrm{H} ; \mathrm{R}^{\prime}=\mathrm{H}, \mathrm{R}^{\prime \prime}=\mathrm{CH}_{3} \mathrm{O}_{2} \mathrm{C}, \mathrm{Ph}, p-\mathrm{Tol}, t-\mathrm{Bu}$ ) (166). In this multistage reaction sequence the first step involves insertion of $\mathrm{R}^{\prime} \mathrm{C} \equiv \mathrm{CR}^{\prime \prime}$. The crystal structure of the insertion product with $\mathrm{PhC}_{2} \mathrm{H}$, i.e., $\mathrm{Ru}_{2}(\mathrm{CO})_{5}[(t-\mathrm{Bu}-$ $\left.\mathrm{DAB})\left(\mathrm{PhC}_{2} \mathrm{H}\right)\right]$ shows that the $\mathrm{DAB}$ ligand and $\mathrm{PhC}_{2} \mathrm{H}$ are coupled via a $\mathrm{C}-\mathrm{C}$ bond. The 3-amino-4-imino-1-butene-1-yl (AIB) so formed is bonded to the $\mathrm{Ru}_{2}(\mathrm{CO})_{5}$ unit as shown in Fig. 28. The length of the $\mathrm{C}-\mathrm{C}$ bond formed is $1.546(10) \AA$. The $\mathrm{Ru}_{2}(\mathrm{CO})_{5}$ entity shows four terminal CO groups and a fifth one bridging a $\mathrm{Ru}-\mathrm{Ru}$ bond of 2.711(1) $\AA$. The $\mathrm{C}=\mathrm{N}$ and $\mathrm{C}-\mathrm{N}$ bonds are $1.259(10)$ and $1.496(9) \AA$, respectively. The original $\mathrm{C} \equiv \mathrm{C}$ bond is reduced to a double $\mathrm{C}=\mathrm{C}$ bond of $1.346(10) \AA$. An interesting feature of this planar olefinic fragment is that it is bonded to the $\mathrm{Ru}_{2}$ pair with the $\mathrm{CH}$ end, while the $\mathrm{C}-\mathrm{Ph}$ end is coupled to the formally

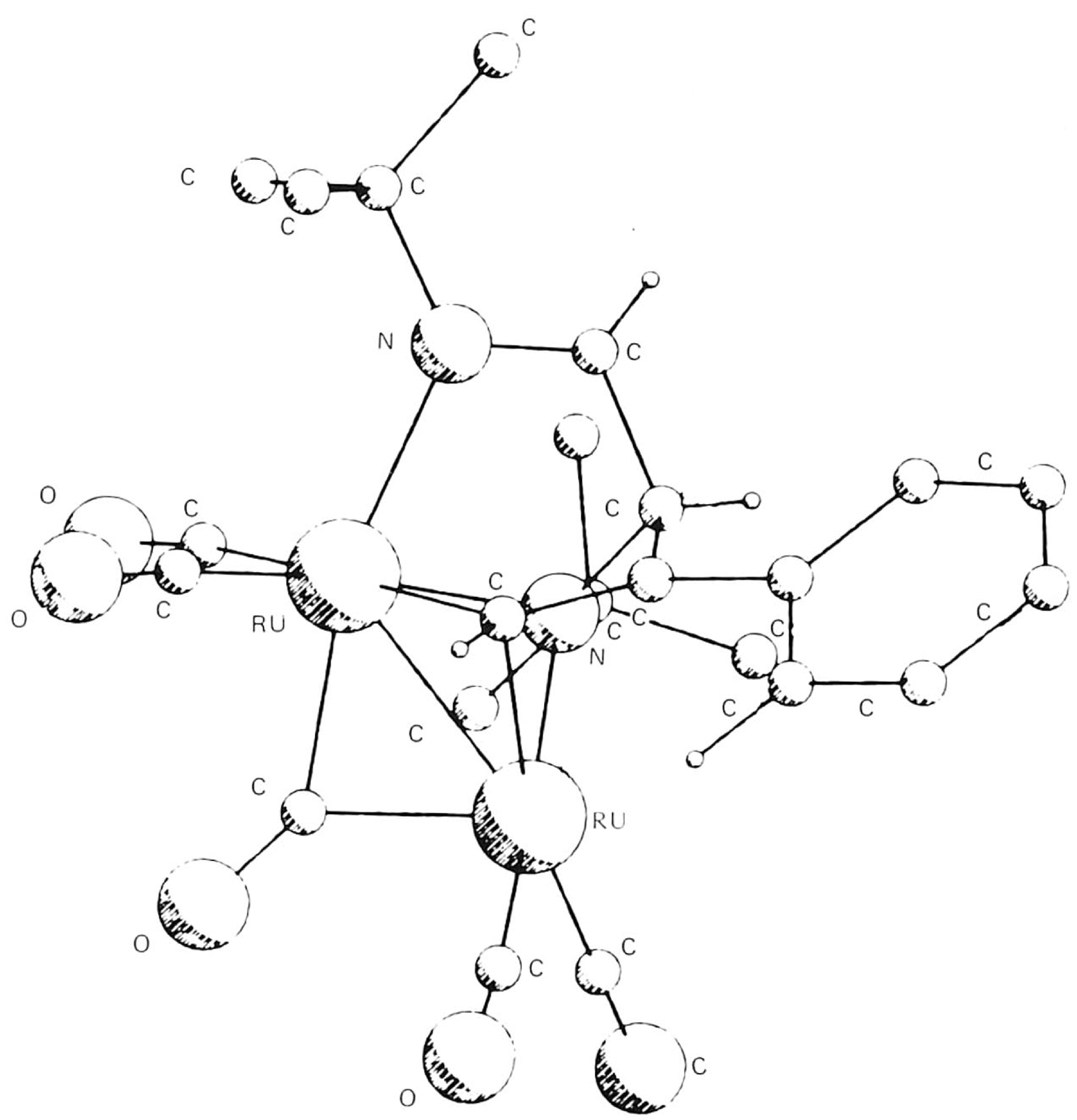

FIG. 28. Structure of $\mathrm{Ru}_{2}(\mathrm{CO})_{5}(t-\mathrm{Bu}-\mathrm{DAB})\left(\mathrm{PhC}_{2} \mathrm{H}\right)$. The $\mathrm{PhC}_{2} \mathrm{H}$ and $t$-Bu-DAB are
coupled via a $\mathrm{C}-\mathrm{C}$ bond $(166)$. 
$\eta^{2}-\mathrm{C}=\mathrm{N}$ bond imine- $\mathrm{C}$ atom. Here therefore we have coupling between a $\mathrm{C}-\mathrm{H}$ and a $\mathrm{C}-\mathrm{Ph}$ fragment in contrast to the $\mathrm{C}-\mathrm{H}$ to $\mathrm{C}-\mathrm{H}$ coupling in the case of insertion of R-DAB (50).

Subsequent reaction of $\mathrm{Ru}_{2}(\mathrm{CO})_{5}(\mathrm{AIB})$ with another alkyne gave $\mathrm{Ru}_{2}(\mathrm{CO})_{5}(\mathrm{AIB})($ alkyne) in which the second alkyne just adds to the first complex as a $2 \mathrm{e}$ donor without substitution, since $\mathrm{Ru}_{2}(\mathrm{CO})_{5}(\mathrm{AIB})$ is electron deficient by $2 \mathrm{e}$. This electron deficiency may be partly relieved by coordination either of the olefinic fragment or (if $\mathrm{R}$ is $\mathrm{CH}_{3} \mathrm{O}_{2} \mathrm{C}$ ) by an oxygen atom of the carboxylate group to the $\mathrm{Ru}$ atom not bearing the $\sigma-\mathrm{N}=\mathrm{C}$ bonded group. The $\mathrm{CO}$ groups in $\mathrm{Ru}_{2}(\mathrm{CO})_{5}(\mathrm{AIB})$ (alkyne) are all terminally bonded. Further heating produced $\mathrm{Ru}_{2}(\mathrm{CO})_{4}(\mathrm{AIB})$ (alkyne) with loss of $\mathrm{CO}$, while the alkyne has changed its bonding from $2 \mathrm{e}$ monodentate to $4 \mathrm{e}$-bridging. Finally, further addition of alkynes at $110^{\circ} \mathrm{C}$ produced substituted benzenes catalytically (Fig. 29) (166). An example of such a reaction, monitored by HPLC, was the trimerization of $\mathrm{CH}_{3} \mathrm{O}_{2} \mathrm{CC} \equiv \mathrm{CCO}_{2} \mathrm{CH}_{3}$ by $\mathrm{Ru}_{2}(\mathrm{CO})_{4}\left(t-\mathrm{Bu}-\mathrm{DAB}-\mathrm{R}^{\prime} \mathrm{C}_{2} \mathrm{R}^{\prime}\right)\left(\mathrm{R}^{\prime} \mathrm{C}_{2} \mathrm{R}^{\prime}\right) \quad\left(\mathrm{R}^{\prime}\right.$ $=\mathrm{CH}_{3} \mathrm{O}_{2} \mathrm{C}-$ ) which gave rapidly in 380 cycles only the substituted benzene $\left[\mathrm{C}_{6}\left(\mathrm{CO}_{2} \mathrm{CH}_{3}\right)_{6}\right]$. Use of mono substituted alkynes $\mathrm{HC}_{2} \mathrm{R}^{\prime}$ afforded with complete regiospecificity only 1,3,5-trisubstituted benzenes. This is very unusual since almost all catalysts produce mixtures of various products (184).

The mechanism of the catalytic reaction is not clear, but none of the present known mechanisms seem to explain the experimental data (185189). Whatever the mechanism, the quantitative symmetry induction to give 1,3,5-substituted benzenes strongly indicates a binuclear intermediate as catalyst (166).

A final point is that involvement of $\mathrm{HC}_{2} \mathrm{H}$ with $\mathrm{Ru}_{2}(\mathrm{CO})_{6}(\mathrm{R}-\mathrm{DAB}) \mathrm{did}$ not give a catalytic reaction, but produced $\mathrm{Ru}_{2}(\mathrm{CO})_{4}\left(\mu^{2}-\mathrm{HC}_{2} \mathrm{H}\right)(\mathrm{R}-\mathrm{DAB})$ via $\mathrm{Ru}_{2}(\mathrm{CO})_{5}(\mathrm{R}-\mathrm{DAB})\left(\mathrm{HC}_{2} \mathrm{H}\right)$ which could be identified as an unstable intermediate. The $\mu^{2}-\mathrm{HC}_{2} \mathrm{H}$ complex is shown in the catalytic scheme of Fig. 29 while the structure was discussed in Section III,F (Fig. 14b). The complex shows no catalytic activity $(31,166)$.

\section{E. Catalytic Reactions}

Very little is known about catalytic reactions in which metal-R-DAB complexes are involved but for which on first sight of the R-DAB itself is not activated. Discussion is unfortunately hampered by the absence of any concrete data, since the available results have been laid down in preliminary discussions that have not been followed up by full papers $(74,105,107$, 

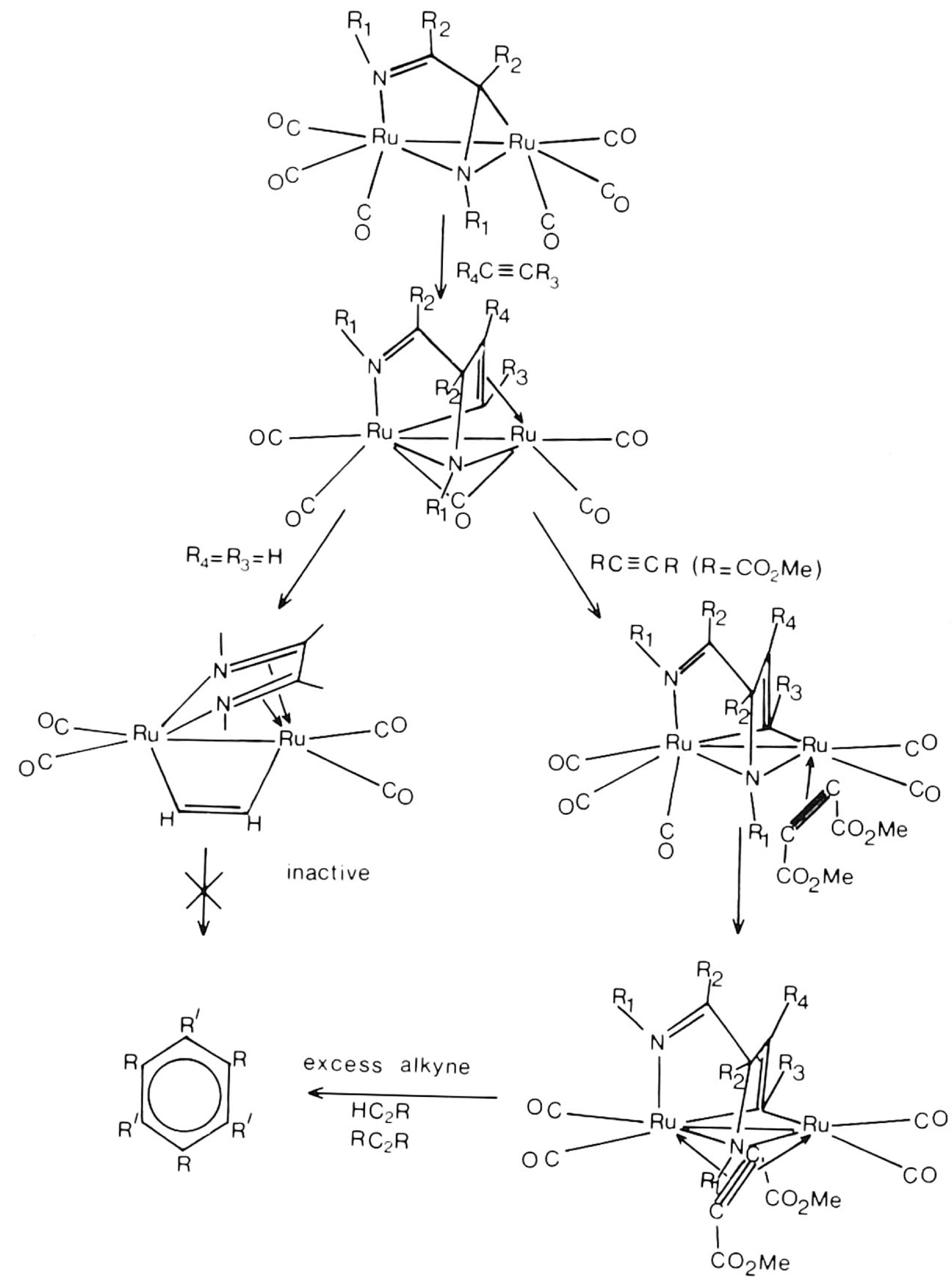

active

Fig. 29. The catalytic reaction of $\mathrm{Ru}_{2}(\mathrm{CO})_{6}\left[\mathrm{R}_{1}-\mathrm{DAB}\left(\mathrm{R}_{2}, \mathrm{R}_{2}\right)\right]$ with $\mathrm{RC}_{2} \mathrm{R}$. Note that $\mathrm{Ru}_{2}(\mathrm{CO})_{4}(\mathrm{R}-\mathrm{DAB})\left(\mu^{2}-\mathrm{HC}_{2} \mathrm{H}\right)$ is the stable end product if $\mathrm{HC}_{2} \mathrm{H}$ is used $(31,166)$. For
asymmetric alkynes only $1,3,5$-substituted benzenes are found. 
148). We shall therefore restrict ourselves by necessity to some scarce details on $\mathrm{Fe}, \mathrm{Ni}$ and $\mathrm{Cr}$ complexes.

For example, tetracoordinate $\mathrm{Fe}\left[\mathrm{R}-\mathrm{DAB}\left(\mathrm{R}^{\prime}, \mathrm{R}^{\prime \prime}\right)\right]_{2}(\mathrm{R}=t$-Bu, $c$-Hex, $i$ $\operatorname{Pr}, i-\mathrm{Pr}_{2} \mathrm{CH}, \mathrm{Ar} ; \mathrm{R}^{\prime}=\mathrm{R}^{\prime \prime}=\mathrm{H}$ or $\mathrm{Me}$ ) which have a 16 e configuration, show in the presence of $\mathrm{Et}_{2} \mathrm{AlOEt}$ or $\mathrm{AlEt}_{3}$ ( 2 mol equivalent) high catalytic activity in the dimerization of conjugated dienes in the temperature range $22-82^{\circ} \mathrm{C}(105)$. In the case of butadiene 1,5-cyclooctadiene (COD) and vinylcyclohexene were formed, while in the case of isopropene 1,6-dimethylCOD and 1,5-dimethyl-COD could be isolated together with methylated vinylcyclohexenes and open chain products.

In the case of $\mathrm{Fe}(\mathrm{NO})_{2}(\mathrm{R}-\mathrm{DAB}(\mathrm{Me}, \mathrm{Me})(\mathrm{R}=\mathrm{Ph})$ the conversion of isoprene both with and without $\left(\mathrm{AlEt}_{3}\right)_{2}$ led to formation of somewhat varying amounts of isoprene polymers as well as 1,4- and 2,4-dimethyl-4vinyl-1-cyclohexene (107).

The complex $\mathrm{Cr}(\mathrm{R}-\mathrm{DAB})_{3}\left(\mathrm{R}=i-\mathrm{Pr}_{2} \mathrm{CH}\right)$ activated by $\mathrm{Et}_{2} \mathrm{AlOEt}$ yielded mainly 2,7-dimethyl-2-trans-4,6-octatriene through a selective tail-to-tail $\mathrm{C}-\mathrm{C}$ coupling accompanied by a double $\mathrm{H}$ shift, in addition to some trimers and some higher molecular weight products. Change of $\mathrm{R}$ to $c$-Hex gave none of the first product, but instead another isomer, 2,7-dimethyl1,3,6-octatriene and a head-to-tail dimer, 2,6-dimethyl-1,3,6-octatriene (74). A similar steric control was mentioned for $\mathrm{V}(\mathrm{R}-\mathrm{DAB})_{3}-\mathrm{AlR}_{3}$ but no details were given (74).

Finally it has been mentioned in a short paragraph of Ref. 148 that the novel complexes $\mathrm{NiMe}_{2}(\mathrm{R}-\mathrm{DAB})\left[\mathrm{R}=2,6-(i-\mathrm{Pr})_{2} \mathrm{C}_{6} \mathrm{H}_{3}\right]$ appear to be active in the catalytic oligomerization of butadiene at $120^{\circ} \mathrm{C}$ and at unstated pressures to give unidentified waxy polymers.

The steric control in some of these reactions seems to indicate the presence of R-DAB in the catalyst. However, in most cases the catalysts are activated by alkylaluminum compounds, which as we have seen are extremely active in the conversion of R-DAB itself (see Section VI,B, Fig. 25) (182). Furthermore, we must expect under these conditions the formation of active clusters.

\section{VII \\ CONCLUDING REMARKS}

In this review we have shown that the $\mathrm{R}-\mathrm{DAB}$ species $\mathrm{RN}=\mathrm{C}$ $\left(R^{\prime}\right) C\left(R^{\prime}\right)=N R$ are highly versatile ligands. The versatility is due to (i) the flexibility of the NCCN skeleton, (ii) the strong $\sigma$-donor and $\pi$-acceptor 
properties, and (iii) the possibility of changing both the R and $\mathrm{R}^{\prime}$ substituents by which both the electronic and steric properties may be influenced
appreciably.

It has been shown that due to this versatility the diimine ligands are able to bind as $2 \mathrm{e}, 4 \mathrm{e}, 6 \mathrm{e}$, or $8 \mathrm{e}$ donor ligands. In the $2 \mathrm{e}$ and $4 \mathrm{e}$ bonding modes the $\mathrm{N}$ atoms are used for bonding while in the $6 \mathrm{e}$ and $8 \mathrm{e}$ bonding modes the $\pi-\mathrm{C}=\mathrm{N}$ orbitals are also employed for metal $-\eta^{2}-\mathrm{C}=\mathrm{N}$ bonding. In the last type of bonding the $\mathrm{C}=\mathrm{N}$ bond length is increased appreciably by virtue of back donation into the low-lying LUMO of the NCCN skeleton.

In addition to the coordination types we have also surveyed the reactivity of coordinated diimine ligands. The most unusual aspect is the activation of the $\eta^{2}-\mathrm{C}=\mathrm{N}$ bonding in the $6 \mathrm{e}$ bonding mode, which results in stoichiometric and catalytic $\mathrm{C}-\mathrm{C}$ coupling reactions.

Considering what is now known about diimine chemistry, it is to be expected that much fruitful work should be carried out in the reactivity of coordinated R-DAB ligands.

\section{ACKNOWLEDGMENTS}

We wish to thank L. H. Staal, H. van der Poel, K. I. Cavell, L. H. Polm, J. Keijsper, R van Vliet, and J. T. B. H. Jastrzebski for their experimental efforts and helpful discussions, D. M. Grove for the careful reading of the manuscript, H. Kraaykamp for assistance with the literature search, and L. C. Taylor for typing the manuscript.

\section{REFERENCES}

1. L. F. Lindoy and S. E. Livingstone, Coord. Chem. Rev. 2, 173 (1967).

2. G. van Koten and K. Vrieze, Recl. Trav. Chim. Pays-Bas 100, 129 (1981).

3. J. M. Kliegman and R. K. Barnes, Tetrahedron 26, 2555 (1970).

4. J. M. Kliegman and R. K. Barnes, J. Org. Chem. 35, 3140 (1970).

5. V. C. Barnay and P. W. D. Mitchell, J. Chem. Soc. p. 3610 (1953).

6. L. Horner and E. Jürgens, Chem. Ber. 90, 2184 (1957).

7. J. F. Carson, J. Am. Chem. Soc. 75, 4337 (1953).

8. H. van der Poel and G. van Koten, Synth. Commun. 8, 305 (1978).

9. M. Svoboda, H. tom Dieck, C. Krüger, and Y.-H. Tsay, Z. Naturforsch. B: Anorg.

10. H. tom. Dreck, M. S6oboda, 814

Chem. 36B, 823 (1981).

1. H tom Dieck, K. D. Fra

Chem. 30B, 922 (1975).

13. O. Exner and Jetrahedron Lett. 24, 1953 (1969).

14. H. tom

15. O. Borgen, B. Mestvedt, and, Chem. Ber. 104, 92 (1971).

16. R. Benedix, P. Birner, F. Birnstock H. Heta Chem. Scand., Ser. A 30, 43 (1976). 51, 99 (1979). 
17. J. Keijsper, G. van Koten, and K. Vrieze, Polyhedron, in press (1982).

18. I. Hargittai and R. Seip, Acta Chem. Scand. Ser. A 30, 540 (1976).

19. J. Tyrell, J. Am. Chem. Soc. 101, 1766 (1979).

20. B. Crociani, G. Bandoli, and D. A. Clemente, J. Organomet. Chem. 184, 269 (1980).

21. H. van der Poel and G. van Koten, Polyhedron, in press (1982).

22. L. L. Merritt, Jr. and E. D. Schroeder, Acta Crystallogr. 9, 801 (1956).

23. K. Folting and L. L. Merritt, Jr., Acta Crystallogr., Sect. B 33, 3540 (1977).

24. M. Lenner and O. Lindgren, Act Crystallogr., Sect. B 32, 1903 (1976).

25. A. Almenningen, O. Bastiansen, and M. Traettenberg, Acta Chem. Scand. 12, 1221 (1958).

26. J. Reinhold, R. Benedix, P. Birner, and H. Hennig, Inorg. Chim. Acta 33, 209 (1979).

27. H. C. Barany, E. A. Braude, and M. A. Pianka, J. Chem. Soc. p. 1898 (1949).

28. P. Krumholz, J. Am. Chem. Soc. 75, 2163 (1953).

29. H. van der Poel, G. van Koten, and K. Vrieze, Inorg. Chem. 19, 1145 (1980).

30. H. W. Frühauf, A. Landers, R. Goddard, and C. Krüger, Angew. Chem. 90, 56 (1978).

31. L. H. Staal, L. H. Polm, K. Vrieze, F. Ploeger, and C. H. Stam, J. Organomet. Chem. 199, C13 (1980).

32. H. van der Poel, G. van Koten, K. Vrieze, M. Kokkes, and C. H. Stam, Inorg. Chim. Acta 39, 197 (1980).

33. L. H. Staal, G. van Koten, and K. Vrieze, F. Ploeger, and C. H. Stam, Inorg. Chem. 20, 1830 (1982).

34. H. van der Poel, G. van Koten, and K. Vrieze, Inorg. Chim. Acta 51, 253 (1981).

35. H. van der Poel, G. van Koten, D. M. Grove, P. S. Pregosin, and K. A. O. Starzewski, Helv. Chim. Act 64, 1174 (1981).

36. H. van der Poel and G. van Koten, J. Organomet. Chem. 217, 129 (1981).

37. T. Mack, Ph.D. Thesis, University of Frankfurt, Frankfurt am Main (1979).

38. A. J. Graham, D. Akrigg, and B. Sheldrick, Cryst. Struct. Commun. 5, 891 (1976).

39. A. J. Graham, D. Akrigg, and B. Sheldrick, Cryst. Struct. Commun. 6, 253 (1977).

40. A. J. Graham, D. Akrigg, and B. Sheldrick, Cryst. Struct. Commun. 6, 571 (1977).

41. A. J. Graham, D. Akrigg, and B. Sheldrick, Cryst. Struct. Commun. 6, 577 (1977).

42. B. Bruder, Ph.D. Thesis, University of Frankfurt, Frankfurt am Main (1979).

43. B. Chaudret, H. Köster, and R. Poilblanc, J. Chem. Soc., Chem. Commun. p. 266 (1981).

44. V. Pank, J. Klaus, K. von Deuten, M. Feigel, H. Bruder, and H. tom Dieck, Transition Met. Chem. 6, 185 (1981).

45. J. Kopf, J. Klaus, and H. tom Dieck, Cryst. Struct. Commun. 9, 783 (1980).

46. H. D. Hausen and K. Krogmann, Z. Anorg. Allg. Chem. 389, 247 (1972).

47. H. tom Dieck, M. Svoboda, and J. Kopf, Z. Naturforsch. B: Anorg. Chem., Org. Chem. 33B, 1381 (1978); A. L. Balch and R. H. Holm, J. Am. Chem. Soc. 88, 5201 (1966); D. Walther, Z. Anorg. Allg. Chem. 431, 17 (1977).

48. H. van der Poel, G. van Koten, M. Kokkes, and C. H. Stam, Inorg. Chem. 20, 2491 (1981).

49. L. Maresca, G. Natile, M. Calligaris, P. Delise, and L. Randaccio, J. Chem. Soc., Dalton Trans. p. 2386 (1976).

50. L. H. Staal, L. H. Polm, R. W. Balk, G. van Koten, K. Vrieze, and A. M. F. Brouwers, Inorg. Chem. 19, 3343 (1980).

51. L. H. Staal, J. Keijsper, G. van Koten, K. Vrieze, J. A. Cras, and W. P. Bosman, Inorg. Chem. 20, 555 (1981).

52. L. H. Staal, L. H. Polm, K. Vrieze, F. Ploeger, and C. H. Stam, Inorg. Chem. 20, 3590 (1981).

53. R. D. Adams, J. Am. Chem. Soc. 102, 7476 (1980). 
54. J. T. B. H. Jastrzebski, G. van Koten, and K. Vrieze, to be published.

55. L. H. Staal, D. J. Stufkens, and A. Oskam, Inorg. Chim. Acta 26, 255 (1978).

56. H. van der Poel, G. van Koten, K. Vrieze, M. Kokkes, and C. H. Stam, J. Organomet. Chem. 175, C21 (1979).

57. B. Crociani, T. Boschi, and P. Uguagliati, Inorg. Chim. Acta 48, 9 (1981).

58. K. J. Cavell, D. J. Stufkens, and K. Vrieze, Inorg. Chim. Act 47, 67 (1980).

59. H. van der Poel, G. van Koten, and K. Vrieze, J. Organomet. Chem. 135, C63 (1977).

60. B. Crociani and U. Belluco, J. Organomet. Chem. 177, 385 (1979).

61. H. van der Poel, G. van Koten, and K. Vrieze, Inorg. Chim. Acta 51, 241 (1981).

62. A. T. T. Hsieh and K. L. Ooi, J. Inorg. Nucl. Chem. 38, 604 (1976).

63. B. Crociani, M. Nicolini, and R. L. Richards, J. Organomet. Chem. 133, C22 (1976).

64. B. Crociani and R. L. Richards, J. Organomet. Chem. 154, 65 (1978).

65. B. Crociani, M. Nicolini, and A. Mantovani, J. Organomet. Chem. 177, 365 (1979).

66. P. L. Sandrini, A. Mantovani, and B. Crociani, J. Organomet. Chem. 185, C13 (1980).

67. P. L. Sandrini, A. Mantovani, B. Crociani, and P. Uguagliati, Inorg. Chim. Acta 50, 71 (1981).

68. J. T. B. H. Jastrzebski, J. M. Klerks, G. van Koten, and K. Vrieze, J. Organomet. Chem. 210, C49 (1981); 224, 107 (1982).

69. H. Bock and H. tom Dieck, Chem. Ber. 100, 228 (1967).

70. D. Walther, Z. Anorg. Allg. Chem. 405, 8 (1974).

71. A. T. T. Hsieh and B. O. West, J. Organomet. Chem. 112, 285 (1976).

72. J. Matei, T. Lixandru, Bul. Inst. Politeh. Iasi 13, 245 (1967); Chem. Abstr. 70, 3626 (1969).

73. D. Walther, Z. Chem. 15, 72 (1975).

74. H. tom Dieck and A. Kinzel, Angew. Chem. 91, 344 (1979).

75. P. Overbosch, G. van Koten, and O. Overbeek, J. Am. Chem. Soc. 102, 2091 (1980).

76. A. Kinzel, Ph.D. Thesis, University of Hamburg, Hamburg (1979).

77. L. H. Staal, A. Oskam, and K. Vrieze, J. Organomet. Chem. 170, 235 (1979).

78. R. W. Balk, D. J. Stufkens, and A. Oskam, Inorg. Chim. Acta 34, 267 (1979).

79. W. Majunke, D. Liebfritz, T. Mack, and H. tom Dieck, Chem. Ber. 108, 3025 (1975).

80. R. W. Balk, T. Snoeck, D. J. Stufkens, and A. Oskam, Inorg. Chem. 19, 3015 (1980).

81. H. tom Dieck, K.-D. Franz, and F. Hohmann, Chem. Ber. 108, 163 (1975).

82. D. Walther and M. Teutsch, Z. Chem. 16, 118 (1976).

83. L. H. Staal, A. Terpstra, and D. J. Stufkens, Inorg. Chim. Acta 34, 97 (1979).

84. H. tom Dieck and I. W. Renk, Chem. Ber. 104, 110 (1971).

85. H. tom Dieck and I. W. Renk, Angew. Chem. 82, 805 (1970).

86. D. Walther, J. Prakt. Chem. 316, 604 (1974).

87. R. W. Balk, D. J. Stufkens, and A. Oskam, Inorg. Chim. Acta 28, 133 (1978).

88. H. tom Dieck, I. W. Renk, and K. D. Franz, J. Organomet. Chem. 94, 417 (1975).

89. G. Häfelinger, R. G. Weissenhorn, F. Hack, and G. Wester-Mayer, Angew. Chem. 84, 769 (1972).

90. D. Walther and U. Dinjus, Z. Chem. 15, 196 (1975).

91. D. Walther and P. Hallpap, Z. Chem. 13, 387 (1973).

92. I. W. Renk and H. tom Dieck, Chem. Ber. 105, 1403 (1972).

93. F. Hohmann, H. tom Dieck, K. D. Franz, and K. A. Ostoja Starzewski, J. Organomet. Chem. 55, 321 (1973).

94. H. tom Dieck and I. W. Renk, Chem. Ber. 105, 1419 (1972).

95. H. Friedel, I. W. Renk, and H. tom Dieck, J. Organomet. Chem. 26, 247 (1971).

96. R. G. Hayter, J. Organomet. Chem. 13, P1 (1968); C. G. Hull and M. H. B. Stiddard, ibid. 9, 519 (1967). 
97. L. H. Staal, A. Oskam, K. Vrieze, E. Roosendaal, and H. Schenk, Inorg. Chem. 18, 1634 (1979).

98. R. W. Balk, D. J. Stufkens, and A. Oskam, J. Mol. Struct. 60, 387 (1980).

99. R. W. Balk, D. J. Stufkens, and A. Oskam, J. Chem. Soc., Chem. Commun. p. 1016 (1978).

100. H. Bock and H. tom Dieck, Angew. Chem. 18, 159 (1966).

101. D. Walther, Z. Chem. 13, 107 (1973).

102. R. W. Balk, D. J. Stufkens, and A. Oskam, J. Chem. Soc., Chem. Commun. p. 604 (1979).

103. L. H. Staal, G. van Koten, and K. Vrieze, J. Organomet. Chem. 175, 73 (1979).

104. R. W. Balk, D. J. Stufkens, and A. Oskam, J. Chem. Soc., Dalton Trans. p. 1124 (1981).

105. H. tom Dieck and H. Bruder, J. Chem. Soc., Chem. Commun. p. 24 (1977).

106. D. Liebfritz and H. tom Dieck, J. Organomet. Chem. 105, 255 (1976).

107. H. tom Dieck, H. Bruder, K. Hellfeldt, D. Liebfritz, and M. Fiegel, Angew. Chem. 92, 395 (1980).

108. S. Otsuka, T. Yoshida, and A. Nakamura, Inorg. Chem. 6, 20 (1967).

109. H. tom Dieck and A. Orlopp, Angew. Chem. 87, 246 (1975).

110. L. H. Staal, L. H. Polm, and K. Vrieze, Inorg. Chim. Acta 40, 165 (1980); M. W. Kokkes, D. J. Stufkens, A. Oskam, and C. H. Stam, to be published.

111 a. H.-W. Frühauf, F.-W. Grevels, and A. Landers, J. Organomet. Chem. 178, 349 (1979).

111 b. H.-W. Frühauf and G. Wolnershäuser, Chem. Ber. 115, 1070 (1982).

112. L. H. Staal, G. van Koten, and K. Vrieze, J. Organomet. Chem. 206, 99 (1981).

113. D. H. Busch and J. C. Bailar, Jr., J. Am. Chem. Soc. 78, 1137 (1956).

114. R. J. H. Clark, P. C. Turtle, D. P. Strommen, B. Streusand, J. Kincaid, and K. Nakamoto, Inorg. Chem. 16, 84 (1977).

115. H. L. Chum and P. Krumholz, Inorg. Chem. 13, 514 (1974).

116. H. L. Chum and P. Krumholz, Inorg. Chem. 13, 519 (1974).

117. H. L. Chum, T. Rabockai, J. Phillips, and R. A. Osteryoung, Inorg. Chem. 16, 812 (1977).

118. T. V. Harris, J. W. Rathke, and E. L. Muetterties, J. Am. Chem. Soc. 100, 6966 (1978).

119. I. P. Evans, G. W. Everett, and A. M. Sargeson, J. Am. Chem. Soc. 98, 8041 (1976).

120. E. Bayer, E. Breitmaier, and V. Schurig, Chem. Ber. 101, 1594 (1968).

121. M. Tubino and E. J. S. Vichi, Inorg. Chim. Acta 28, 29 (1978).

122. D. Soria, M. L. de Castro, and H. L. Chum, Inorg. Chim. Acta 42, 121 (1980).

123. H. L. Chum, D. Koran, and R. A. Osteryoung, J. Am. Chem. Soc. 100, 310 (1978).

124. H. L. Chum, A. M. G. da Costa, and P. Krumholz, J. Chem. Soc., Chem. Commun. p. 772 (1972).

125. P. Krumholz, O. A. Serra, and M. A. de Paoli, Inorg. Chim. Acta 15, 25 (1975).

126. H. L. Chum and M. L. de Castro, J. Am. Chem. Soc. 96, 5278 (1974).

127. P. Krumholz, H. L. Chum, M. A. de Paoli, and T. Rabockai, Electroanal. Chem. Interfacial Electrochem. 51, 465 (1974).

128. D. W. Clack, L. A. P. Kane-Maguire, D. W. Knight, and P. A. Williams, Transition Metal Chem. 5, 376 (1980).

129. R. D. Gillard, D. W. Knight, and P. A. Williams, Transition Metal Chem. 5, 321 (1980).

130. A. M. G. de Costa Ferreira, P. Krumholz, and J. M. Riveros, J. Chem. Soc., Dalton Trans. p. 896 (1977).

131. V. Pauk, J. Klaus, K. von Deuten, M. Feigel, H. Bruder, and H. tom Dieck, Transition Metal Chem. 6, 185 (1981).

132. B. Chaudret and R. Poilblanc, J. Organomet. Chem. 174, C51 (1979).

133. B. Chaudret and R. Poilblanc, J. Chem. Soc., Dalton Trans. p. 539 (1980). 
134. F. S. Hall and W. L. Reynolds, Inorg. Chem. 5, 931 (1966).

135. C. Tänzer, R. Price, E. Breitmaier, G. Jung, and W. Voelter, Angew. Chem. 82, 957
(1970).

136. K. Nakamoto, in "Advances in the Chemistry of the Coordination Compounds" (S. Kirschner, ed.). Macmillan, New York, 1961; K. Nakamoto, "Infrared Spectra of In-

137. B. Chaudret and R. Poilblanc, J. Organomet, Chew York, 1963.

138. R. Benedix, J. Reinhold, and H. Organomet. Chem. 204, 115 (1981).

139. J. Reinhold, R. Benedix, H. Hennig, Inorg. Chim. Acta 40, 47 (1980).

140. L. H. Staal, P. Bosma, and K. Vrieze, Inorg. Chimnig, Z. Phys. Chem. 5, 989 (1980).

141. A. J. Graham, D. Akrigg, and B. Sheldrick. Chim. Acta 43, 125 (1980).

142. G. Häfelinger, R. G. Weiszenhorn, F. Hack, and G. Westermayer, 6, 577 (1977). 769 (1972).

143. B. Crociani, M. Nicolini, and R. L. Richards, J. Chem. Soc., Dalton Trans. p. 1478
(1978).

144. A. L. Balch and R. H. Holm, J. Am. Chem. Soc. 80, 520 (1966).
145. D. Walther, Z. Chem. 17, 348 (1977).

146. H. Hoberg and C. Fröhlich, J. Organomet. Chem. 209, C69 (1981).

147. H. tom Dieck and M. Svoboda, Chem. Ber. 109, 1657 (1976).

148. M. Svoboda and H. tom Dieck, J. Organomet. Chem. 191, 321 (1980).

148a. P. Overbosch, G. van Koten, and O. Overbeek, Inorg. Chem., 21, 2373 (1982). (1977).

150. P. Overbosch, G. van Koten, D. M. Grove, and A. L. Spek, Inorg. Chem., in press (1982); W. Beck and F. Holsboer, Z. Natürforsch. B: Anorg. Chem., Org. Chem. 28B,
511 (1973).

151. P. Overbosch, G. van Koten, and K. Vrieze, J. Organomet. Chem. 208, C21 (1981).
152. L. Cattalini, F. Casparrini, L. Maresca, and G. Natile, J. Chem. Soc., Chem. Commun.
p. 369 (1973).

153. N. Chaudhury and R. J. Puddephatt, Inorg. Chem. 20, 467 (1981).

153a. A. De Rentzi, B. Di Blasio, A. Saporito, M. Scalone, and A. Vitagliano, Inorg. Chem.
19, 960 (1980).

154. H. van der Poel and G. van Koten, Inorg. Chem. 20, 2950 (1981).

155. H. van der Poel and G. van Koten, J. Organomet. Chem. 187, C17 (1980).
156. H. van der Poel, G. van Koten, and G. C. van Stein, J. Chem. Soc., Dalton Trans. p.
2164 (1981).

157. H. Aryanci, C. Daul, M. Zobrist, and A. von Zelewsky, Helv. Chim. Acta 58, 1732
(1975).

158. G. van Koten, J. T. B. H. Jastrzebski, and J. G. Noltes, J. Org. Chem. 42, 2047 (1977).

159. J. T. B. H. Jastrzebski and G. van Koten, to be published.

160. G. van Koten and J. G. Noltes, J. Am. Chem. Soc. 101, 6593 (1979).

161. G. C. van Stein, G. van Koten, and C. Brevard, J. Organomet. Chem. 226, C27 (1982).
161 a. C. Brevard, G. C. van Stein, and G. van Koten, J.Am. Chem. Soc. 103, 6746 (1981)

162. M. Dvolaitzky, presented by M. H. Normant, C. R. Hebd. Seances 103, 6746 (1981). (1970).

163. L. H. Staal, J. Keijsper, L. H. Polm, and K. Vrieze, J. Organomet. Chem. 204, 101
(1981).

164. A. de Cian and R. Weiss, J. Chem. Soc., Chem. Commun. p. 249 (1976).
165. L. H. Staal, L. H. Polm G.

165. L. H. Staal, L. H. Polm, G. van Koten, and K. Vrieze, Inorg. Chim. Acta 37, L485
(1979). 
166. L. H. Staal, G. van Koten, K. Vrieze, B. van Santen, and C. H. Stam, Inorg. Chem. 20, 3598 (1981).

167. F. A. Cotton, Prog. Inorg. Chem. 21, 1 (1976).

168. A. A. Hock and O. S. Mills, Acta Crystallogr. 14, 139 (1961).

169. H. B. Chin and R. Bau, J. Am. Chem. Soc. 95, 5068 (1973).

170. Y. Degreve, J. Meunier-Piret, M. van Meersche, and P. Piret, Acta Crystallogr. 23, 119 (1962).

171. M. R. Churchill, F. J. Hollander, and J. P. Hutchinson, Inorg. Chem. 16, 2655 (1977).

172. K. Wade, J. Chem. Soc., Chem. Commun. p. 792 (1971); Chem. Br. p. 177 (1975); Adv. Inorg. Chem. Radiochem. 18, 1 (1976).

173. C. H. Gast, J. C. Kraak, L. H. Staal, and K. Vrieze, J. Organomet. Chem. 208, 225 (1981).

174. E. König and S. Herzog, J. Inorg. Nucl. Chem. 32, 585, 601, 613 (1970).

175. H. tom Dieck and K.-D. Franz, Angew. Chem. 87, 244 (1975); Angew. Chem., Int. Ed. Engl. 14, 249 (1975).

176. P. Clopath and A. von Zelewsky, Helv. Chim. Acta 55, 52 (1972).

177. K.-D. Franz, H. tom Dieck, U. Krynitz, and I. W. Renk, J. Organomet. Chem. 64, 361 (1974).

178. K.-D. Franz, Ph.D. Thesis, University of Frankfurt (1975).

179. J. T. B. H. Jastrzebski, G. van Koten, and K. Vrieze, to be published.

180. K.-D. Franz, H. tom Dieck, K. A. Ostoja Starzewski, and F. Hohmann, Tetrahedron 31, 1465 (1975).

181. E. S. Raper and P. H. Crackett, Inorg. Chim. Acta 50, 159 (1981).

182. J. M. Klerks, D. J. Stufkens, G. van Koten, and K. Vrieze, J. Organomet. Chem. 181, 271 (1979).

183. J. M. Klerks, J. T. B. H. Jastrzebski, G. van Koten, and K. Vrieze, J. Organomet. Chem. 224, 107 (1982).

184. C. W. Bird, "Transition Metal Intermediates in Organic Synthesis." Academic Press, New York, 1967.

185. W. Hübel and C. Hoogzand, Chem. Ber. 93, 103 (1960).

186. J. P. Collman and J. W. Kang, J. Am. Chem. Soc. 89, 844 (1967).

187. S. Otsuka and A. Nakamura, Adv. Organomet. Chem. 14, 245 (1976).

188. F. L. Bowden and A. B. P. Lever, Organomet. Chem. Rev. 3, 227 (1968).

189. J. Browning, M. Green, J. L. Spencer, and F. G. A. Stone, J. Chem. Soc., Dalton Trans. p. 97 (1974). 